\begin{tabular}{|l|l|}
\hline $\begin{array}{l}\text { 2. To: (Receiving Organization) } \\
\text { SST Engineering }\end{array}$ & $\begin{array}{l}\text { 3. From: (Originating Organization) } \\
\text { TWRS Equipment Engineering }\end{array}$ \\
\hline $\begin{array}{l}\text { 5. Proj./Prog./Dept./Div.: } \\
\text { IO1-SY RAPID Response }\end{array}$ & $\begin{array}{l}\text { 6. Design Authority/Design Agent/Cog. Engr.: } \\
\text { W. J. Powel] }\end{array}$ \\
\hline
\end{tabular}

8. Originator Remarks:

This document is the design review report for the 101-SY RAPID mitigation. It is being routed for review and approval.

11. Receiver Remarks: 11A. Design Baseline Document? $Q$ Yes $O$ No

\section{Related EDT No.: \\ $\mathrm{N} / \mathrm{A}$ 7. Purchase Order No: \\ $\mathrm{N} / \mathrm{A}$ \\ 9. Equip./Component No.: \\ $\mathrm{N} / \mathrm{A}$ \\ 10. System/BIdg./Facility: \\ 24 1-SY}

12. Major Assm. Dwg. No.:

$\mathrm{N} / \mathrm{A}$

13. PermitPermit Application No.:

$\mathrm{N} / \mathrm{A}$

14. Required Response Date: $5 / 20 / 99$

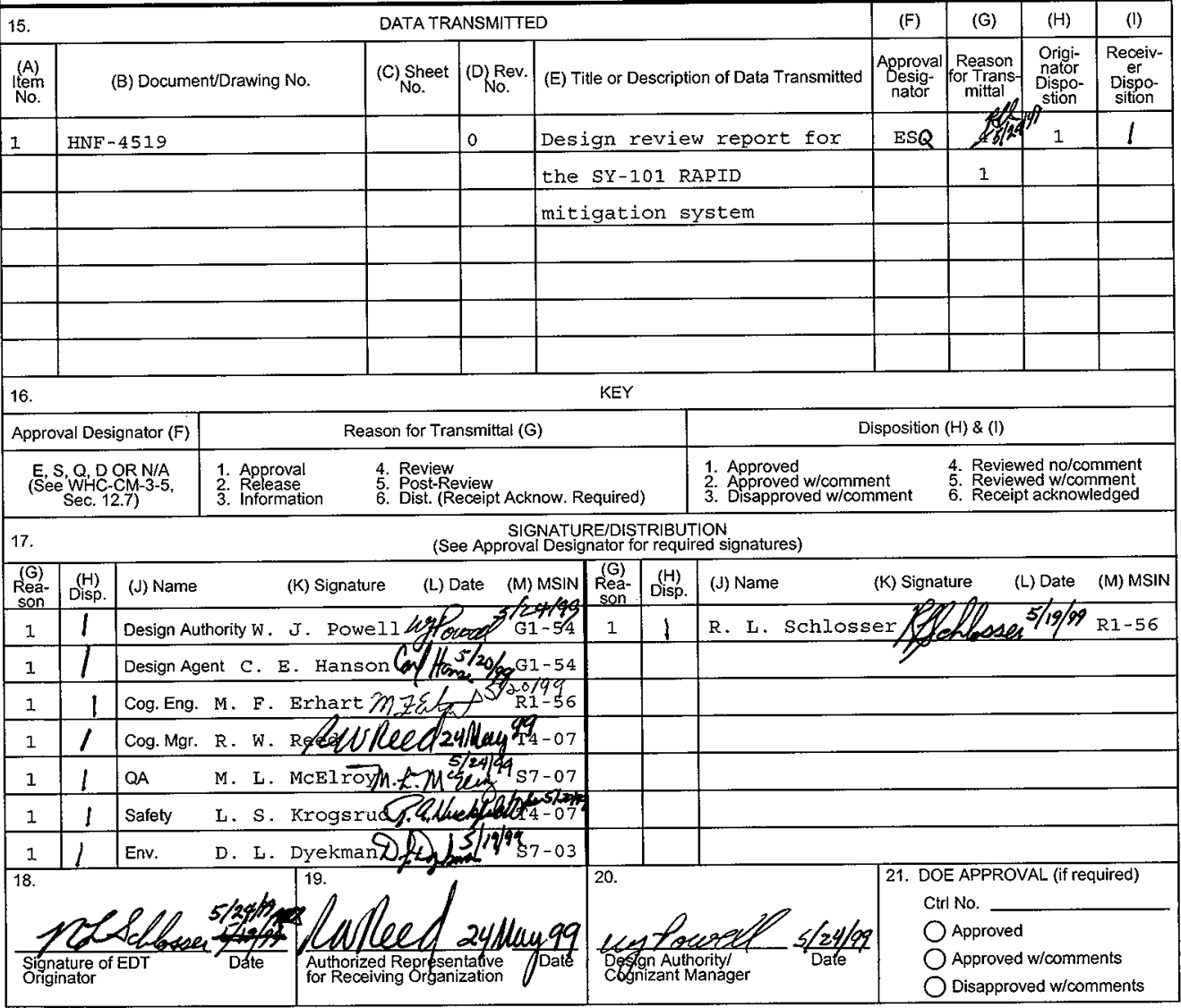

BD-7400-172-1 


\title{
Design Review Report For the SY-101 Rapid Mitigation System
}

\author{
Richard I. Schlosser \\ Lockheed Martin Hanford Corporation \\ Richland, WA 99352 \\ U.S. Department of Energy Contract DE-AC06-96RL13200 \\ EDT/ECN: 624019 \\ UC: 2000 \\ Org Code: 74700 \\ Charge Code: 108968 \\ B\&R Code: EW3130000 \\ Total Pages: 240
}

Key Words: Tank 241-SY-I01, Mitigation, Pump, Transfer, Design Review RAPID Mitigation system

Abstract: This report documents the system design review completed for the SY-101 RAPID Mitigation System. The report documents acceptability of the system design for design implementation, identifies the documents that were reviewed, the members of the review team, the scope of review, and identifies remaining open items.

TRADEMARK DISCLAIMER. Reference herein to any specific commercial product, process, or service by trade name, trademark, manufacturer, or otherwise, does not necessarily constitute or imply its endorsement, recommendation, or favoring by the United States Government or any agency thereof or its contractors or subcontractors.

Printed in the United States of America. To obtain copies of this document, contact: Document Control Services, P.O. Box 950, Mailstop H6-08, Richland WA 99352, Phone (509) 372-2420; Fax (509) 376-4989.

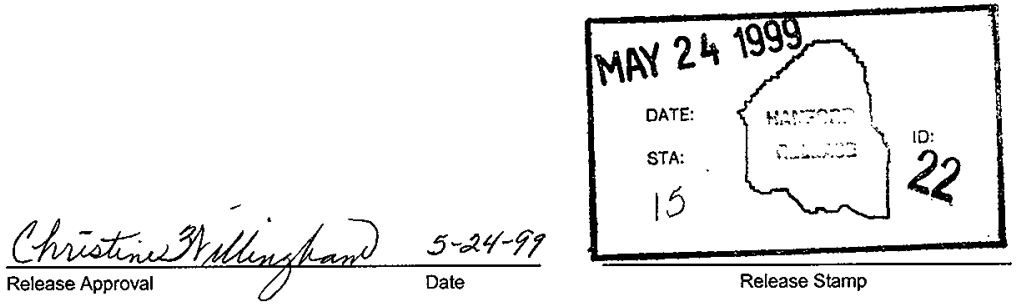

\section{Approved For Public Release}




\section{HNF-4519}

\section{DESIGN REVIEW REPORT FOR THE SY-101 RAPID MITIGATION SYSTEM}

Richard L. Schlosser

May 21, 1999 


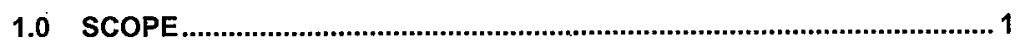

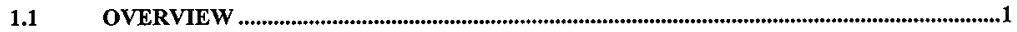

Table 1.1. SY-101 System Design Review Sequence.............................................................................................3

1.2 RAPID SYSTEM DESIGN

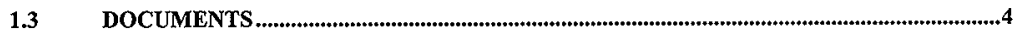

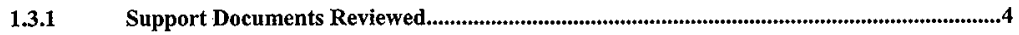

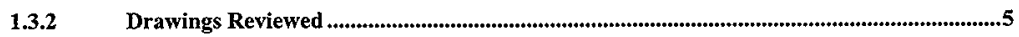

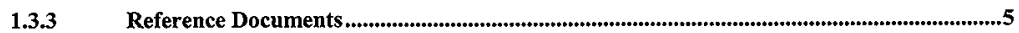

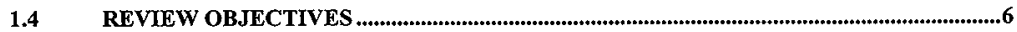

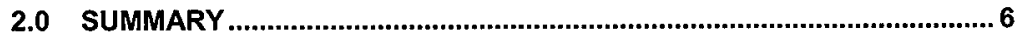

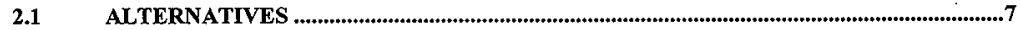

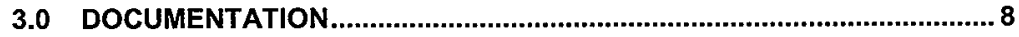

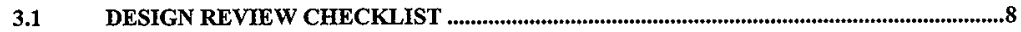

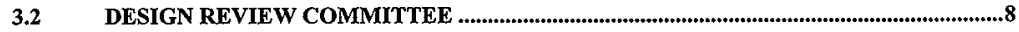

OUTSTANDING ACTION ITEMS

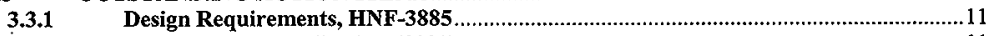

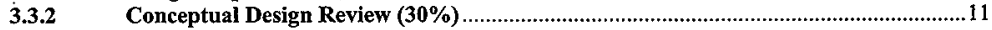

3.3.3 Prefabricated Pump Pit, HNF-4169 …................................................................... 12

3.3.4 Transfer Pump Piping, HNF-4170 ........................................................................12

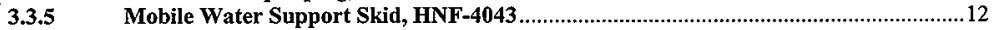

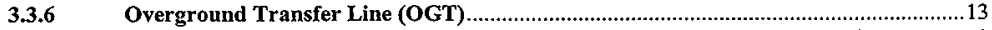

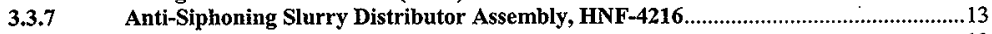

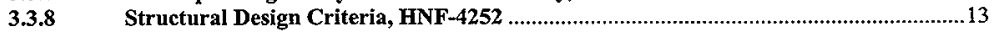

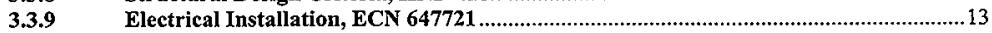

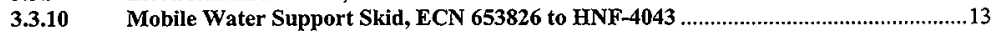

3.3.11 System Design Review and Hose in Hose Option, HNF-4407 ..................................13

Appendix A, Design Review Checklist System Design Review

Appendix B, Functional Requirements and Technical Criteria Design Review Meeting Minutes

Appendix C， 30\% Conceptual Design Review Meeting Minutes and Review Comment Records

Appendix D, Design Review Meeting Minutes Specification HNF-4169, "Prefabricated Pump Pit"

Appendix E, Design Review Meeting Minutes Specification HNF-4170, "Transfer Pump Piping" 
Appendix F, Design Review Meeting Minutes Specification HNF-4043, "Mobile Water Support Skid"

Appendix G, Design Review Meeting Minutes 30\% Conceptual Design Review Temporary Overground Transfer Line

Appendix H, Design Review Meeting Minutes Specification Anti-Syphoning Skurry Distributor Assembly

Appendix I, Design Review Meeting Minutes HNF-4252, "Structural Design Criteria"

Appendix J, Design Review Meeting Minutes ECN 647721, "Electrical Installation"

Appendix K, Design Review Meeting Minutes ECN 652826, Revision to "Specification for Mobile Water Support Skid"

Appendix L, System Design Review Agenda, Meeting Minutes

Appendix M, Draft Control Decision Record

Appendix N, Draft HNF-4264, "Process Control Plan" 


\section{HNF-4519 \\ DESIGN REVIEW REPORT FOR THE SY-101 RAPID MITIGATION SYSTEM}

\section{$1.0 \quad$ SCOPE}

\section{1,1 OVERVIEW}

This report documents design reviews conducted of the SY-101 Respond And Pump In Days (RAPID) Mitigation System. As part of the SY-101 Surface-Level-Rise Remediation Project, the SY-101 RAPID Mitigation System will reduce the potential unacceptable consequences of crust growth in Tank 241-SY-101 (SY-101). Projections of the crust growth rate indicate that the waste level in the tank may reach the juncture of the primary and secondary confinement structures of the tank late in 1999. Because of this time constraint, many design activities are being conducted in parallel and design reviews were conducted for system adequacy as well as design implementation throughout the process.

Design implementation, as used in this design review report, is the final component selection (e.g., which circuit breaker, valve, or thermocouple) that meets the approved design requirements, system design, and design and procurement specifications. Design implementation includes the necessary analysis, testing, verification, and qualification to demonstrate compliance with the system design and design requirements. Design implementation is outside the scope of this design review. The design activities performed prior to detailed design implementation (i.e., system mission requirements, functional design requirements, technical criteria, system conceptual design, and where design and build contracts were placed, the procurement specification) have been reviewed and are within the scope of this design review report. Detailed design implementation will be controlled, reviewed, and where appropriate, approved in accordance with Tank Waste Remediation System (TWRS) engineering procedures. Review of detailed design implementation will continue until all components necessary to perform the transfer function are installed and tested.

Likewise, radiological design reviews are integrated into this process, thus providing assurance that the design incorporates features to minimize personnel exposure. Aspects of this review will also continue during operation of the completed system to ensure that subsequent transfers and back dilution of the waste in SY-101 are conducted safely.

The review process was initiated with a review of design criteria based on verbal descriptions of the system mission, a review of the initial design concepts (and subsequent changes), reviews of each procurement specification requiring supplied design, and the completed integrated system design. Each review relied on the completion of earlier reviews and the design criteria established. The reviews focused on ensuring that the system design meets requirements of the TWRS Authorization Basis 
(Basis for Interim Operation and Technical Safety Requirements), applicable safety, health, and environmental requirements, appropriate codes and standards, and DOE Orders. Those documents and drawings depicting or specifying system design, especially for safety-related design features were reviewed. The reviews did not specifically address all equipment; i.e., individual procurement of components was only addressed where the procurement involved engineered equipment. Changes to reviewed documents were processed without additional review if the changes were found to be bounded by the completed review. However, changes to reviewed documents were addressed if they were found to be outside the scope of the previous review. The individual reviews encompassed by this design review are summarized in Table 1.1.

Each individual review was documented by Meeting Minutes or Review Comment Records (RCRs). Employing a graded approach, Meeting Minutes provided a record of comments generated for relatively small-scope review sessions, while RCRs were developed for the extensive reviews conducted of the conceptual design and the integrated system design. In addition to comments developed during presentation of design media at meetings, the review team members also provided comments based on their specific disciplinary responsibility for inclusion in the RCRs. During reviews of procurement specifications, numerous reviewer comments were evaluated, responded to, and incorporated during the review meeting. Those comments were not specifically documented. 
Table 1.1. SY-101 System Design Review Sequence.

\begin{tabular}{|c|c|c|c|}
\hline Review & Date(s) & Record & $\begin{array}{l}\text { Comments } \\
\text { Identified/Open }\end{array}$ \\
\hline $\begin{array}{l}\text { HNF-3885, Rev. } 0 \\
\text { (Design Criteria) } \\
\text { Appendix B } \\
\end{array}$ & February 4, 1999 & Meeting Minutes & $67 / 0$ \\
\hline $\begin{array}{l}30 \% \text { Design Review } \\
\text { (Conceptual Design) } \\
\text { Appendix C }\end{array}$ & February $16-17,1999$ & $\begin{array}{l}\text { Meeting Minutes } \\
\text { \& RCRs }\end{array}$ & $157 / 4$ \\
\hline $\begin{array}{l}\text { HNF-4169, Rev. } 0 \\
\text { (PPP Enclosure) } \\
\text { Appendix D }\end{array}$ & March 9, 1999 & Meeting Minutes & $20 / 1$ \\
\hline $\begin{array}{l}\text { HNF-4170, Rev. 0 } \\
\text { (Transfer Pump Piping) } \\
\text { Appendix E }\end{array}$ & March 9, 1999 & Meeting Minutes & $8 / 0$ \\
\hline $\begin{array}{l}\text { HNF-4043, Rev 0 } \\
\text { (Water Skid Specification) } \\
\text { Appendix F }\end{array}$ & March 10, 1999 & Meeting Minutes & $8 / 0$ \\
\hline $\begin{array}{l}33 \% \text { Design Review } \\
\text { (Overground Transfer } \\
\text { Option) } \\
\text { Appendix G }\end{array}$ & March 11, 1999 & Meeting Minutes & $21 / 1$ \\
\hline $\begin{array}{l}\text { HNF-4216 } \\
\text { (Slurry Distributor) } \\
\text { Appendix H }\end{array}$ & March 25, 1999 & Meeting Minutes & $18 / 0$ \\
\hline $\begin{array}{l}\text { HNF-4252 } \\
\text { (Structural Design } \\
\text { Criteria) } \\
\text { Appendix I } \\
\end{array}$ & March 26, 1999 & Meeting Minutes & $3 / 0$ \\
\hline $\begin{array}{l}\text { ECN } 647721 \\
\text { (electrical installation) } \\
\text { Appendix J }\end{array}$ & April 9, 1999 & Meeting Minutes & $34 / 0$ \\
\hline $\begin{array}{l}\text { ECN 653826 } \\
\text { (modification of Water } \\
\text { Skid Specification) } \\
\text { Appendix K }\end{array}$ & April 13, 1999 & Meeting Minutes & $10 / 0$ \\
\hline $\begin{array}{l}\text { SY-101 RAPID } \\
\text { Mitigation System - } \\
\text { System Design, and } \\
\text { HNF-4407 } \\
\text { (Hose in Hose Option) } \\
\text { Appendix L }\end{array}$ & $\begin{array}{l}\text { April 29-May 10, } \\
1999\end{array}$ & $\begin{array}{l}\text { Meeting Minutes } \\
\text { and RCRs }\end{array}$ & $46 / 18$ \\
\hline
\end{tabular}




\subsection{RAPID SYSTEM DESIGN}

The SY-101 RAPID Mitigation System consists of a transfer pump located in Tank 241-SY-101; a transfer line from the transfer pump to Tank 241-SY-102, and a discharge connection to disperse transferred waste into Tank 241-SY-102. In order to meet process limitations and flushing of transfer components, a water supply system is included to provide dilution and flush water to the transfer pump and lines. Requisite supporting structures, instrumentation, controls, and interconnections to utilities and other support systems are also included in the system design.

Portions of the system have more than one design. The multiple designs provide appropriate assurance that the risk of system completion can be reduced. As the design progressed, design options were eliminated based on technical, cost, and schedule impacts. Likewise as the design matured, new alternative designs were developed. At this time, the transfer line has two designs (secondary containment by either piping or flexible hose), and the power supply interface has criteria to implement changes should load analysis results indicate the need for additional power.

\subsection{DOCUMENTS}

\subsubsection{Support Documents Reviewed}

- HNF-3885, "Functional Requirements and Technical Criteria for the 241-SY-101 RAPID Mitigation System"

- HNF-4043, "Specification for SY101 RAPID Mitigation Mobile Water Support Skid" and revision by ECN 653826

- HNF-4169, "Specification for SY-101 RAPID Mitigation Prefabricated Pump Pit"

- HNF-4170, "Specification for SY-101 RAPID Mitigation Transfer Pump Piping"

- HNF-4216, "Specification for SY-101 RAPID Mitigation System Anti-Siphoning Slurry Distributor Assembly"

- HNF-4252, "Structural Design Criteria for the SY-101 RAPID Mitigation System"

- HNF-4407, "Specification for SY-101 RAPID Mitigation System Hose and Hose Assembly" 


\subsubsection{Drawings Reviewed}

H-14-103558, Sheet 1 of 2, Rev. 0 H-14-103559, Sheet 1 of 2, Rev. 0 H-14-103565, Sheet 2 of 2, Rev. 0 H-14-103570, Sheet 1 of 2, Rev. 0 H-14-103591, Sheet 1, Rev. 0 H-14-103610, Sheet 1, Rev. 0 H-14-103640, Sheet 1 of 2, Rev. 0 H-14-103641, Sheet 1 of 3, Rev. 0 H-14-103641, Sheet 3 of 3, Rev. 0 H-14-103643, Sheet 1 of 3, Rev. 0 H-14-103643, Sheet 3 of 3, Rev. 0 H-14-103649, Sheet 1 of 6, Rev. 0 H-14-103649, Sheet 3 of 6, Rev. 0 H-14-103649, Sheet 5 of 6 , Rev. 0 H-14-103651, Sheet 1 of 1, Rev. 0 H-14-103652, Sheet 2 of 2, Rev. 0 H-14-103653, Sheet 2 of 5, Rev. 0 H-14-103653, Sheet 4 of 5, Rev. 0 H-14-103654, Sheet 1 of 4, Rev. 0 H-14-103654, Sheet 3 of 4, Rev. 0 H-14-103655, Sheet 1 of 2, Rev. 0 H-14-103656, Sheet 1 of 1 , Rev. 0
H-14-103558, Sheet 2 of 2, Rev. 0 H-14-103565, Sheet 1 of 2, Rev. 0 H-14-103566, Sheet 1, Rev. 0 H-14-103590, Sheet 1, Rev. 0 H-14-103607, Sheet 1 of 1 , Rev. 0 H-14-103616, Sheet 1, Rev. 0 H-14-103640, Sheet 2 of 2, Rev. 0 H-14-103641, Sheet 2 of 3, Rev. 0 H-14-103642, Sheet 1 of 1 , Rev. 0 H-14-103643, Sheet 2 of 3, Rev. 0 H-14-103647, Sheet 1 of 1 , Rev. 0 H-14-103649, Sheet 2 of 6, Rev. 0 H-14-103649, Sheet 4 of 6, Rev. 0 H-14-103649, Sheet 6 of 6, Rev. 0 H-14-103652, Sheet 1 of 2, Rev. 0 H-14-103653, Sheet 1 of 5, Rev. 0 H-14-103653, Sheet 3 of 5, Rev. 0 H-14-103653, Sheet 5 of 5, Rev. 0 H-14-103654, Sheet 2 of 4, Rev. 0 H-14-103654, Sheet 4 of 4, Rev. 0 H-14-103655, Sheet 2 of 2, Rev. 0

\subsubsection{Reference Documents}

Benegas, T. R., Engineering Task Plan for Waste Transfer from Tank 241-SY-101 to 241-SY-102, HNF-4044, dated April 27, 1999.

Estey, S. D., Draft Process Control Plan for Tank 241-SY-101 Surface Level Rise Remediation, HNF-4264, dated March 29, 1999. (Appendix N)

Kripps, L. J., Draft Control Decision Record - Tank 241-SY-101 Waste Transfer, dated May 1999. (Appendix M)

Noorani, Y. G., Tank Waste Remediation System Basis for Interim Operation, Revision 1-C, dated March 4, 1999.

Noorani, Y. G., Tank Waste Remediation System Technical Safety Requirements, Revision 0-R, dated March 10, 1999. 
HNF-4519

Revision 0

\subsection{REVIEW OBJECTIVES}

The objective of the system design review for the SY-101 RAPID Mitigation System was to provide a technical assessment of the acceptability of the system design. Since the design progressed at an accelerated rate, the system review provided a determination of the overall system satisfaction of process, nuclear safety, industrial safety, acceptance testing, availability, operability, and maintainability, and radiological control aspects of the design. Where the design was sufficiently mature, the detailed implementation of design requirements was addressed.

In some cases, detailed component level design to implement the system design basis has been finalized, while in others only the overall system design has been finalized. For the case where only the system design is complete, the system design review objective was to ensure that appropriate criteria and requirements are established to ensure that any alternative satisfies the basic system needs.

If multiple designs were fully developed, each option was reviewed. The objective in these cases was to ensure that management decisions based on schedule and cost may be treated independently of the technical concept selected since each alternative meets its design requirements.

Review comments for which dispositions have not been accepted were placed in to one of three categories: (1) requires closure for system design, (2) requires closure in implementing the design or prior to system operation, or (3) recommendations for risk reduction to be implemented if cost and schedule allow.

\subsection{SUMMARY}

Based on the system design reviews performed, the SY-101 Surface-Level-Rise Remediation Project waste transfer system was found to meet the applicable requirements related to system design. Some engineering calculations are still being completed and need to be documented; however, because of SY-101 Surface-Level-Rise Project time constraints, a number of activities are being completed in parallel. Material procurements, fabrication and field construction are underway proceeding at some risk.

Two designs were reviewed for the transfer line -- a hose in an encasement pipe and a hose in an encasement hose. Both designs were found acceptable. The existing available facility electrical power was found deficient. The planned design solutions; 1) upgrade the existing power distribution system and/or 2) provide temporary additional portable power, are acceptable.

As each item on the Design Review Checklist and the remaining open items from individual reviews were evaluated, the item was checked against these categories. None of the Design Review Checklist items or remaining open action items from individual 
reviews requires disposition prior to accepting the system design. The Design Review Committee concludes that applicable criteria are in place, and the system is ready for design implementation.

\subsection{ALTERNATIVES}

During the conduct of the system design review, numerous solutions to identified problems were considered. This section summarizes various major alternatives. In addition, the alternatives that were incorporated into the design, based in part on review comments and associated discussions, are indicated.

Review of HNF-3885 resulted in the addition of critical assumptions, a requirement to complete design requirement matrices, and significant rewording of the document to establish the functions and requirements at a level that did not assume particular design alternatives.

The 30\% design review resulted in several significant comments associated with the conceptual design selection of an underground transfer line configuration. The comments and discussion addressed the ability to construct the line in the time constraints of the SY-101 Surface-Level-Rise Project. The comments raised about an underground transfer line were a major factor in selecting the overground transfer line.

Development of assumptions and analyses to meet comments about the electrical design resulted in a specific load redistribution and criteria to ensure alternative power sources are available to meet system needs. A number of specific implementation details were discussed and various options considered, with alternatives selected based on collective programmatic, technical, legal, and radiological inputs.

Multiple design alternatives were also discussed to address the requirement to minimize dome loading while providing adequate shielding, particularly in the area of the Prefabricated Pump Pit (PPP). The use of very conservative radiological source terms for development of the shielding design and determining administrative controls were extensively discussed, resulting in the application of more realistic source terms and application of related engineered features and administrative radiological controls to ensure worker protection.

The review of the design and fabrication specification for the PPP (FNF-4169) addressed specific design alternatives to limit riser loading by changes to the interface with the tank riser. In addition to limiting the riser loading, the alternative selected does not involve Washington Administrative Code periodic surveillance requirements. Numerous issues associated with design details and related alternative design solutions were discussed, which resulted in a design better suited for decontamination. As part of this review, provisions were incorporated for using temporary shielding to allow lighter weight construction of the PPP while limiting the permanently installed weight of the equipment. Based on discussions of various potential accidents and related design concepts that 
would require assignment of functional attributes to the PPP enclosure, the enclosure was required to meet Safety Class requirements, conforming to requirements developed later in the hazard and accident analysis process.

The review of the design and fabrication specification for the transfer pump piping (HNF-4170) addressed alternatives to improve constructability of the piping, minimize potential leakage sources, and ensure proper fit-up of the piping to the pump, the PPP enclosure, the transfer line, and the water supply systems.

The review of the design and fabrication specification for the water skid (HNF-4043) provided discussion of appropriateness of various approaches to satisfy required control, monitoring, and isolation requirements.

Conceptual design for the selected overground transfer option was reviewed at the " $33 \%$ " design review. Alternatives discussed at this review focused on significant radiological control concerns associated with routing a major source of radiation in a relatively unshielded location. These discussions resulted in selection of an administratively controlled high radiation area that would minimize impacts on other operations and maintenance activities in adjacent areas. In addition, significant discussion of the proposed flanged connection design resulted in application of a PUREX connector at the SY-102 discharge to allow dismantling without the requirement to cut the discharge flange, minimizing potential exposure and special cutting and line closure requirements during line removal after use. Maximum radius changes for the encasement piping were incorporated after discussion of alternatives available to ease both installation and removal of the temporary transfer line. The drop leg attachment enclosure at SY-102 was extensively discussed to provide multiple design options for improved accessibility, leakage monitoring, and confinement testing.

\subsection{DOCUMENTATION}

\subsection{DESIGN REVIEW CHECKLIST}

As part of the design review, a design review checklist was prepared to document the overall assessment of system satisfaction of requirements. This checklist addresses major design considerations rather than specific requirements. Open items from the checklist are summarized in Section 3.3.11 of this report. The checklist is included as Appendix A of this report.

\subsection{DESIGN REVIEW COMMITTEE}

The Design Review Committee was selected to provide an independent assessment and review of various aspects of the design for the SY-101 RAPID Mitigation System. Members selected are listed below (note - all members selected by the Chairperson were assigned by agreement with their respective managers): 
- Chairperson: Richard L. Schlosser-Mr. Schlosser was selected by the TWRS Chief Engineer, with concurrence of the Project Manager for the SY-101

Surface-Level-Rise Remediation Project. In addition to satisfying responsibilities of the chairperson, Mr. Schlosser provided specific technical expertise for mechanical engineering and nuclear engineering aspects of the design. He is also a qualified Radiological Control Design Reviewer.

- Alternate Co-Chairperson: Shafik H. Rifaey was selected by the Chairperson to serve as Co-Chairperson. Mr. Rifaey's selection was accepted by both the TWRS Chief Engineer and the Project Manager for the SY-101 Surface-Level-Rise Remediation Project. Mr. Rifaey also provided specific technical expertise for both mechanical engineering and nuclear engineering. He is also a qualified Radiological Control Design Reviewer.

- Alternate Co-Chairperson: Timothy C. Oten was selected by the Chairperson to serve with Mr. Rifaey as Co-Chairperson. Mr. Oten also provided specific technical expertise for both mechanical engineering and instrumentation and controls engineering. He is also a qualified Radiological Control Design Reviewer.

- Secretary: Chris E. Jensen was selected to provide secretarial services and mechanical engineering expertise.

- Secretary: Shakir U. Zaman was selected to provide secretarial services and mechanical engineering expertise.

- Mazen G. Al-Wazani was selected to provide electrical engineering and electrical code expertise. $\mathrm{He}$ is also a qualified Radiological Control Design Reviewer.

- John W. Bloom was selected to provide nuclear safety and licensing expertise. He is a qualified Radiological Control Design Reviewer.

- As the Cognizant Engineer for the SY Tank Farm, Mark H. Brown was selected, to be a design review team member.

- Robert J. Giordano was assigned by the TWRS Radiological Control Manager to provide radiological control expertise.

- John D. Guberski was selected to provide environmental compliance expertise.

- John W. Hobbs was assigned by the TWRS Radiological Control Manager to provide radiological control expertise.

- Rick A. Huckfeldt was selected to provide fire protection and industrial safety expertise. 
- Laroy S. Krogsrud was selected as the Cognizant Safety Engineer for the SY Tank Farm.

- Douglas C. Larsen was selected to provide operations expertise. He is a qualified Radiological Control Design Reviewer.

- Michael L. McElroy was assigned as the Cognizant Quality Assurance Engineer.

- Louis E. Pokos was selected to provide maintenance engineering expertise. He is a qualified Radiological Control Design Reviewer.

- Daniel A. Reynolds was selected to provide process engineering expertise. He is a qualified Radiological Control Design Reviewer.

- Charles C. Scaief, III was selected to provide instrumentation and control engineering and electrical engineering expertise. He is a qualified Radiological Control Design Reviewer.

- Craig P. Shaw was selected to provide pump design engineering expertise. He is a qualified Radiological Control Design Reviewer.

- Hassan H. Ziada was selected to provide structural engineering, stress analysis, and mechanical and structural code compliance expertise.

In addition to the core reviewers identified above, the SY-101 RAPID Mitigation System Cognizant Engineer (Michael F. Erhart), Design Authority (William J. Powell), and Cognizant Engineering Manager (Ronald W. Reed) actively participated in the review and their comments were treated as comments provided by the review team. Messrs. Powell and Reed are also Qualified Radiological Control Design Reviewers.

Since many of the review team activities were conducted at meetings with a large crosssection of project design team members, the inputs of project team members were beneficial in clearly stating the comments. Special acknowledgement for assistance is given to J. R. Biggs for his extensive input to both constructability and operability issues and their resolution, and to Richard M. Pierson for his significant input to and resolution of radiological control and shielding issues.

\subsection{OUTSTANDING ACTION ITEMS}

This Section summarizes outstanding action items resulting from the system design review. The summary is organized into groupings associated with the particular portion of the review that identified the action. 


\subsubsection{Design Requirements, HNF-3885}

Sixty-seven action items were identified in meeting minutes for review of HNF-3885. The action items were incorporated into a listing of all comments received from both internal reviews and the Design Review Committee. The Design Review Committee members reviewed the full disposition document and concurred that all Action Items were provided with acceptable dispositions. No open action items remain.

\subsubsection{Conceptual Design Review (30\%)}

One hundred fifty seven action items were identified in Review Comment Records, including forty-five action items identified in meeting minutes for review sessions conducted February 16-17, 1999. Remaining open action items are summarized below:

- RCR 45: "Replacement of the pump is a critical should seismic or other conditions warrant. The design needs to include provisions (including removal hardware) for pump replacement. Also, procedures and training need to be developed to enable timely pump replacement."

The design impacts have been addressed. Training and Procedure development remain open. The open action item is in the second category, i.e., "requires closure in implementing the design or prior to operation." (see Section 1.4). The system design is acceptable. Resolution is required prior to system operation.

- RCR 84: "Why is the drop leg at 160 inches? Justify and document the length?"

The design was set to prevent disturbance of the sludge layer in Tank 241-SY-102 and provide adequate mixing of the transferred waste to ensure waste compatibility (control phosphate settling). The minimum waste level in Tank 241-SY-102 must be sufficiently above the drop leg discharge to mitigate ammonia release and remains an open item. The open action item is in the second category (see Section 1.4). The system design is acceptable. This minimum submergence needs to be ensured by Operations prior to system operation. The open action item for RCR 38 in section 3.3.11 also addresses this item from another perspective.

- RCR 93: "Design limits and bases including temperature limits (upper and lower), flow ranges, critical velocities, and dilution rates for the dilution and flush water need to be provided."

The design has been established based on the developed functions and requirements provided by HNF-3885 and input taken from the draft of HNF-4264. Design limits and bases need to be conformed to the approved HNF-4264 after its release. The open item is in the second category (see Section 1.4). The system design is acceptable. The design limits and capabilities of the structures, systems and 
components of the SY-101 RAPID Mitigation System need to be confirmed as part of design implementation.

- RCR 98: "Instrumentation needs to reflect the logic of operations developed in the Process Control Plan as well as critical characteristics and interactions of the system and its components."

As is the case for RCR 93 above, the instrumentation design was established based on the developed functions and requirements provided by HNF- 3885 with input taken from the draft of HNF-4264. Instrumentation application needs to conform to the approved HNF-4264 after its release. The open item is in the second category (see Section 1.4). The system design is acceptable. The suitability of the instrumentation for the SY-101 RAPID Mitigation System needs to be confirmed with both the Process Control Plan and the completed safety analysis as part of design implementation.

\subsubsection{Prefabricated Pump Pit, HNF-4169}

Twenty action items were identified in meeting minutes on March 9, 1999. The remaining open action item is summarized below:

- Action Item 99-007-018: The committee recommended that a painting specification be provided to ensure proper coating materials are applied. The project agreed to provide this specification after HNF-4169 is issued.

The painting specification is required to ensure that carbon steel components are protected from the environment. The open action item is in the second category (see Section 1.4). The system design is acceptable. Resolution is required as part of design implementation.

\subsubsection{Transfer Pump Piping, HNF-4170}

Eight action items were identified in meeting minutes on March 9, 1999. No open action items remain.

\subsubsection{Mobile Water Support Skid, HNF-4043}

Eight action items were identified in meeting minutes on March 10,1999. No open action items remain. 


\subsubsection{Overground Transfer Line (OGT)}

Twenty-one action items were identified in meeting minutes on March 11, 1999. The remaining open action item is summarized below:

- Action Item 99-009-014: A concern was raised as to the meaning of the OGT being "temporary". The project agreed to establish some end of activity to begin D\&D activities.

The Application of a "temporary" designation is necessary to ensure that use of various system components such as power and instrument cables, are confirmed to be acceptable. The end of activity for the overground transfer line needs to be defined. The open action item is in the second category (see Section 1.4). The system design is acceptable. Resolution is required as part of design implementation.

\subsubsection{Anti-Siphoning Slurry Distributor Assembly, HNF-4216}

Eighteen action items were identified in meeting minutes on March 25, 1999. No open action items remain.

\subsubsection{Structural Design Criteria, HNF-4252}

Three action items were identified in meeting minutes on March 26, 1999. No open action items remain.

\subsubsection{Electrical Installation, ECN 647721}

Thirty-four action items were identified in meeting minutes on April 9, 1999. No open action items remain.

\subsubsection{Mobile Water Support Skid, ECN 653826 to HNF-4043}

Ten action items were identified in meeting minutes on April 13, 1999. No open action items remain.

\subsubsection{System Design Review and Hose in Hose Option, HNF-4407}


Forty-six action items were identified by RCRs generated during review of the system design of the SY-101 RAPID Mitigation System and review of the Hose in Hose Option Specification, HNF-4407. The remaining open action items are summarized below:

- RCR 3: "How is ASME B31.1 applied? What testing is applied to ensure the hose does not leak in actual application? How do you show equivalency to ASME Section III requirements? We also need an analysis for evaluating the tensile strength. It was suggested that a group evaluate all aspects of HAHA [hose and hose assembly] design."

DOE Order 6430.1A requires that Safety Class designs comply with ASME III or other comparable safety related codes and standards appropriate for the system being designed. The standards for synthetic rubber hose only address inspection and testing of hoses; they do not address analysis of the hose design. The hose will be qualified for service based on an engineering evaluation to document compliance with the requirements comparable to ASME III and testing of the hose to demonstrate it's suitability for service. The open action item is in the second category (see Section 1.4). The system design is acceptable. The engineering evaluation and suitability testing must be completed as part of design implementation.

- RCR 4: "Provide heat transfer analysis for heat trace and airflow effects on the primary and secondary hose."

The hose in hose assembly is heat traced and insulated to prevent the waste from cooling as it is transferred. A heat transfer analysis is being performed to determine the appropriate set point for the heat trace temperature controller and to confirm that the operating temperature of the hose material is not exceeded. The open action item is in the second category (see Section 1.4). The system design is acceptable. The analysis must be documented as part of design implementation.

- RCR 6: "Mark Brown will set up a meeting to resolve concerns and issues regarding draining and supporting the transfer line [hose in hose option]."

A meeting was held on May 13, 1999. Discussion at the meeting indicated a number of unresolved issues related to drainage and support of the hose in hose transfer line should this option be selected. Design alternatives vary from allowing the line to follow the existing contour of the soil to providing a supporting berm for continuous slope from SY-101 to SY-102. Allowing the line to follow the surface contour will result in a dead-leg that is approximately one foot below the discharge at SY-102 and two feet below the attachment at the PPP at SY-101. Although flushing will provide some removal of radioactive material, administrative control of transfer line removal will be required to ensure proper drainage of the hose after completion of the transfer. The open action item is in the second category (see Section 1.4). The system design is acceptable. Transfer line routing and drainage provisions must be completed and documented as part of design implementation. 
- RCR 7: "A requirement to engineering evaluation for the hose assembly stress evaluation will be added to the SDC [Structural Design Criteria] in HNF-4252."

The hose in hose assembly design needs to be structurally analyzed to appropriate criteria for the application. The proposed design analysis will address fluid flow reaction forces for steady-state and transient conditions. Support structures and restraints for reaction loads and applicable natural phenomena loads will also be included in the analysis. The open action item is in the second category (see Section 1.4). The system design is acceptable. Applicable acceptance criteria must be included in the criteria of HNF-4252 and a requisite analysis completed and documented as part of design implementation.

- RCR 10: "Add local alarms for the leak detectors on the P\&ID."

The specific action requested by this comment has been addressed; however, potential impacts to other documentation have not been finalized. The open action item is in the second category (see Section 1.4). The system design is acceptable. All design impacts must be resolved as part of design implementation.

- RCR 11: "MEL [Master Equipment List] shall include instrument set points and accuracy and should reference any calculations. This shall be referenced as a note on the drawing."

A definitive response has not been provided for this comment. The concern reflected by the comment is that instrument set points and accuracy are design requirements that must be documented in appropriate locations to maintain configuration management of the information. The open action item is in the second category (see Section 1.4). The system design is acceptable. Applicable configuration control needs to be established for these design details and instrument set point and accuracy requirements documented as part of design implementation.

- RCR 13: "HNF-3885 needs to be revised. This shall also include the limits of the VFD [variable frequency drive]."

HNF-3885 provides functions and requirements for the SY-101 RAPID Mitigation System. The document needs to provide all functions and requirements imposed on the design. Also, the document was prepared before related safety and process control analyses were finalized. Criteria for the system must be revised to be consistent with safety analysis, process control, and other applicable requirements developed after the document was issued. Specific conditions assumed in the initial issue of the functions and requirements need to conform to an analysis completed afterward. Spare VFD units have been procured as like-for-like replacements, not requiring imposition of specific component requirements. The open action item is in the second category (see Section 1.4). The system design is acceptable. For system acceptance, the finalized functions and requirements must documented as part of design implementation. 
- RCR 21: "H-14-103641: Comments by Mazen [M. G. Al-Wazani] need to be resolved before May 28, 1999."

Specific design media corrections are required. Specific corrections identified have been incorporated and drawing release is in process. The open action item is in the second category (see Section 1.4). The system design is acceptable. For system acceptance, the design must be documented on appropriate design media as part of design implementation. The HOLD Point has been removed.

- RCR 25: "Electrical power load analysis shall be completed to show adequacy of power to meet system demand. The load analysis shall be prepared as a revision to the facility loading analysis. Both the 252-S facility load analysis and the revision ECN shall be completed and issued by May $28^{\text {th }}$."

The adequacy of the power supply is critical to system design. Directed changes were incorporated into HNF-3885 to ensure that power sources are appropriately evaluated for adequacy and appropriate design features are incorporated. The open action item is in the second category (see Section 1.4). The system design is acceptable. For system acceptance, the design must be within the capabilities of the electrical power supply system provided as part of design implementation. With revision of the criteria to establish appropriate requirements for electric power supply, the HOLD and completion date identified with this item have been removed.

- RCR 26: "An evaluation shall be performed whether lightning protection is warranted for the new 101-SY to 102-SY transfer line and its associated components."

Lightning protection needs to be consistent with the conditions analyzed in the facility Authorization Basis. The open action item is in the second category (see Section 1.4). The system design is acceptable. For system acceptance, the SY-101 RAPID Mitigation System design must be shown to comply with requirements of the Authorization Basis as part of design implementation.

- RCR 27: "A red line mark up of electrical [and instrumentation] drawings has been provided to Jerry Wilk. These comments need to be resolved."

Comments included on electrical drawings depict changes necessary to adequately describe the facility on design media. As a normal part of the design process, incorporation of comment resolutions on the drawings is being completed. The open action item is in the second category (see Section 1.4). The system design is acceptable. For system acceptance, the drawings must document the system configuration as part of design implementation.

- RCR 36: "[On drawing H-14-] 103616, to allow the waste flowmeter to operate full, there is space in the spool piece following it to put in an offset - to allow a high 
point in the system. This change is simple, inexpensive and fast; it would do a lot of good for process control. It is recommended for good engineering and process control improvement, if we do not have time, this goes away. If the next comment (37) is implemented this goes away."

Based on extensive discussion, changes to the installation would have an unacceptable impact on the implementation schedule. Flowmeter accuracy will be evaluated during system operation; however, it has been assessed to be acceptable to allow an initial setting of dilution flow. The open action item is in the third category; i.e., recommended for risk reduction if cost and schedule allow (see Section 1.4). The system design is acceptable. Since the operational requirement has been satisfied by the current design, improvement of the design is desirable for risk reduction.

- RCR 37: "[On drawing H-14-] 103616, to allow the waste flowmeter to operate full we could put in a valve between valves V-354, -355 and pressure switch PS-370. This would allow an operational high point purge and allow us to recycle diluted waste to SY-101. This could be a possible solution to some of the problem of crust level rise and is recommended - if time allows."

Based on extensive discussion, changes to the installation would have an unacceptable impact on the implementation schedule. Flowmeter accuracy will be evaluated during system operation; however, it has been assessed to be of acceptable accuracy to allow an initial setting of dilution flow. The open action item is in the third category (see Section 1.4). The system design is acceptable. Since the operational requirement has been satisfied by current design, improvement of the design is desirable for risk reduction.

- RCR 38: "[On drawing H-14-] 103590, the dropleg is shown at 160 inches above the tank bottom. The lower administrative level for the tank level is 130 inches. Modify the dropleg to add 30 inches to extend it to 130 inches from the tank bottom. This will allow the dropleg to be covered whenever the next cross-site transfer is done. This will allow us the flexibility in this and other transfers."

This condition is related to the conceptual design review comment, RCR 84, described in Section 3.3.2 above. A longer drop leg would provide more flexible operation of the system; however, the design would require evaluation for impact on various parameters governed by the process controls developed. This open action item is in the third category (see Section 1.4). The system design is acceptable. Disposition to provide a drop leg of greater length would provide risk reduction, cost and schedule permitting. The open action item for RCR 84 in Section 3.3.2 also addresses this item from another perspective.

- RCR 39: "[On drawing H-14-] 103607, the identifiers C, D, and $\mathrm{J}$ do not appear to be accurate. The $\mathrm{C}$ identifier, primary transfer line, should be 370 psi working pressure, and 60 psi working pressure for the encasement. Both at $155^{\circ} \mathrm{F}$, per 
HNF-4407. What does SST mean? Is this appropriate in identifier C? Identifier J does not exist with hose in hose line design. Revise."

Values developed for HNF-4407 will be included, as applicable, and Item J has been deleted, consistent with the disposition of RCR 31 from this review. The open action item is in the second category (see Section 1.4). The system design is acceptable. For system acceptance, the drawings must document the system configuration as part of design implementation.

- RCR 43: "Same comment [as RCR comment 42] for pump outlet line flush, and pump internal flush. The pump internal flush, how did we get $10 \mathrm{gpm}$ ? Is it a limit? Best estimate? Sounds low for pump internals."

The disposition provided delineates the basis for selection of the value and describes anticipated system performance. The open action item is in the second category (see Section 1.4). The system design is acceptable. For system acceptance, the basis for the flow value, limit, and related information must confirmed to be acceptable as part of design implementation.

- RCR 45: "[On drawing H-14-] 103656, P\&ID, we need something to slow down the flow of water, from the 75 gal. Tank, during emergency conditions (loss of power at the water skid). This will allow the operator time to monitor the flush water to the pump and to the transfer line. The option recommended is an orifice at the outlet of the75 gal. Tank that could fit between two flanges. The rate needs to be reduced to about $45 \mathrm{gal} / \mathrm{min}$. This will allow half of the volume to be flushed to the pump $(47 \mathrm{sec}$.) and half to the line. HOLD Point."

Initial requirements imposed included the requirement to provide transfer line flushing in the event of a loss of the water supply for flow dilution. The system provides termination of the transfer and immediate flush of the transfer line as originally required. This open action item is in the second category (see Section 1.4). The system design is acceptable. Adequacy of protection provided for the transfer pump under upset indications must be resolved as part of design implementation. The HOLD Point is removed.

- RCR 46: "The process flow meter must have a totalizer on it. H-14-103652 shows FIT-367 to be a "LCD INDICATOR/TOTALIZER." This is what is necessary for process control. H-14-103656 does not show the totalizer function for FE-367. HOLD Point."

See related discussions for the open action items, RCR 36 and RCR 37, in this section above. Based on extensive discussion, changes to the installation are easily incorporated into the design. This design change may provide useful data for confirmation of the material balance required and may prove valuable if acceptable accuracy can be verified during initial operation of the system. Flow totalizer accuracy will be evaluated during system operation. The open action item is in the 
third category (see Section 1.4). The system design is acceptable. Since the operational requirement for flow balance setting and performance of required mass balances have been satisfied by current design, this improvement of the design is not required, but rather, desirable for risk reduction. The design team has agreed to add the totalizer function. The HOLD Point is removed.

In addition to the remaining open items from the system design review, several open items were identified from the Design Review Checklist. These open items are summarized below:

- Calculation completion - There are several engineering calculations that need to be completed and documented. The analyses are continuing; however, because of the time constraints required to complete the first waste transfer, construction is already underway and proceeding at risk. This item is in the second category (see Section 1.4). The system design is acceptable. Design calculations must be completed and issued as part of design implementation.

- The structural design criteria assumption that "vortex shedding loads created by jet flow past the transfer pump will not develop" requires verification. Similar analyses have been performed for other equipment demonstrating component load applicability. This item is in the second category (see Section 1.4). The system design is acceptable. The assumption must be verified as part of design implementation.

- Assumptions, requirements, and criteria included in the Functional Requirements and Technical Criteria that were based on preliminary safety analysis and process control information must be verified with final information. This item is in the second category (see Section 1.4). The system design is acceptable. Requirements and criteria must conform to the design basis as part of design implementation.

- Design based on current draft information, e.g., safety analysis results (as described in Control Decision Records) and process controls (as described in the Process Control Plan), must be verified with final information. This item is in the second category (see Section 1.4). The system design is acceptable. Design must conform to the design basis as part of design implementation.

- Additional testing requirements for the transfer line encasement must be finalized for the encasement hose option. This item is in the second category (see Section 1.4). The system design is acceptable. Appropriate quality requirements for the encasement hose must be documented as part of design implementation.

- A compliance matrix to identify requirements, the design attributes that satisfy the requirements, and the Structures, Systems, and Components (SSCs) that implement the requirements must be completed. This item is in the second category (see Section 1.4). The system design is acceptable. Ensured compliance with requirements is necessary as part of design implementation. 
- The implementation of electrical power supply requirements based on a load analysis must be completed. This item is in the second category (see Section 1.4). The system design is acceptable. The electrical power system interfaces and design must be completed as part of design implementation.

- Routing of the hose-in-hose transfer line including hydraulic gradient must be finalized. In particular, the gradient of the hose to be self draining to SY-102 or with a dead leg between the PPP and SY-102 must be finalized by considering a combination of radiological controls, shielding, access restrictions, line protection, and worker protection concerns. The resolution must address installation and removal as well as operation of the system. This item is in the second category (see Section 1.4). The system design is acceptable. The hose-in-hose option routing and gradient must be completed as part of design implementation if this option is selected. See also RCR 6 above.

- Critical Characteristics for each safety-related component must be defined. This item is in the second category (see Section 1.4). The system design is acceptable. Critical characteristics must be determined to ensure that appropriate equipment qualification requirements are established as part of design implementation. 
HNF-4519

Revision 0

\section{APPENDIX A}

\section{DESIGN REVIEW CHECKLIST SYSTEM DESIGN REVIEW}




\section{APPENDIX A}

DESIGN REVIEW CHECKLIST

System Design Review

\begin{tabular}{|c|c|c|c|}
\hline \multicolumn{2}{|c|}{ SY-101 RAPID MITIGATION SYSTEM } & \multirow{2}{*}{$\begin{array}{l}\text { Applicable } \\
\text { (yes/no/NA) }\end{array}$} & \multirow{2}{*}{$\begin{array}{l}\text { Design Review Remarks } \\
\text { And Pending Actions }\end{array}$} \\
\hline Item & Review Consideration & & \\
\hline \multicolumn{4}{|c|}{ DESIGN BASIS } \\
\hline 1 & $\begin{array}{l}\text { Have assumptions necessary to perform } \\
\text { the design task been adequately } \\
\text { described and are they reasonable? }\end{array}$ & Yes & $\begin{array}{l}\text { Assumptions have been delineated in HNF- } \\
3885 \text {, Section } 1.2 .1 \text { and Control Decision } \\
\text { Records. }\end{array}$ \\
\hline 2 & $\begin{array}{l}\text { Have assumptions been identified for } \\
\text { verification during design execution or } \\
\text { when the design has been completed? }\end{array}$ & Yes & $\begin{array}{l}\text { Assumptions associated with waste volume } \\
\text { and waste compatibility require completion of } \\
\text { a waste compatibility assessment prior to } \\
\text { transfer, which is required for any transfer. } \\
\text { Assumptions identified related to safety } \\
\text { classification in HNF-3885, Revision 0 } \\
\text { require verification based on the hazard and } \\
\text { accident analysis performed. This has been } \\
\text { imposed as a requirement during the design } \\
\text { review process and must be completed as part } \\
\text { of design implementation. } \\
\text { The assumption in HNF-4252 that "vortex } \\
\text { shedding loads created by jet flow past the } \\
\text { transfer pump [from mixer pump operation in } \\
\text { tank SY-101] will not develop" requires } \\
\text { verification. This assumption must be verified } \\
\text { as part of design implementation. } \\
\text { Design based on the draft Process Control } \\
\text { Plan (HNF-4264) must be verified as part of } \\
\text { the design implementation. Although not } \\
\text { specifically stated as an assumption in the } \\
\text { documentation reviewed, all design has been } \\
\text { based on a draft of the Process Control Plan } \\
\text { and close coordination of the design with } \\
\text { ongoing development of the Process Control } \\
\text { Plan. As part of design implementation, } \\
\text { design must be verified against the issued } \\
\text { HNF-4264. }\end{array}$ \\
\hline 3 & $\begin{array}{l}\text { Has testing been defined to complete } \\
\text { verification after design completion? }\end{array}$ & Yes & $\begin{array}{l}\text { The hose supplier will perform pressure } \\
\text { testing and vacuum testing of the hose prior to } \\
\text { shipment. The pressure test will be } \\
\text { performed at } 150 \% \text { of the rated pressure, in } \\
\text { accordance with ASME B } 31.3 \text {. Due to the } \\
\text { unique application, additional testing will be } \\
\text { defined and performed after receipt as part of } \\
\text { design implementation. }\end{array}$ \\
\hline
\end{tabular}




\section{APPENDIX A \\ DESIGN REVIEW CHECKLIST \\ System Design Review}

\begin{tabular}{|c|c|c|c|}
\hline \multicolumn{2}{|c|}{ SY-101 RAPID MITIGATION SYSTEM } & \multirow{2}{*}{$\begin{array}{l}\text { Applicable } \\
\text { (yes/no/NA) }\end{array}$} & \multirow{2}{*}{$\begin{array}{c}\text { Design Review Remarks } \\
\text { And Pending Actions }\end{array}$} \\
\hline Item & Review Consideration & & \\
\hline 3 & (continued) & & $\begin{array}{l}\text { All other testing appropriate for design } \\
\text { verification has been identified and specified } \\
\text { for various portions of the design. The } \\
\text { system design precludes full testing of the } \\
\text { completed system with simulated or actual } \\
\text { materials, geometry, and environmental } \\
\text { conditions. }\end{array}$ \\
\hline 4 & $\begin{array}{l}\text { Have adequate acceptance criteria been } \\
\text { specified and are the verification } \\
\text { methods stated appropriately? }\end{array}$ & Yes & $\begin{array}{l}\text { Equipment acceptance criteria have been } \\
\text { established and imposed on the suppliers to } \\
\text { ensure that equipment provided has } \\
\text { satisfactorily met specified requirements. } \\
\text { Component and equipment acceptance criteria } \\
\text { have also been established to verify } \\
\text { subassemblies completed on site to verify } \\
\text { performance. Run-in testing of the transfer } \\
\text { pump has been specified and performed to } \\
\text { verify suitability of the pump for the } \\
\text { application. To the extent practical, } \\
\text { verification by specific testing has been } \\
\text { specified. }\end{array}$ \\
\hline 5 & $\begin{array}{l}\text { Have the appropriate Quality Assurance } \\
\text { requirements been specified? }\end{array}$ & Yes & $\begin{array}{l}\text { Specific quality assurance requirements have } \\
\text { been imposed in design/construct } \\
\text { specifications and procurement } \\
\text { documentation. See HNF-4043, HNF-4169, } \\
\text { HNF-4170, HNF-4216, and HNF-4407 for } \\
\text { application of both standard, and where } \\
\text { appropriate for the design application, } \\
\text { augmented Quality Assurance requirements } \\
\text { for testing, inspections, and documentation } \\
\text { have been applied. Engineered equipment } \\
\text { has been provided by vendors qualified to } \\
\text { NQA-1. }\end{array}$ \\
\hline 6 & Were sources of information identified? & Yes & $\begin{array}{l}\text { Sources have been delineated for design, } \\
\text { environmental, and process information } \\
\text { utilized in developing design. Interfaces with } \\
\text { existing facilities have been attributed to } \\
\text { applicable facility documentation (in addition, } \\
\text { the design provided updating of interface } \\
\text { documents to ensure configuration } \\
\text { management). }\end{array}$ \\
\hline
\end{tabular}




\section{APPENDIX A}

\section{DESIGN REVIEW CHECKLIST}

\section{System Design Review}

\begin{tabular}{|c|c|c|c|}
\hline \multicolumn{2}{|c|}{ SY-101 RAPID MITIGATION SYSTEM } & \multirow{2}{*}{$\begin{array}{l}\text { Applicable } \\
\text { (yes/no/NA) }\end{array}$} & \multirow{2}{*}{$\begin{array}{l}\text { Design Review Remarks } \\
\text { And Pending Actions }\end{array}$} \\
\hline Item & Review Consideration & & \\
\hline 7 & $\begin{array}{l}\text { Does the design meet the established } \\
\text { requirements and/or design criteria? }\end{array}$ & Yes & $\begin{array}{l}\text { The system has been designed to the } \\
\text { requirements of HNF-3885. In addition, the } \\
\text { design activity requires development of } \\
\text { compliance matrices to document satisfaction } \\
\text { of regulatory, environmental, and process } \\
\text { control requirements. Equipment relied on } \\
\text { for safety is identified in a Safety Equipment } \\
\text { List being developed in concert with } \\
\text { completion of the hazard and accident } \\
\text { analysis performed for the system. }\end{array}$ \\
\hline 8 & $\begin{array}{l}\text { Does the design meet established } \\
\text { requirements for associated system } \\
\text { physical and functional interfaces? }\end{array}$ & Yes & $\begin{array}{l}\text { Physical and functional interface requirements } \\
\text { are specified in HNF-3885. Where interfaces } \\
\text { have been found incompatible with available } \\
\text { physical and functional interfaces, the design } \\
\text { requirements have been revised to reflect as- } \\
\text { found interface conditions. The electrical } \\
\text { power interface with the } 252-S \text { substation was } \\
\text { found to be inadequately specified in HNF- } \\
3885 \text {. HNF- } 3885 \text { has been revised to correct } \\
\text { this deficiency. }\end{array}$ \\
\hline 9 & $\begin{array}{l}\text { Have the interface requirements with } \\
\text { existing facility documentation been } \\
\text { clearly presented? }\end{array}$ & Yes & $\begin{array}{l}\text { As stated in Item } 6 \text { above, interface } \\
\text { requirements with the existing facility have } \\
\text { been clearly defined, including update of } \\
\text { existing facility documentation and field } \\
\text { verification of interface conditions. }\end{array}$ \\
\hline 10 & Are there any open interface problems? & Yes & $\begin{array}{l}\text { The system interface with existing facility } \\
\text { electrical power has been identified as a } \\
\text { problem. The requirements of HNF- } 3885 \text { are } \\
\text { being changed to provide specific } \\
\text { requirements for augmentation of power from } \\
\text { the } 252-S \text { substation. }\end{array}$ \\
\hline 11 & $\begin{array}{l}\text { Have engineering standards and criteria } \\
\text { been specified properly in the design? }\end{array}$ & Yes & $\begin{array}{l}\text { Engineering standards and criteria have been } \\
\text { specified properly. HNF }-3885 \text { requires } \\
\text { application of appropriate standards and } \\
\text { criteria. }\end{array}$ \\
\hline 12 & $\begin{array}{l}\text { Has appropriate consideration been } \\
\text { given to use of standardized parts, } \\
\text { materials and processes? }\end{array}$ & Yes & $\begin{array}{l}\text { The design incorporates application of TWRS } \\
\text { standardized designs, such as application of } \\
\text { PUREX connectors, leak detector circuit } \\
\text { design, and valve operator connections. }\end{array}$ \\
\hline
\end{tabular}




\section{APPENDIX A}

\section{DESIGN REVIEW CHECKLIST}

System Design Review

\begin{tabular}{|c|c|c|c|}
\hline \multicolumn{2}{|c|}{ SY-101 RAPID MITIGATION SYSTEM } & \multirow{2}{*}{$\begin{array}{l}\text { Applicable } \\
\text { (yes/no/NA) }\end{array}$} & \multirow{2}{*}{$\begin{array}{c}\text { Design Review Remarks } \\
\text { And Pending Actions }\end{array}$} \\
\hline ltem & Review Consideration & & \\
\hline 13 & $\begin{array}{l}\text { Does the design represent the simplest } \\
\text { design consistent with functional } \\
\text { requirements and expected service } \\
\text { conditions? }\end{array}$ & Yes & $\begin{array}{l}\text { The design has been simplified to the extent } \\
\text { practical for operation and maintenance of the } \\
\text { system. Based on incorporation of design } \\
\text { features to simplify installation, inspection, } \\
\text { and removal, the system has been designed to } \\
\text { specifically meet the expected service } \\
\text { conditions, with full design consideration of } \\
\text { decontamination and radiological control } \\
\text { needs, especially for removable temporary } \\
\text { portions of the system. }\end{array}$ \\
\hline 14 & $\begin{array}{l}\text { Are the applicable codes, standards, and } \\
\text { requirements, including revisions, } \\
\text { property identified and are their design } \\
\text { requirements provided for? }\end{array}$ & Yes & $\begin{array}{l}\text { Specific codes, standards, and requirements } \\
\text { have been delineated in HNF-3885, in } \\
\text { addition to application of codes and standards } \\
\text { compatible with interfacing systems. } \\
\text { Supplemental requirements have been } \\
\text { specified, where appropriate, to ensure } \\
\text { satisfaction of potentially inconsistent or more } \\
\text { stringent requirements. }\end{array}$ \\
\hline 15 & $\begin{array}{l}\text { Does the design minimize life-cycle cost } \\
\text { to the extent practicable? }\end{array}$ & Yes & $\begin{array}{l}\text { The design has provided simplified design for } \\
\text { components that are anticipated to need } \\
\text { periodic replacement, such as the transfer line } \\
\text { design. }\end{array}$ \\
\hline 16 & $\begin{array}{l}\text { Have available data on similar designs } \\
\text { been considered? }\end{array}$ & Yes & $\begin{array}{l}\text { The design has relied on similar applications } \\
\text { for transfer systems. The transfer pump was } \\
\text { selected based on availability to support the } \\
\text { urgent need to provide the installed system. } \\
\text { Although the pump is not a comparable } \\
\text { design to other transfer pumps, the pump was } \\
\text { specifically developed for operation in the } \\
\text { intended service. }\end{array}$ \\
\hline 17 & $\begin{array}{l}\text { Does the design meet functional } \\
\text { requirements to: } \\
\text { a Ensure stresses are within design } \\
\text { limits? }\end{array}$ & Yes & $\begin{array}{l}\text { Design for stress has been controlled by HNF- } \\
4252 \text {, developed specifically for system } \\
\text { structural analysis. In addition, pressure } \\
\text { boundary components have been designed to } \\
\text { meet allowable loading conditions. } \\
\text { Calculations will be documented in HNF- } \\
4358 \text {. }\end{array}$ \\
\hline
\end{tabular}


APPENDIX A

DESIGN REVIEW CHECKLIST

System Design Review

\begin{tabular}{|c|c|c|c|c|}
\hline \multicolumn{3}{|c|}{ SY-101 RAPID MITIGATION SYSTEM } & \multirow{2}{*}{$\begin{array}{l}\text { Applicable } \\
\text { (yes/no/NA) }\end{array}$} & \multirow{2}{*}{$\begin{array}{l}\text { Design Review Remarks } \\
\text { And Pending Actions }\end{array}$} \\
\hline Item & & Review Consideration & & \\
\hline 17 & & $\begin{array}{l}\text { Meet defined steady-state, transient, } \\
\text { and faulted conditions? }\end{array}$ & Yes & $\begin{array}{l}\text { Specific design features have been } \\
\text { incorporated to serve all normal operating } \\
\text { conditions. } \\
\text { Transient operation is accommodated by } \\
\text { inclusion of design features to provide } \\
\text { flushing and break siphon on transfer pump } \\
\text { shutdown. } \\
\text { To address potential faulted conditions, such } \\
\text { as loss of power, instruments have been } \\
\text { provided with fail-safe design or are powered } \\
\text { from the same source as the equipment } \\
\text { requiring shutdown to restore safe conditions. } \\
\text { To minimize potential for line plugging and } \\
\text { personnel exposure, the design has been } \\
\text { provided with a pressurized flush water } \\
\text { reservoir. }\end{array}$ \\
\hline 18 & & $\begin{array}{l}\text { I the design meet the following } \\
\text { ironmental conditions? } \\
\text { Temperature (steady-state and } \\
\text { transient) } \\
\text { Flow (steady-state and transient) } \\
\text { including induced Vibration }\end{array}$ & $\begin{array}{l}\text { Yes } \\
\text { Yes }\end{array}$ & $\begin{array}{l}\text { Equipment has been specified and designed to } \\
\text { meet process control temperature } \\
\text { requirements, including transient conditions. } \\
\text { All system components have been designed to } \\
\text { accommodate design flow conditions. The } \\
\text { primary transfer line is a flexible hose. For } \\
\text { the application, specific analysis is being } \\
\text { performed to ensure that the hose is } \\
\text { appropriately restrained. Starting transients } \\
\text { are controlled by use of a variable frequency } \\
\text { drive to control the transfer pump. } \\
\text { As stated in Item } 2 \text {, the assumption in HNF- } \\
4252 \text { that vortex shedding loads created by jet } \\
\text { flow past the transfer pump [from mixer pump } \\
\text { operation in tank } S Y-101] \text { will not develop } \\
\text { requires verification. }\end{array}$ \\
\hline
\end{tabular}




\section{APPENDIX A \\ DESIGN REVIEW CHECKLIST \\ System Design Review}

\begin{tabular}{|c|c|c|c|c|}
\hline \multicolumn{3}{|c|}{ SY-101 RAPID MITIGATION SYSTEM } & \multirow{2}{*}{$\begin{array}{l}\text { Applicable } \\
\text { (yes/no/NA) }\end{array}$} & \multirow{2}{*}{$\begin{array}{l}\text { Design Review Remarks } \\
\text { And Pending Actions }\end{array}$} \\
\hline item & & Review Consideration & & \\
\hline \multirow[t]{5}{*}{18} & & Pressure (steady-state and transient) & Yes & $\begin{array}{l}\text { Pressure containing components have been } \\
\text { designed to accommodate the design pressure } \\
\text { conditions for their application. Pressure } \\
\text { retaining components are pressure tested at } \\
150 \% \text { of design pressure to ensure } \\
\text { acceptability. } \\
\text { Overpressure protection is provided for } \\
\text { system components that could be exposed to } \\
\text { higher pressure due to the pumps provided as } \\
\text { part of the Mobile Water Support Skid. }\end{array}$ \\
\hline & d & $\begin{array}{l}\text { Seismic/natural phenomena (as } \\
\text { required by safety analysis) }\end{array}$ & Yes & $\begin{array}{l}\text { All components required for safety are being } \\
\text { evaluated for loading due to applicable } \\
\text { seismic and other natural phenomena. }\end{array}$ \\
\hline & & Nuclear radiation & Yes & $\begin{array}{l}\text { All components have been selected to meet } \\
\text { anticipated radiation exposure. }\end{array}$ \\
\hline & $f$ & $\begin{array}{l}\text { For Safety Class items, impact of } \\
\text { non-qualified equipment that will be } \\
\text { near-by ( } 3 \text { over } 1 \text { problem) }\end{array}$ & Yes & $\begin{array}{l}\text { Safety related portions of the system have } \\
\text { been evaluated considering the impact of non- } \\
\text { safety SSCs due to loading combinations } \\
\text { including the response to natural phenomena } \\
\text { events. For example, the PPP enclosure and } \\
\text { the } 241-S Y-101 \text { riser below the PPP are being } \\
\text { analyzed considering the weight and response } \\
\text { of the suspended transfer pump prior t } \\
\text { installation. }\end{array}$ \\
\hline & & Ambient environmental conditions & Yes & $\begin{array}{l}\text { The design SSCs are either protected by } \\
\text { enclosures or designed to perform in the } \\
\text { ambient conditions applicable, as delineated } \\
\text { in HNF- } 3885 \text { and other applicable } \\
\text { documents. } \\
\text { Outdoor electrical equipment is installed in } \\
\text { weatherproof enclosures. Likewise } \\
\text { submerged portions of the transfer pump } \\
\text { motor are designed to provide isolation from } \\
\text { immersion. }\end{array}$ \\
\hline
\end{tabular}


APPENDIX A

DESIGN REVIEW CHECKLIST

System Design Review

\begin{tabular}{|c|c|c|c|}
\hline \multicolumn{2}{|c|}{ SY-101 RAPID MITIGATION SYSTEM } & \multirow{2}{*}{$\begin{array}{l}\text { Applicable } \\
\text { (yes/no/NA) }\end{array}$} & \multirow{2}{*}{$\begin{array}{c}\text { Design Review Remarks } \\
\text { And Pending Actions }\end{array}$} \\
\hline Item & Review Consideration & & \\
\hline 18 & $\mathrm{~g}$ (continued) & & $\begin{array}{l}\text { Components located in areas subject to } \\
\text { potential exposure to elevated levels of } \\
\text { flammable gases have been designed to } \\
\text { applicable requirements of the Authorization } \\
\text { Basis and the specific requirements imposed } \\
\text { for tank SY-101 as a formally classified } \\
\text { NFPA Class I, Division 2, Group B hazardous } \\
\text { location. }\end{array}$ \\
\hline 19 & Have allowable leakages been specified? & Yes & $\begin{array}{l}\text { Primary boundary leakage is limited as } \\
\text { required by the Authorization Basis. This } \\
\text { limitation is specified as a requirement to } \\
\text { limit the total quantity of material released to } \\
\text { less than analyzed for the Authorization } \\
\text { Basis. Leakage is detectable within twenty- } \\
\text { four hours as required by the Washington } \\
\text { Administrative Code. }\end{array}$ \\
\hline 20 & $\begin{array}{l}\text { Does the design meet all established } \\
\text { safety requirements? }\end{array}$ & Yes & $\begin{array}{l}\text { The design has incorporated safety features } \\
\text { necessary to meet industrial safety } \\
\text { requirements. SSCs in exposed locations } \\
\text { have been designed and constructed to meet } \\
\text { OSHA requirements for their application. } \\
\text { The design has incorporated safety features as } \\
\text { Safety Class or Safety Significant to prevent } \\
\text { or mitigate potential accident conditions } \\
\text { developed in the Authorization Basis and } \\
\text { system specific hazard and accident analysis } \\
\text { developed. }\end{array}$ \\
\hline 21 & $\begin{array}{l}\text { Has an acceptable level of radiation } \\
\text { exposure been defined? }\end{array}$ & Yes & $\begin{array}{l}\text { Based on multiple design constraints, the } \\
\text { design has been developed to make provisions } \\
\text { for addition of temporary shielding to } \\
\text { minimize personnel exposure. However the } \\
\text { design constraints led to establishment of a } \\
\text { high radiation work area encompassing to the } \\
\text { system components during transfer system } \\
\text { operations. All other operations are } \\
\text { performed utilizing monitoring and control } \\
\text { stations located to allow operation of the } \\
\text { system without entry into the high radiation } \\
\text { area. }\end{array}$ \\
\hline
\end{tabular}




\section{APPENDIX A \\ DESIGN REVIEW CHECKLIST}

System Design Review

\begin{tabular}{|c|c|c|c|}
\hline \multicolumn{2}{|c|}{ SY-101 RAPID MITIGATION SYSTEM } & \multirow{2}{*}{$\begin{array}{l}\text { Applicable } \\
\text { (yes/no/NA) }\end{array}$} & \multirow{2}{*}{$\begin{array}{l}\text { Design Review Remarks } \\
\text { And Pending Actions }\end{array}$} \\
\hline Item & Review Consideration & & \\
\hline 21 & (continued) & & $\begin{array}{l}\text { The only entry into the high radiation area } \\
\text { will be for two to four minutes post transfer to } \\
\text { initiate flush to further reduce the source } \\
\text { term. Dilution flow will be maximized two to } \\
\text { four minutes prior to planned pump } \\
\text { shutdown. }\end{array}$ \\
\hline 22 & $\begin{array}{l}\text { Have calculations been performed to } \\
\text { define expected radiation exposure and } \\
\text { establish acceptable shielding design? }\end{array}$ & Yes & $\begin{array}{l}\text { Calculations have been performed to } \\
\text { determine radiation exposure and determine } \\
\text { shielding requirements. Based on the } \\
\text { analysis, appropriate exposure minimization } \\
\text { utilizing both design and administrative } \\
\text { controls has been developed. }\end{array}$ \\
\hline 23 & $\begin{array}{l}\text { Have nuclear criticality safety } \\
\text { considerations been incorporated? }\end{array}$ & Yes & $\begin{array}{l}\text { The waste compatibility assessment will } \\
\text { address criticality. In addition, nuclear } \\
\text { criticality safety is addressed by existing } \\
\text { administrative controls. The tanks contain } \\
\text { wastes with a significant quantity of } \\
\text { transuranic material. Concentrations of } \\
\text { transuranic elements in the tanks are low and } \\
\text { the tanks remain highly subcritical. Transfer } \\
\text { of wastes from one tank to another does not } \\
\text { segregate the fissile and fissionable material } \\
\text { from neutron absorbing material. Therefore, } \\
\text { the waste material remains highly subcritical. }\end{array}$ \\
\hline 24 & $\begin{array}{l}\text { Has the design been anaiyzed to } \\
\text { appropriate requirements of HNF-PRO- } \\
097 \text { and is the analysis appropriately } \\
\text { documented? }\end{array}$ & Yes & $\begin{array}{l}\text { HNF-PRO-097 requirements are being } \\
\text { satisfied by application of conditions as } \\
\text { delineated in the TWRS Authorization Basis. } \\
\text { Applicable load combinations and } \\
\text { performance categories for natural } \\
\text { phenomena loads have been determined for } \\
\text { the equipment making up the RAPID } \\
\text { Mitigation System in HNF-4252. }\end{array}$ \\
\hline 25 & $\begin{array}{l}\text { Will separate Acceptance Test } \\
\text { Specification(s)/ Procedure(s) be } \\
\text { required? } \\
\text { - If yes, identify responsible } \\
\text { organization(s) for preparation and issue } \\
\text { (TBD if unknown) }\end{array}$ & Yes & $\begin{array}{l}\text { SY-101 RAPID Mitigation System } \\
\text { Acceptance Tests will be performed as } \\
\text { delineated in the Engineering Task Plan, } \\
\text { HNF-4044 }\end{array}$ \\
\hline
\end{tabular}


APPENDIX A

\section{DESIGN REVIEW CHECKLIST}

\section{System Design Review}

\begin{tabular}{|c|c|c|c|}
\hline \multicolumn{2}{|c|}{ SY-101 RAPID MITIGATION SYSTEM } & \multirow{2}{*}{$\begin{array}{l}\text { Applicable } \\
\text { (yes/no/NA) }\end{array}$} & \multirow{2}{*}{$\begin{array}{c}\text { Design Review Remarks } \\
\text { And Pending Actions }\end{array}$} \\
\hline Item & Review Consideration & & \\
\hline 26 & $\begin{array}{l}\text { Have calculations been developed to } \\
\text { provide proper component specifications } \\
\text { and/or requirements? }\end{array}$ & Yes & $\begin{array}{l}\text { Calculations necessary to specify components } \\
\text { are being prepared for the system. } \\
\text { Structural loads and load combinations are } \\
\text { being calculated to ensure that components of } \\
\text { appropriate design are specified. For } \\
\text { components procured as part of a design and } \\
\text { fabrication specification, applicable loads and } \\
\text { load combinations have been provided in the } \\
\text { specification, or the specification has imposed } \\
\text { submittal requirements for the supplier to } \\
\text { provide the design information for analysis by } \\
\text { the design team. Analysis is scheduled for } \\
\text { completion; however, procurement is } \\
\text { proceeding at risk. }\end{array}$ \\
\hline 27 & $\begin{array}{l}\text { Have safety systems, structures, and } \\
\text { components been identified? }\end{array}$ & Yes & $\begin{array}{l}\text { Through the hazard and accident analysis } \\
\text { process, controls have been developed and } \\
\text { allocated to the systems, structures, and } \\
\text { components (SSCs) of the system. Specific } \\
\text { safety functions are allocated to the safety } \\
\text { SSCs and are being documented in the Safety } \\
\text { Equipment List. } \\
\text { As in item } 2 \text { above, the safety SSCs must be } \\
\text { verified to the completed safety analysis } \\
\text { prepared as part of design implementation. }\end{array}$ \\
\hline 28 & $\begin{array}{l}\text { Have all credible non-standard conditions } \\
\text { been properly considered? }\end{array}$ & Yes & $\begin{array}{l}\text { Hazards have been evaluated and credible } \\
\text { events analyzed to meet nuclear safety } \\
\text { requirements. } \\
\text { In addition, radiological and process concerns } \\
\text { associated with operational upsets have led to } \\
\text { a redundant design with transfer line flushing } \\
\text { from an accumulator tank. This provides } \\
\text { flushing of the line in the event of a loss of } \\
\text { power to reduce radiation sources and prevent } \\
\text { waste crystallization in the line. The anti- } \\
\text { siphoning slurry distributor at SY-102 ensures } \\
\text { that waste transfer is terminated under any } \\
\text { pump shutdown condition. }\end{array}$ \\
\hline 29 & $\begin{array}{l}\text { Are existing Authorization Basis analyses } \\
\text { implemented in the design? }\end{array}$ & Yes & $\begin{array}{l}\text { Existing Authorization Basis analyses have } \\
\text { been applied to the design. }\end{array}$ \\
\hline
\end{tabular}




\section{APPENDIX A}

DESIGN REVIEW CHECKLIST

System Design Review

\begin{tabular}{|c|c|c|c|}
\hline \multicolumn{2}{|c|}{ SY-101 RAPID MITIGATION SYSTEM } & \multirow{2}{*}{$\begin{array}{l}\text { Applicable } \\
\text { (yes/no/NA) }\end{array}$} & \multirow{2}{*}{$\begin{array}{l}\text { Design Review Remarks } \\
\text { And Pending Actions }\end{array}$} \\
\hline Item & Review Consideration & & \\
\hline 30 & $\begin{array}{l}\text { Has the need for safety analysis of this } \\
\text { design been determined? }\end{array}$ & Yes & $\begin{array}{l}\text { Safety analysis including hazard } \\
\text { identification, accident analysis, and control } \\
\text { development have been identified and results } \\
\text { have been incorporated in the design. } \\
\text { As stated in Items } 2 \text { and } 27 \text { above, the safety } \\
\text { SSCs must be verified against the completed } \\
\text { safety analysis prepared as part of design } \\
\text { implementation. }\end{array}$ \\
\hline 31 & $\begin{array}{l}\text { Are existing Authorization Basis controls } \\
\text { implemented in the design? }\end{array}$ & Yes & $\begin{array}{l}\text { Existing Authorization Basis controls have } \\
\text { been applied to the design. } \\
\text { In addition, specific controls for flammable } \\
\text { gas hazards have been implemented as if they } \\
\text { were Authorization Basis controls. }\end{array}$ \\
\hline 32 & $\begin{array}{l}\text { Do the requirements incorporate } \\
\text { appropriate environmental compliance } \\
\text { controls? }\end{array}$ & Yes & $\begin{array}{l}\text { An environmental compliance matrix has } \\
\text { been prepared to document compliance with } \\
\text { environmental design requirements. } \\
\text { This compliance matrix must be completed as } \\
\text { part of design implementation. }\end{array}$ \\
\hline 33. & $\begin{array}{l}\text { Does the design comply with applicable } \\
\text { environmental design requirements (i.e. } \\
\text { WAC } 173-303 \text {, etc.)? }\end{array}$ & Yes & $\begin{array}{l}\text { An environmental compliance matrix has } \\
\text { been prepared to document compliance with } \\
\text { environmental design requirements. } \\
\text { This compliance matrix must be completed as } \\
\text { part of design implementation. }\end{array}$ \\
\hline 34 & $\begin{array}{l}\text { Will new or modified environmental } \\
\text { permits be required? }\end{array}$ & No & $\begin{array}{l}\text { The current environmental permit governs } \\
\text { operation of the SY-101 RAPID Mitigation } \\
\text { System. }\end{array}$ \\
\hline 35 & $\begin{array}{l}\text { Has availability of power to meet } \\
\text { requirements for the systems, structures, } \\
\text { and components been verified? }\end{array}$ & Yes & $\begin{array}{l}\text { Electric load analysis of the } 252-\mathrm{S} \text { substation } \\
\text { identified the requirement to supplement the } \\
\text { existing power supply for operation of the } \\
\text { system. As a result of this determination, the } \\
\text { electrical requirements of HNF- } 3885 \text { were } \\
\text { revised to provide specific criteria for } \\
\text { application of supplemental power supplies. } \\
\text { Final allocation of electrical loads to the } 252- \\
\text { S substation and any supplemental power } \\
\text { supply source(s) must be completed to the } \\
\text { requirements of HNF-3885 as part of design } \\
\text { implementation. }\end{array}$ \\
\hline
\end{tabular}




\section{APPENDIX A}

\section{DESIGN REVIEW CHECKLIST}

\section{System Design Review}

\begin{tabular}{|c|c|c|c|}
\hline \multicolumn{2}{|c|}{ SY-101 RAPID MITIGATION SYSTEM } & \multirow{2}{*}{$\begin{array}{l}\text { Applicable } \\
\text { (yes/no/NA) }\end{array}$} & \multirow{2}{*}{$\begin{array}{l}\text { Design Review Remarks } \\
\text { And Pending Actions }\end{array}$} \\
\hline Item & Review Consideration & & \\
\hline 36 & $\begin{array}{l}\text { Have requirements for receiving and } \\
\text { storing the equipment item(s) been } \\
\text { defined? }\end{array}$ & Yes & $\begin{array}{l}\text { Receiving requirements are applied for all } \\
\text { equipment. Uniquely purchased components } \\
\text { are specified to require vendor submittal of } \\
\text { storage requirements. } \\
\text { In addition, all equipment is received and } \\
\text { inspected in accordance with a Quality } \\
\text { Inspection Plan. }\end{array}$ \\
\hline 37 & $\begin{array}{l}\text { Has a compliance matrix been prepared } \\
\text { to ensure that applicable codes, } \\
\text { standards, and Authorization Basis, } \\
\text { Environmental, DOE Order, and system } \\
\text { functional requirements are properly } \\
\text { identified and controlled? }\end{array}$ & Yes & $\begin{array}{l}\text { Compliance matrices have been developed to } \\
\text { document compliance with requirements. } \\
\text { The compliance matrices must be completed } \\
\text { as part of detailed design. }\end{array}$ \\
\hline 38 & $\begin{array}{l}\text { Have the interface requirements with } \\
\text { existing facility equipment and systems } \\
\text { been clearly presented? }\end{array}$ & Yes & $\begin{array}{l}\text { Design drawings have identified interfaces } \\
\text { with existing facility equipment and systems. } \\
\text { To facilitate clarity of presentation, the } \\
\text { designers have incorporated all completed } \\
\text { changes to the drawings prior to providing the } \\
\text { appropriate interfaces. }\end{array}$ \\
\hline \multicolumn{4}{|c|}{ COMPONENT SELECTION } \\
\hline 39 & $\begin{array}{l}\text { Can the equipment be readily } \\
\text { assembled/disassembled as designed? }\end{array}$ & Yes & $\begin{array}{l}\text { All designs have been prepared for ease of } \\
\text { assembly. Consideration has been given to } \\
\text { identifying critical dimensions and to ensuring } \\
\text { that mating surfaces have appropriate } \\
\text { fabrication tolerances to facilitate assembly. }\end{array}$ \\
\hline 40 & $\begin{array}{l}\text { Have applicable modifications to } \\
\text { commercial grade items and any } \\
\text { associated verification operations or tests } \\
\text { been appropriately documented? }\end{array}$ & N/A & \\
\hline 41 & $\begin{array}{l}\text { Have qualified and certified parts been } \\
\text { specifled? }\end{array}$ & Yes & $\begin{array}{l}\text { Based on specific design applications and the } \\
\text { applicable codes and standards, requisite } \\
\text { qualification criteria for parts bave been } \\
\text { determined and imposed on suppliers. }\end{array}$ \\
\hline 42 & $\begin{array}{l}\text { Is the design producible by conventional } \\
\text { means? }\end{array}$ & Yes & $\begin{array}{l}\text { The design was predicated on application of } \\
\text { standard commercial parts and items to } \\
\text { minimize the potential schedule impacts of } \\
\text { special order parts and equipment. }\end{array}$ \\
\hline 43 & $\begin{array}{l}\text { Do manufacturing, processing, and } \\
\text { fabrication procedures minimize stress } \\
\text { corrosion and fatigue? }\end{array}$ & Yes & $\begin{array}{l}\text { The system design documents reviewed } \\
\text { provide requirements to address stress } \\
\text { corrosion, particularly for fabrication of } \\
\text { stainless steel parts. }\end{array}$ \\
\hline
\end{tabular}


APPENDIX A

\section{DESIGN REVIEW CHECKLIST}

\section{System Design Review}

\begin{tabular}{|c|c|c|c|}
\hline \multicolumn{2}{|c|}{ SY-101 RAPID MITIGATION SYSTEM } & \multirow{2}{*}{$\begin{array}{l}\text { Applicable } \\
\text { (yes/no/NA) }\end{array}$} & \multirow{2}{*}{$\begin{array}{l}\text { Design Review Remarks } \\
\text { And Pending Actions }\end{array}$} \\
\hline Item & Review Consideration & & \\
\hline 44 & $\begin{array}{l}\text { Do the part and assembly clearances } \\
\text { and tolerances take into account the } \\
\text { effects of age, wear, thermal movement, } \\
\text { and applied loads? }\end{array}$ & Yes & $\begin{array}{l}\text { Thermal movement is the only applicable } \\
\text { condition for the system design. Flexible } \\
\text { connections accommodate the thermal } \\
\text { movement. }\end{array}$ \\
\hline 45 & $\begin{array}{l}\text { Are mechanical tolerances within the } \\
\text { limits of normal shop practice? }\end{array}$ & Yes & $\begin{array}{l}\text { All tolerances were compared to applicable } \\
\text { standards and guidance. With the exception } \\
\text { of critical dimensions, tolerances, and surface } \\
\text { finishes, standard shop tolerances have been } \\
\text { applied. Where dimensions, surface finish, } \\
\text { and/or tolerances were identified as critical, } \\
\text { the critical parameter was set to meet } \\
\text { requirements and evaluated for machining } \\
\text { capability. }\end{array}$ \\
\hline 46 & $\begin{array}{l}\text { Are assembly clearances adequate to } \\
\text { prevent unacceptable damage to } \\
\text { adjacent components? }\end{array}$ & Yes & $\begin{array}{l}\text { The design applied maximum clearances to } \\
\text { protect components from damage. } \\
\text { Components in the Prefabricated Pump Pit are } \\
\text { fairly close to each other, but are fabricated as } \\
\text { an assembly, minimizing the chance of } \\
\text { component damage. }\end{array}$ \\
\hline 47 & $\begin{array}{l}\text { For large and heavy components } \\
\text { designed with built-in rigging to minimize } \\
\text { personnel exposure during installation, } \\
\text { maintenance, and decontamination? }\end{array}$ & Yes & $\begin{array}{l}\text { All large and heavy components have been } \\
\text { designed with appropriate lifting points to } \\
\text { allow rigging and hoisting using standard } \\
\text { rigging practices. }\end{array}$ \\
\hline 48 & $\begin{array}{l}\text { Are operations, surveillance, and } \\
\text { maintenance access provisions designed } \\
\text { to minimize personnel exposure? }\end{array}$ & Yes & $\begin{array}{l}\text { Operations and surveillance activities } \\
\text { specifically addressed exposure minimization. } \\
\text { Once the valve lineup is set, the system can be } \\
\text { operated from remote locations. The design } \\
\text { has also been assessed for impacts on other } \\
\text { operations and surveillance activities to } \\
\text { ensure that those activities can be performed } \\
\text { outside the high radiation area. } \\
\text { Design features for system flushing and } \\
\text { decontamination are provided to minimize } \\
\text { personnel exposure during maintenance } \\
\text { activities. }\end{array}$ \\
\hline 49 & $\begin{array}{l}\text { Have adequate equipment laydown areas } \\
\text { been provided? }\end{array}$ & Yes & $\begin{array}{l}\text { Field verification was performed to verify } \\
\text { adequacy of laydown areas for staging, } \\
\text { installation, and removal of equipment. }\end{array}$ \\
\hline
\end{tabular}


APPENDIX A

DESIGN REVIEW CHECKLIST

System Design Review

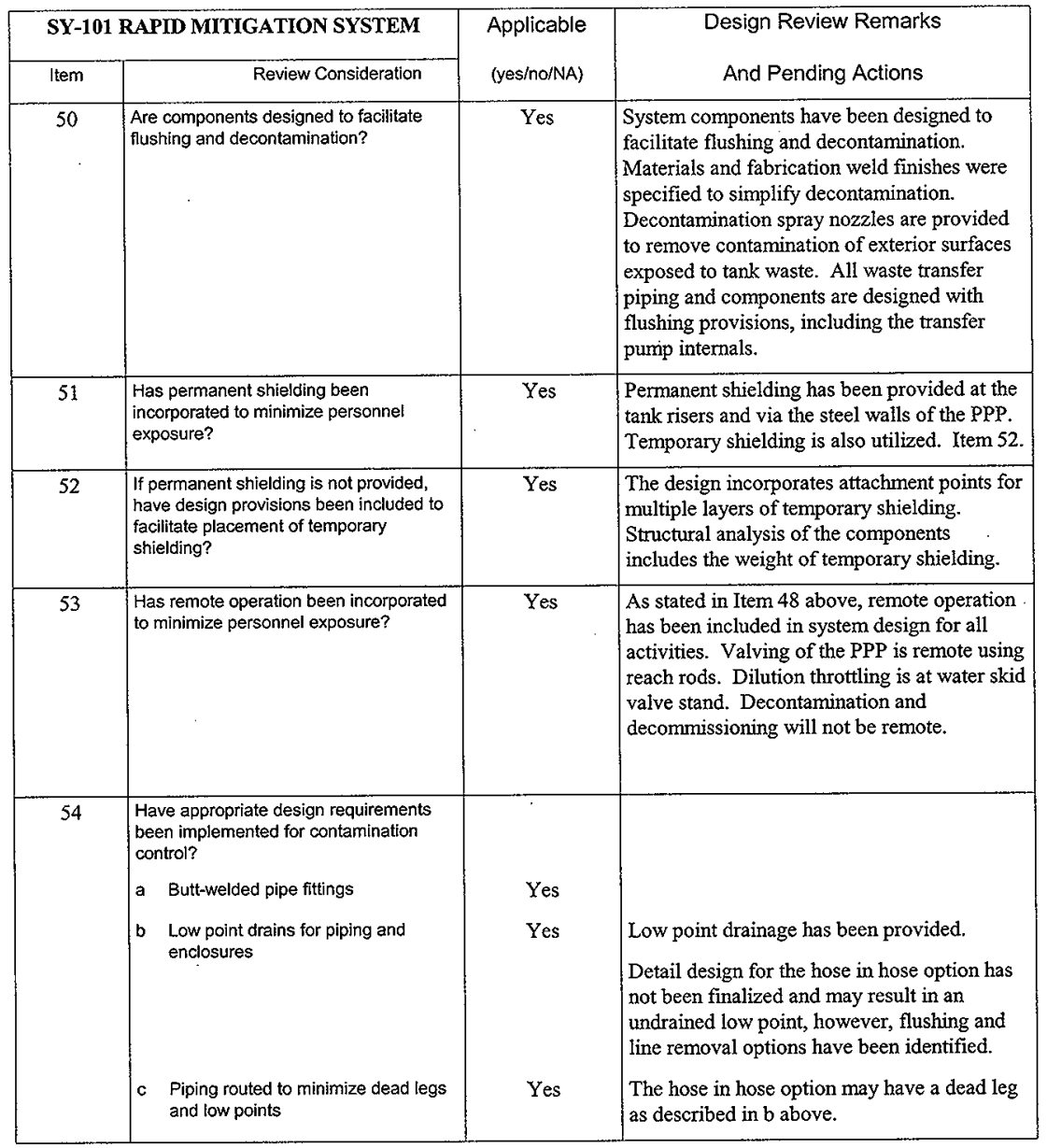




\section{APPENDIX A}

\section{DESIGN REVIEW CHECKLIST}

\section{System Design Review}

\begin{tabular}{|c|c|c|c|}
\hline \multicolumn{2}{|c|}{ SY-101 RAPID MITIGATION SYSTEM } & \multirow{2}{*}{$\begin{array}{l}\text { Applicable } \\
\text { (yes/no/NA) }\end{array}$} & \multirow{2}{*}{$\begin{array}{l}\text { Design Review Remarks } \\
\text { And Pending Actions }\end{array}$} \\
\hline Item & Review Consideration & & \\
\hline 54 & d Curbed radioactive floor drains & No & $\begin{array}{l}\text { The Prefabricated Pump Pit has been } \\
\text { designed with a slope to ensure that leakage } \\
\text { will be routed to the drain. The SY-102 drop } \\
\text { leg enclosure is provided with a curbed sector } \\
\text { to ensure that leaks can be detected prior to } \\
\text { the leakage draining into the tank. }\end{array}$ \\
\hline & $\begin{array}{l}\text { No cross-connection of radioactive } \\
\text { and non-radioactive drains? }\end{array}$ & N/A & \\
\hline . & $\begin{array}{l}\text { Isolation of non-radioactive fluid } \\
\text { systems from radioactive fluid } \\
\text { systems to prevent cross- } \\
\text { contamination }\end{array}$ & Yes & $\begin{array}{l}\text { Check valves and interlocked pressure } \\
\text { switches are provided to isolate the water skid } \\
\text { from potential radioactive waste leakage. In } \\
\text { addition, the water skid normally provides an } \\
\text { air gap isolation from the service water } \\
\text { system to preclude service water } \\
\text { contamination should the check valves and } \\
\text { pressure switches fail to perform their } \\
\text { function. }\end{array}$ \\
\hline 55 & $\begin{array}{l}\text { Are tolerances, fabrication techniques, } \\
\text { processes, etc., consistent with standard } \\
\text { practices and the proposed application? }\end{array}$ & Yes & $\begin{array}{l}\text { Critical dimensional tolerances and material } \\
\text { finishes have been included in specification of } \\
\text { the Prefabricated Pump Pit and other SSCs. } \\
\text { These dimensions and tolerances have been } \\
\text { verified to be within standard machining } \\
\text { capabilities. For critical finishes on the } \\
\text { welded fabrication, machining has been } \\
\text { specified after fabrication. }\end{array}$ \\
\hline 56 & $\begin{array}{l}\text { Can the design and its parts be easily } \\
\text { inspected for conformance to engineering } \\
\text { specifications? }\end{array}$ & Yes & \\
\hline 57 & $\begin{array}{l}\text { Have welding, bolting, joining methods } \\
\text { been adequately specified? }\end{array}$ & Yes & $\begin{array}{l}\text { Welding has been specified to appropriate } \\
\text { codes and standards. In addition, heat input } \\
\text { and tool and material controls have been } \\
\text { specified for fabrication of stainless steel } \\
\text { components. }\end{array}$ \\
\hline 58 & $\begin{array}{l}\text { Have NDE methods been applied } \\
\text { correctly? }\end{array}$ & Yes & $\begin{array}{l}\text { Nondestructive examination has been } \\
\text { specified to the applicable codes and } \\
\text { standards. For critical applications, } \\
\text { supplemental NDE has been specified. }\end{array}$ \\
\hline
\end{tabular}




\section{APPENDIX A \\ DESIGN REVIEW CHECKLIST \\ System Design Review}

\begin{tabular}{|c|c|c|c|}
\hline \multicolumn{2}{|c|}{ SY-101 RAPID MITIGATION SYSTEM } & \multirow{2}{*}{$\begin{array}{l}\text { Applicable } \\
\text { (yes/no/NA) }\end{array}$} & \multirow{2}{*}{$\begin{array}{l}\text { Design Review Remarks } \\
\text { And Pending Actions }\end{array}$} \\
\hline Item & Review Consideration & & \\
\hline 59 & $\begin{array}{l}\text { If the design includes safety SSCs, have } \\
\text { the critical characteristics been } \\
\text { identified? }\end{array}$ & Yes & $\begin{array}{l}\text { Critical characteristics have been identified } \\
\text { and are being applied to dedication of safety } \\
\text { SSCs. } \\
\text { Identification of critical characteristics must } \\
\text { be completed and verified to be consistent } \\
\text { with the finalized safety analysis as part of } \\
\text { design implementation. }\end{array}$ \\
\hline 60 & $\begin{array}{l}\text { If locking provisions or locking devices } \\
\text { have been included: } \\
\text { a Are they accessible? } \\
\text { b If inaccessible after assembly, have } \\
\text { they been sufficiently evaluated and } \\
\text { tested to ensure their adequacy? }\end{array}$ & $\begin{array}{l}\text { N/A } \\
\text { N/A }\end{array}$ & . \\
\hline 61 & $\begin{array}{l}\text { If the design includes safety SSCs, has a } \\
\text { Safety Equipment List (or input to the } \\
\text { facility Safety Equipment List) been } \\
\text { prepared? }\end{array}$ & Yes & $\begin{array}{l}\text { A system Safety Equipment List has been } \\
\text { prepared. } \\
\text { The Safety Equipment List must be } \\
\text { completed, verified to be consistent with the } \\
\text { completed safety analysis, and issued as part } \\
\text { of design implementation. }\end{array}$ \\
\hline \multicolumn{4}{|c|}{ MATERIAL SELECTION } \\
\hline 62 & $\begin{array}{l}\text { Have non-corrosive materials been used } \\
\text { where required? }\end{array}$ & Yes & $\begin{array}{l}\text { The primary material of construction used is } \\
\text { stainless steel, not susceptible to corrosion } \\
\text { from the waste material to be handled. } \\
\text { Carbon steel components have been used for } \\
\text { structural components and enclosures that will } \\
\text { be exposed to an outdoor environment. In } \\
\text { these applications, suitable protective } \\
\text { coatings are specified. } \\
\text { Protective coating specification for carbon } \\
\text { steel portions of the Prefabricated Pump Pit } \\
\text { must be completed and coating performed as } \\
\text { part of design implementation. }\end{array}$ \\
\hline 63 & $\begin{array}{l}\text { Can the assemblies be stored for } \\
\text { extended periods of time without } \\
\text { degrading effects? }\end{array}$ & Yes & \\
\hline 64 & $\begin{array}{l}\text { Does the design avoid any materials } \\
\text { unproven for use in the anticipated } \\
\text { environment? }\end{array}$ & Yes & $\begin{array}{l}\text { All materials have been selected based on } \\
\text { their known properties when exposed to the } \\
\text { anticipated environment. }\end{array}$ \\
\hline
\end{tabular}




\section{APPENDIX A \\ DESIGN REVIEW CHECKLIST \\ System Design Review}

\begin{tabular}{|c|c|c|c|}
\hline \multicolumn{2}{|c|}{ SY-101 RAPID MITIGATION SYSTEM } & \multirow{2}{*}{$\begin{array}{l}\text { Applicable } \\
\text { (yes/no/NA) }\end{array}$} & \multirow{2}{*}{$\begin{array}{l}\text { Design Review Remarks } \\
\text { And Pending Actions }\end{array}$} \\
\hline Item & Review Consideration & & \\
\hline 65 & $\begin{array}{l}\text { Are coatings (or finishes) compatible with } \\
\text { the expected environment and } \\
\text { application? }\end{array}$ & Yes & See Item 62 above. \\
\hline 66 & $\begin{array}{l}\text { Are surface finish requirements the least } \\
\text { stringent possible? }\end{array}$ & Yes & $\begin{array}{l}\text { See Item } 55 \text { above. In addition to specifying } \\
\text { sequence of machining, the least stringent } \\
\text { finish requirement necessary is selected for } \\
\text { each machined surface. Fabrication } \\
\text { workmanship has been limited to finish } \\
\text { requirements for decontamination and } \\
\text { personnel safety } \\
\text { Protective finishes (coatings) are limited to } \\
\text { those material surfaces requiring protection. } \\
\text { Stainless Steel components suitable for their } \\
\text { environment have no specified coating } \\
\text { requirements. }\end{array}$ \\
\hline 67 & $\begin{array}{l}\text { Are the specified materials compatible } \\
\text { with each other and the environmental } \\
\text { conditions to which the material will be } \\
\text { exposed? }\end{array}$ & Yes & $\begin{array}{l}\text { Selection conditions are as described in Items } \\
48,50,54,62 \text {, and } 64 \text { above. }\end{array}$ \\
\hline 68 & $\begin{array}{l}\text { Are the specified construction materials } \\
\text { resistant to the following as applicable: } \\
\text { a Moisture? } \\
\text { b Oxygen/Oxidizers? } \\
\text { c Acids? } \\
\text { d Salts? } \\
\text { e Radiation? }\end{array}$ & $\begin{array}{l}\text { Yes } \\
\text { Yes } \\
\text { N/A } \\
\text { Yes } \\
\text { Yes }\end{array}$ & $\begin{array}{l}\text { EPDM rubber specified for hose in hose has } \\
\text { had extensive use in similar environments at } \\
\text { Hanford. }\end{array}$ \\
\hline \multicolumn{4}{|c|}{ OPERATIONS \& MAINTENANCE } \\
\hline 69 & $\begin{array}{l}\text { Has the design appropriately considered } \\
\text { maintenance, operation and reliability, } \\
\text { including maintenance procedures and } \\
\text { techniques, unique maintenance } \\
\text { requirements and frequencies? }\end{array}$ & Yes & $\begin{array}{l}\text { Operational and safety reliability has been } \\
\text { considered throughout the design. Specific } \\
\text { maintenance reliability consideration has not } \\
\text { been a significant input due to the short } \\
\text { operational cycle for the system. The design } \\
\text { provisions include a full set of spare } \\
\text { equipment, with spare subassemblies such as } \\
\text { the transfer pump piping provided to } \\
\text { minimize maintenance activities required } \\
\text { should replacement be required. }\end{array}$ \\
\hline
\end{tabular}


APPENDIX A

DESIGN REVIEW CHECKLIST

System Design Review

\begin{tabular}{|c|c|c|c|}
\hline \multicolumn{2}{|c|}{ SY-101 RAPID MITIGATION SYSTEM } & \multirow{2}{*}{$\begin{array}{l}\text { Applicable } \\
\text { (yes/no/NA) }\end{array}$} & \multirow{2}{*}{$\begin{array}{l}\text { Design Review Remarks } \\
\text { And Pending Actions }\end{array}$} \\
\hline Item & Review Consideration & & \\
\hline 70 & $\begin{array}{l}\text { Does the design use engineered safety } \\
\text { and operational protections to avoid an } \\
\text { excessive risk-taking dependence on } \\
\text { administrative infallibility? }\end{array}$ & Yes & $\begin{array}{l}\text { Due to the critical need to complete design, } \\
\text { construction, and testing within a limited time } \\
\text { period, every design aspect was reviewed to } \\
\text { establish the minimum overall risk. This } \\
\text { review developed design approaches to } \\
\text { maximize use of engineered features, while } \\
\text { limiting administrative controls to those that } \\
\text { are routine within TWRS. }\end{array}$ \\
\hline 71 & $\begin{array}{l}\text { Have human factors engineering and } \\
\text { operability been considered? }\end{array}$ & Yes & $\begin{array}{l}\text { Specific consideration of human factors has } \\
\text { been included throughout the design. This } \\
\text { has resulted in design such as selection of } \\
\text { specific audible and visual alarms, orientation } \\
\text { of outdoor instrument readouts relative to the } \\
\text { sun, and design to ensure that shutdown } \\
\text { controls will operate under all selection } \\
\text { modes at all control locations. }\end{array}$ \\
\hline 72 & $\begin{array}{l}\text { Is an Operation and Maintenance Manual } \\
\text { required? If so, have requirements been } \\
\text { clearly identified? }\end{array}$ & No & $\begin{array}{l}\text { A specific Operation and Maintenance } \\
\text { Manual is not necessary for the system. } \\
\text { Vendor provided manuals are required for all } \\
\text { components or subassemblies that require } \\
\text { operational setting or calibration. For } \\
\text { subsystems such as the Mobile Water Support } \\
\text { Skid, applicable instructions are provided to } \\
\text { meet a specification requirement. }\end{array}$ \\
\hline 73 & $\begin{array}{l}\text { Are current operating documents } \\
\text { (procedures, specifications, etc.) } \\
\text { applicable to the design? }\end{array}$ & Yes & $\begin{array}{l}\text { Specific operating procedures and } \\
\text { specifications are required for the design. } \\
\text { The operational control of the pump variable } \\
\text { frequency drive is unique to this transfer } \\
\text { system. Requirements for dilution are } \\
\text { consistent with low flow saltwell pumping, } \\
\text { however, dilution has not been routinely } \\
\text { required for double-shell tank transfers in the } \\
\text { recent past. }\end{array}$ \\
\hline 74 & $\begin{array}{l}\text { Has adequate accessibility been provided } \\
\text { for in-service inspection? }\end{array}$ & $\mathrm{N} / \mathrm{A}$ & $\begin{array}{l}\text { In-service inspection is not required for the } \\
\text { application. }\end{array}$ \\
\hline 75 & $\begin{array}{l}\text { Have personnel radiation protection } \\
\text { requirements been considered and } \\
\text { identified? }\end{array}$ & Yes & $\begin{array}{l}\text { The design incorporates a four meter corridor } \\
\text { established as a high radiation area during } \\
\text { operation of the system. The design locates } \\
\text { system controls and monitoring outside the } \\
\text { corridor. }\end{array}$ \\
\hline
\end{tabular}




\section{APPENDIX A}

\section{DESIGN REVIEW CHECKLIST \\ System Design Review}

\begin{tabular}{|c|c|c|c|}
\hline \multicolumn{2}{|c|}{ SY-101 RAPID MITIGATION SYSTEM } & \multirow{2}{*}{$\begin{array}{l}\text { Applicable } \\
\text { (yes/no/NA) }\end{array}$} & \multirow{2}{*}{$\begin{array}{l}\text { Design Review Remarks } \\
\text { And Pending Actions }\end{array}$} \\
\hline Item & Review Consideration & & \\
\hline 76 & $\begin{array}{l}\text { Have necessary features been provided } \\
\text { to maintain personnel radiation exposure } \\
\text { as low as reasonably achievable? }\end{array}$ & Yes' & $\begin{array}{l}\text { Operational monitoring and control is } \\
\text { performed remotely to ensure doses are kept } \\
\text { ALARA. As stated in Item } 48 \text { above, the } \\
\text { design does result exposure of the operators } \\
\text { for a short duration while the flush flow is } \\
\text { established. }\end{array}$ \\
\hline 77 & $\begin{array}{l}\text { Can the hardware be adequately } \\
\text { decontaminated and disposed of after } \\
\text { use if it is radiologically or chemically } \\
\text { contaminated? }\end{array}$ & Yes & See Item 50 above. \\
\hline 78 & $\begin{array}{l}\text { Have locking provisions or locking } \\
\text { devices been required where critical to } \\
\text { operation or maintenance? }\end{array}$ & $\mathrm{N} / \mathrm{A}$ & . \\
\hline \multicolumn{4}{|c|}{ RADIOLOGICAL \& TOXICOLOGICAL CONSIDERATIONS } \\
\hline 79 & $\begin{array}{l}\text { Equipment design and administrative } \\
\text { controls ensure that doses are ALARA } \\
\text { a How does the design incorporate } \\
\text { physical design features as the } \\
\text { primary method to maintain } \\
\text { exposures ALARA? } \\
\text { b } \\
\text { relied on to maintain exposures } \\
\text { ALARA, how were design features } \\
\text { demonstrated to be impractical? } \\
\text { c How are the administrative controls } \\
\text { that are used demonstrated to be } \\
\text { practical? } \\
\text { d How are ALARA decision-making } \\
\text { methods applied to justify the design } \\
\text { and administrative controls and } \\
\text { assure that occupational exposure is } \\
\text { maintained ALARA? }\end{array}$ & Yes & $\begin{array}{l}\text { The design incorporates remote operation and } \\
\text { monitoring to maintain exposures ALARA. } \\
\text { Due to the overground routing of the transfer } \\
\text { line, exposure reduction relies on a combined } \\
\text { application of shielding and administrative } \\
\text { control. } \\
\text { Weight restrictions to control tank dome } \\
\text { loading precluded application of additional } \\
\text { shielding for the above grade portions of the } \\
\text { system. Excavation and burial of the system } \\
\text { was not technically feasible. } \\
\text { The controls applied for the high radiation } \\
\text { area (access control and posting ) are a } \\
\text { practical solution, allowing installation of a } \\
\text { temporary fence boundary and temporary } \\
\text { shielding with controlled access points. } \\
\text { Specific review of the routing ensured that } \\
\text { establishment of the high radiation area would } \\
\text { not have significant impact on other operation } \\
\text { and surveillance requirements. } \\
\text { Each portion of the design has been designed } \\
\text { for simplicity. At each stage of the process, } \\
\text { the assigned radiological control and } \\
\text { shielding design engineers evaluated options } \\
\text { to provide both appropriate design measures } \\
\text { and administrative controls. }\end{array}$ \\
\hline
\end{tabular}




\section{APPENDIX A}

\section{DESIGN REVIEW CHECKLIST}

System Design Review

\begin{tabular}{|c|c|c|c|c|}
\hline \multicolumn{3}{|c|}{ SY-101 RAPID MITIGATION SYSTEM } & \multirow{2}{*}{$\begin{array}{l}\text { Applicable } \\
\text { (yes/no/NA) }\end{array}$} & \multirow{2}{*}{$\begin{array}{l}\text { Design Review Remarks } \\
\text { And Pending Actions }\end{array}$} \\
\hline Item & & Review Consideration & & \\
\hline \multirow[t]{5}{*}{79} & e & $\begin{array}{l}\text { For continuously occupied areas, } \\
\text { how does the design meet the } \\
\text { objectives of maintaining exposure } \\
\text { ALARA and }<0.5 \text { mrem/hr dose } \\
\text { rate? }\end{array}$ & Yes & $\begin{array}{l}\text { All activities performed in the DACS trailer } \\
\text { and at the MCC are performed outside the SY } \\
\text { Tank Farm. } \\
\text { All activities performed at the } 302 \mathrm{C} \text { water } \\
\text { system are performed outside the SY Tank } \\
\text { Farm. For these portions of the system, } \\
\text { isolation from radiation sources is achieved } \\
\text { by water isolation as described in Item } 54 \mathrm{f} \\
\text { above. }\end{array}$ \\
\hline & $f$ & $\begin{array}{l}\text { For areas not continuously occupied, } \\
\text { how does the design meet the } \\
\text { objectives of maintaining exposure } \\
\text { ALARA and }<20 \% \text { of applicable } \\
\text { standards of } 10 \text { CFR835.202? }\end{array}$ & Yes & $\begin{array}{l}\text { Control and monitoring functions are limited } \\
\text { to areas remote from potential radiation } \\
\text { sources during system operation. Those } \\
\text { activities performed in the high radiation area } \\
\text { are reduced to simplified operations of short } \\
\text { duration. }\end{array}$ \\
\hline & $g$ & $\begin{array}{l}\text { How does the design meet the } \\
\text { objective to avoid releases of } \\
\text { airborne radioactivity to the } \\
\text { workplace atmosphere under normal } \\
\text { conditions? }\end{array}$ & Yes & $\begin{array}{l}\text { All system boundaries are established with } \\
\text { both a primary and a secondary confinement. } \\
\text { Airborne releases are controlled by the } \\
\text { existing ventilation system. }\end{array}$ \\
\hline & h & $\begin{array}{l}\text { How do the design controls meet the } \\
\text { objective to avoid inhalation of } \\
\text { radioactive material in any situation? }\end{array}$ & Yes & $\begin{array}{l}\text { The system maintains full isolation from the } \\
\text { radioactive material. Specific construction } \\
\text { steps that will require breaching the } \\
\text { containments of SY- } 101 \text { and SY-102 that will } \\
\text { be performed under work controls specifically } \\
\text { developed for work at open risers. }\end{array}$ \\
\hline & $i$ & $\begin{array}{l}\text { How does the design and material } \\
\text { selection include features that } \\
\text { facilitate maintenance. } \\
\text { decontamination, and } \\
\text { decommissioning? }\end{array}$ & Yes & $\begin{array}{l}\text { The primary features of the system minimize } \\
\text { components requiring maintenance access in } \\
\text { potentially contaminated or high radiation } \\
\text { areas. The system has specifically designed } \\
\text { features to flush system components and } \\
\text { decontaminate externally contaminated } \\
\text { surfaces except the encasement for the hose in } \\
\text { hose option. The primary material of } \\
\text { construction selected is stainless steel to } \\
\text { simplify decontamination except the transfer } \\
\text { line. }\end{array}$ \\
\hline
\end{tabular}




\section{APPENDIX A}

DESIGN REVIEW CHECKLIST

System Design Review

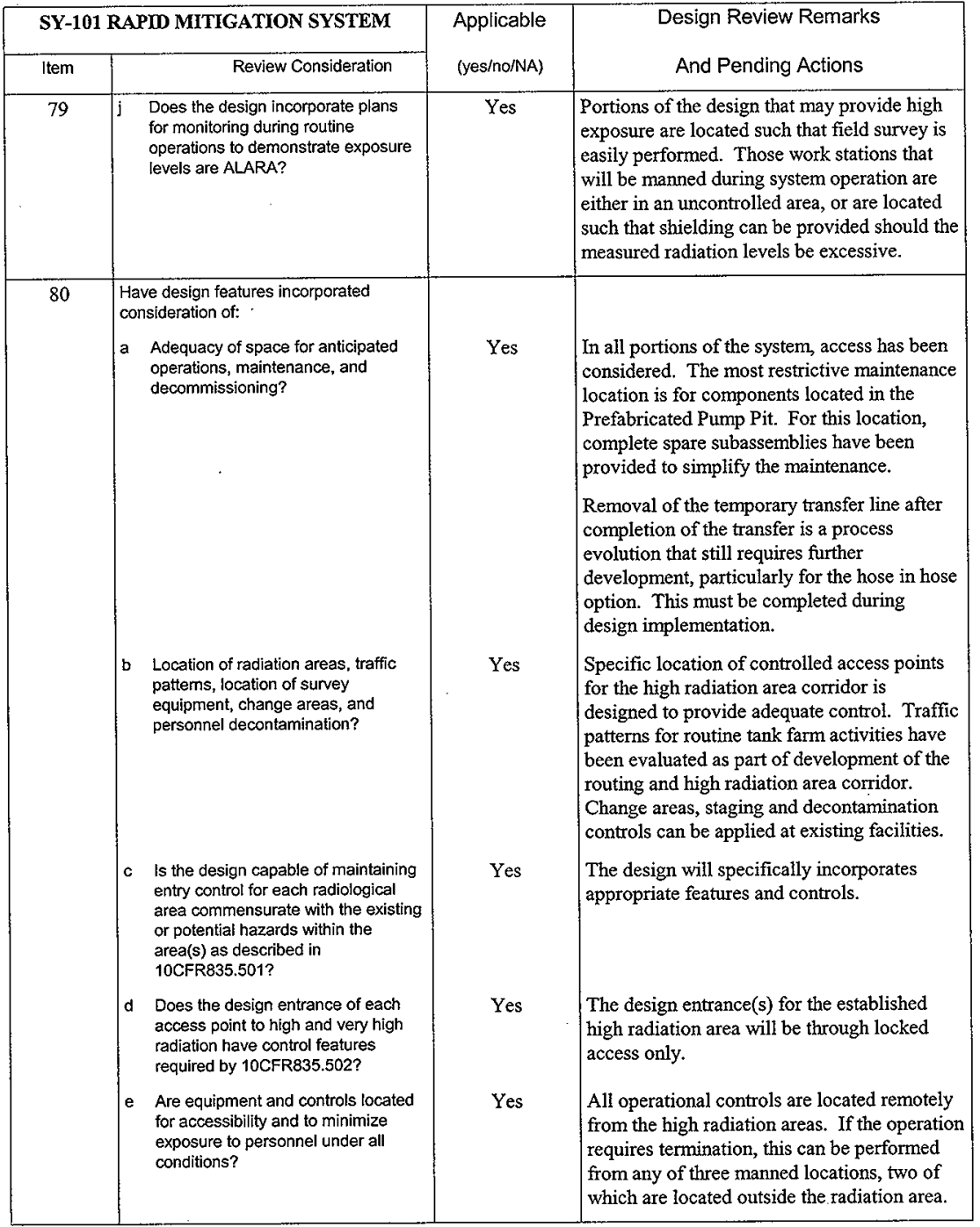


APPENDIX A

\section{DESIGN REVIEW CHECKLIST}

\section{System Design Review}

\begin{tabular}{|c|c|c|c|c|}
\hline \multicolumn{3}{|c|}{ SY-101 RAPID MITIGATION SYSTEM } & \multirow{2}{*}{$\begin{array}{l}\text { Applicable } \\
\text { (yes/no/NA) }\end{array}$} & \multirow{2}{*}{$\begin{array}{l}\text { Design Review Remarks } \\
\text { And Pending Actions }\end{array}$} \\
\hline Item & & Review Consideration & & \\
\hline 80 & $f$ & $\begin{array}{l}\text { Are entry control points adequately } \\
\text { sized to allow personnel and } \\
\text { equipment access? }\end{array}$ & Yes & $\begin{array}{l}\text { The entry control point(s) for the high } \\
\text { radiation area is in an outdoor area with } \\
\text { ample access. The entry control point for the } \\
\text { SY tank farm provides facilities for full crew } \\
\text { changes and appropriate monitoring and } \\
\text { decontamination. }\end{array}$ \\
\hline & g & $\begin{array}{l}\text { Are exits from radiological areas } \\
\text { adequate for personnel and } \\
\text { equipment monitoring and } \\
\text { decontamination? }\end{array}$ & Yes & $\begin{array}{l}\text { The exits for personnel and equipment are } \\
\text { adequate for construction, operation, and } \\
\text { removal activities. This has been } \\
\text { demonstrated within the last ten years by } \\
\text { comparable system installation work } \\
\text { performed at Tank SY-101. }\end{array}$ \\
\hline . & h & $\begin{array}{l}\text { Has maximum distance been } \\
\text { provided between the serviceable } \\
\text { components and manned control } \\
\text { locations and the substantial } \\
\text { radiation sources? }\end{array}$ & Yes & $\begin{array}{l}\text { The serviceable components and manned } \\
\text { locations have been remotely located. } \\
\text { Serviceable components within the } \\
\text { Prefabricated Pump Pit have been designed as } \\
\text { a replaceable assembly to minimize personnel } \\
\text { exposure if service is required. }\end{array}$ \\
\hline
\end{tabular}




\section{APPENDIX B \\ FUNCTIONAL REQUIREMENTS AND TECHNICAL CRITERIA DESIGN REVIEW MEETING MINUTES}




\section{MEETING MINUTES}

SUBJECT: Design Review Group (DRG) 99-004, Design Requirements Document for the SY-101 Rapid Mitigation System

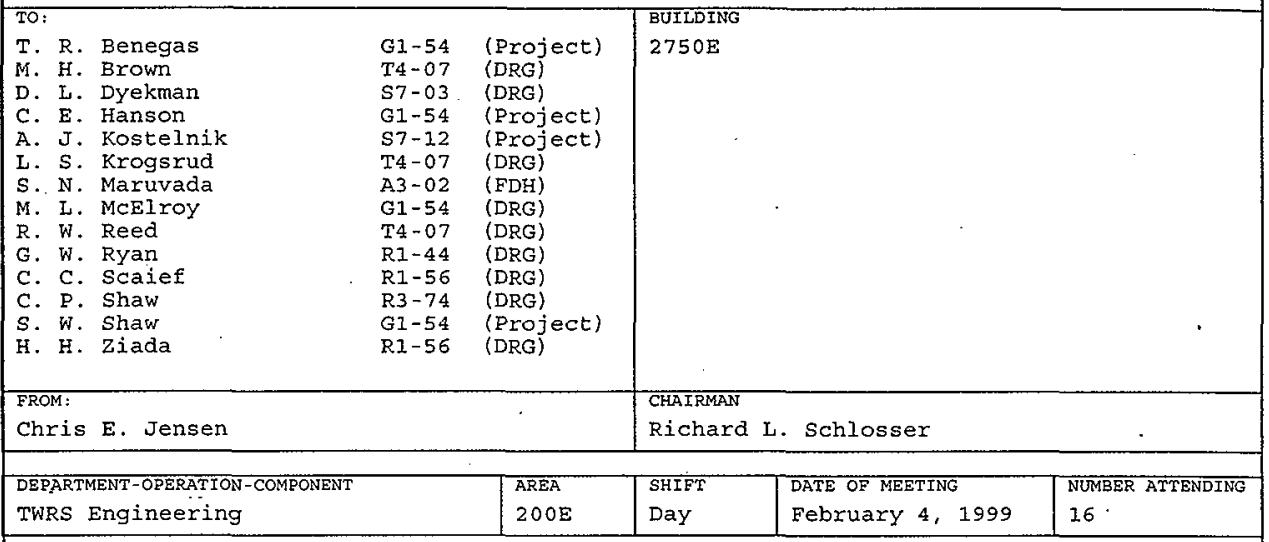

The review of the subject design requirements was introduced by the chairman. The comments for this meeting will be documented via the meeting minutes.

The chairman emphasized that compliance with the procedural requirements for engineering documents will be adhered to for this review.

The review committee agreed that all documents that are to be generated should be captured in the Engineering Task Plan (ETP). The project people at the meeting agreed to include the documents to be generated as part of the ETP (Action Item 99-004-001).

The chairman recommended that the project advise Maintenance and surveillance Engineering, to ensure that maintenance and calibration procedures are developed in a timely manner. The project agreed to do so (Action Item 99-004-002).

Action Item 99-004-003 (Benegas): page 1, item 1.I, first paragraph, delete "...temporary above ground...". This is not a design requirement.

Action Item 99-004-004 (Benegas): Page 1, item 1.1, Mr. C. P. Shaw raised the issue of waste compatibility in the transfer of waste from SY-101 to SY-102. The project did not recall any studies that address the issue. The project agreed to identify this as an assumption that the waste is compatible or verify that it is compatible.

Action Item 99-004-005 (Benegas): Page 2, item 2.1, The chairman pointed out that there are several government documents missing in the list. The title of this item is to be changed to "Major" Government Documents, and Washington Administrative Code 173.303, 1OCFR830.120, and DOE Order $6430.1 \mathrm{~A}$ are required to be added to the list.

Action Item 99-004-006 (Benegas): Page 2, item 2.2, Mr. Jensen commented that the reference to ASME B31.3 was not the current edition. The current edition will be identified. Dr. Ziada and Mr. Jensen also pointed out that the requirements in FNFPRO-097 requires that safety class process equipment shall be designed to ASME Boiler and Pressure Vessel Code (B\&PVC) Section II.I. Dr. Ziada pointed out that the ANSI B30 standard for lifting equipment needs to be identified. Mr. Brown also pointed out that ACI requirements need to be identified as well. The DRG agreed that to limit the number of non-government documents in the list the following statement needs to be added to item 2.2: "These are the codes and Standards identified at this time. Others 
may be identified as the design progresses." Mr. Benegas agreed to the actions above.

Action Item 99-004-007 (Benegas): Dr. Ziada discussed requirements for the piping codes. He explained that the requirements of HNF-PRO-097 may be able to be waived, if DOE is willing to agree. This could allow the use of ASME B31.3 with addition quality requirements. The chairman agreed that this could save significant time on the schedule, due to the significant requirements imposed by ASME B\&PVC section III.

Action Item 99-004-008 (Benegas): Page 3, item 3.0, Mr. Brown recommended that the "Flush and Dilution System" be added to the bulleted list in this section. The project agreed.

Action Item 99-004-009 (Benegas): Page 3, item 3.0, Dr. Ziada recommended that the project component interfaces be systematically identified. This should be accomplished by adding a section in this section specifically identifying component interfaces using component identification. The project agreed to add an interface matrix or list.

Action Item 99-004-010 (Benegas): Page 4, item 3.2.1, Dr. Ziada recommended that Table 3-1 be referenced in this item. The DRG also recommended the last sentence be deleted and the reference to Table $3-1$ be included.

Action Item 99-004-011 (Benegas): Page 4, item 3.2.1, Dr. Ziada suggested that the safety class of the pump be identified.

Action Item 99-004-012 (Benegas): Page 4, item 3.2.2.1.1, delete the viscosity values.

Action Item 99-004-013 (Benegas): Page 4, item 3.2.2.2.1, Mr. C. P. Shaw pointed out that there is a requirement that the Reynolds number for fluid fiow in piping is required to be greater than 20,000, per WHC-SD-OCD-15, to prevent plugging. The performance numbers in the design requirements may not reach the Reynolds number requirements. Mr. Reed asked if there is an ability to unplug the line, should it. become plugged. The project agreed to add the requirements in WHC-SD-OCD-15 and address the unplugging issue.

Action Item 99-004-014 (Benegas): Page 4, item 3.2.2.2.2, Mr. C. P. Shaw expressed a concern that the maximum discharge head on the pump couid exceed the design pressure of the transfer lines and jumper connections. The DRG recommended the pressure limit on the system be $230 \mathrm{psig}$ and that pressure protection shall be considered.

Action Item 99-004-015 (Benegas): Page 4, item 3.2.2.2.2, Mr. Reed recommended that the NPSH requirements be added to this item.

Action Item 99-004-016 (Benegas): Page 5, item 3.2.2.2.3, the flow rate was discussed and the recommendation is to change it to $130 \mathrm{gpm}$ to $180 \mathrm{gpm}$.

Action Item 99-004-017' (Benegas): Page 5, item 3.2.2.3.1, the DRG recommended that the maximum dilution range or factor requiring control and adjustment, the extent of the dilution, the total transfer volume, and the impact on tank waste volumes all be added to this item. In addition, the DRG recommended that the statement "Provide dilution at pump suction side" be added to this item.

Action Item 99-004-018 (Benegas): Page 5, item 3.2.2.4, the DRG recommended that the statement "either isolated or Class 1, Div. 1, Group B" replace "...non-classified..." and add "Below the PPP, pump design must meet Class 1, Div. 1, Group B".

Action Item 99-004-019 (Benegas): Page 5, item 3.2.2.5, first paragraph, this paragraph is not a design criteria, therefore it should be deleted. 
Action Item 99-004-020 (Benegas): Page 6, item 3.2.2.5, the chairman suggested that the term "liquids" be replaced with "fluid media" to include solids being transported. In addition, the statement "up to 5 \%" needs to be deleted.

Action Item 99-004-021 (Benegas): Page 6, item 3.3.1, Mr. Brown suggested that another bullet be added: provide drain-back to tank.

Action Item 99-004-022 (Benegas): Page 6, item 3.3.2.1, the DRG asked if the riser has been surveyed to verify the dimensions. The project agreed to provide a requirement in the text to perform a survey and as-build the riser.

Action Item 99-004-023 (Benegas): Page 6, item 3.3.2.1, the DRG recommended that the dimension $2.44 \mathrm{~m}$ be replaced with "junction of the primary and secondary tank walls".

Action Item 99-004-024 (Benegas): Page 7, item 3.3.2.1.2, the DRG recommended deletion of this item as it is not a design criteria.

Action Item 99-004-025 (Benegas): Page 7, item.3.3.2.1.3, the DRG recommended that this item should only state "The design of the PPP shall not amplify the pump resonant frequencies."

Action Item 99-004-026 (Benegas): Page 7, item 3.3.2.2.2, the DRG recommended that the statement "...shall not exceed...riser flange" be replaced by "shall not damage the riser or the tank", and the statement "shall not be" in the last sentence be replaced with "are considered as part of the TWRS authorization basis".

Action Item 99-004-027 (Benegas): Page 7, item 3.3.2.2.2, Dr. Ziada recommended that a new item 3,7 be added to require a structural design criteria be developed. Dr. ziada provided the suggested wording as follows:

\section{"3.7 Structural Design}

The applied loads (Dead weight, pressure, vibration, seismic, wind, ...etc.) and load combinations for each component and structures are defined in the structural design criteria (SDC) document (TBD). The natural phenomena loadings shall be a function of the safety classes of the SSCs and evaluated in accordance with HNF-PRO-097 and DOE$6430.3 \mathrm{~A}$.

The SDC also provides codes and standards that are used to evaluate and qualify the sscs of the waste transfer system."

Action Item 99-004-028 (Benegas): Page 7, item 3.3.2.2.3, the DRG suggested that the references for the cyclic reaction forces and the "existing analysis" be identified.

Action Item 99-004-029 (Benegas): Page 8, Table 3-1, Mr. C. P. Shaw expressed the concern that the waste viscosity is too high $>30 \mathrm{cP}$ to properly lubricate and maintain the stability of the pump bearings. This issue needs to be addressed.

Action Item 99-004-030 (Benegas): Page 8, item 3.3.2.2.4, the DRG recommended this item be deleted. The wording should be used to prepare the new item 3.7 (see Action Item 99-004-027).

Action Item 99-004-031 (Benegas): Page 8, item 3.3.2.3.1, the DRG recommended replacing the phrase "by gravity...transfer pump" with "without plugging or be capable of being unplugged. The seal loop fluid shall be environmentally and waste compatible".

Action Item 99-004-032 (Benegas): Page 9, item 3.3.2.3.3, add the phrase "monitoring 
and" after the word "remote".

Action Item 99-004-033 (Benegas): Page 9, item 3.3.2.3.4, the DRG recommended deletion of this item. It is not a design criteria.

Action Item 99-004-034. (Benegas): Page 9, item 3.3.2.5, the DRG recommended the title Leak Detector be changed to Transfer System Leak Detector and that a $g$ lobal change also be made to the document.

Action Item 99-004-035 (Benegas): Page 9, item 3.3.2.5, the DRG recommended the statement "The dxain design shall allow for adequate accumulation of waste for leak detection and for consequences given a 20 gpm leak per TSR AC 5.12."

Action Item 99-004-036 (Benegas): Page 9, item 3.3.2.6, the DRG recommended the term "Dog House Cover" be globally replaced by the term "Transfer system Cover", to reflect the term used in the authorization basis.

Action Item 99-004-037 (Benegas): Page 9, item 3.3.2.6.2, the DRG recommended the term "purging" be-replaced with "venting" to reflect the actual function.

Action Item 99-004-038 (Benegas): Page 10, item 3.3.2.8, the DrG recommended that a new item under 3.3 .2 .8 be added for the design to prevent solids accumulation during pump shutdown.

Action Item 99-004-039 (Benegas): Page 10, item 3.3.2.8.7, the DRG recommended that where the piping material $304 \mathrm{I}$ is identified, it be replaced by "300L".

Action Item 99-004-040 (Benegas): Page 10, item 3.3.2.9, the DRG recommended that the 12 " size requirement be deleted and the statement "minimum diameter to accommodate the safety function of the encasement" be added after "...transfer line..." in the last sentence.

Action Item 99-004-041 (Benegas): Page 11, item 3.3.2.10, Dr, Ziada recommended that the phrase "... with safety factor of 3 ... PpP assembly Design..." be deleted. In addition, insert the phrase "and below hook Iifting" in the third sentence between "points" and "shall".

Action Item 99-004-042 (Benegas): Page 11, item 3.4.1, the DRG recomended that all of this item aftex the first sentence be deleted. Insert the phrase "double-encased transfer lines not physically connected to other active or inactive waste transfer Iines" between "dedicated" and "transfer". Delete the phrase "...riser 13...SY-102".

Action Item 99-004-043 (Benegas): Page 12, item 3.4.2.1.3, Mr. Jensen pointed out that ASME B\&PVC section IX does not provide approved weld connection, it does provide qualification requirements for welders and welding processes. This item should be revised to state "Welders and welding procedures shall be qualified to AsME B\&PVC Section IX."

Action Item 99-004-044 (Benegas): Page 12, item 3.4.2.1.4, Mr. Jensen recommended that the current edition of ASME B31.3 be corrected to 1996.

Action Item 99-004-045 (Benegas): Page 12, item 3.4.2.1.5, the chairman pointed out that the bend radius of " $2 \mathrm{R} "$ is incorrect and should be 5 diameters. In addition, the DRG could not identify what the acronym "DRIP" is intended to represent.

Action Item 99-004-046 (Benegas): Page 12, item 3.4.2.1.6, DRg recommended that the phrase "...compatible with. . Note \#5)" be replaced by "to prevent precipitation of solids". The DRG also recommended including the waste temperatures in this item as 
well.

Action Item 99-004-047 (Benegas): Page 12, item 3.4.2.1.7, the DRG recommended deletion of this item and the last sentence be moved to item 3.4.2.18.

Action Item 99-004-048 (Benegas): Page 13, item 3.4.2.1.8, the DRG recommended adding the sentence from Action Item 99-004-046 to this item and replace the phrase "...as required... working pressure" with "to be tested in accordance with ASME B31.3".

Action Item 99-004-049 (Benegas): Page 13, item 3.4.2.1.9, the DRG recommended that this item be moved to the flush system item.

Action Item 99-004-050 (Benegas): Page 13, items 3.4.2.1.10 and 3.4.2.2.3, the DRG recommended deletion of these item as they are not considered design criteria.

Action Item 99-004-051 (Benegas): Page 13, item 3.4.2.2.1, the DRG recommended replacing "containment in the event" with "routing of waste to a leakage collection and detectión pit".

Action Item 99-004-052 (Benegas): Page 13, item 3.4.2.2, the DRG recommended adding the statement "A leak detector system which complies with wAC 173.303 requirements shall be provided for the encasement".

Action Item 99-004-053 (Benegas): Page 13, item 3.4.2.2.2, the DRG recommended revising this item to be similar to item 3.4 .2 .1 .4 except referencing the design code as ASME B\&PVC Section III or authorized equivalent.

Action Item 99-004-054 (Benegas): Page 14, items 3.4.2.3.1, 3.4.2.3.2, 3.4.2.3.3, and 3.4 .2 .4 .1 , the DRG recommended the deletion of these items as they are not considered design criteria.

Action Item 99-004-055 (Benegas): Page 14, item 3.4.2.3.4, the DRG recommended the first sentence be deleted and the second sentence be revised by repIacing "Hanford" with "design" and replacing "in accordance" with "compatible".

Action Item 99-004-056 (Benegas): Page 14, item 3.4.2.4.3, the DRG recommended deletion of the second sentence and the first sentence be revised as follows: "Drop leg discharge to the tank shall be accomplished without damage to dropleg or attachments. Drop Ieg attachments shall be designed with appropriate requirements."

Action Item 99-004-057 (Benegas): Page 14, item 3.4.2.4.4, the DRG recommended this item be revised to read the same as 3.3 .2 .10 (see Action Item 99-004-040).

Action Item 99-004-058 (Benegas): Page 15, item 3.5, the DRG recommended that the accuracy ranges are not required for design criteria and should be removed.

Action Item 99-004-059 (Benegas): Page 15, item 3.5, the DRG recommended addition of statements for encasement leak detector flamable gas controls. The encasement is open to the pit where there may be flammable gas controls, requiring the same classification of the encasement, with respect to flammable gas controls, as the pit. This should be identified in the interface control matrix (see Action Item 99-004-009 above). In addition, a statement "Any leak detector within an area requiring ignition controls shall be have the appropriate ignition control requirements." should be added to this item.

Action Item 99-004-060 (Benegas): Page 19, item 3.6.2.2.2, the DRG recommended wording be added to explain the reasons for limiting the amount of dilution/flush water. This explanation should include minimizing waste generation, prevention of tank over 
filling, and maintaining tank. chemistry within acceptable limits to prevent corrosion. Action Item 99-004-061 (Benegas): Pages 21 to 33, the DRG recommended deletion of these pages as they are facility descriptions from the TWRS BIO.

Action Item 99-004-062.(Benegas): Pages 34 to 39 , the DRG recommended adding a reference to DOE order 6430.1A.

Action Item 99-004-063 (Benegas): Page 36, item 6.6, Mr. McElroy recommended referencing NQA-1 and ASME B\&PVC section III within this item.

Action Item 99-004-064 (Benegas): Page 36, item 6.6.3, Mr. McElroy recommended rewording in accordance with the design codes to be used. As it is written now, it does not meet the requirements of NQA-1 and ASME B\&PVC Section III.

Action Item 99-004-065 (Benegas): The DRG recommends that the terms service water, filtered water, and filtered service water be replaced by raw water to reflect the current term usage within TwRS.

Action Item 99-004-066 (Benegas): The DRG recommends that a design requirements matrix be developed.

Action Item 99-004-067 (Benegas): The DRG recommends that a waste chemistry compatibility determination be performed.

The chairman explained that the DRG will need to be re-convened to address the closure of these action items next week.

The meeting was adjoured. 


\section{APPENDIX C}

\section{0\% CONCEPTUAL DESIGN REVIEW AGENDA, MEETING MINUTES, AND REVIEW COMMENT RECORDS}




\section{1-SY TRANSFER SYSTEM DESIGN REVIEW AGENDA/PRESENTATIONS \\ 2/16/99}

\begin{tabular}{|c|c|}
\hline 8:00am & Introduction (C. Hanson) \\
\hline 8:10am & $\begin{array}{l}\text { Process (B. Barton) } \\
-\quad \text { Objective } \\
-\quad \text { Process Flow }\end{array}$ \\
\hline 8:30am & $\begin{array}{l}\text { Design Definition Documents } \\
\text { ETP - T. Benegas } \\
\text { - } \\
\text { DRD - S. Shaw }\end{array}$ \\
\hline $8: 50 \mathrm{am}$ & $\begin{array}{l}\text { Overall Integrated System (General Overview) T. Benegas } \\
\text { P\&ID } \\
\text { General Arrangement } \\
\text { - } \quad \text { Drawing Tree } \\
\text { Interface Drawing }\end{array}$ \\
\hline
\end{tabular}

9:00am Dose Rate Calculations/ALARA Overview (R. Pierson)

9:10am Pump (K. Morris)

- Procurement

- Test Plan

9:30am BREAK

9:40am P3 (P. Titzler)

- $\quad$ Site Layout

- P3 Arrangement

- Concrete Enclosure

- Installation/Removal

10:30am Transfer Line (S. Shaw)

- Transfer Line

- Drop Leg

- Jumpers

11:00am I\&C (J. Wilk)

11:30am Power (R. Merriman)

- Electrical Distribution 


\section{2:00pm LUNCH}

1:00pm Water Supply/Skid (K. Witwer)

1:30pm Design Documents

- Structural (J. Strehlow)

- $\quad$ MEL and SDD (K. Morris)

- $\quad$ SEL (K. Morris)

\section{2:00pm BREAK}

2:10pm Safety and Licensing (G. Ryan)

- Hazop's

- BIO Issues

2:30pm Questions/Directions (R. Schlosser) 


\section{1-SY-101 TRANSFER RAPID MITIGATION SYSTEM CONCEPTUAL (30\%) DESIGN REVIEW}

\section{MEETING MINUTES}

Prepared by C. E. Jensen

\section{BLDG, CONFERENCE ROOM 274}

February, 16-17, 1999

\section{Design Review Team Members}

\author{
R. L. Schlosser, Chairman \\ C. E. Jensen, Secretary/Mechanical Engineering \\ M. G. Al-Wazani, Electrical \\ M. H. Brown, Cognizant Engineer \\ M. F. Erhart, Chemical Engineer \\ R. J. Giordano, Radcon \\ J. D. Guberski, Environmental Compliance \\ R. A. Huckfeldt, Safety \\ D. C. Larsen, Operations Representative \\ D. E. McElroy, Cognizant QA
}

L. Pokos, Maintenance Engineering

W. J. Powell, Design Authority

R. E. Raymond, Project/KINGS

R. W. Reed, Cognizant Manager

D. A. Reynolds, Process Engineering

G. W. Ryan, Nuclear Safety and Licensing

C. C. Scaief, I\&C Engineer

F. A. Schmorde, Operations Representative

C. P. Shaw, Pump Engineering

H. H. Ziada, Structural and Rigging

\section{Design Review Guideline/Introductions}

Mr. Schlosser introduced the design review committee. Mr. Hanson introduced the design team. The ground rules were explained as to the schedule, objectives, and expectations. The design team provided presentations on the $30 \%$ design.

\section{SY-101 Transfer System Overview}

Mr. Hanson provided an overview of the SY-101 Transfer system. A question on why 100,000 gallons of waste was chosen as the volume to be transferred to SY-102. It was pointed out that the operational limit is 406 inches and the projected level after the 100,000 gallons is pumped is approximately 420 inches - well above the 406 inch level. The response was with the required dilution, the total volume transferred will be approximately 200,000 gallons. Furthermore, it is expected that there will be additional transfers when the waste rises again. The 100,000 comes from the desire to reduce the level by 36 inches, to avoid overfilling the tank to a level above the primary/secondary tank interface. The project team will continue to evaluate what is required to be pumped out (Action Item 99-005-001).

\section{Process}

Mr. Barton introduced the process presentation and the objectives of the process engineering activities.

Mr. Estes provided the presentation on the process flow. A question on the viscosity was raised in that the presented waste viscosity expected is 50 to $200 \mathrm{cP}$, and the waste in the tank could be greater than $1000 \mathrm{cP}$ at the pump inlet. In addition, the requirements for waste transfers requires Reynolds number of greater 
than 20,000 . The raising of the pump suction could resolve the issue. The project team agreed to further evaluate (Action Item 99-005-002).

A question on the possibility of the 101-SY waste solidifying in the tank 102-SY was raised. The project responded that the issue is being evaluated at the 222-S laboratory. When the results are known, they will be included in the design of the system (Action Item 99-005-003).

The issue of the lack of a waste compatibility report was discussed. Concern over proceeding down a design path without knowing the compatibility of the waste is very risky. Mr. Hanson pointed out that this project is proceeding at risk with several normally series activities being performed in parallel to assure completion before the tank overflows. Mr. Barton explained that although the waste in 102-SY is not what will be there when the waste is transferred, the waste expected in the tank will be from salt well pumping. The salt well waste looks like it will be compatible at this time. Modeling is being done at this time and is expected to be complete on April 22, 1999, with a draft completed somewhere around the first of April. The project assured the review committee that one will be prepared (Action Item 99-005-004). In addition, this activity is captured in the test plan.

It was pointed out that a schedule that pulls all the activities in this project is needed. Without the waste compatibility study, required dilution of the 101-SY waste is not well known.

It was pointed out that a vapor flow chart is required to determine emissions from this activity. This is required to determine what permitting will be required. It is needed as soon as possible to get the permitting activity underway so the pumping can begin as soon as possible. The project explained that it is being prepared at this time (Action Item 99-005-005).

\section{Design Definition Documents}

It was asked if an evaluation was performed on the decision to proceed at risk. It was explained that it was identified and evaluated as part of the TBR process.

The maintenance of the pump and "bumping" to ensure subsequent use after the initial pumping was discussed. It was suggested that a "maintenance requirements document" be prepared to address this issue. It was pointed out that this issue is part of the ABU checklist in the Engineering Task Plan, HNF-4044, which is provided to the committee for review. It is necessary for the committee to review the ETP by the end of the week, including the ABU (Action Item 99-005-006).

\section{Overall Integrated System}

It was pointed out that the 100\% design will be completed by April 20, 1999.

\section{Dose Rate Calculations/ALARA Overview}

Mr. Greenborg presented the dose rate calculations for the project and Mr. Pierson provided the presentation on ALARA.

It was pointed out that a probe was inserted into riser 7 in the MIT on 101-SY. The dose inside the MIT in the waste was found to be $200 \mathrm{R} / \mathrm{hr}$. The design basis used is $400 \mathrm{R} / \mathrm{hr}$. The committee discussed this and pointed out that this can be used as a basis for reducing the amount of the shielding and consequently the dome load from this project. The committee suggested that the measured levels be considered in the design process (Action Item 99-005-007).

A concern was raised as to the capability of the canned pump motor to withstand the radiation levels. The canned pump is designed to with stand $1000 \mathrm{M}$ Rad. 
A concern over the exposure from waste buildup on the equipment from operation and the affect on maintenance activities and subsequent operation of the pump was expressed. Mr. Greenborg explained that this was not considered in the evaluation. The committee suggested that this be considered by the project (Action Item 99-005-008).

\section{Pump}

Ms. Morris provided the presentation on the design and operation of the pump.

The design of the pump provides a screen on the inlet to the pump. A concern on screen plugging was raised. There are nozzles providing a screen cleaning and dilution flow. The nozzles are located on the downstream side of the screen and are directed toward the screen, clearing the screen of any debris.

A concern over the mixing of the waste in the pump resulting in excessive vibration. Mr. Hanson pointed out that this is being evaluated by PNNL and the results will be available when completed (Action Item 99005-009).

A concern on if any debris greater than 0.25 -inch diameter, such as a long small diameter wire, pass through the screen. The project agreed to evaluate this issue (Action Item 99-005-010).

The committee asked if the structural loads on the pump have been considered. It was explained that such loads will be identified in the structural design criteria document (Action Item 99-005-011).

Additional discussion on the pump stability at low speeds occurred. It was explained that the operational speeds of the pump are within a stable operating region.

\section{Pre-Fabricated Pump Pit}

Mr. Titzler provided the discussion of the pre-fabricated pump pit.

The issue of dome loading and the PPP was raised. The current design indicated a load of approximately $36,000-1 \mathrm{~b}$. This weight will preclude core-sampling operation in the future, due to dome loading limits. The committee requested that the design be further optimized to allow the core sampling operation to be performed in the future (Action Item 99-005-012).

The $P \& I D$ indicated that there is no double isolation of flush and dilution systems from the waste. The committee recommended that additional valves be added to V-3, V-4, V-5, and V-11 (Action Item 99-005013).

There was a concern on the human factors and the necessity for special tooling to operate or maintain the equipment in the PPP. The project agreed to address this issue (Action Item 99-005-014).

The design of the vertical drop out of the pump assemble concerned the committee. The vertical drop provides an environment for line plugging from the waste, should the flow be stopped for some length of time. In addition, the design puts a low point in the discharge system, allowing waste or water to accumulate, potentially leading to corrosion failure. The project agreed to evaluate this issue (Action Item 99-005-015).

\section{Transfer Line}

Mr. S. Shaw provided the presentation for this item.

The committee was concerned that the tie in to an existing line could result in Washington Department of Health issues, if the line has been used or contaminated. A notice of construction and contamination

\section{3 of 7}

Chris E. Jensen

05/11/99

C:My DocumentsWESREVSY-101102 30\% 30DR-Min.doc 
control issues associated with the welding of contaminated materials would come into play. The project agreed to address the issue (Action Item 99-005-016).

A concern that there is no overpressure protection of the transfer lines. The issue revolves around the use of the variable frequency drive (VFD) unit as the method of preventing overpressure by controlling the pump speed. The project agreed to determine if the VFD meets the requirements for pressure protection and document it or provide appropriate overpressure protection to the transfer line (Action Item 99-005017).

A concern on why the three inch line was selected in lieu of an available 2 inch line. It was explained that the 2-inch line is not a dedicated route and would need to be shared with other transfer activities. The existing 3-inch line and the new 3-inch line to it would provide a dedicated transfer route to 102-SY. In addition, based on available documentation, the line has not been used to transfer waste.

The issue of critical velocity precipitation of solids in the line was raised. The design requirement is to maintain a 6-fps velocity to prevent precipitation of solids in the line. The committee requested that the use of the 3-inch line will maintain a sufficient velocity to prevent precipitation of solids in the line and subsequent plugging (Action Item 99-005-018).

It was also pointed out that process documentation for this project is essential.

The use of the piping codes was discussed. The SY farm used ASME B31.1, the Power Piping Code. The other code used for transfer systems in TWRS is ASME B31.3, Process Piping Code. The use of the appropriate code and reconciliation between the original and the code to be used needs to be done. In addition, proper quality assurance requirements need to be incorporated for the containment piping which is a safety class component (Action Item 99-005-019).

There was a concern on the integrity of the existing 3-inch line. It was installed with the farm and as indicated by existing documentation not used or tested. It is not clear if the line has been cathodically protected over the years. The project agreed to check on the operation of the cathodic protection system and the integrity of the line and assess the risk of using the existing line (Action Item 99-005-020).

The potential plugging of the down leg in tank 102-SY is a concern. The lower temperature of the waste in 102-SY around the down leg could lead to solidification of the waste from 101-SY. Or could the line plug from the waste crystallizing from 102-SY. The project agreed to evaluate this issue (Action Item 99-005021).

\section{Instrument and Control}

Mr. Wilk provided the presentation on this subject.

The committee questioned that there are no interlocks from the leak detectors to the waste pump and the water skid pumps. The accident prevention and mitigation use of the leak detectors will be accomplished through operator action. The operators have 30 minutes in which to shut down the pumps. This is within the authorization basis. This, however, requires alarms to be safety class. The selected SC alarms have not been identified. The project will identify the appropriate SC alarms (Action Item 99-005-022).

A concern on how the effectiveness of dilution within the pump is determined. The committee recommended that the project evaluate a method such as measuring specific gravity or mass. The project agreed to evaluate (Action Item 99-005-023).

It was recommended that the local instrument read out panels be oriented to be read out of direct sunlight. In addition, the instrumentation needs to be relocated to away from the PPP or, for those that cannot be removed, provision for placement of temporary shielding be provided (Action Item 99-005-024). 
A question was asked about the transfer of 101-SY waste into 102-SY and if that will cause 102-SY to become classified as a hydrogen-generating tank. The project assumption is that it will not become a hydrogen-generating tank.

\section{Power}

Mr. Merriman provided the presentation on this subject.

The design of the PPP electrical penetrations needs to be changed due to radiological concerns over streaming through the penetrations. It was suggested that the penetrations be placed at an appropriate angle to prevent unnecessary exposure (Action Item 99-005-025).

\section{Water Supply/Skid}

Mr. Witwer provided the presentation on this subject.

The committee asked that the design limits and bases be provided. This includes the temperature limits (upper and lower), flow ranges, critical velocities, and dilution rates for the dilution and fiush water (ActionItem 99-005-026).

The committee requested that a "horn" be added as an audible alarm in addition to the visual alarms. And that the action on low water tank level be shut down the heat trace system and not the pumps, to prevent precipitation and subsequent plugging of the transfer lines and pump (Action Item 99-005-027).

The committee also recommended that check valves be added to the discharge of the pumps to prevent recirculation of water to the shut down parallel pump (Action Item 99-005-028).

The committee requested that heat tracing be added to the skid (Action Item 99-005-029).

The committee was concerned with the head and flow rates supplied by the skid pumps. The head that can be generated by the pumps exceed the design limits of the transfer piping. The committee recommended that design flow rates be determined for the dilution and flushing and the pumps sized appropriately (Action Item 99-005-030).

It was requested that consideration be made to not place the water skid on a trailer and just left on a skid to eliminate the need to bring a truck into the farm to move it. The project agreed to look at this issue (Action Item 99-005-031).

It was pointed out that a LCO or engineered feature be used to prevent the dilution/flush water from accidentally being left on to run into 101-SY and cause, by dissolving the waste crust, a GRE. The preferred method is an engineered feature. The project agreed to evaluate this issue (Action Item 99-005032).

\section{Design Documents}

Mr. Strehlow discussed structural design.

The assumption of the use of the plastic hinge for the pump assembly was explained. He further explained that the pump assembly cannot withstand the current UBC 1997 seismic requirements. The pump assembly was built to withstand UBC 1994 requirements (the required code at time of design). The pump will yield during the current design seismic load requirements. It was pointed out that the plastic hinge design limits the loads on the tank and the PPP, protecting them from damage due to pump assembly seismic response. 
It was asked if we can accept a plastic hinge in the pump assembly. It was explained that the point of the plastic hinge only contains process, dilution, and flush piping. There is no pump shaft. There should not be a problem from a hypothetical plastic hinge.

A concern was raised on the fact that the current codes and standards required by HNF-PRO-097 and the DOE Orders may not be met by the current design. There may be a need for an exemption to the HNFPRO-097 and DOE Orders. This design code issue above also needs to be identified and discussed in the structural design criteria document. The project agreed to resolve this issue (Action Item 99-005-033).

The committee recommended that the structural design criteria document include a discussion on the use of "beyond design basis accident" design loads in the analysis, vibration loads on the pump assembly, and the use of the plastic hinge analysis (Action Item 99-005-034).

It was asked if there is a requirement to consider the effect of a burn event on the pump assembly and the PPP. The project agreed to address this issue (Action Item 99-005-035).

The structural analysis of the drop leg was not significantly discussed. The structural analysis of the drop leg in 102-SY needs to be provided (Action Item 99-005-036).

It was asked if the computer codes being used in the structural analysis have been properly validated. It was explained that there are several methods of validation and that the project will validate the analysis in accordance with procedures (Action Item 99-005-037).

The location of the PPP is just above two existing transfer lines. If the analysis demonstrates the need for a "protective bridge" to take the load off the transfer lines, an independent review of the design will be required, by an independent qualified registered professional engineer, as defined in the Washington Administrative Code, Section 173.303. The project agreed to resolve this issue, should it become an issue (Action Item 99-005-038).

Ms. Morris provided a presentation on the SDD, MEL, and the SEL.

The committee suggested that the critical characteristics be included in the SEL for safety class and safety significant components (Action Item 99-005-039).

\section{Safety and Licensing}

Mr. Van Keuren provided the presentation on HAZOPs and BIO.

There were no actions as a result of this subject.

\section{Questions/Directions}

Mr. Schlosser requested any further discussion or questions.

The committee suggested that a pump startup management plan be provided for the water skid and the transfer pump (Action Item 99-005-040).

The committee suggested that the existing transfer lines being used be tested to determine the integrity. This needs to be included in the test plan for the project (Action Item 99-005-041).

It was pointed out that on the water skid there are high-pressure gas bottles designed for forcing flush water into the piping and transfer pump. The high-pressure gas, when released into the piping, will expand and 
freeze the water line or the waste line. The committee recommended that the system be analyzed and the lowest pressure gas be used (Action Item 99-005-042).

The committee recommended that the project re-consider cutting down the 42-inch riser and routing the new transfer line to eliminate the vertical drop plugging and the low points issues (Action Item 99-005043).

The issue of heat load reduction in 101-SY due to removing waste also needs to be addressed by the project (Action Item 99-005-044).

The committee strongly recommends a contingency plan be developed and ready to go in the event that the proposed design has a failure in the existing transfer line being used (Action Item 99-005-45).

Mr. Schlosser explained the importance of completing the discipline reviews by Monday, February $2 I$, 1999. Comments are to be sent to Mr. Schlosser and Mr. Zaman for incorporation into an official Review Comment Record.

The meeting was adjourned. 


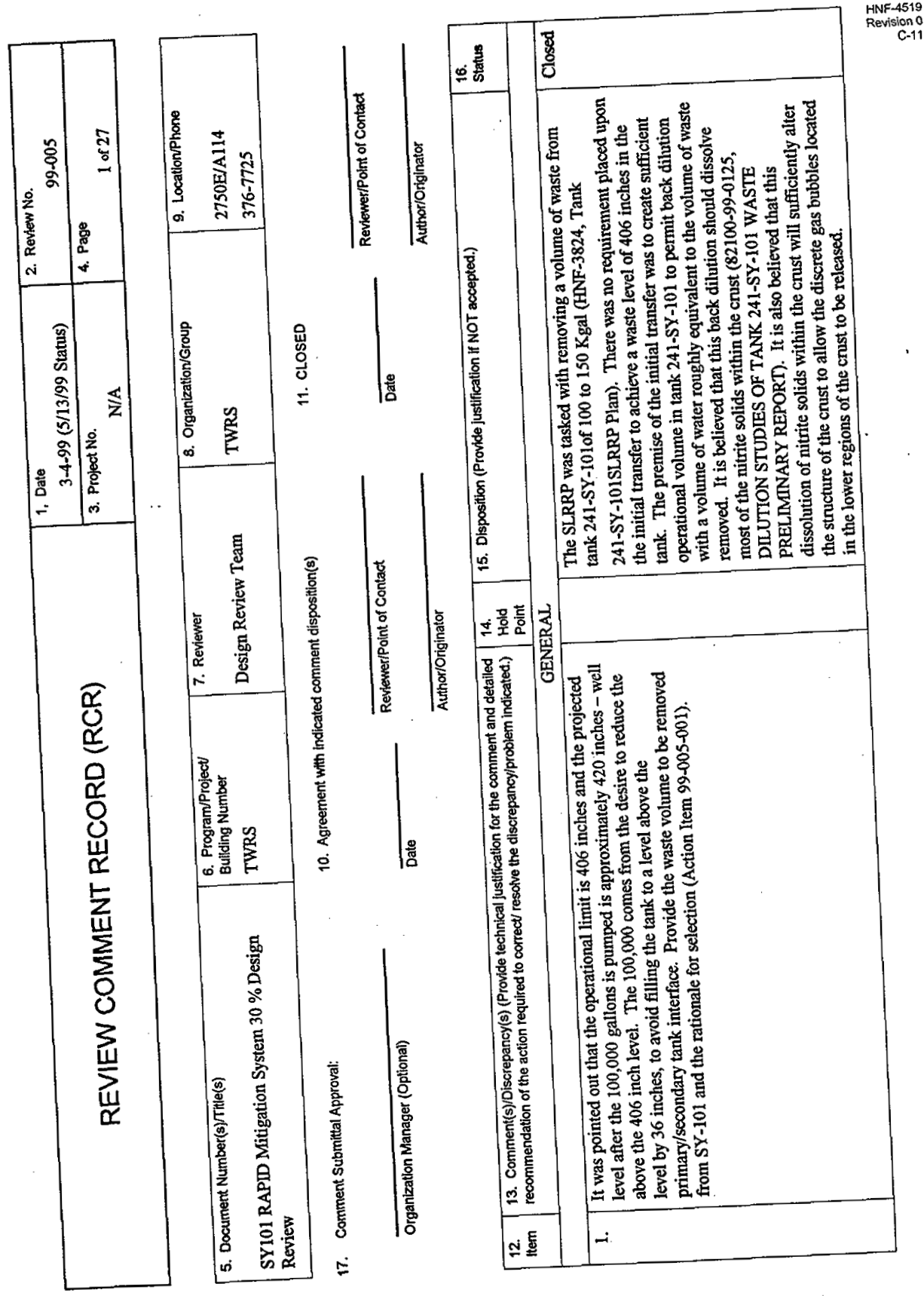




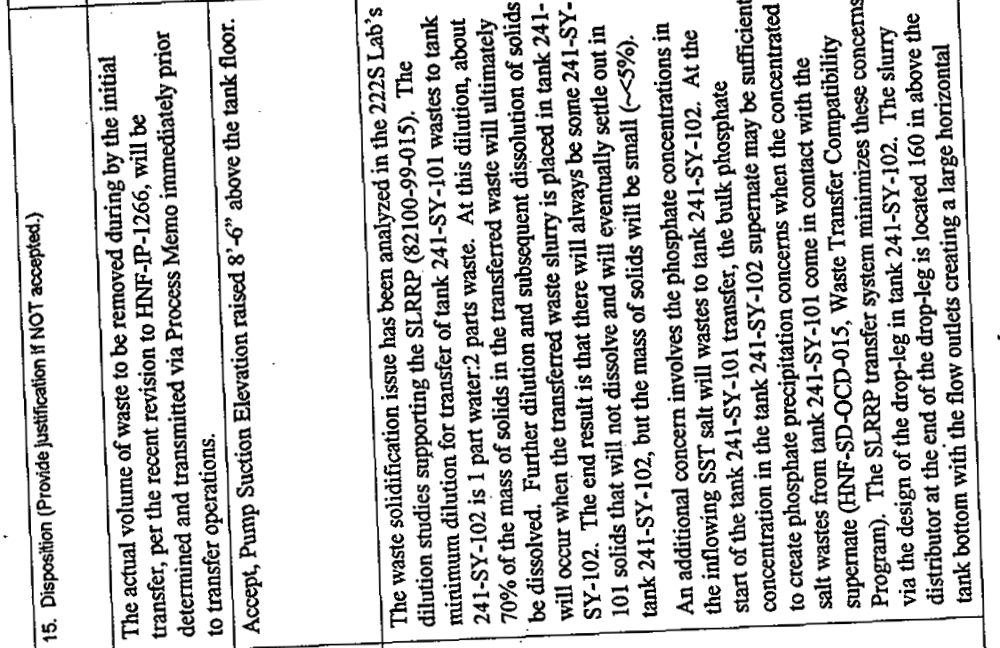

훙ㅎㅇㅇ

\begin{tabular}{|c|c|}
\hline 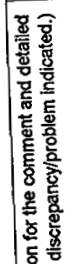 & 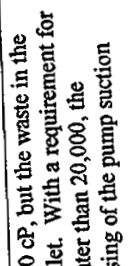 \\
\hline
\end{tabular}

菒

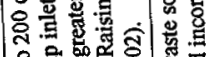

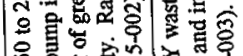

을 要的

.

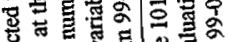

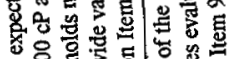

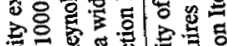

家을 西

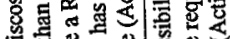

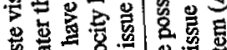

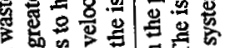

兽

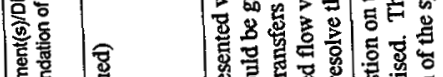

|

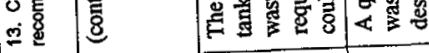

\begin{tabular}{l|l|l|l} 
iE & $-i$ & i & i
\end{tabular}




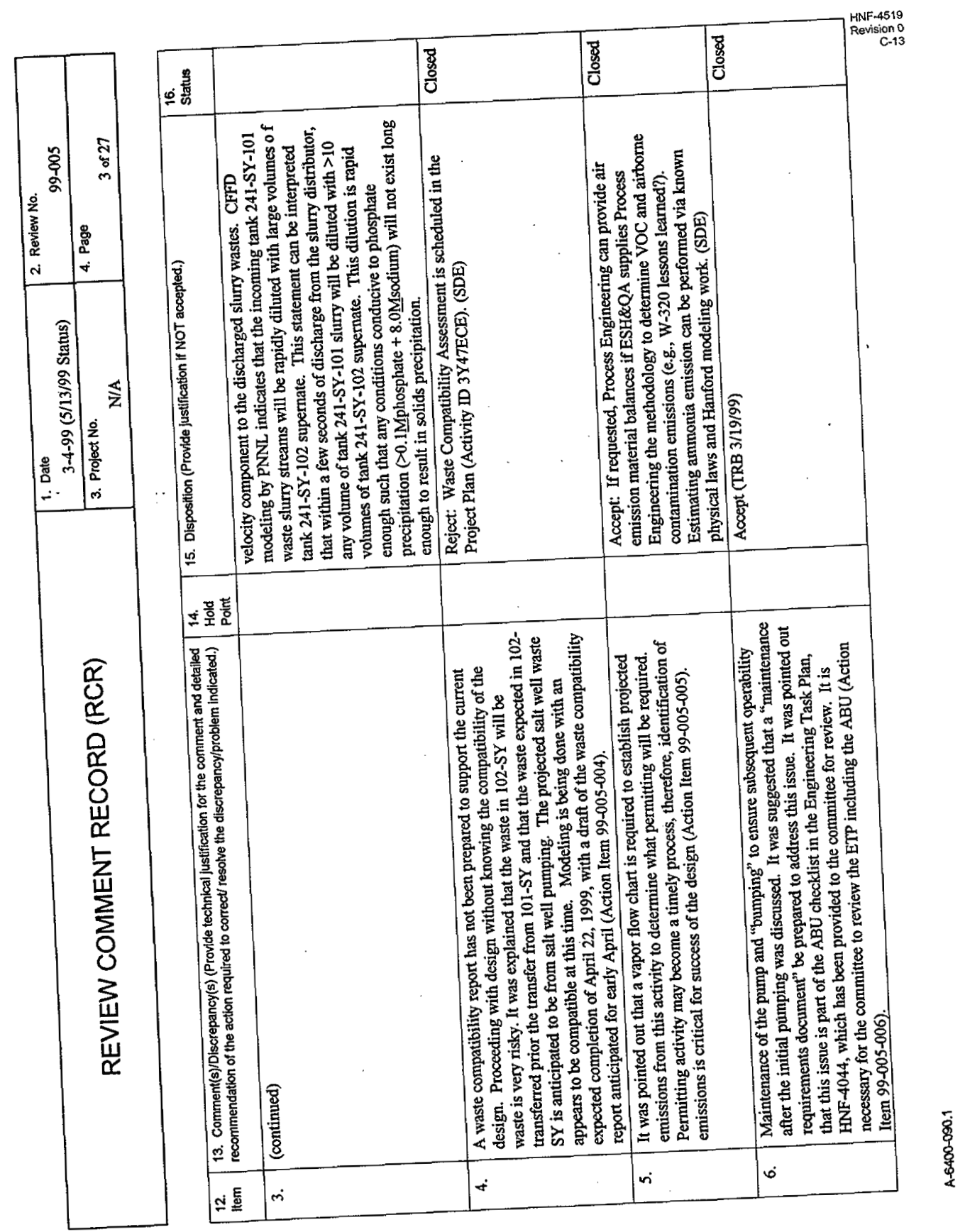




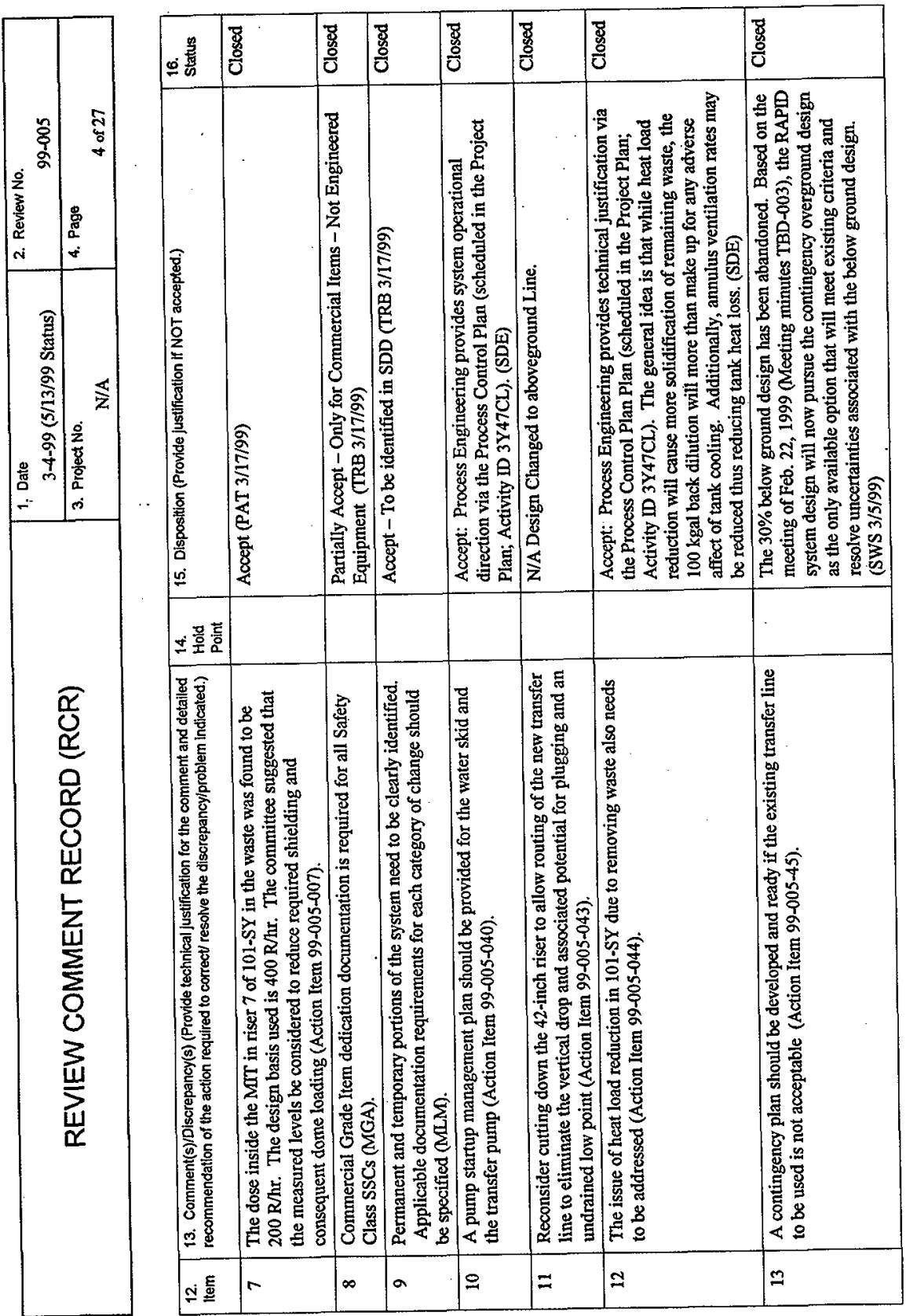




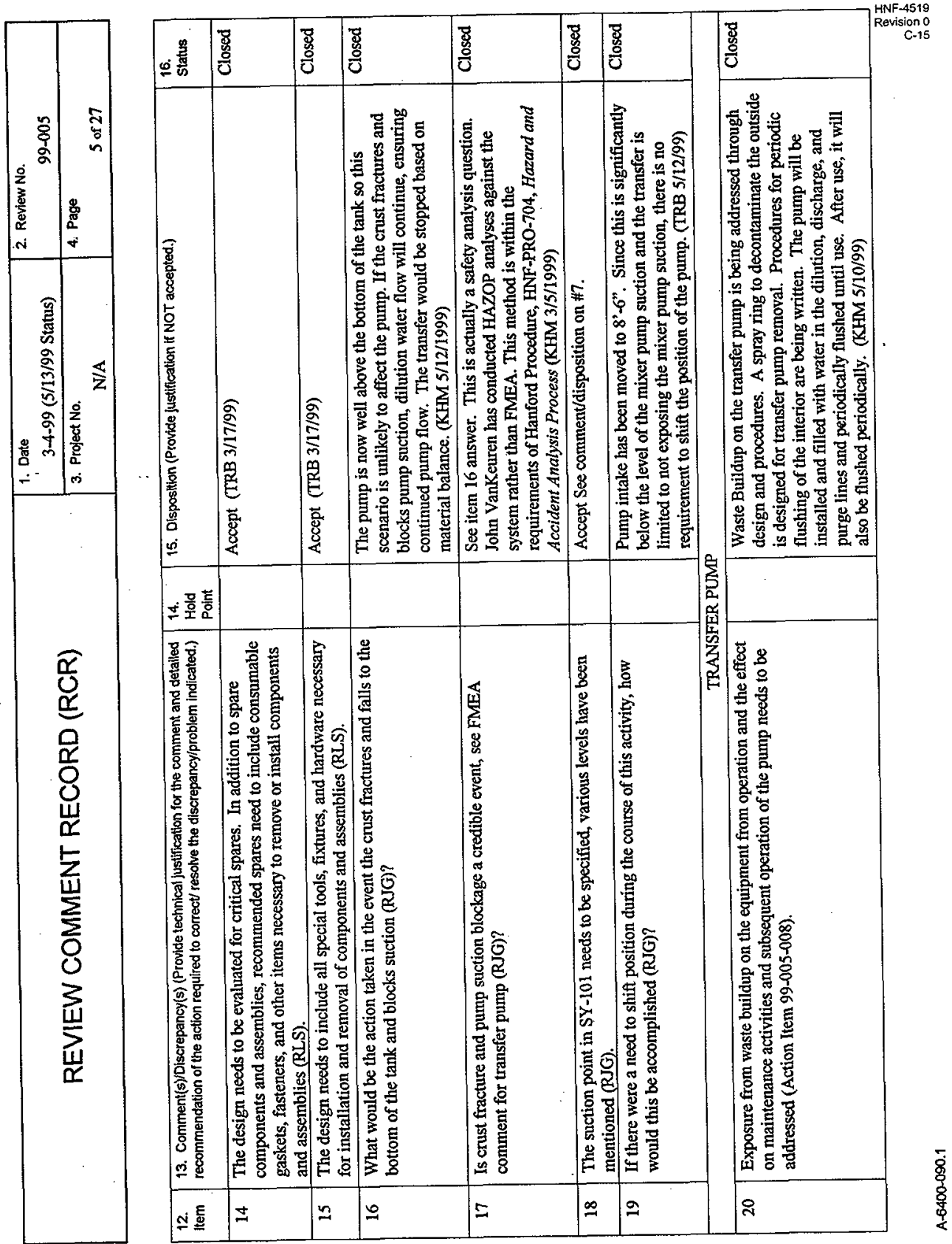




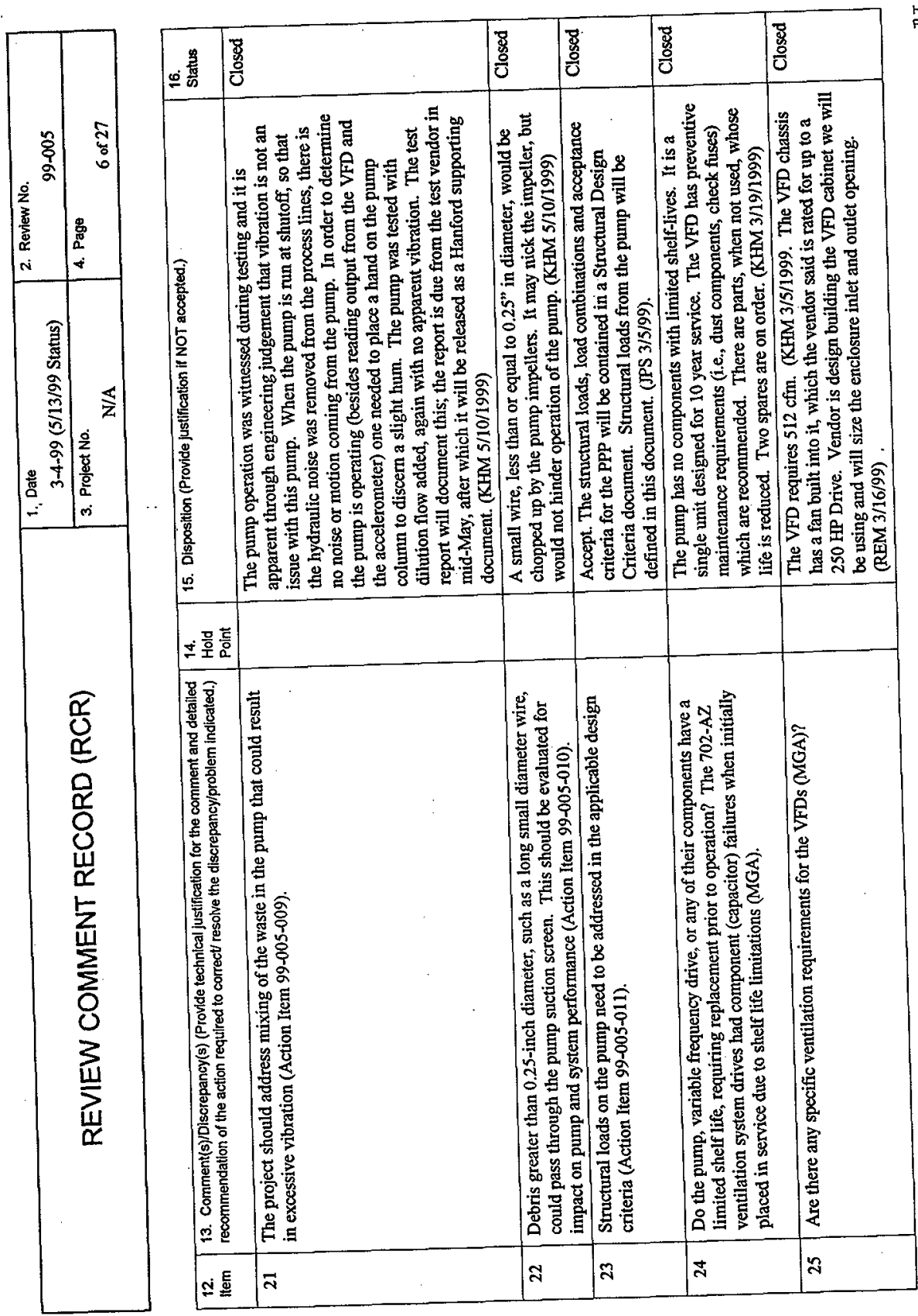




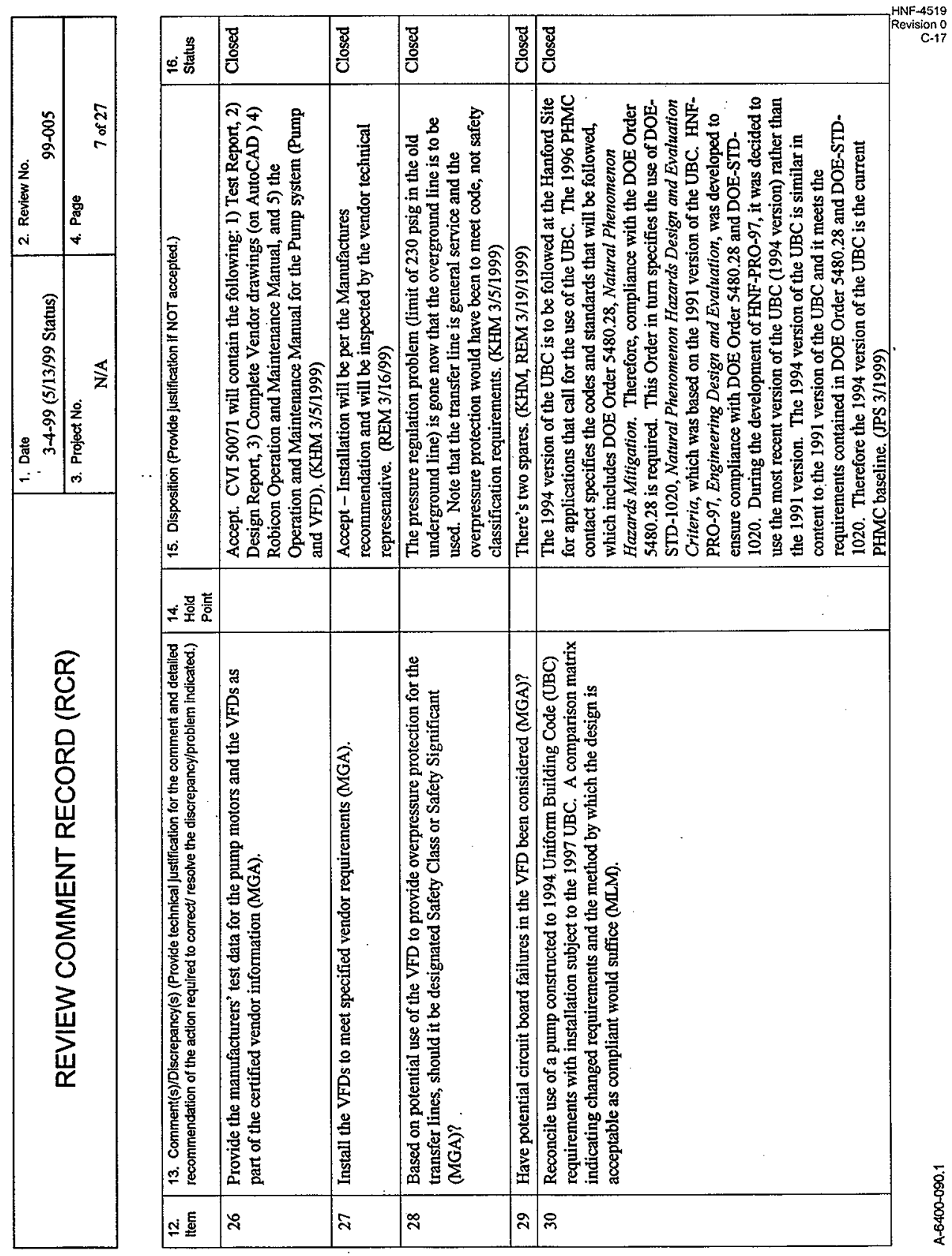




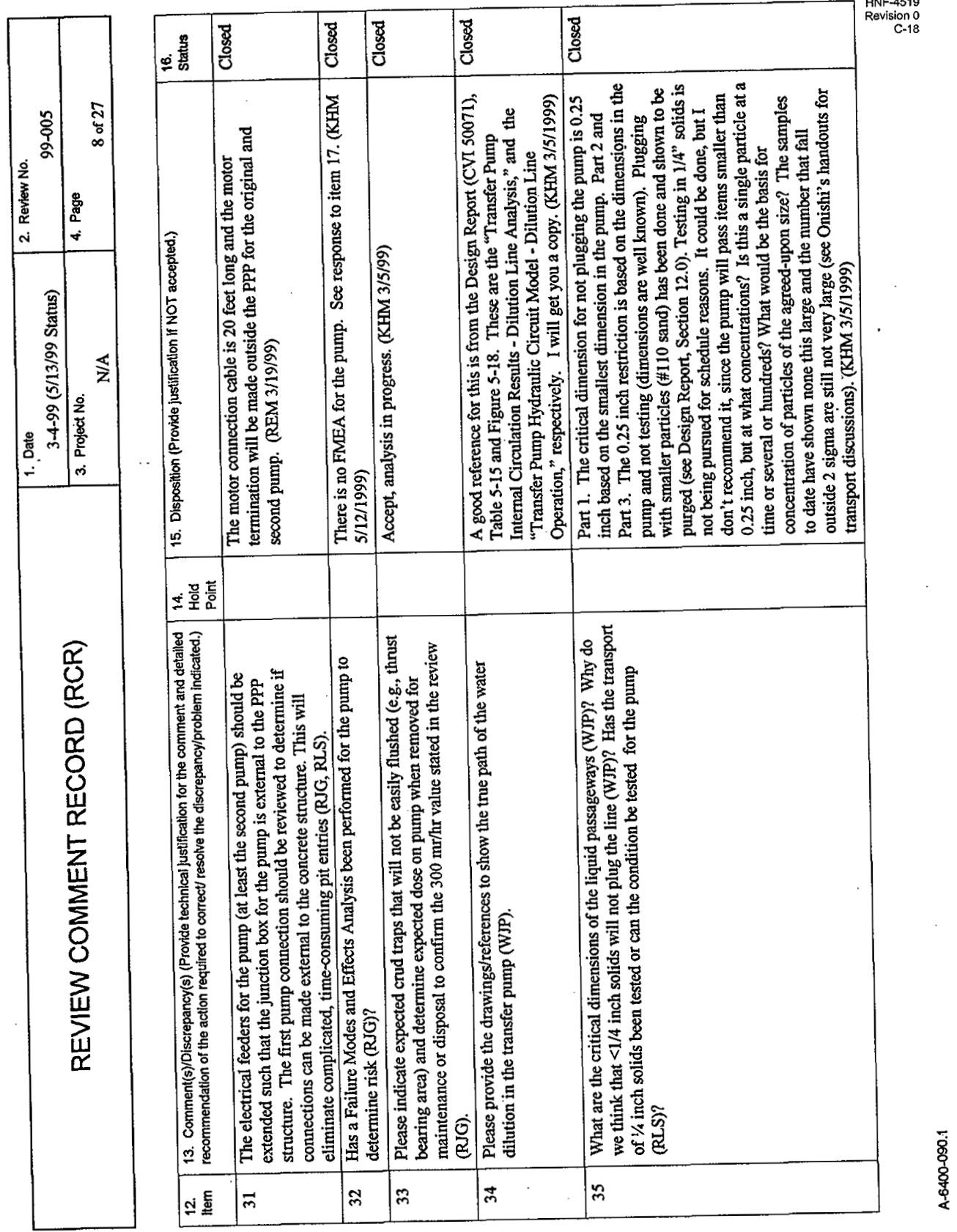




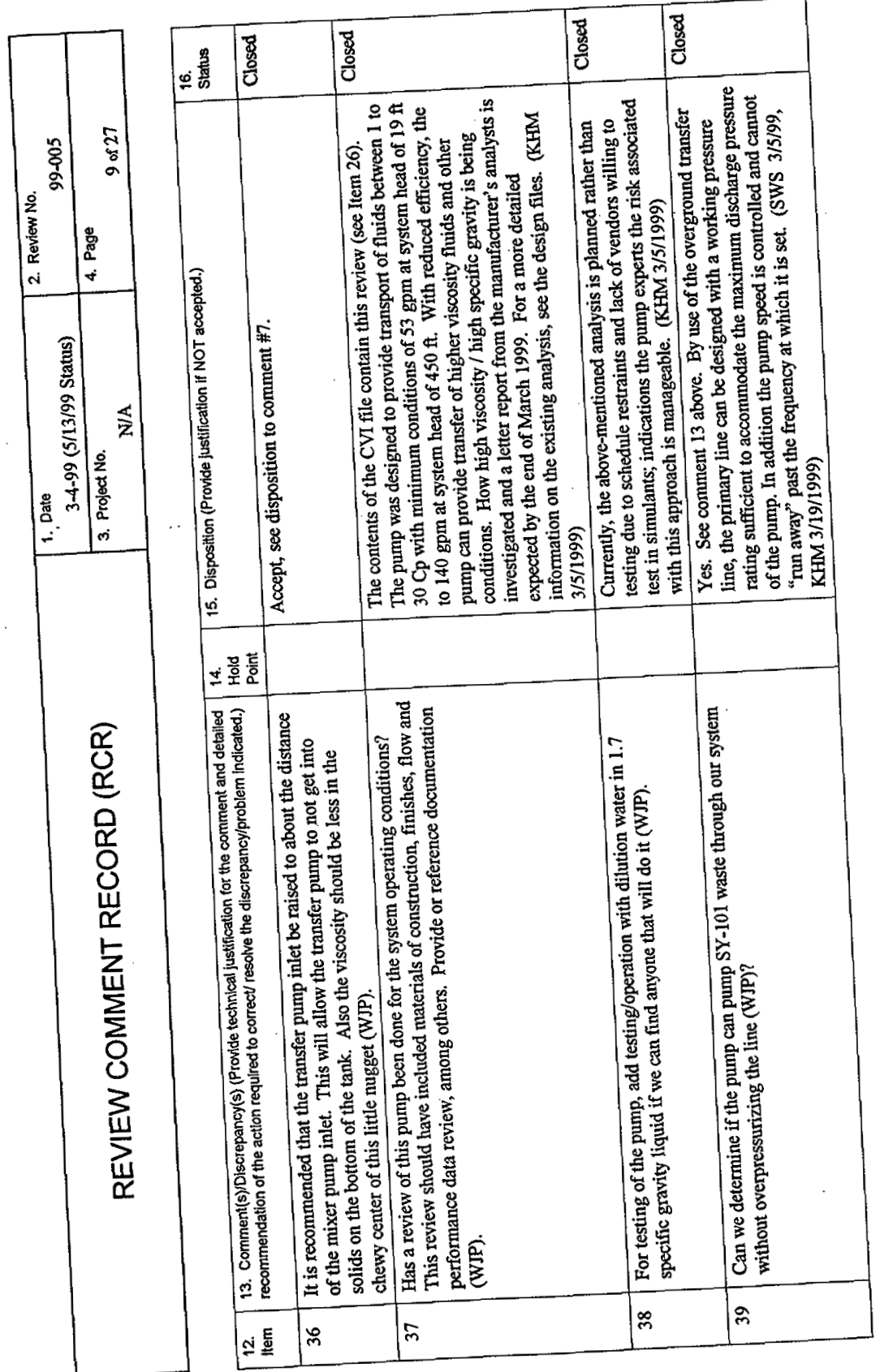




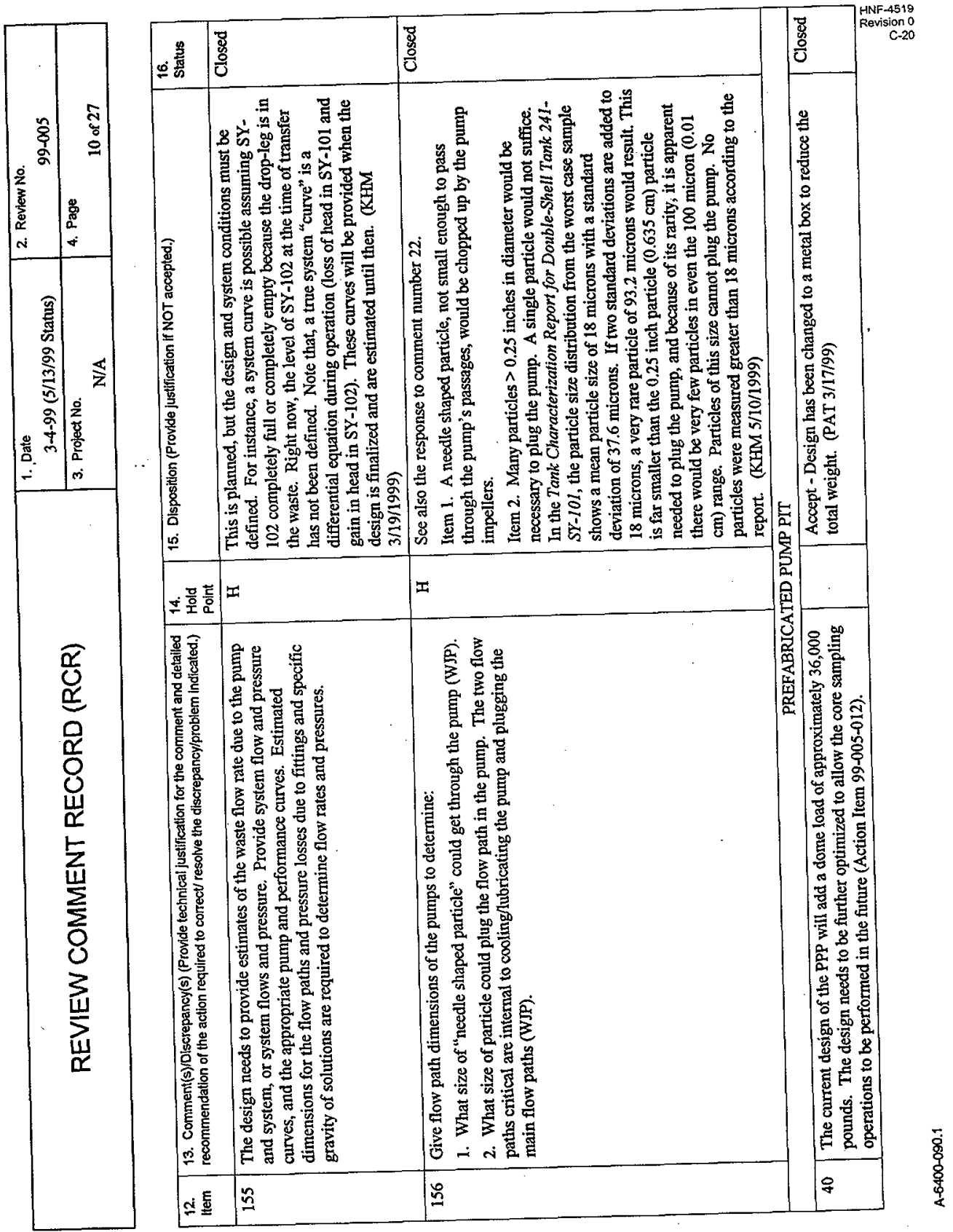




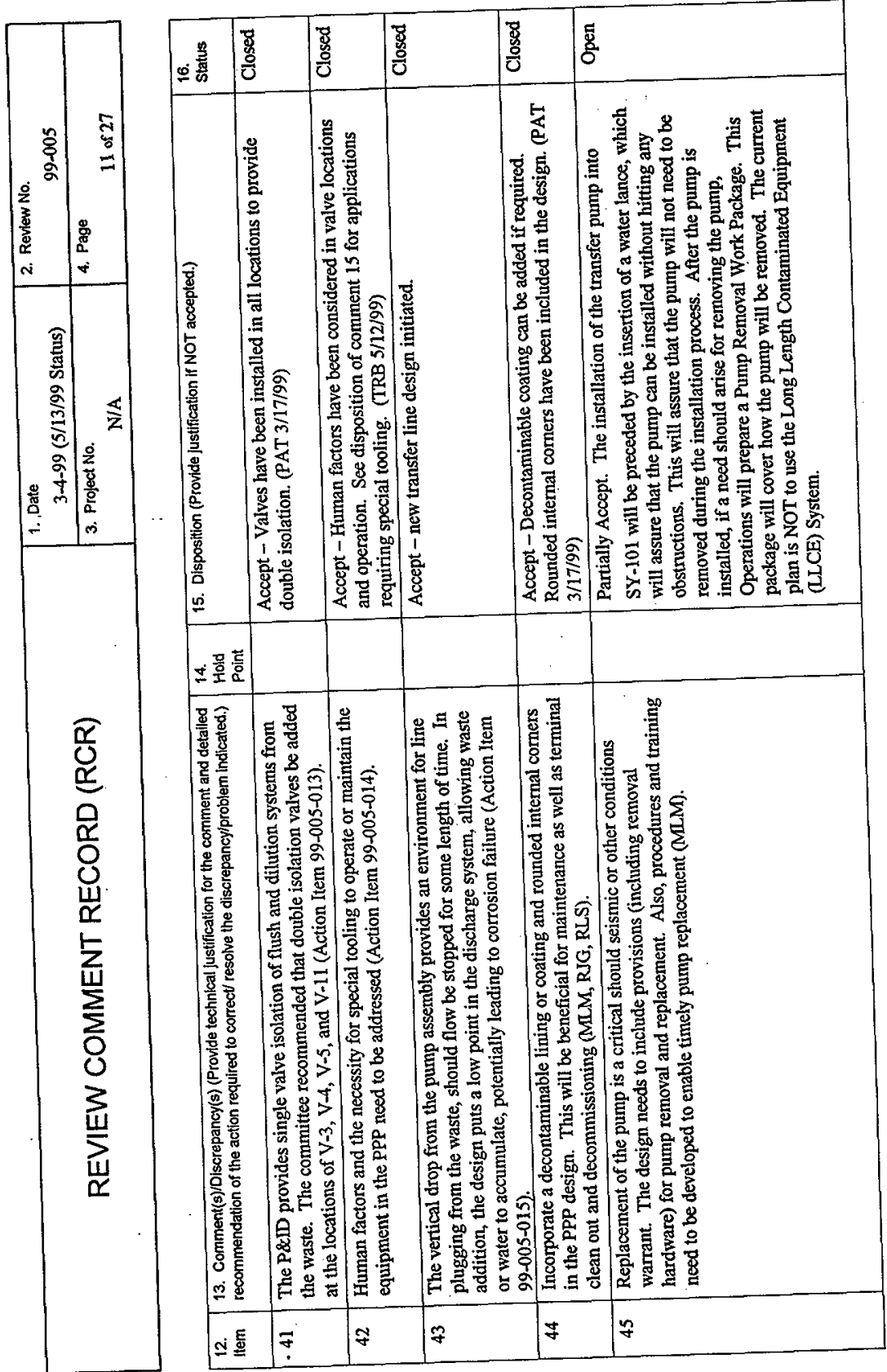









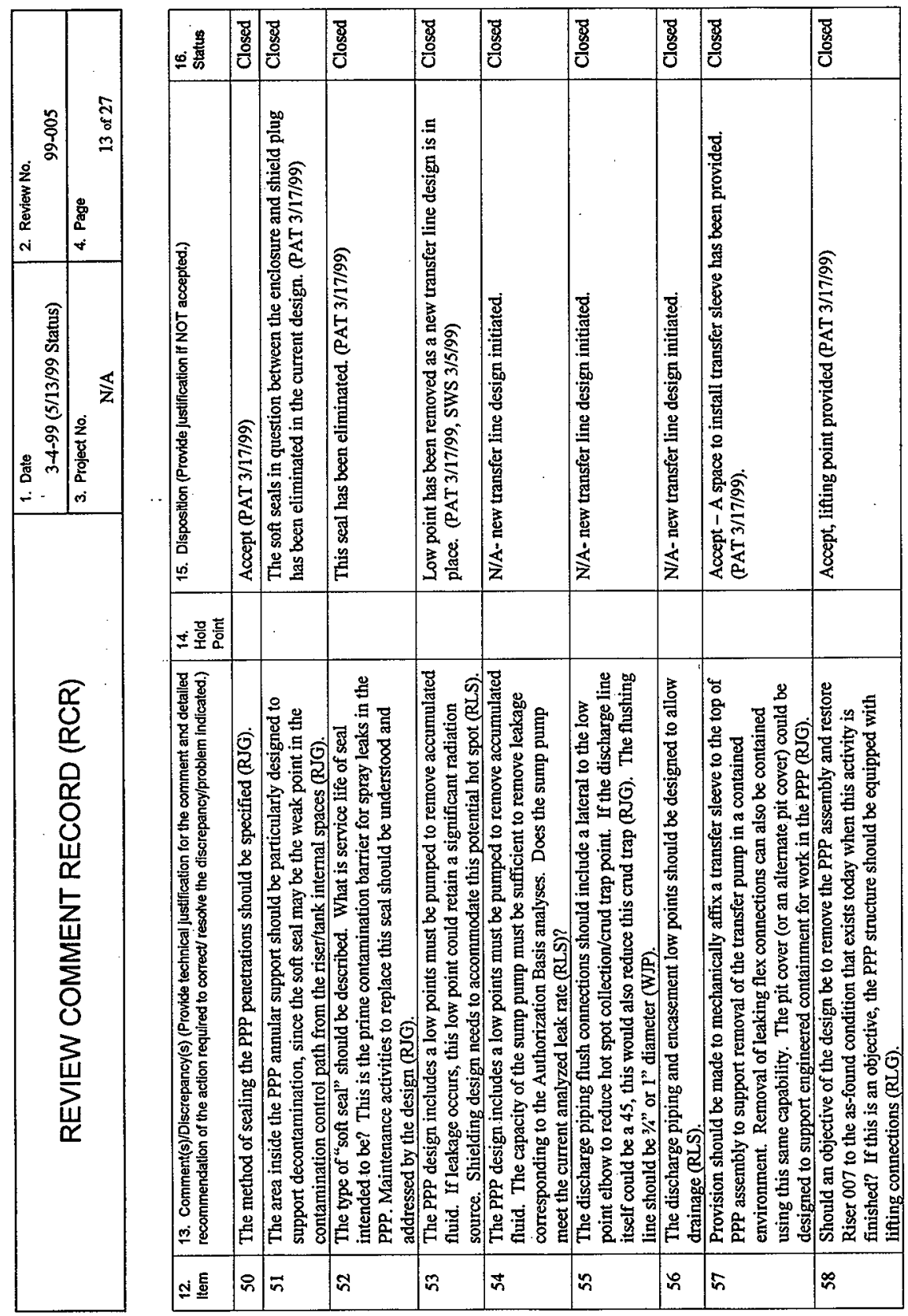




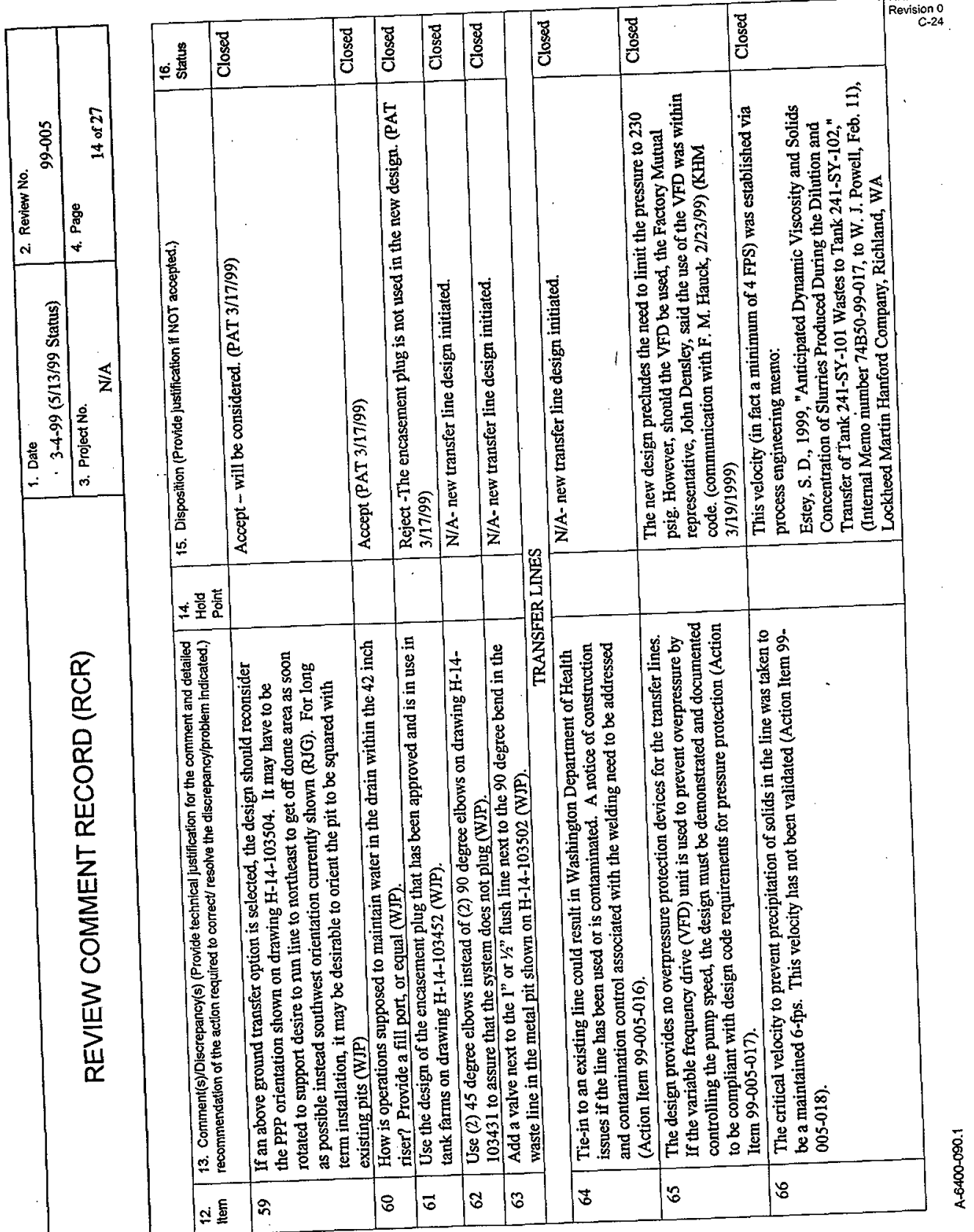




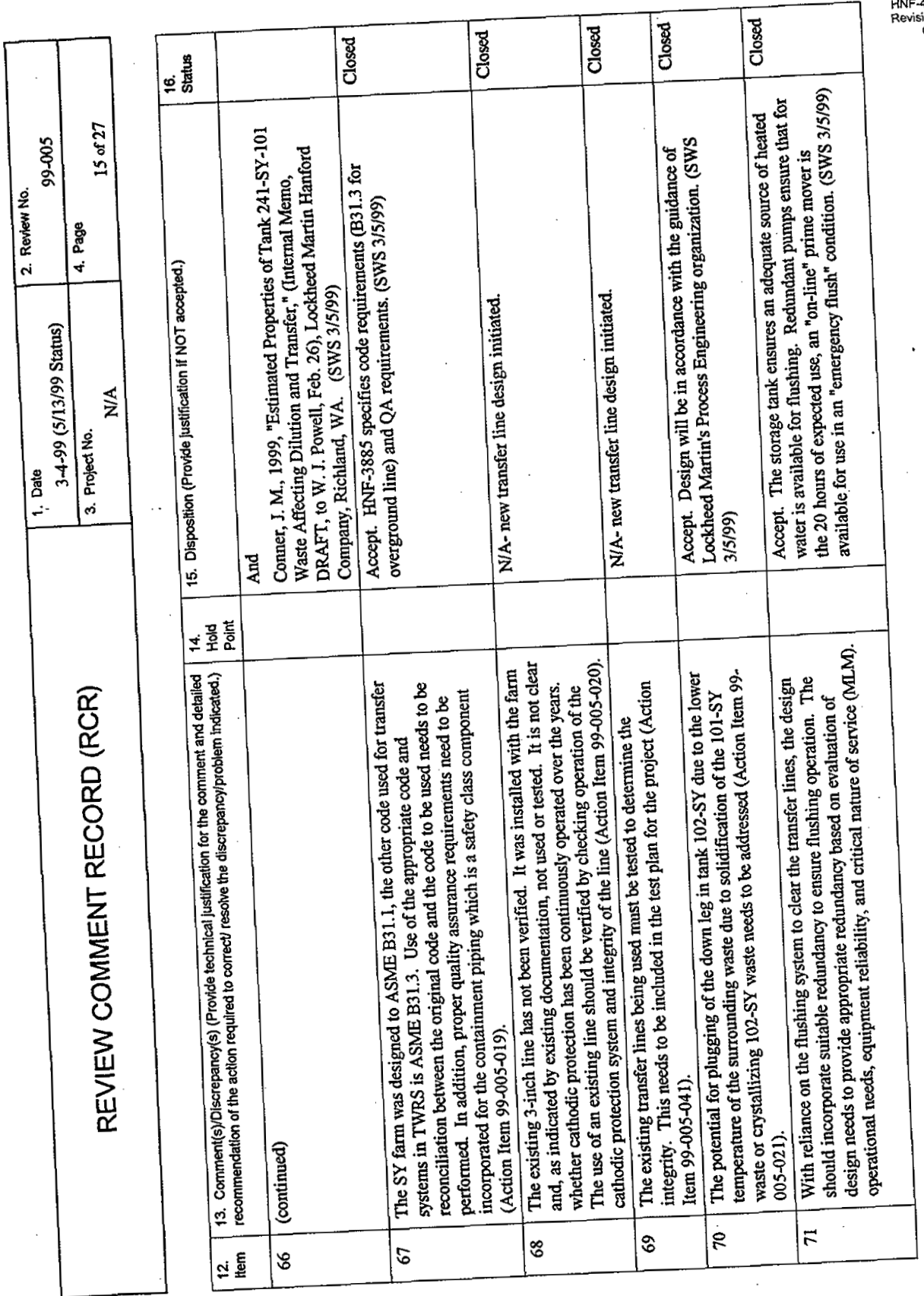




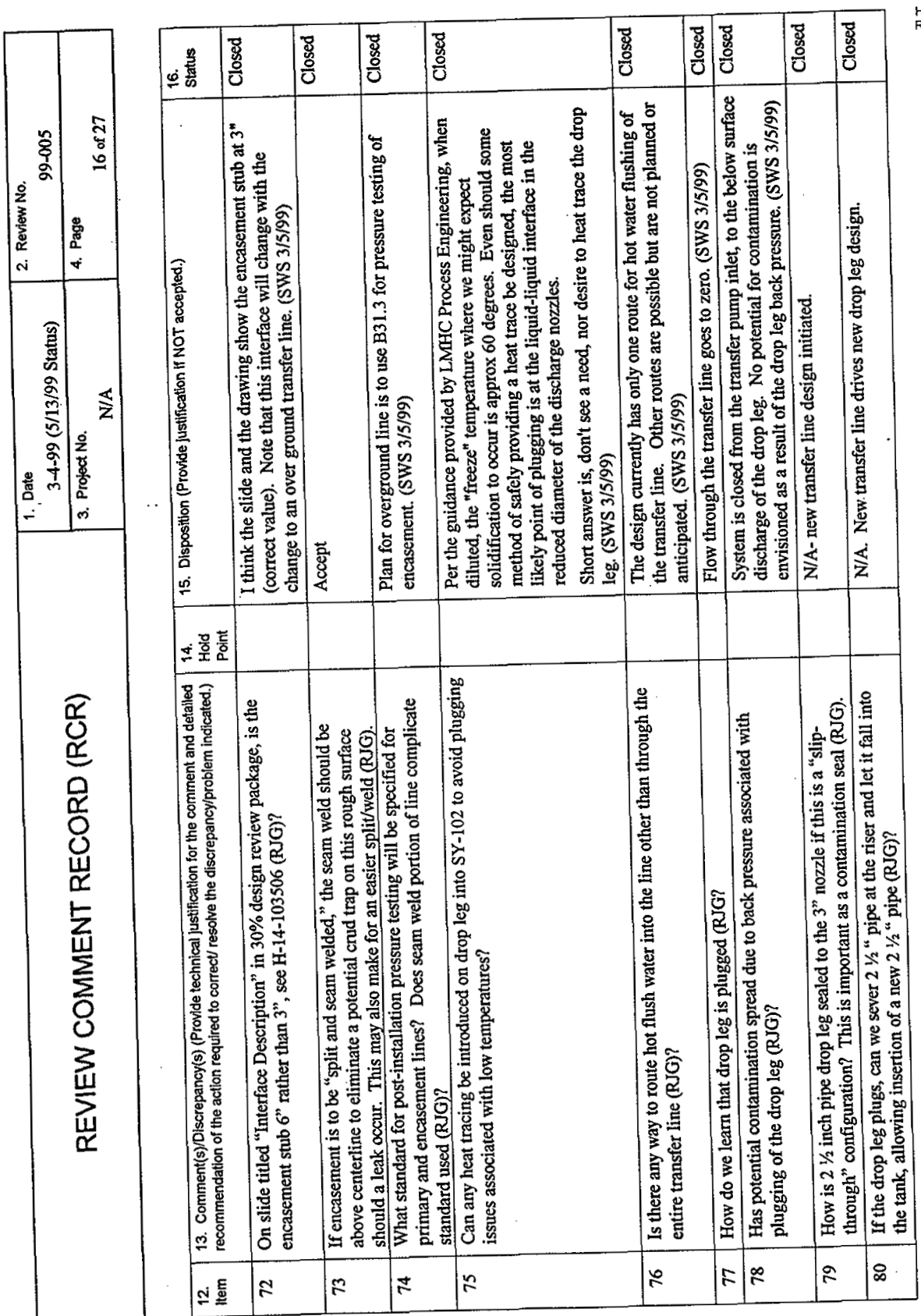




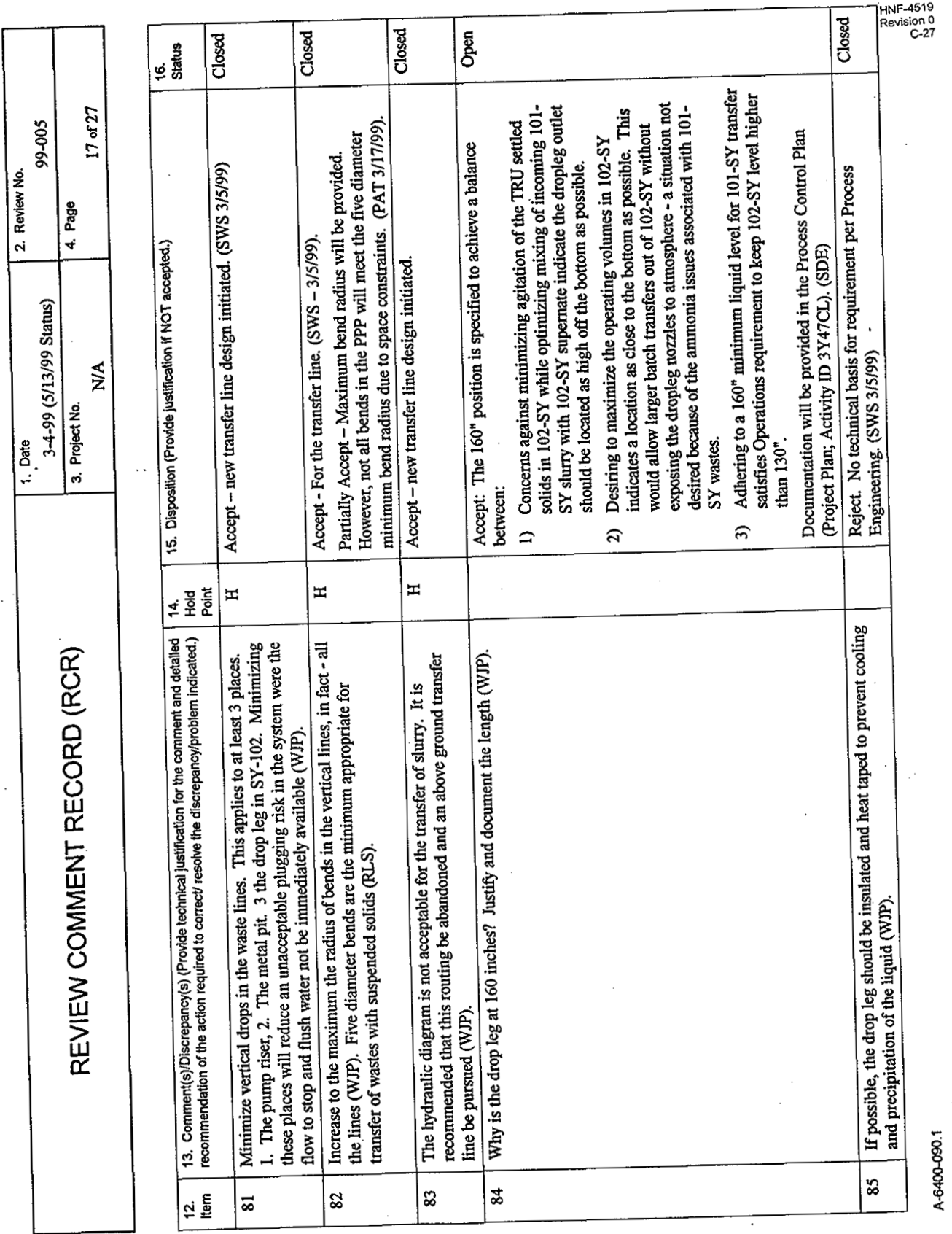




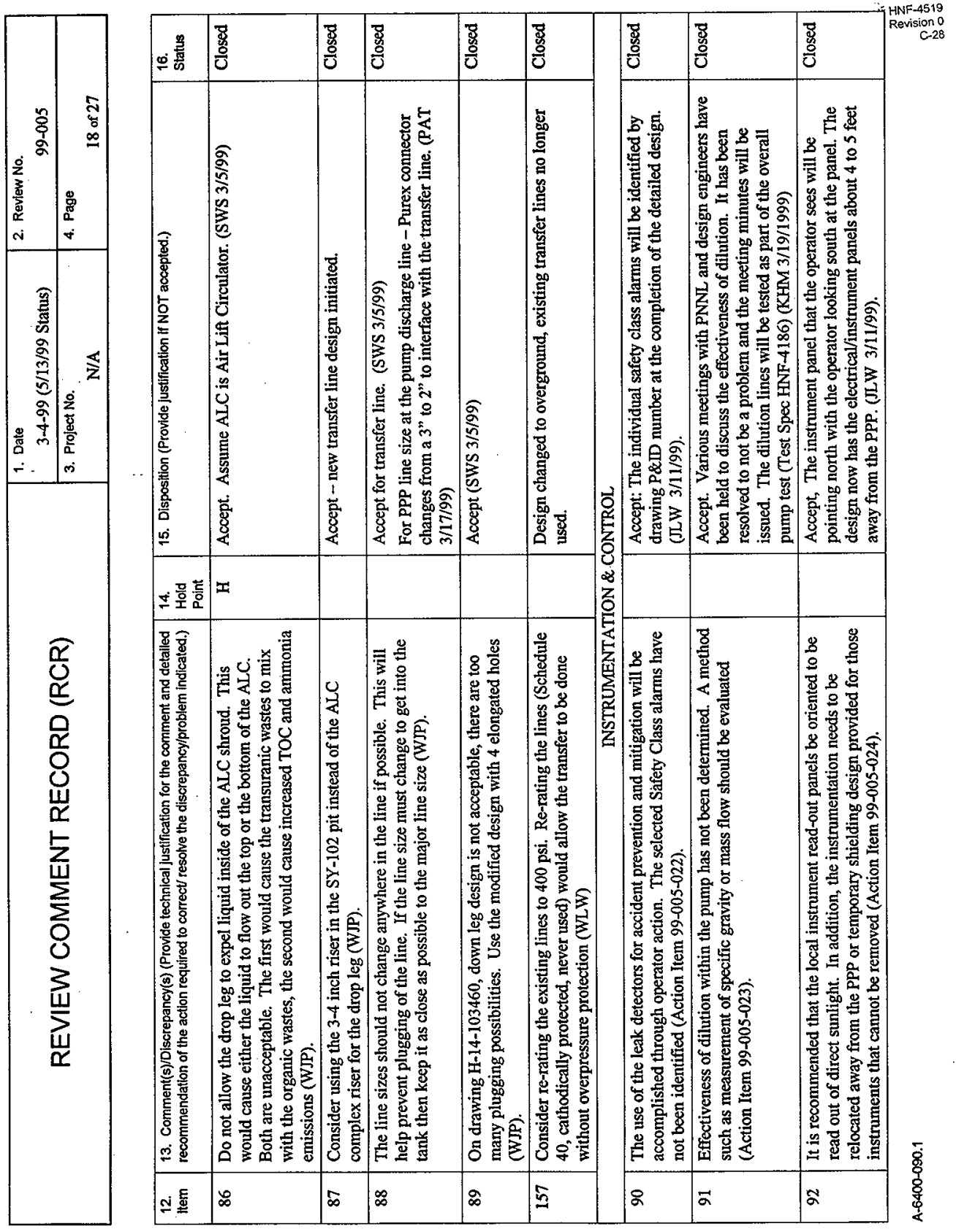




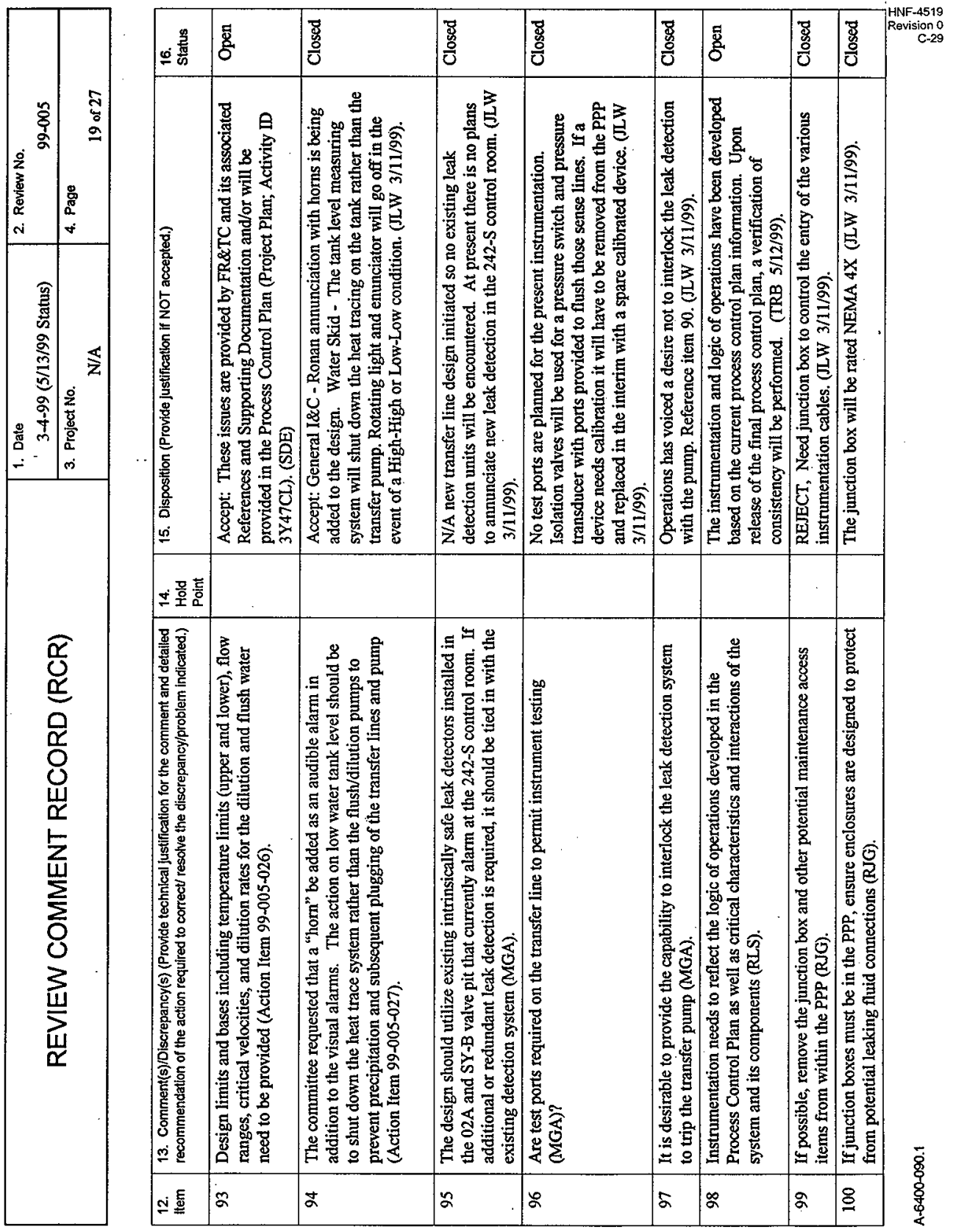




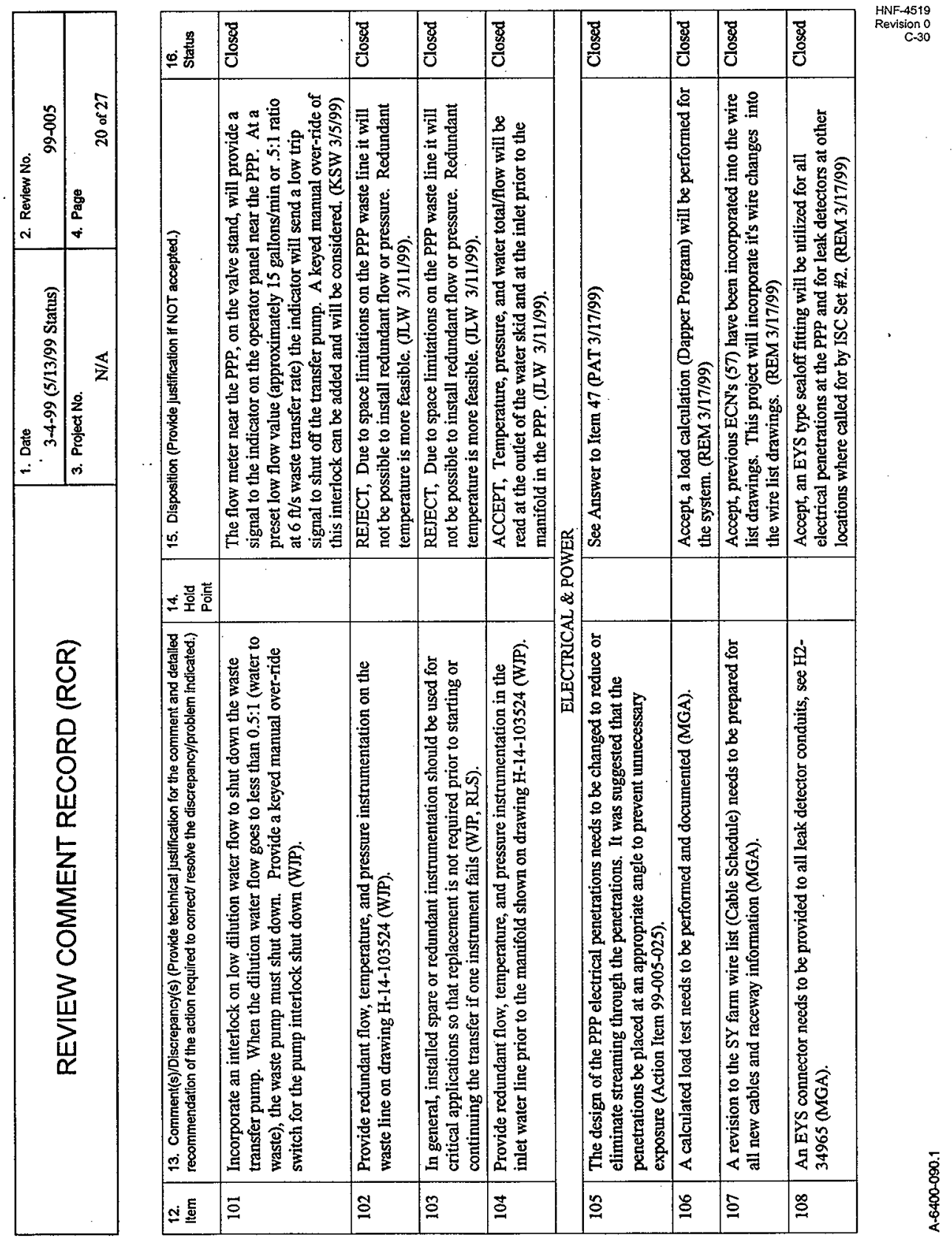




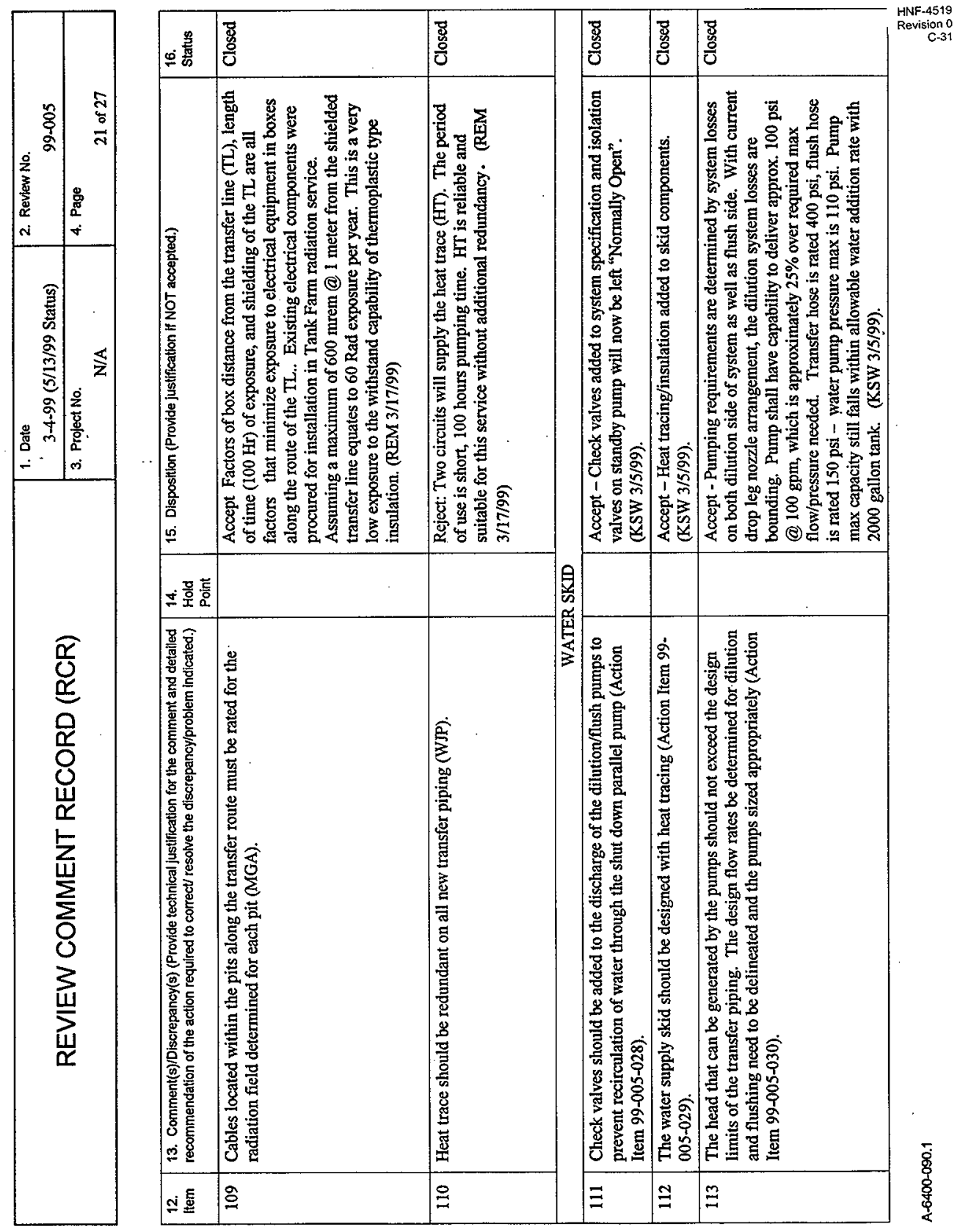




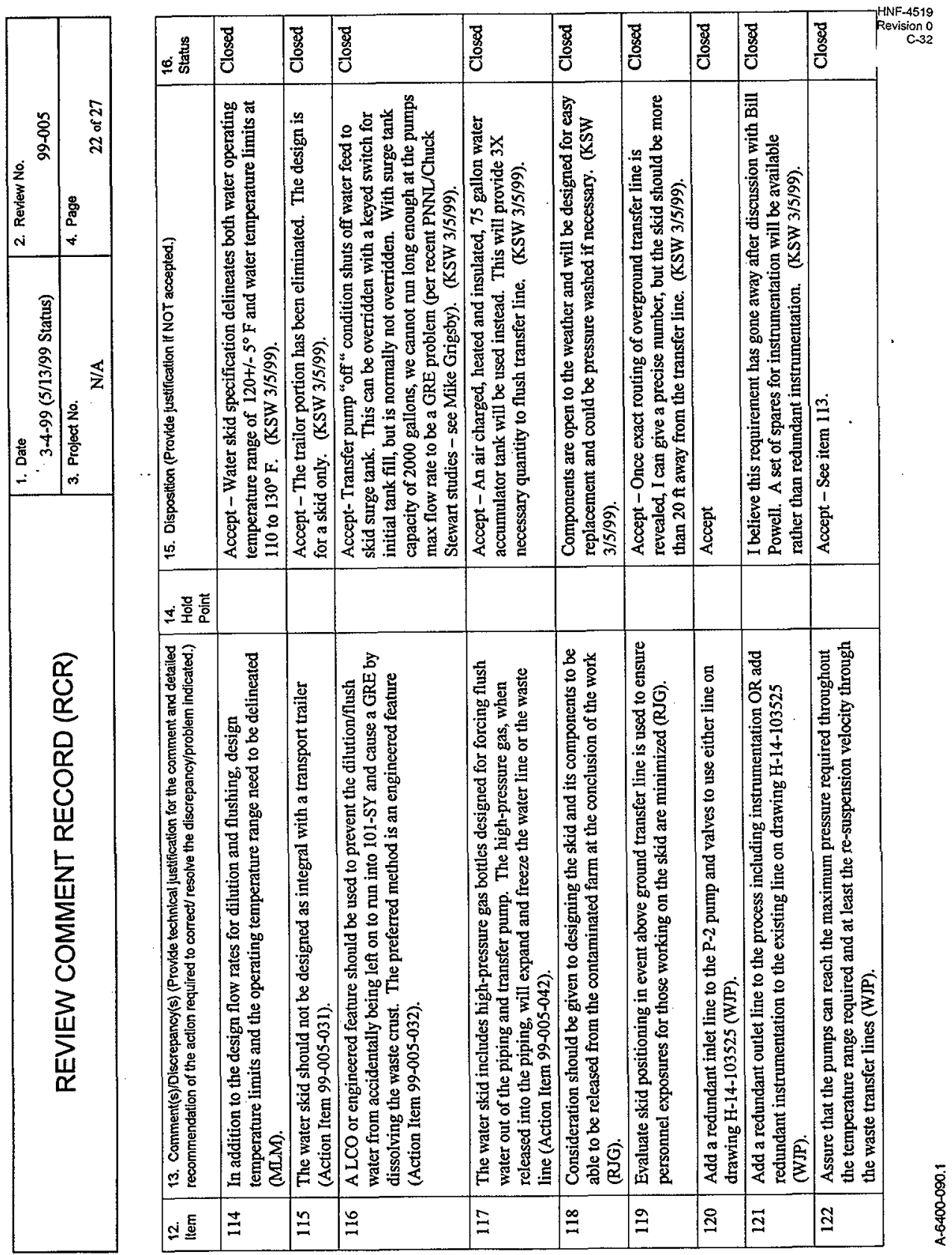




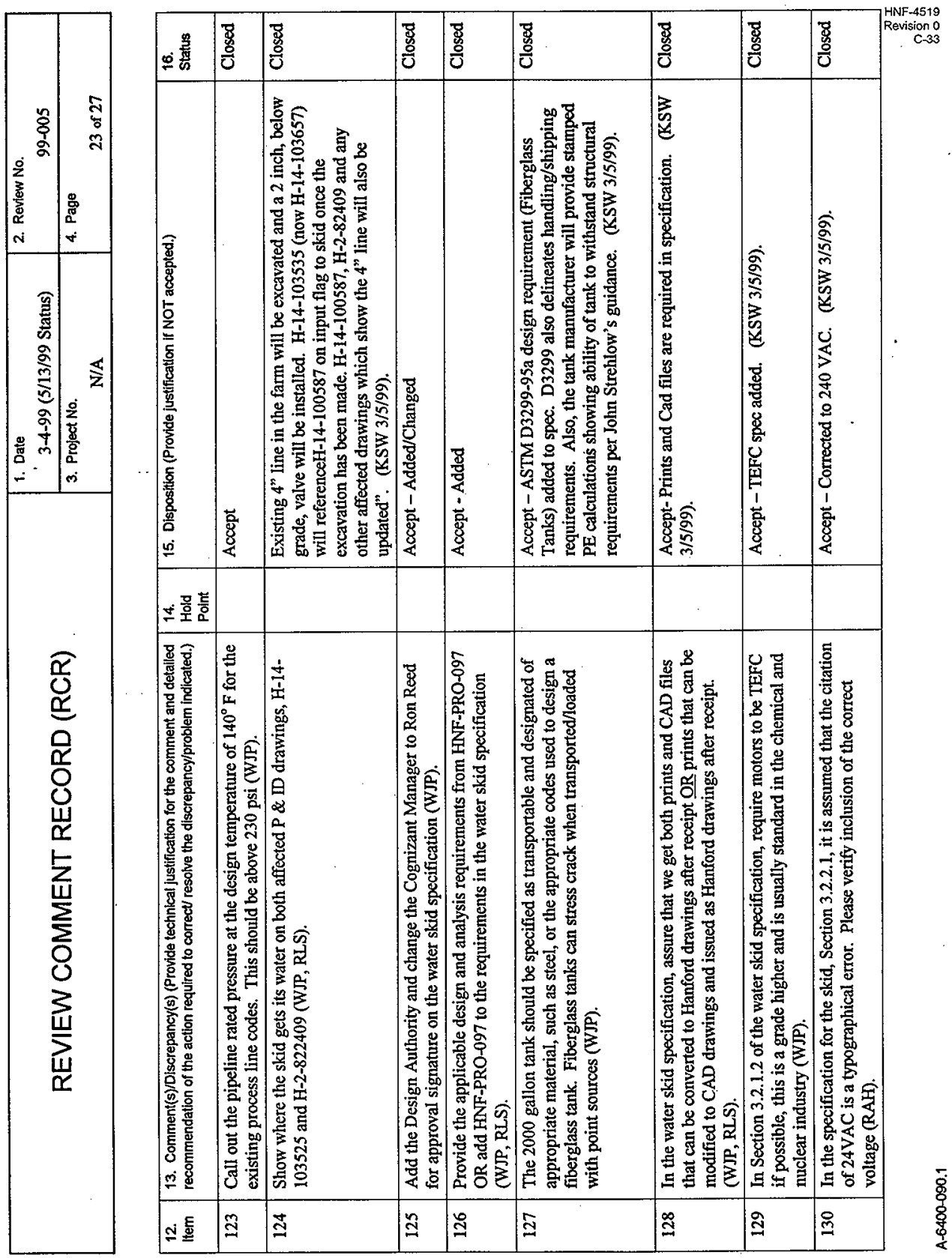




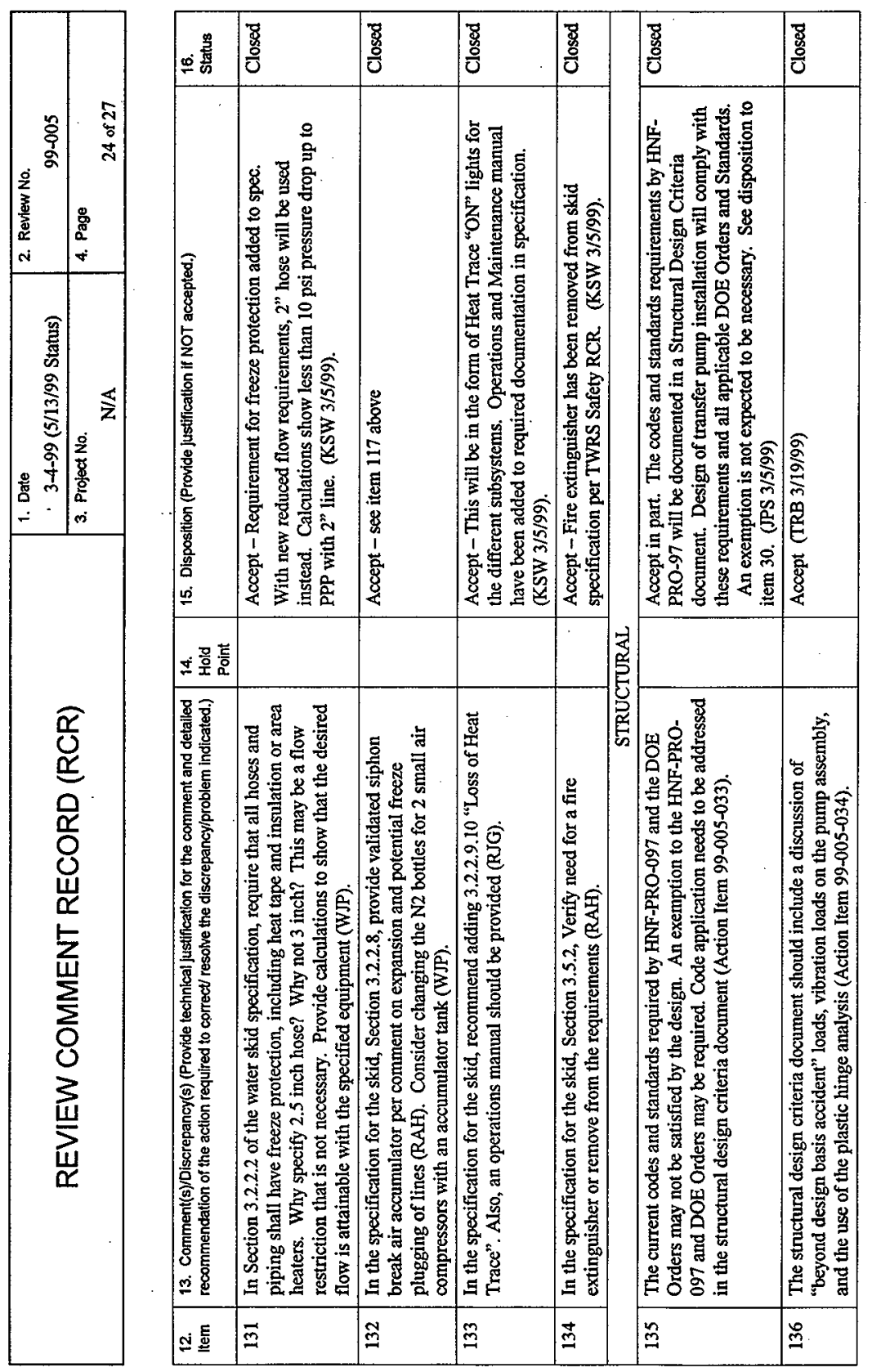




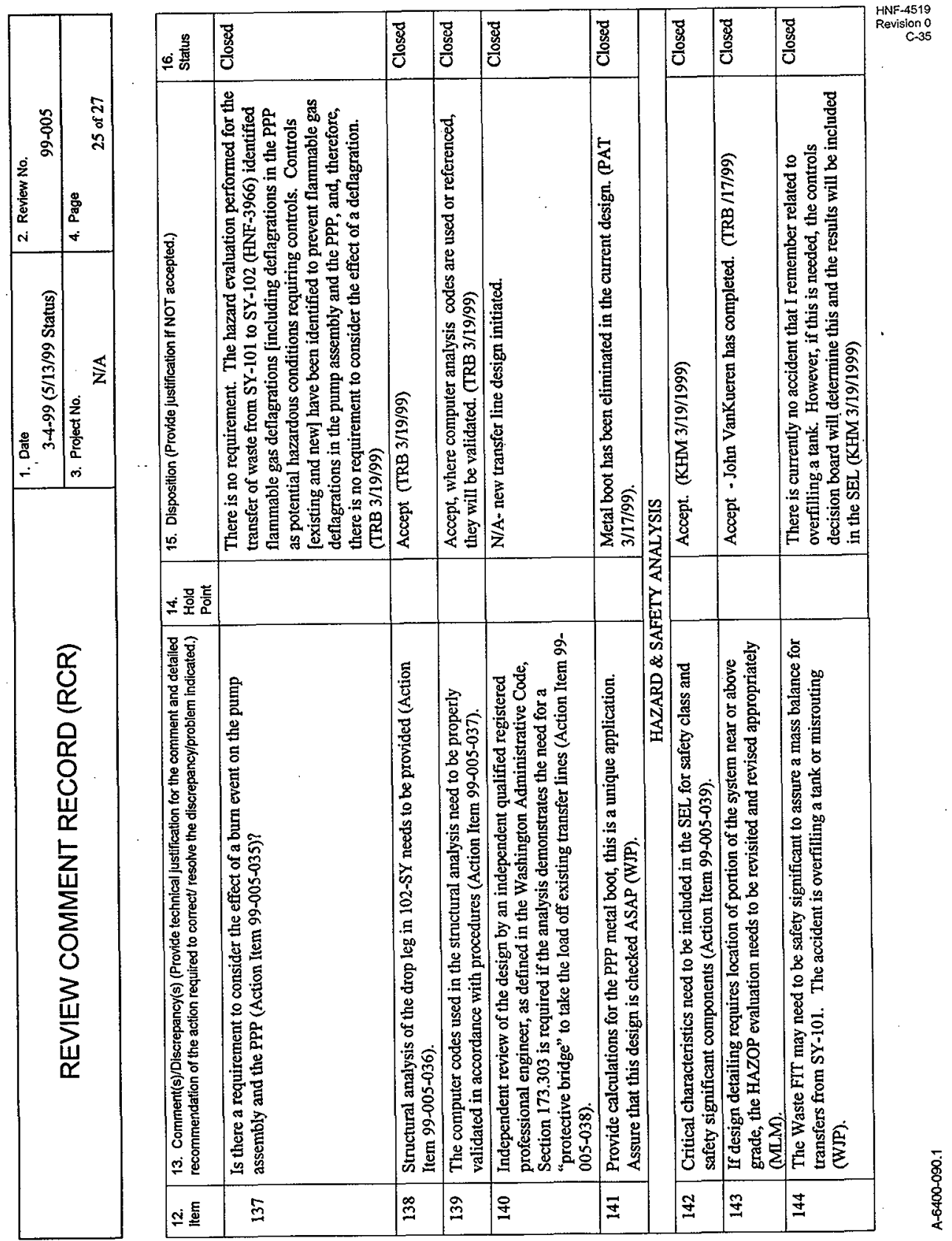




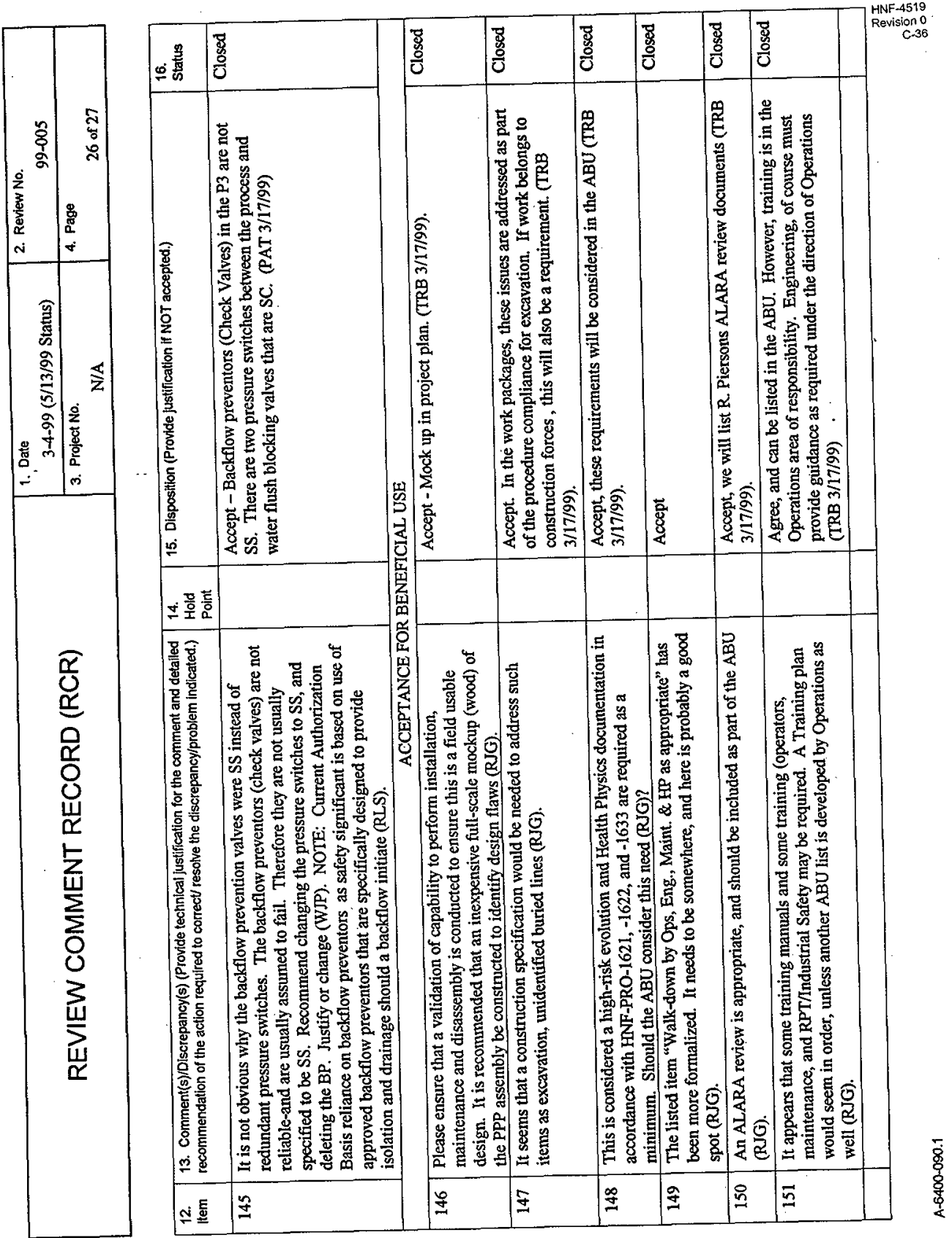




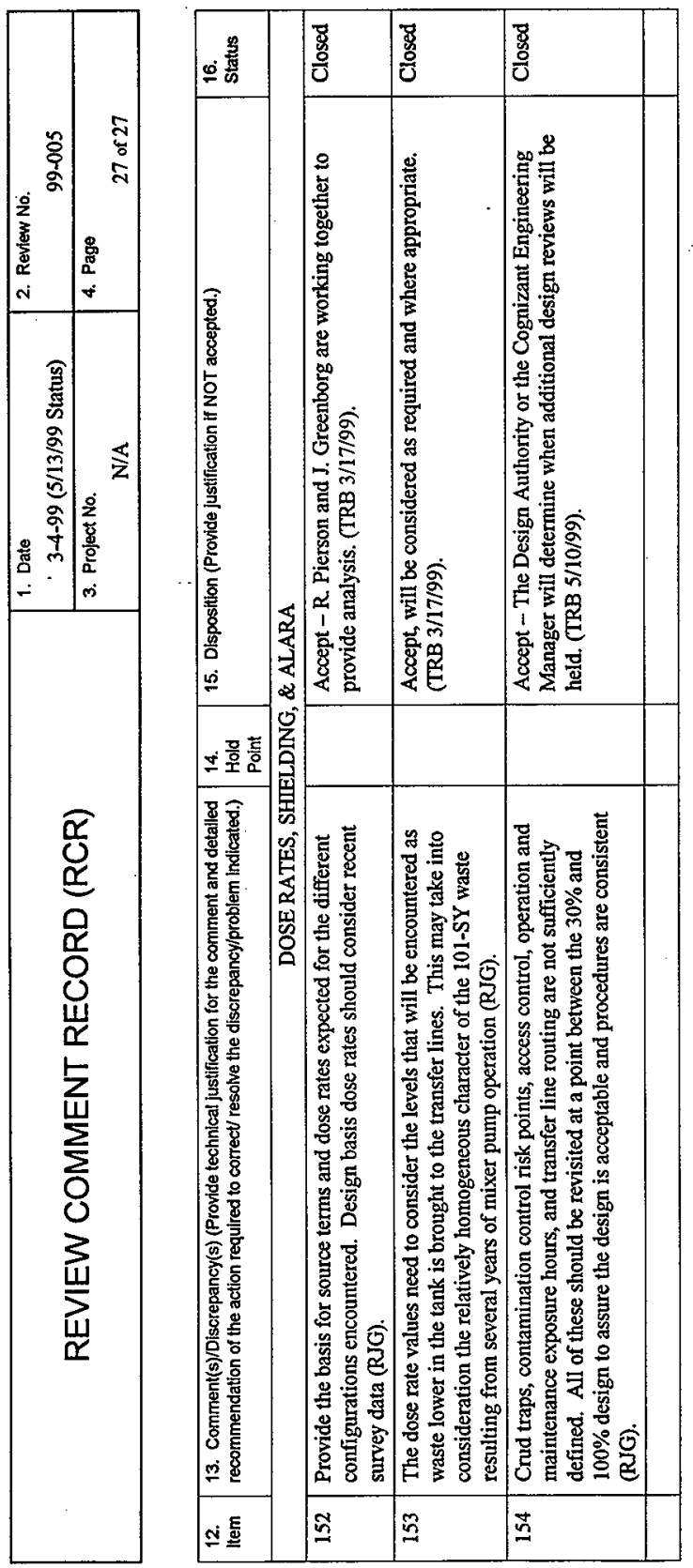




\section{APPENDIX D}

\section{DESIGN REVIEW MEETING MINUTES SPECIFICATION HNF-4169 PREFABRICATED PUMP PIT}




\title{
241-SY-101 TRANSFER RAPID MITIGATION SYSTEM SPECIFICATION FOR SY-101 PREFABRICATED PUMP PIT, HNF- 4169, DESIGN REVIEW
}

\section{MEETING MINUTES}

Prepared by C. E. Jensen

\section{BLDG, CONFERENCE ROOM 274}

March 9, 1999

\section{Design Review Team Members}

\author{
R. L. Schlosser, Chairman \\ C. E. Jensen, Secretary/Mechanical Engineering \\ M. H. Brown, Cognizant Engineer \\ M. F. Erhart, Project Cognizant Engineer \\ R. J. Giordano, Radcon \\ J. D. Guberski, Environmental Compliance \\ R. A. Huckfeldt, Safety \\ L. S. Krogsrud, Nuclear Safety \\ D. C. Larsen, Operations Representative \\ M. L. McElroy, Cognizant QA
}

L. Pokos, Maintenance Engineering

W. J. Powell, Design Authority

R. W. Reed, Cognizant Manager

D. A. Reynolds, Process Engineering

J. W. Bloom, Nuclear Safety and Licensing

C. C. Scaief, I\&C Engineer

J. R. Biggs, Operations Representative

C. P. Shaw, Pump Engineering

H. H. Ziada, Structural and Rigging

\section{DESIGN REVIEW}

- Mr. Titzler provided the presentation of the proposed Prefabricated Pump Pit (PPP). Only those comments that were not incorporated into the document during the meeting and not resolved are identified in these meeting minutes.

A concern as to the spray leak accident from the cover sitting on the PPP. The project agreed to evaluate the overfilling of the PPP to demonstrate that it will not result in a spray leak scenario. If there is a spray leak scenario, it will be evaluated to determine if it remains within the analyzed accident. In addition, the committee recommended that a lip be provided to prevent, in the event of a spray leak or overfilling, any spray from the lid (Action Item 99-007-001).

It was pointed out that the Washington Administrative Code (WAC) requires an independent corrosion engineer to review pit coatings, dissimilar material connections, and other corrosion issues. The project agreed to evaluate and determine the necessity of such an independent review (Action Item 99-007-002).

Reference 5 on page 4, ANSL/ASME B36.19M needs to verified as the correct standard for the reference. The project agreed (Action Item 99-007-003).

Bolting standards need to be identified. The project agreed to provide in this specification (Action Item 99007-004). 
The committee agreed that a compliance matrix is required for all the specifications. The committee also agreed that the matrix is not required before the specifications are issued. It was pointed out that not having the matrix requires the project to proceed at risk. The project agreed to provide this information at a later date (Action Item 99-007-005).

The O-ring seals for the PPP mounting on the riser need to be provided with the means to test the seals at 3 psig. The project agreed to provide a test port (Action Item 99-007-006).

A compliance matrix is required for fabrication. If waivers are required, they need to be generated or changes to the design and fabrication requirements need to be made. The project agreed to provide a compliance matrix (Action Item 99-007-007).

The safety classification of the PPP and the effect on natural phenomena hazards (NPH) analysis is not clear and the effect on the original USQ needs to be evaluated. The PPP is above grade, implying the classification may be safety class. Mr. Bloom agreed to review the USQ Determination to clarify effect on the USQ (Action Item 99-007-008).

The design of the PPP cover needs to include all the applicable NPH loads. The project agreed to consider the appropriate NPH loads in the design of the PPP (Action Item 99-007-009).

The electrical power junction box needs to be re-designed due to potential contamination and gas accumulation concerns with the current proposed design. It was recommended that the design use a type CGB connector through the wall and the junction box be installed on the exterior of the PPP, allowing access to the terminal block. It was further recommended that the CGB connector be placed above any expected liquid levels to prevent any waste or liquid from contaminating the junction box and any conduit. The project agreed to perform this task (Action Item 99-007-010).

It was recommended that one of the access ports in the PPP cover be placed over the PPP drain, to allow placement and removal of the dam and to allow clean out of the drain, if needed. The project agreed to place an access port over the drain (Action Item 99-007-011).

The PPP drawings lack the appropriate weld symbols for fabrication. The committee recommended that the all weld symbols be included on the drawings. The project agreed to do this (Action Item 99-007-012).

There was a significant discussion on the installation of the PPP on the riser. Concerns were raised on how loading of the riser would be prevented. The concrete piers supporting the PPP that prevent loading of the tank riser, can not be guaranteed not to settle. This could result in damage to the riser, should the loading be excessive. It was required that the project address and resolve this issue. The project agreed to resolve the loading issue (Action Item 99-007-013).

The committee requires that all critical dimensions have tolerances identified on the drawings. The project agreed to add the tolerances to the drawings (Action Item 99-007-014).

Discussion on the problems of using the shield plug inserts occurred. After much discussion of potential streaming concerns without the inserts and installation risks with the inserts, the committee agreed the inserts were not necessary and suggested they be removed, along with the shield counter-boring. The project agreed to eliminate the shield plugs (Action Item 99-007-015).

The committee recommended that the project ensure that there are extra gaskets and O-rings provided for spare parts. The project agreed to ensure additional gaskets and O-rings are on site for the transfer operation (Action Item 99-007-016).

The committee identified the need for provisions to allow visual inspection of the exterior O-ring. This inspection is required to comply with WAC requirements since the O-rings provide a barrier to leakage (Action Item 99-007-017). 
The committee recommended that a painting specification be provided to ensure proper coating materials and application is done. The project agreed to provide this specification after HNF-4169 is issued (Action Item 99-007-018).

The committee recommended that a template for the top of the PPP cover be provided to ensure proper valve line-up. The project agreed to provide the template (Action Item 99-007-019).

The committee recommended provisions be included in the design to ensure that the seal loop maintain isolation between the PPP and the SY-101 tank dome region. This can be accomplished by inclusion of filling provisions and, possibly, a loop seal level sensor (Action Item 99-007-020).

As stated earlier, the committee identified several items related to design, material specification, machining and fabrication controls, documentation requirements, and finishing requirements that were resolved and the acceptable resolution incorporated in the specification during the review.

The meeting was adjoumed. 


\section{APPENDIX E}

\section{DESIGN REVIEW MEETING MINUTES SPECIFICATION HNF-4170 TRANSFER PUMP PIPING}




\section{1-SY-101 TRANSFER RAPID MITIGATION SYSTEM SPECIFICATION FOR SY-101 TRANSFER PUMP PIPING, HNF- 4170, DESIGN REVIEW}

\section{MEETING MINUTES}

Prepared by C. E. Jensen

\section{BLDG, CONFERENCE ROOM 274}

March 9, 1999

\section{Design Review Team Members}

\author{
R. L. Schlosser, Chairman \\ C. E. Jensen, Secretary/Mechanical Engineering \\ M. H. Brown, Cognizant Engineer \\ M. F. Exhart, Project Cognizant Engineer \\ R. J. Giordano, Radcon \\ J. D. Guberski, Environmental Compliance \\ R. A. Huckfeldt, Safety \\ L. S. Krogsrud, Nuclear Safety \\ D. C. Larsen, Operations Representative
}

\author{
M. L. McElroy, Cognizant QA \\ L. Pokos, Maintenance Engineering \\ W. J. Powell, Design Authority \\ R. W. Reed, Cognizant Manager \\ D. A. Reynolds, Process Engineering \\ J. W. Bloom, Nuclear Safety and Licensing \\ C. C. Scaief, I\&C Engineer \\ J. R. Biggs, Operations Representative \\ H. H. Ziada, Structural and Rigging
}

\section{DESIGN REVIEW}

Mr. J. R. Buchanan provided the presentation of the transfer pump piping specification.

There was discussion on the necessity of pressure switch/gauge threadolets. The committee recommended the removal of unnecessary taps. The project agreed to remove the taps (Action Item 99-008-001).

The location of $\mathrm{V}-10$ was discussed. The committee recommended that the valve be located as close to the process line as possible, with out valve handle interference. The project agreed to make this change (Action Item 99-008-002).

A concern as to the seismic loading on the pump and flush line connections was raised. The only anchor point is on the connections because the lines are not anchored. The project agreed to evaluate the seismic stresses separate from this specification (Action Item 99-008-003).

The committee recommended that the standard design for the valve operators be included in the specification so the valve operator cones will be consistent with the TWRS standard. The project agreed to attach the standard design drawings to the specification (Action Item 99-008-004).

The seal loop pipe assembly drawing needs to identify the maximum discharge leg dimension and the correct orientation. The project agreed to make the changes (Action Item 99-008-005).

It was pointed out that the flatness and parallel tolerances of the bulkhead flanges on the PPP needs to be specified on the PPP drawings. The project agreed to provide this information (Action Item 99-008-006). 
The critical dimension tolerances ( $+/-1 / 32$ ") need to be identified on the drawings. This includes critical dimensions and tolerances for the purex head as well. The project agreed to include the critical dimension tolerances on the drawings (Action Item 99-008-007).

The flush or the dilution water connection is recommended to be a flex connection to the purex head at the pump. Support of the purex head may be required. The project agreed to include this on the drawings (Action Item 99-008-008).

In addition to the action items above, the committee identified several items related to design, material specification, fabrication controls, documentation requirements, and finishing requirements. These items were resolved and the acceptable resolution incorporated in the specification during the review.

The meeting was adjourned. 


\section{APPENDIX F}

\section{DESIGN REVIEW MEETING MINUTES SPECIFICATION HNF-4043 MOBILE WATER SUPPORT SKID}




\section{1-SY-101 TRANSFER RAPID MITIGATION SYSTEM SPECIFICATION FOR SY-101 MOBILE WATER SUPPORT SKID, HNF-4043, DESIGN REVIEW}

\section{MEETING MINUTES}

Prepared by C. E. Jensen

\section{BLDG, CONFERENCE ROOM 274}

March 10, 1999

\section{Design Review Team Members}

R. L. Schlosser, Chairman

C. E. Jensen, Secretary/Mechanical Engineering

M. H. Brown, Cognizant Engineer

M. F. Erhart, Project Cognizant Engineer

R. J. Giordano, Radcon

J. D. Guberski, Environmental Compliance

R. A. Huckfeldt, Safety

L. S. Krogsrud, Nuclear Safety

D. C. Larsen, Operations Representative

M. L. McElroy, Cognizant QA
L. Pokos, Maintenance Engineering

W. J. Powell, Design Authority

R. W. Reed, Cognizant Manager

D. A. Reynolds, Process Engineering

J. W. Bloom, Nuclear Safety and Licensing

C. C. Scaief, I\&C Engineer

C. P. Shaw, Pump Engineer

J. R. Biggs, Operations Representative

H. H. Ziada, Structural and Rigging

\section{DESIGN REVIEW}

The review group previously reviewed this specification and there were significant changes made to the document as a result of the initial review and other inputs. Therefore, it was decided that a second review was merited.

Mr. K. S. Witwer provided the presentation of the specification.

Only those comments that were not incorporated into the document during the meeting and not resolved are identified in these meeting minutes.

The P\&ID require a change to the location of the relief valve on the accumulator to show the correct relief valve location and discharge path. The project agreed to make the change (Action Item 99-010-001).

The P\&ID requires changing. Valves V-10 and 11 are identified as "normally closed". The project agreed to make the change (Action Item 99-010-002).

The P\&ID requires changing. Relief valves be installed between the P-1 an V-4 and between P-2 and V-6. The relief valves are to discharge into Tank $T-1$. The project agreed to make the change (Action Item 99 010-003).

The committee recommended that the P\&ID be checked to ensure that the symbols and terminology are consistent with drawing H-14-020000 (Action Item 99-010-004). 
The alarm panel alarm lenses require engraving. The committee recommended a schedule for engraving to be provided to the vendor for engraving. The project agreed to make the change (Action Item 99-010-005).

The control panel on the P\&ID does not identify the instrumentation indicators. The committee recommended that the indicators be provided on the P\&ID. The project agreed to make the change (Action Item 99-010-006).

The specification needs to provide insulation requirements or specifications for the insulation of the piping. The project agreed to make the change (Action Item 99-010-007).

The P\&ID should not specify line sizing for safety and relief valve inlets and discharges. For the design and build specification, the supplier is responsible for providing the valves and the piping needs to be sized based on applicable Code and Standard requirements based on the valves selected (Action Item 99-010007).

As stated earlier, the committee identified several items related to design, material specification, machining and fabrication controls, and documentation requirements that were resolved and the acceptable resolution incorporated in the specification during the review.

The meeting was adjourned. 


\section{APPENDIX G}

\section{DESIGN REVIEW MEETING MINUTES $33.33 \%$ CONCEPTUAL DESIGN REVIEW TEMPORARY OVERGROUND TRANSFER LINE}




\title{
241-SY-101 TRANSFER RAPID MITIGATION SYSTEM CONCEPTUAL (33.33\%) DESIGN REVIEW FOR A TEMPORARY OVERGROUND TRANSFER LINE
}

\section{MEETING MINUTES}

Prepared by C. E. Jensen

\section{BLDG, CONFERENCE ROOM 274}

\author{
March 11, 1999
}

\section{Design Review Team Members}

\author{
R. L. Schlosser, Chairman \\ C. E. Jensen, Secretary/Mechanical Engineering \\ M. G. Al-Wazani, Electrical \\ M. F. Erhart, Project Cognizant Engineer \\ R. J. Giordano, Radcon \\ J. D. Guberski, Environmental Compliance \\ R. A. Huckfeldt, Safety \\ M. L. McElroy, Cognizant QA \\ T. C. Oten, Equipment Engineering
}

\author{
L. Pokos, Maintenance Engineering \\ W. J. Powell, Design Authority \\ R. W. Reed, Cognizant Manager \\ J. W. Bloom, Nuclear Safety and Licensing \\ C. C. Scaief, I\&C Engineer \\ J. R. Biggs, Operations Representative \\ C. P. Shaw, Pump Engineering \\ H. H. Ziada, Structural and Rigging
}

\section{Design Review}

Mr. S. Shaw provided the presentation on the re-design of the transfer system for the RAPID mitigation system project. The review was required due to the significant issues with the proposed buried transfer line proposed in the $30 \%$ review.

An issue on the classification of the SY-102 transition from the temporary overground transfer line (OGT) to the drop-leg was a concern. There are significant differences in requirements for pits, tank riser extensions, and continuation of the containment system. The project agreed to determine which classification to be used and make the appropriate changes to the design (Action Item 99-009-001).

The OGT will result in additional exposure in the SY farm. The review group discussed the issue of routine activities that are performed such as operator rounds and maintenance activities. Suggestions included the use of remote methods such a optical devices, performance of required surveillances prior to transfer operations, or delay the routine activities until completion of the transfer operations. Mr. Biggs agreed to evaluate activities requiring performance during OGT transfers (Action Item 99-009-002).

It was recommended that the use of a narrow "purex" head could be used in place of the flanged connection on the flexible line at the SY-102 end. This would allow ease of removal through the encasement line back at the PPP, and be less likely to bind up in the encasement at the curves. It was also pointed out that a custom design closure cap would be required to prevent contamination of the encasement (existing "purex" head blanks include a large closure fitting). The project agreed to evaluate this suggestion (Action Item 99-009-003). 
With the proposed OGT elevated, the environmental requirements for daily inspection for leakage are a requirement. It is not clear that this is required for the enclosure. The project agreed to evaluate the issue to ensure inspection capability if required (Action Item 99-009-004).

The OGT will have lead shielding applied to lower doses, requiring a 4-meter fenced high radiation corridor along the length of the OGT. This corridor will need alternative access for operations personnel. Those areas requiring access for operations activities need to have the shielding maximized, consistent with the dome loading tequirements. The project agreed to evaluate this recommendation (Action Item 99-009005).

It was recommended that the spacing of the OGT supports be optimized to reduce dome loading, resulting from the weight of the supports. The project agreed to optimize the spacing (Action Item 99-009-006).

It was pointed out that on page 6 , note 1 , needs to identify the applicable documents such as ASME B31.3. The project agreed to include any applicable documents (Action Item 99-009-007).

Since the flexible hose is contained in a rigid encasement, a concern on the movement of the flexible line damaging the encasement from a hammer event, such as pump start. Such movement or reaction may require the use of restraints to prevent thrusting of the OGT. The project agreed to evaluate (Action Item. 99-009-008).

On page 8 notes, it is recommended that a reference to testing in accordance with ASME 31.3. The project agreed to include (Action Item 99-009-009).

The leak detector tape will be required to meet ignition control set 2 requirements. The project agreed to ensure this occurs (Action Item 99-009-010).

A concern on damage to the leak detector tape during installation and operation by movement of the flex line in the encasement was raised. The project agreed to evaluate and protect the tape if necessary (Action Item 99-009-011).

Any "doghouse" design for the terminal ends of the OGT should include provisions for the attachment of glove bags for removal of equipment. The project agreed (Action Item 99-009-012).

The flex line should be designed to be removed in one piece, designed to allow removal of waste from inside the line or prevent leakage from the line upon removal, and any internal appurtenances to guide or center the line in the encasement not impede the removal of the flex line through the PPP. The project agreed (Action Item 99-009-013).

A concern was raised as to the meaning of this OGT being "temporary". The project agreed to establish some end of activity to begin D\&D activities (Action Item 99-009-014).

It was also recommended that a survey plan for the $D \& D$ process be developed. The project agreed (Action Item 99-009-015).

The design of the dropleg nozzles needs to be reconsidered. The design shown would have a tendency to plug. The Project agreed to evaluate (Action Item 99-009-016).

It was pointed out that the "doghouse" and the OGT encasement will be subject to flammable gas controls. Consideration for this needs to be included in the design (Action Item 99-009-017).

On pages 11 and 12 , the drawing needs to be corrected to show the correct piping configuration at $\mathrm{SY}-102$ inlet. The project agreed (Action Item 99-009-018).

There needs to be a detail on how the lead blankets shall be attached to the encasement. In addition, the insulation attachment details also need to be detailed. The project agreed (Action Item 99-009-019). 
The concern over binding of the flex line during installation and removal was discussed. The recommendation was to use sweeping bends rather the bends identified. This will reduce the risk of jamming the flex line during installation and removal. The Project agreed (Action Item 99-009-020).

Remote exposure readouts should be provided for the PPP to provide better control of operator exposure at the PPP. The project agreed to evaluate (Action Item 99-009-021).

The meeting was adjourned. 


\section{APPENDIX H}

\section{DESIGN REVIEW MEETING MINUTES SPECIFICATION ANTI-SYPHONING SLURRY DISTRIBUTOR ASSEMBLY}




\title{
241-SY-101 TRANSFER RAPID MITIGATION SYSTEM SPECIFICATION FOR ANTI-SYPHONING SLURRY DISTRIBUTOR ASSEMBLY
}

\section{MEETING MINUTES}

Prepared by C. E. Jensen

\section{BLDG, CONFERENCE ROOM 274}

March 25, 1999

\section{Design Review Team Members}

\author{
T. C. Oten, Acting Chairman \\ C. E. Jensen, Secretary/Mechanical Engineering \\ M. G. Al-Wazani, Electrical Engineer \\ P. Bartley, Safety \\ J. W. Bloom, Nuclear Safety and Licensing \\ M. H. Brown, Cognizant Engineer \\ D. L. Dyekman, Environmental \\ M. F. Erhart, Cognizant Engineer \\ R. A. Huckfeldt, Industrial Safety \\ G. P. Janicek, Design Authority \\ L. S. Krogsrud, Safety \\ D. C. Larsen, Operations
}

\author{
M. L. McElroy, Cognizant QA \\ L. E. Pokos, Maintenance Engineering \\ W. J. Powell, Design Authority \\ R. W. Reed, Design Authority Manager \\ D. Reynolds, Process Engineer \\ C. C. Scaief, Instrument Engineer \\ J. S. Schofield, Operations Representative \\ C. P. Shaw, Pump Engineer \\ H. H. Ziada, Structural and Rigging
}

\section{Other Attendees}

G. A. Bames, SY-101 RAPID Engineer

S. H. Rifaey, Manager, Equipment Engineering

S. W. Shaw, Project Engineer

\section{DESIGN REVIEW}

This review was done with the document changes made during the meeting. Those that could not be incorporated into the document or require additional actions are identified below. Mr. S. Shaw provided the discussion on the drop leg.

It was recommended that the bulkhead connector in the riser extension be changed to remove the test flange. An inflatable plug will be used in lieu of a flanged connection. Mr. Shaw agreed to make that change (Action Item 99-013-001).

A concern about the streaming of radiation through the vent ducts was raised. It was recommended that the vent ducts in the shield plug have a "jog" in them to eliminate radiation streaming. Mr. Shaw agreed to make this change (Action Item 99-013-002). 
A concern was raised on how much ammonia generation will occur due to the design of the drop leg. Mr. Reynolds agreed to provide the generation numbers before the installation (Action Item 9-013-003).

The committee requested that the documentation verifying the drop leg will not plug be provided, to ensure the structural design is satisfactory. Mr. Shaw agreed to provide the documentation (Action Item 99-013004).

A concern was raised that the actual structural load criteria is in a referenced document rather than spelled out in the specification. Mr. Shaw agreed to include the actual information into the specification (Action Item 99-012-005). This item is a HOLD until it is included into the specification.

The risk of having a single drop leg design was discussed. It was suggested that a second design be developed and procured, to reduce the risk of failure. Mr. Reed agreed to discuss this issue with Mr. Raymond and resolve (Action Item 99-013-006).

The design authority stated that the current drop leg design being considered is not adequate and represents a high-risk design. Mr. Powell agreed to work with Mr. Shaw to develop a more acceptable design (Action Item 99-013-007). This item is a HOLD item to be resolved before approval of the design.

It was suggested that the shield plug aftachment be changed from threaded holes to studs to reduce the potential of contamination collecting in the holes. Mr. Shaw agreed to make the changes (Action Item 99013-008).

A discussion on the leak detectors and the ability to detect a leak occurred. The design of the vents is to be changed to add a 1 -inch lip to collect waste to be detected on 3 of the 4 vents. The fourth vent line will have a removable plug to drain the riser extension. In addition, the access hole in the riser extension cover will be located to facilitate the removal of the plug. Mr. Shaw agreed to make the changes (Action Item 99-013-009).

A discussion on the necessity of the o-ring gaskets verses regular gaskets occurred. Mr. Reed agreed to evaluate the need for 0 -ring gaskets and determine if standard gaskets can be used (Action Item 99-013$010)$.

It was suggested that radiation and environmental requirements be added to all material specifications. $\mathrm{Mr}$. Shaw agreed to include this item (Action Item 99-013-011).

There was a concern that the specification does not require the drawings be submitted for review and approval by the buyer prior to fabrication. It was suggested that a critical design-drawing list be provided to the seller to permit the buyer a review of critical components. Mr. Powell agreed to provide such a list to Mr. Shaw (Action Item 99-013-012).

It was suggested that the proper dimensions be provided for the riser flange bolt hole arrangement. Mr. Shaw agreed to provide this information on the drawing(s) (Action Item 99-013-013).

It was pointed out that inspection of the welds needs to be more specific. The weld examination needs to be specified as a " $5 \mathrm{X}$ " visual exam or a liquid penetrant. Mr. Shaw agreed to include this in the specification (Action Item 99-013-014).

It was suggested that the leak detector be set up similar to the PPP set up, except that the junction box will be on the outside of the riser extension. Mr. Scaief agreed to review this item and provide the wording to Mr. Shaw for incorporation into the specification (Action Item 99-013-015).

In sections 3.3,4.2, and 4.3, the welding and inspection codes and standards need to be specified. Mr. Shaw agreed to incorporate this item and have it reviewed by Dr. Ziada, prior to issuing the specification (Action Item 99-013-016). 
Item 4.10.2 needs to be re-written to include minimum requirements for performing required calculations. Mr. Shaw agreed to include this item (Action Item 99-013-017).

Item 4.10.4 needs to be re-written to identify which components are required to have certified material and test reports provided to the buyer. Mr. Shaw agreed to include this item (Action Item 99-013-018).

The meeting was adjourned. 


\section{APPENDIX I}

\section{DESIGN REVIEW MEETING MINUTES HNF-4252 STRUCTURAL DESIGN CRITERIA}




\section{1-SY-101 TRANSFER RAPID MITIGATION SYSTEM STRUCTURAL DESIGN CRITERIA - HNF-4252}

\section{MEETING MINUTES}

Prepared by C. E. Jensen

\section{BLDG, CONFERENCE ROOM 274}

March 26, 1999

\section{Design Review Team Members}

T. C. Oten, Acting Chairman

C. E. Jensen, Secretary/Mechanical Engineering

J. W. Bloom, Nuclear Safety and Licensing

M. F. Erhart, Cognizant Engineer

M. L. McElroy, Cognizant QA

\section{Other Attendees}

G. A. Barnes, SY-101 RAPID Engineer

T. R. Benegas, Project Engineer

S. H. Rifaey, Manager, Equipment Engineering

J.P. Strehlow, Structural Engineer

P. A. Titzler, Engineer, 101-SY

\section{DESIGN REVIEW}

This review was done with the document changes made during the meeting. Those that could not be incorporated into the document or require additional actions are identified below. Mr. Strehlow provided the discussion of the structural design criteria.

A discussion on the leak detectors and their function occurred. It was recommended that the leak detectors be procured as Safety Class to provide a conservative approach. Mr. Benegas agreed to make this happen (Action Item 99-014-001).

It was pointed out that all referenced and checked analyses need to be identified in this document. In addition, it was suggested that the analysis of the pump be reviewed to ensure the pump will withstand the PC-3 event. Dr. Ziada and Mr. Powell agreed to review the analysis (Action Item 99-014-002).

A concern on the requirements discussed in the structural design criteria with respect to ASME B\&PVC Section III and ANSI N690 and the other design specifications reviewed to date. It is not clear if these requirements have been identified in the other documents. Mr. Benegas agreed to review the previously reviewed documents to ensure the criteria is identified and incorporated (Action Item 99-014-003).

The meeting was adjourned. 


\section{APPENDIX J}

\section{DESIGN REVIEW MEETING MINUTES \\ ECN 647721 \\ ELECTRICAL INSTALLATION}




\section{1-SY-101 TRANSFER RAPID MITIGATION SYSTEM ELECTRICAL INSTALLATION ECN - \#647721}

\section{MEETING MINUTES}

Prepared by T. C. Oten

\section{BLDG, CONFERENCE ROOM 274}

April 9, 1999

\section{Design Review Team Members}

T. C. Oten, Acting Chairman

M. G. Al-Wazani, Electrical Engineer

P. L. Bartley, Safety

M. F. Erhart, Cognizant Engineer

L. S. Krogsrud, Safety

M. L. McElroy, Cognizant QA

\section{Other Attendees}

R. E. Merriman, Electrical Engineer

J. L. Wilk, Instrumentation Engineer
W. J. Powell, Design Authority

R. W. Reed, Design Authority Manager

S. H. Rifaey, Manager, Equipment Engineering

C. C. Scaief, Instrumentation Engineer

\section{DESIGN REVIEW}

Page 1

- Prepare a new USQ for this ECN, remove the USQ reference from block 13 a and place the USQ number in Block 4.

- Revise the date in Block 5.

- Enter the Work Package No. in Block 12b.

- Add the following note to Block 14b:" Formal Design Review was selected in accordance with HNFIP-0842, Vol. IV, Section 3.14."

- Add M. H. Brown and T. C. Oten to Block 15, and verify that MSINs are correct.

Page 2

- In Block 19, check the box for Safety Equipmient List, and remove the check in the box for Electric Circuit Schedule.

- In Block 20, add a reference to HNF-SD-WM-SEL-040, Rev. 1, and the note, "Project to modify documents checked in Block 19.

- In Block 20, add M. F. Erhart next to "Other," verify that MSIN's are correct, and replace R. L. Schlosser with T. C. Oten.

Page 3 - Add a discussion of the "HOLDs" in the ECN and explain why they are required. 
Page 7 - Add a "HOLD" cloud around the Variable Frequency Drive (VFD).

Page 8

- Add the 225A breaker (BKR-115) to the Parts List, including the Mfg./Model number.

- Add a "HOLD" cloud around the VFD, Item 3.

Page 9

- Note 8 of "ECN REFERENCE NOTES" will be added to the existing notes on the drawing and will be revised to read " New grounding cables shall be $4 / 0$ bare copper cadwelded to existing 5/8" steel cable unless otherwise noted. Install buried ground cable a minimum of 24 " below grade." Additionally, a notation stating "SEE NOTE 8 " will be added to the section of the drawing that depicts the new ground cable. The first seven notes identified under "ECN REFERENCE NOTES" will be deleted from this page since they are already notes on the drawing.

- Revise the drawing to show the instrument panel and the leak detection enclosure on two separate support structures.

Page 10 - Label the Fire Alarm Panel.

Page 11

- Specify that RTV will be used to seal new conduit access openings in trenway.

- Correct spelling of " burial " in the Reference Note.

Page 16 - Revise the Phase A power subtotal in the Table.

Page 17 - Show the Phase A power requirement for the SY 101 transfer pump control panel on this Table.

Page 18

- Revise the LDSTA tag number.

- Revise the drawing to indicate that the LD-CABLE is "BY OTHERS."

- Show location of the leak detection box adjacent to transfer pipe.

Page 19

- Add a Reference Note to "Coordinate installation of conduit with the installation of the transfer line."

- Revise the LDSTA tag number.

- Verify that the size is correct for conduit SY-564-NL.

- Show the new conduit routing and enclosure on the drawing.

Page 20

- Add the Load Center identification number.

- 6.00 should read 6" for the depth below grade.

Page $22-6.00$ should read 6" for the depth below grade.

Page 24 - Show conduit SY-135 as being deleted.

Page 26 - Add a ECN Reference Note to hold installation of wire runs until the related piece of equipment is installed and the wire can be terminated. 


\section{OTHER COMMENTS}

- $\quad$ "HOLDS" are only required to be placed on the variable speed drive installation, pages 7 and 10 .

- Redundant pressure switches will be required in the PPP to sense leakage between the water system and the waste transfer system piping (Action Item 99-015-001).

- The leak detection panel in the DACS trailer will be Safety Class to provide redundant annunciation for Operations (Action Item 99-015-002).

The meeting was adjourned. 


\section{APPENDIX K}

\section{DESIGN REVIEW MEETING MINUTES ECN 653826 REVISION TO SPECIFICATION FOR MOBILE WATER SUPPORT SKID}




\section{1-SY-101 TRANSFER RAPID MITIGATION SYSTEM ECN 653826 REVISION TO SPECIFICATION FOR SY-101 MOBILE WATER SUPPORT SKID, HNF-4043, DESIGN REVIEW}

\section{MEETING MINUTES}

Prepared by R. L. Schlosser

\section{BLDG, CONFERENCE ROOM 274}

April 13, 1999

\section{Design Review Team Members}

\author{
R. L. Schlosser, Chairman, Session Secretary \\ M. L. McElroy, Cognizant QA \\ W. J. Powell, Design Authority
}

\section{Other Attendees}

\author{
P. Bartley, \\ T. Benegas, SY-101 Design Lead \\ J. R. Biggs, Operations Representative \\ R. Merriman, SY-101 Design Engineer
}

\author{
R. W. Reed, Cognizant Manager \\ H. H. Ziada, Structural and Rigging
}

\section{DESIGN REVIEW}

Keith Witwer presented changes to the Mobile Water Support Skid Specification, HNF-4043, included in a proposed Engineering Change Notice, ECN 653826. The major change encompassed by this ECN is the addition of a remotely located valve stand and location of various safety-related components at the valve stand. In addition, the ECN incorporates several minor modifications including equipment numbering and reworded text.

The committee requested that the ECN distribution be extended to include appropriate personnel including Mark H Brown, SY Tank Farm Cognizant Engineer, Operations Procedure writers, and Maintenance Engineering to ensure that appropriate interface requirements are satisfied. The design team agreed. (Action Item 990413-1)

The committee questioned coordination of the ECN changes with $\mathrm{ECN} 647721$ for electrical changes. Ray Merriman, design engineer for the electrical ECN provided assurance that the two ECNs were coordinated. (Action Item 990413-2)

The committee requested that the connection hose lengths be added at the hose reel (HR1 and HR2) locations and the connection to the Rapid Mitigation System P\&ID on Drawing H-14-103657, Sheet 1. The design team agreed. (Action Item 990413-3)

The committee recommended removal of a drain line with drain valve V-412. The location identified is not a low point of the system, low point drainage is provided through drain valve $V-411$. The design team agreed. (Action Item 990413-4) 
The committee recommended that testing of the skid and low point drains be added to the system Acceptance Test Procedure. The design team agreed. (Action Item 990413-5)

The committee required text changes in Section 3.3 of the specification, to include re-evaluation of the structural analysis performed by the Buyer to provide design configuration sketches for the remote valve stand. The design team agreed. (Action Item 990413-6)

The committee required specification of submittals required to complete the Buyer supplied re-analysis identified in Section 3.3. The design team agreed. (Action Item 990413-7)

Since component identification tagging is applied based on reference Hanford drawings, the committee suggested that component tagging requirements be removed from the scope of the specification, in particular as required by the Water Supply Valve \& Instrument Stand and Water Supply Spool Piece sketches. It was recommended that tagging be performed after the vendor submitted drawings were converted to Hanford drawings. The design team agreed. (Action Item 990413-8)

The committee required addition of flange bolting requirements to the remote valve stand specification requirements to control assembly of various government furnished equipment. The design team agreed to add a requirement to assemble the flowmeter and pressure transducer using manufacturer's recommended torque requirements. (Action Item 990413-9)

The committee recommended that the specification require the weight of the valve stand assembly be permanently marked on the completed assembly. The design team agreed. (Action Item 990413-10)

The design review chairman summarized the action items and polled the review team, identifying no HOLD point items. The review team members agreed that the action items could be closed by review of the modified ECN by the chairman, with the chairman's signature on the ECN as record of acceptable closure. The meeting was adjourned. 
HNF-4519

Revision 0

\section{APPENDIX L}

\section{DESIGN REVIEW AGENDA, MEETING MINUTES AND REVIEW COMMENT RECORDS RAPID SYSTEM DESIGN REVIEW}




\section{RAPID SYSTEM DESIGN REVIEW AGENDA/PRESENTATIONS \\ 1163 Building/Rm. 274 \\ $4 / 29 / 99$}

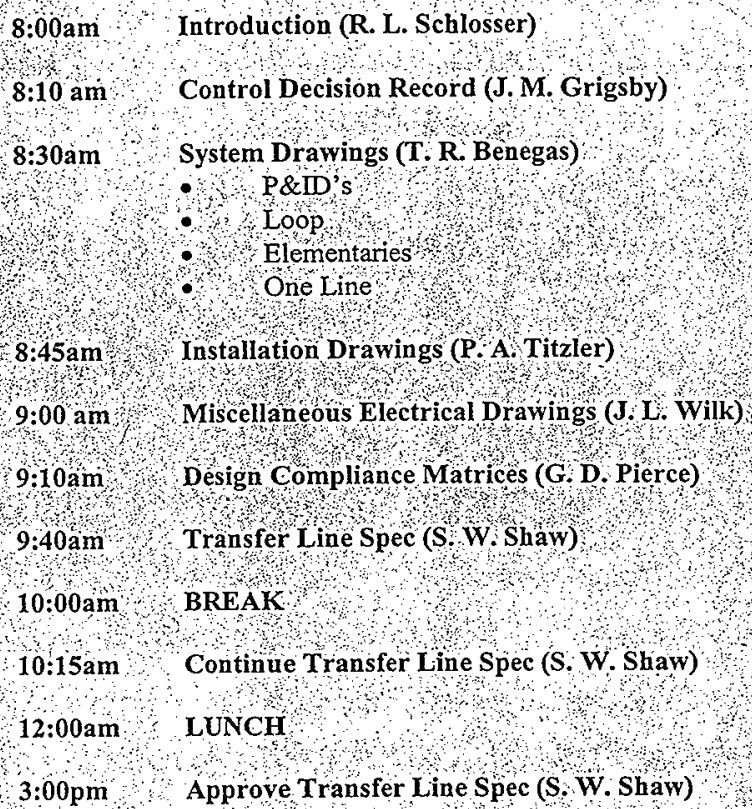

CONTINUE WITH RAPID SYSTEM DESIGN REVIEW AGENDA/PRESENTATIONS (IF REQUIRED)

1163 Building/Rm. 274

$8 \mathrm{am}-4: 30 \mathrm{pm}$

$2 / 29 / 99$ 


\section{1-SY-101 RAPID MITIGATION SYSTEM, FORMAL DESIGN REVIEW}

\section{MEETING MINUTES}

Prepared by Shakir Zaman

\section{Building 1163, CONFERENCE ROOM 272}

April 29-30, 1999

\section{Design Review Team Members}

R. L. Schlosser, Chairman

S. U. Zaman, Secretary/Equipment Engineering

M. G. Al-Wazani, Electrical Engineering

R. W. Reed, Cognizant Engineering Manager

L. S. Krogsrud, Nuclear Safety

T. Oten, Equipment Engineering

H. H. Ziada, Structural and Rigging

Lou. Pokos, Equipment Engineering

Michael McElroy, Quality Engineering

Rick Huckfeldt, Safety

\section{Other Attendees}

Jerry Wilk, I\&C

Carl Hanson, Engineering Manager

Peter Titzler, Design Engineer

Glenn Pierce, Compliance Matrices
Joe Meacham, Nuclear Safety and Licensing

W.J. Powell, Design Authority

Mark H. Brown, Cognizant Engineer

Shafik Rifaey, Equipment Engineering

Tim. Oten, Equipment Engineering

Michaell Erhart, Cognizant Engineer

Daniel A. Reynolds, Process Control

Craig Shaw, Retrieval Engineering

Bob. Giordano, Radiological Engineering
Carl W. Holmes, Electrical/I\&C

Gary L. Hickman, I\&C

Larry Kripps, Nuclear Safety and Licensing

\section{DESIGN REVIEW}

The chairman presented an overview of the two day design review for the 241-SY-101 RAPID Mitigation System Final design, the approach to review, comments, resolution in relationship to the Performance Agreement (PA) of June $1^{\text {st }}$. 1999. He stated that presently there are 19 unresolved items from the previous design review meeting; 9 of them are awaiting response from the process engineering. Some critical issues and hold points such as pump performance should be closed through this final design review. He also stated that the remaining issues need team consensus. Any additional comments should be submitted no later than Tuesday, the May $4^{\text {th }}$. In order to meet the PA. milestone. 
The Nuclear Safety and Licensing presented the new controls associated with the RAPID Mitigation design. It was the team consensus that these controls have already be subjected to a review and approval by Nuclear Safety and Licensing with the appropriate review by other departments and therefore are outside the purview of this design review team i.e. no approval by this design review team is required. Furthermore, these new controls are not to be a part of the Authorization Basis $(\mathrm{AB})$ and no approval is required from the DOE. These controls are voluntary, contractor imposed internal controls and will be incorporated in HNF-1266 manual as required over and above the $A B$ controls.

It was the team consensus that the control for the water addition should remain as manual.

An issue, raised by Craig Shaw, is that the waste temperature trapped in the pump may rise to a high temperature due to high winding/oil temperature. This has not been analyzed yet. This analysis needs to be performed.

The rest of the open items are included in the attached RCR 


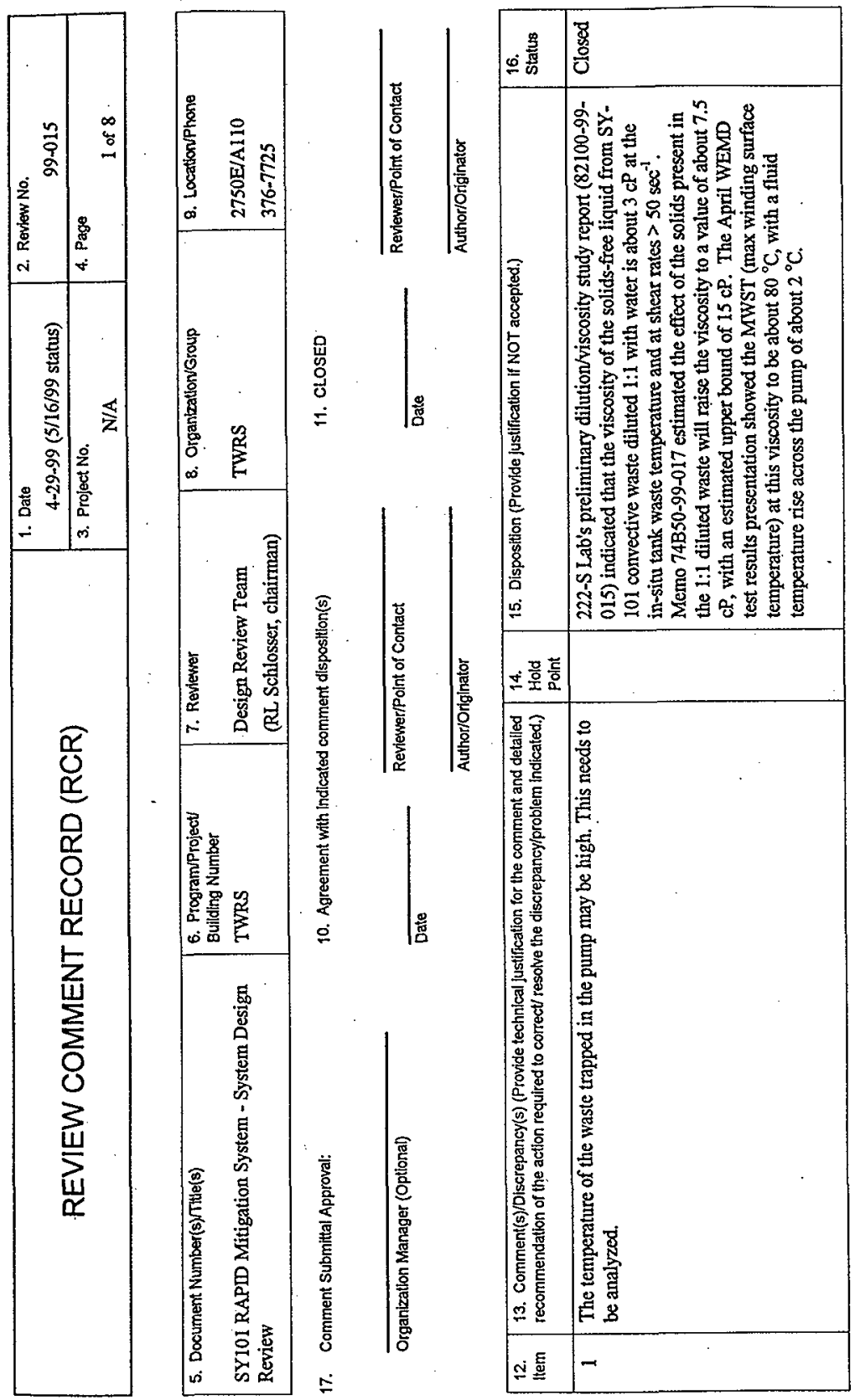




\begin{tabular}{|c|c|c|c|c|c|c|}
\hline 量 & & & 㔛 & 芯 & 焉 & 范 \\
\hline 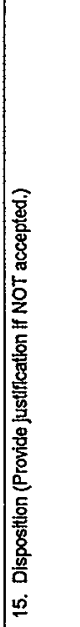 & 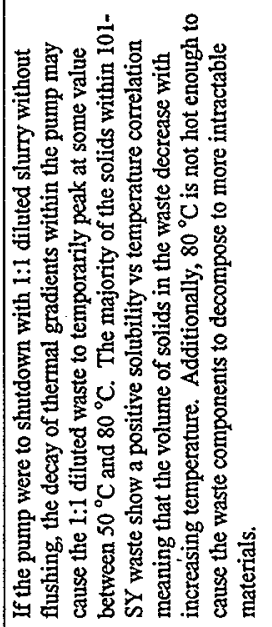 & 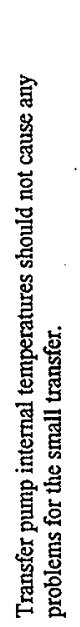 & $\begin{array}{l}\text { 㟧 } \\
\text { \& }\end{array}$ & 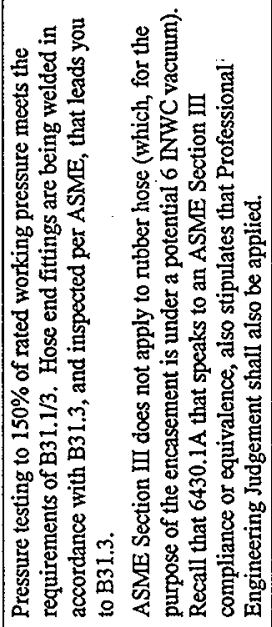 & 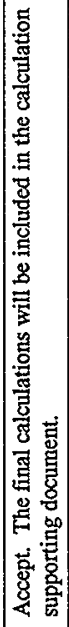 & 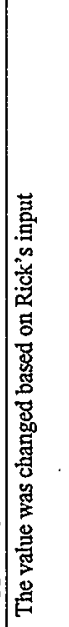 \\
\hline 壮흠홍 & & & & & & \\
\hline 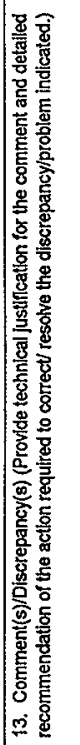 & 疍 & & 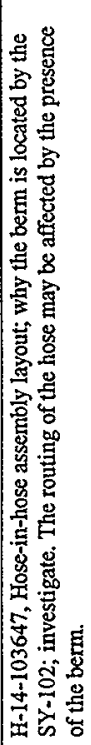 & 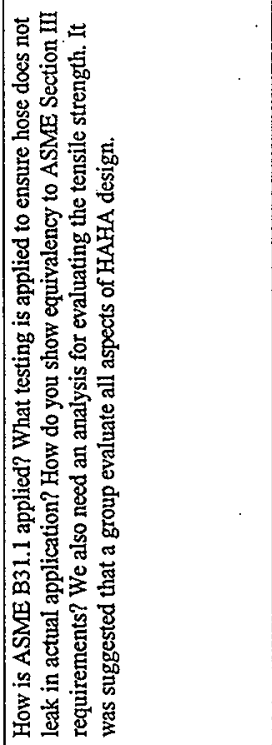 & 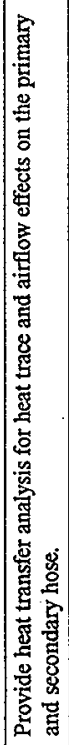 & 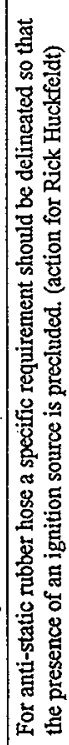 \\
\hline Q & - & & $\sim$ & $m$ & $\theta$ & in \\
\hline
\end{tabular}

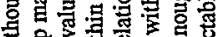

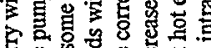

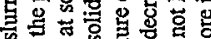

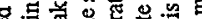




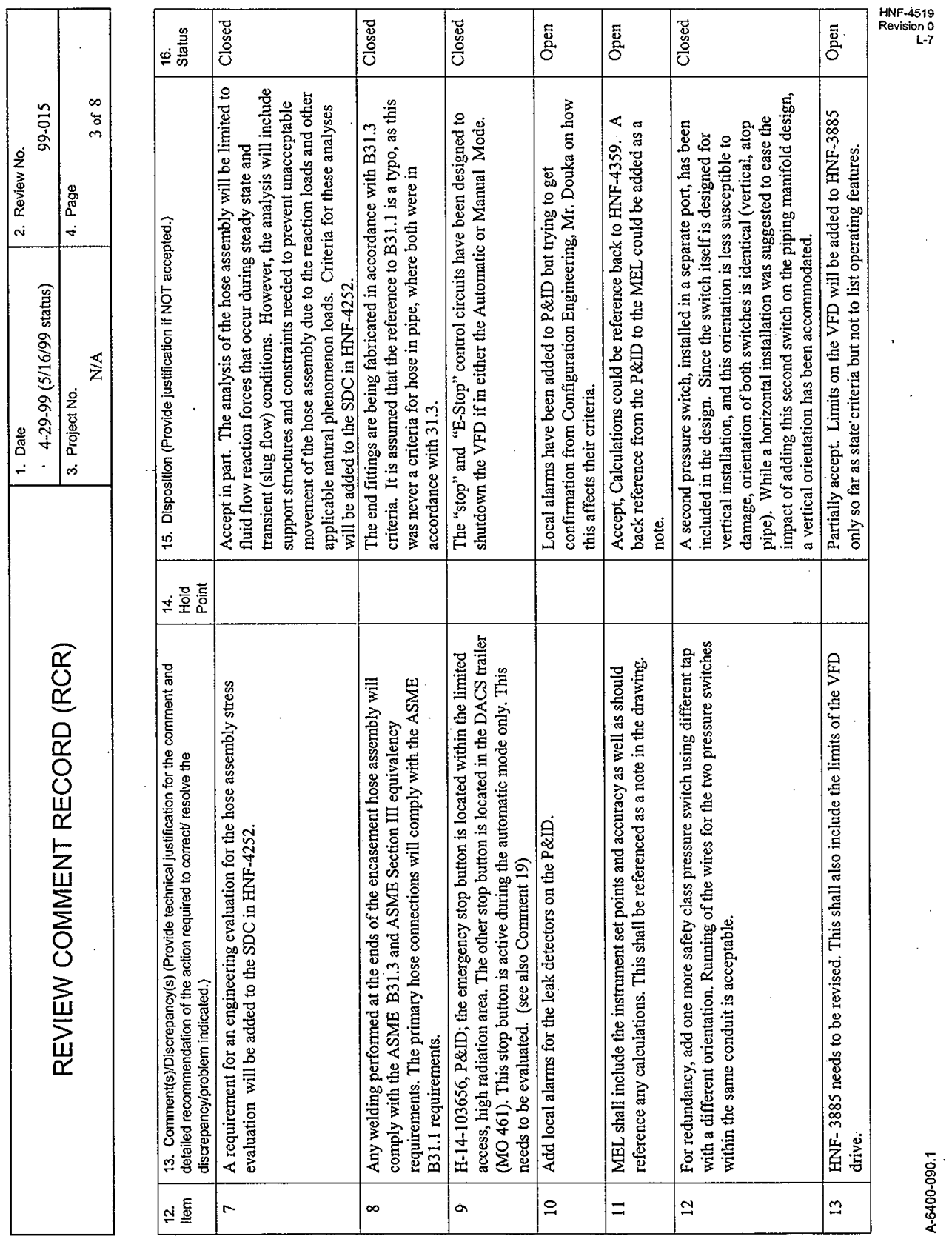




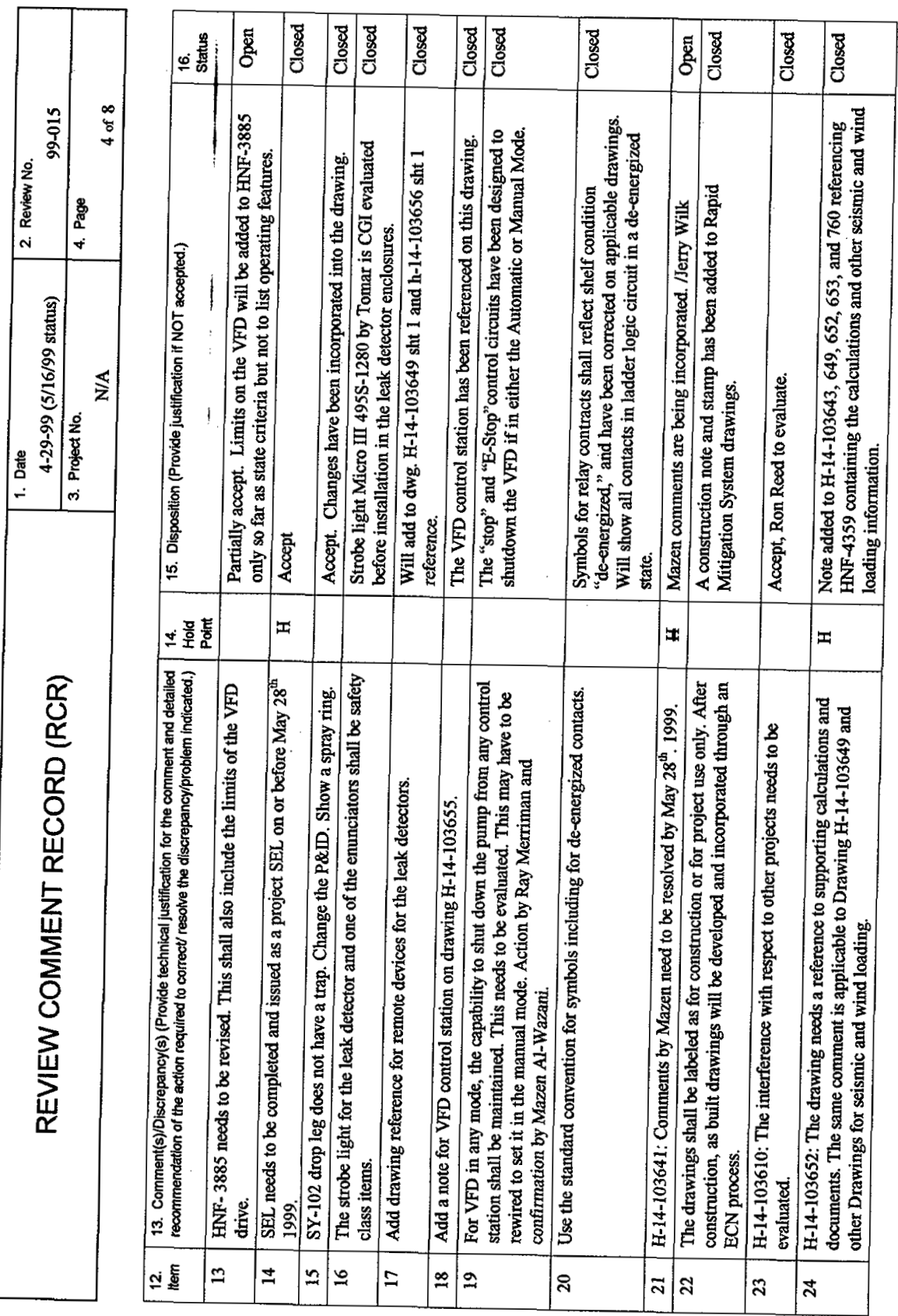




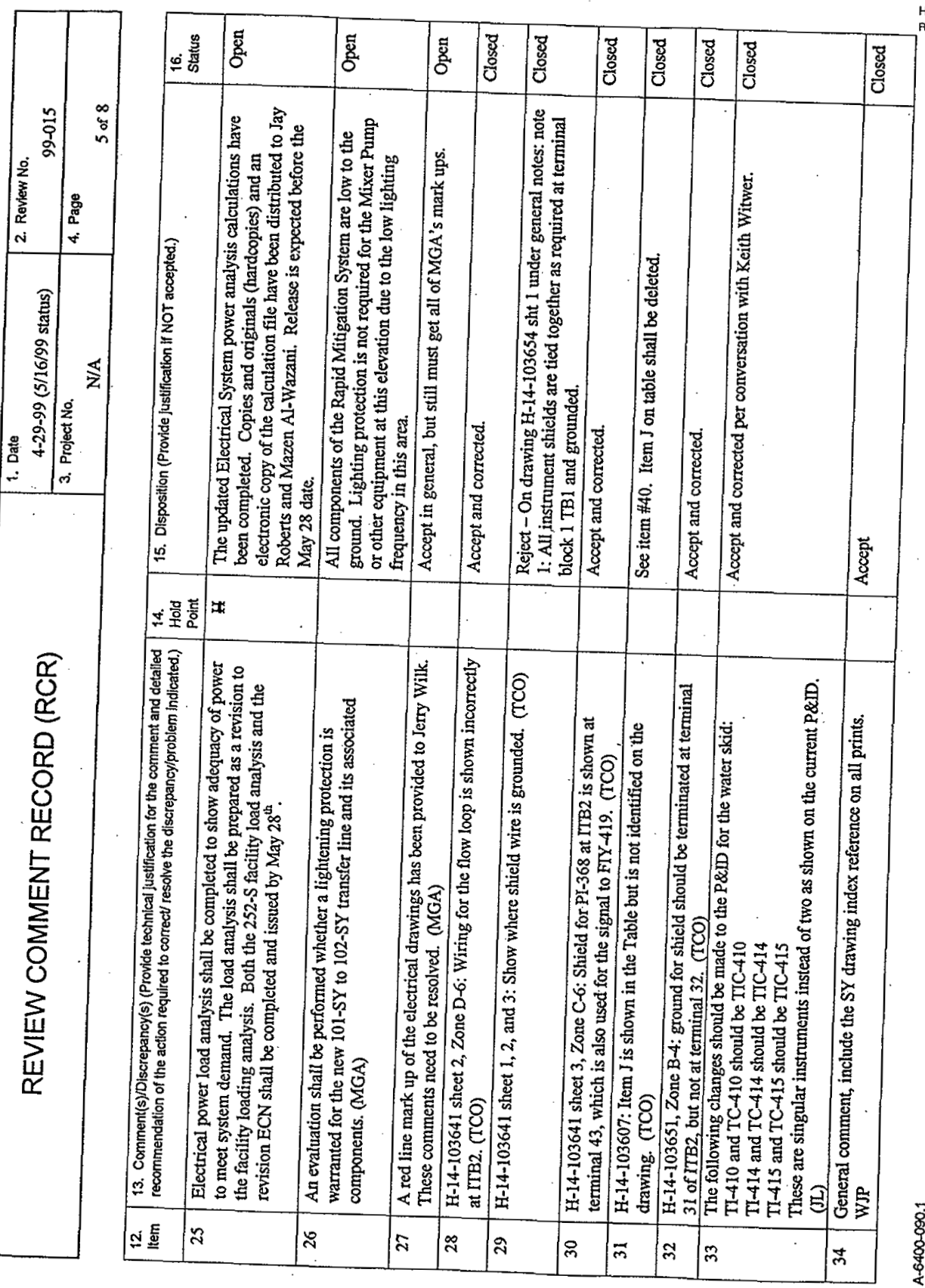




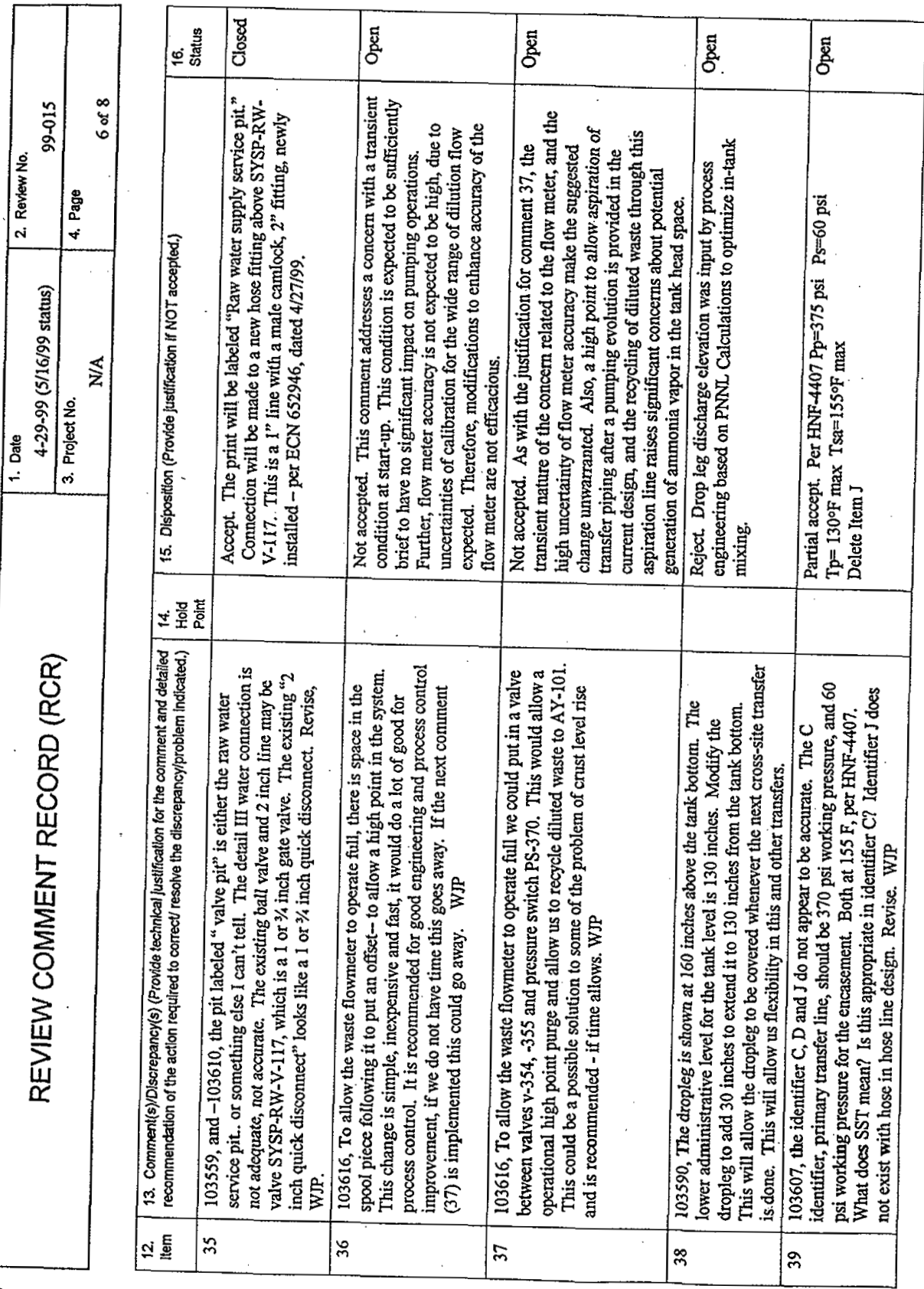




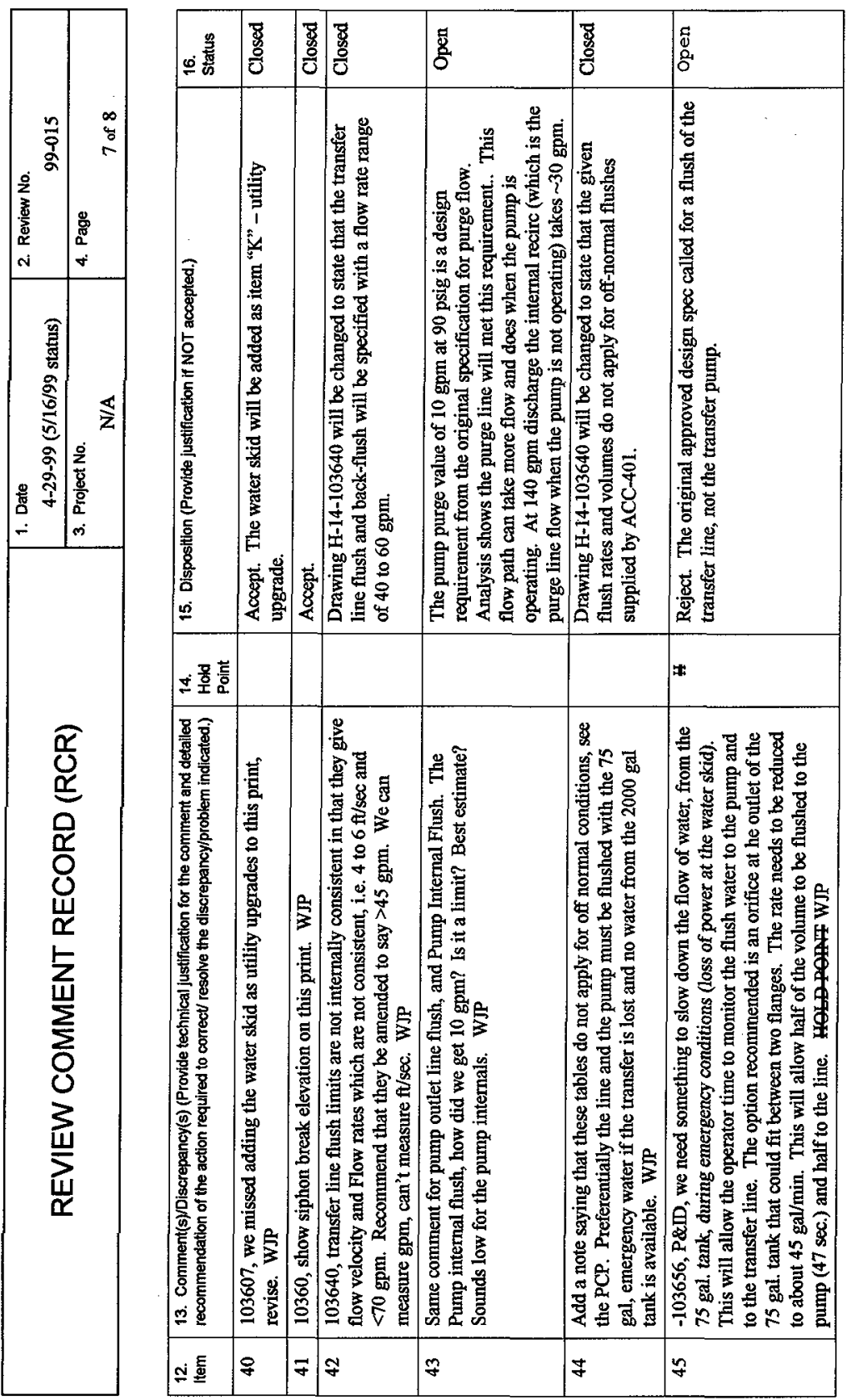




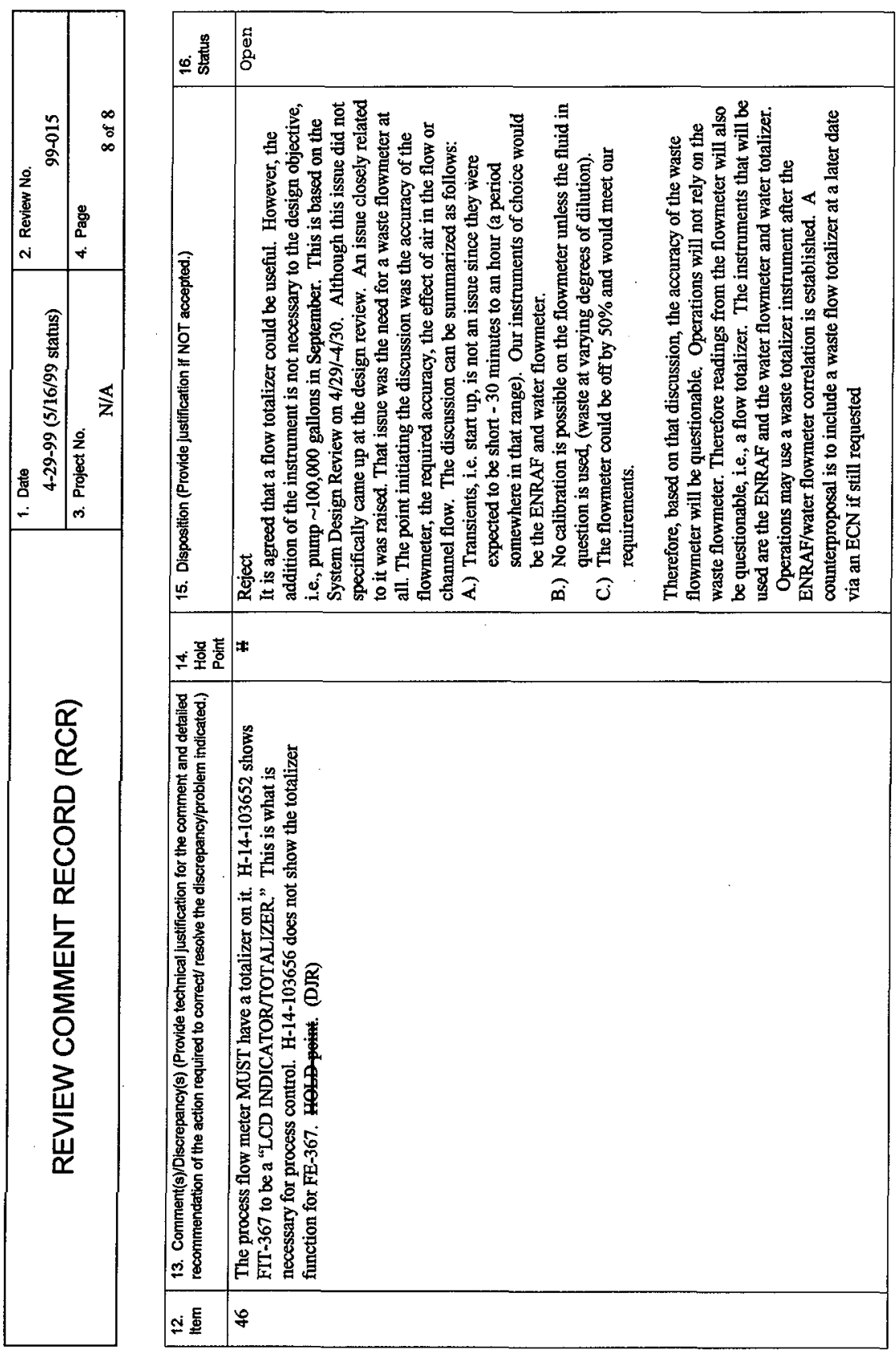




\section{APPENDIX M}

\section{DRAFT CONTROL DECISION RECORD}




\section{DRAFT}

CONTROL DECISION RECORD

TANK 241-SY-101 WASTE TRANSFER

MAY 1999 


\section{CONTROL DECISION RECORD \\ TANK 241-SY-101 WASTE TRANSFER}

\subsection{Introduction}

Control decision meetings for the transfer of waste from Tank 241-SY-101 to Tank 241-SY-102 were held on March 15 and 16, 1999. The agenda for the control decision meetings is included in Enclosure 1, and a list of meeting attendees is included in Enclosure 2.

The purpose of the control decision meetings was to identify existing controls and/or select new controls to protect the public, onsite workers, facility workers, and the environment from potential hazardous conditions and postulated accidents for a Tank 241-SY-101 waste transfer. Controls include safety-class and safety-significant . structures, systems, and components (SSCs); technical safety requirements (TSRs); and other controls that provide defense-in-depth or environmental protection.

The scope of the control decision meetings covered waste transfers fromTank 241-SY-101 to Tank 241-SY-102 that are planned to remediate the Tank 241-SY-101 surface-level rise condition (see Tank 241-SY-101 Surface-Level-Rise Remediation Project Plan, HENF-3824). The first waste transfer will move approximately 380,000 to 570,000 liters $(100,000$ to 150,000 gallons) of waste and is schedule for September 1999. The possible back dilution of Tank 241-SY-101 waste with water following the waste transfer was not within the scope of the control decision meetings.

The control decision meetings were conducted in accordance with the established and approved process and criteria described in the Tank Waste Remediation System (TWRS) Basis for Interim Operation (HNF-SD-WM-BIO-001). A summary of the control decision process and criteria was presented at the start of the control decision meetings and is included in Enclosure 3. Control decisions were based on the best available information from the waste transfer hazard and accident analyses and on the technical expertise and experience of the meeting participants. Decisions were made by consensus.

Subsequent to the March 15 and 16, 1999 control decision meetings, several revisions to controls occurred. Control revisions were based on the results of actions assigned at the meetings (i.e., a subsequent design decision to provide a passive siphon break and a subsequent decision on the specific instrument systems that will be used to measure the quantity of waste transferred from Tank 241-SY-101). A revision also resulted from the resolution of a subsequent safety classification issue raised by the TWRS Design Authority (i.e., safety-class versus safety-significant SSC instrument systems to measure the quantity of waste transferred from Tank 241-SY-101). These control revisions and their bases are specifically identified in the summary of the control decision discussions in Section 3. 
In addition, the control decisions were reviewed against the final waste transfer design and the final documented waste transfer hazard and accident analyses since these were not completed until after the March 15 and 16, 1999 meetings. Onsert sentence, if required, identifying any control revisions based on this reviev-e.g., ammonia controls?). These control revisions and their bases are also specifically identified in the Section 3 summary of the control decision discussions. (Replace the latter sentence with one that states "No control revisions resulted from these reviews" depending on review results.)

Section 2 is an overview of the meeting presentations. The presentations described the Tank 241-SY-101 waste transfer system design and operation and the results of the waste transfer hazard and accident analyses. The presentations provided the background and the basis for the subsequent control decision discussions. Copies of the presentations are included in the enclosures to this Control Decision Record.

Section 3 is a summary of the control decision discussions on the representative accidents and the associated represented hazardous conditions that were considered at the March 15 and 16, 1999 meetings. The discussion summary identifies the controls that were considered, and the reasons why specific controls were selected or not selected.

Attachment 1 is a summary of new controls for the Tank 241-SY-101 waste transfer. Attachments 2-7 contain the individual control decision records of the selected safety SSCs, TSRs, and defense-in-depth controls for each representative accident, and the associated represented hazardous conditions, considered at the control decision meetings.

\subsection{Overview of Presentations on the Waste Transfer System Design and Operation and the Hazard and Accident Analyses}

The first presentation described the current design and planned operation of the Tank 241-SY-101 waste transfer system (see Enclosure 4). This design and operation information was used as the basis for the control decisions at the March 15 and 16, 1999 meetings. Subsequent to the control decision meetings, the waste transfer system design .was finalize at the final waste transfer system design review on April 29 and 30, 1999 (To be confirmed). The final design of the waste transfer system was reviewed to determine whether any design revisions occurred subsequent to March 15 and 16, 1999 that could affect the control decisions. The results of this review are included in the Section 3.0 control decision discussion summary.

The next presentations provided an overview (Enclosure 5) and the results (Enclosure 6) of the hazard analysis performed on the Tank 241-SY-101 waste transfer. The hazardous conditions resulting from the hazard analysis included the following.

1. Hazardous conditions having potential onsite or offsite consequences addressed by the Authorization Basis, but presenting control allocation concerns (i.e., hazardous conditions that after the allocation of existing controls were either a) judged to 
potentially require additional controls or b) determined to pose issues with respect to the application of existing controls). (See Enclosure 6, Part 1)

2. Hazardous conditions having potential onsite or offsite consequences addressed by the Authorization Basis (i.e., hazardous conditions that after the allocation of existing controls were judged to be acceptably prevented or mitigated). (See Enclosure 6, Part 2)

3. Hazardous conditions having no consequences or consequences impacting only the facility worker. (See Enclosure 6, Part 3)

Analyses demonstrating that existing controls acceptably prevent or mitigate hazardous. conditions for the Tank 241-SY-101 waste transfer (i.e., hazardous conditions in the second group above) were presented (see Enclosures 7 and 8 ). These analyses were finalized subsequent to the control decision meeting and are documented in Transfer Accident Analysis for 101-SY Small Transfers (HNF-4302). HNF-4302 was reviewed to determine whether any revisions occurred subsequent to the control decision meetings that could affect the control decisions. The results of this review are included in the Section 3.0 control decision discussion summary.

Note: Prior to the March 15 and 16, 1999 control decision meetings, a group of individuals with knowledge of the existing Authorization Basis and the Tank 241-SY-101 waste transfer hazard analysis met to review all of the hazardous conditions with potential onsite or offsite consequences (S2 and S3, respectively). At this meeting, existing controls were allocated to these hazardous conditions and the hazardous conditions were placed in either the first or second group above. This enabled the control decision meetings to focus on hazardous conditions that required control determinations. Subsequent to the control decision meetings, another group of knowledgeable individuals reviewed all of the hazardous conditions with facility worker consequences that are anticipated (S1, F3), and all of the hazardous conditions with potentially significant environmental consequences (E2 and E3). The purpose of this review was to identify the need for additional controls to protect facility workers or the environment for the Tank 241-SY-101 waste transfer. No new facility worker or environmental controls were identified from this review (i.e., existing controls in the Authorization Bassis and new Tank 241-SY-101 controls acceptably provide for protection of facility workers and environment).

Presentations were then made providing the results of accident analyses of representative flammable gas accidents for the Tank 241-SY-101 waste transfer. These included presentations on the following.

- The estimated risk (i.e., frequency and consequences) of representative flammable gas accidents from the existing Authorization Basis (Enclosure 9) 
- Postulated gas release mechanisms from the Tank 241-SY-101 crust, and gas release models developed for estimating potential crust gas releases from waste transfer operations and activities (Enclosure 10)

- Tank 241-SY-101 waste transfer flammable gas accident results from the Refined Safety Analysis Tool (Enclosure 11)

The above accident analyses were finalized subsequent to the control decision meetings and are documented in Flammable Gas Calculation Note for 101-SY Small Transfer (HNF-4333). HNF-4333 was reviewed to determine whether any revisions occurred subsequent to the control decision meetings that could affect the control decisions. The results of this review are included in the Section 3.0 control decision discussion summary.

\subsection{Control Decision Discussion Summary}

Based on the Tank 241-SY-101 waste transfer hazard and accident analyses, control decisions were required for the following three new representative flammable gas accident scenarios, and the potential hazardous conditions that these accident scenarios represented.

- Flammable gas deflagration - induced gas release from crust disturbance

- Flammable gas deflagration - induced gas release from crust dissolution

- Flammable gas deflagration - buoyant displacement gas release event plus additional gas release from the crust.

In addition, control decisions were required for potential hazardous conditions that were represented by the following existing representative accidents, but where issues were identified concerning whether existing controls acceptably prevented and/or mitigated the hazardous conditions.

- Flammable gas deflagration - general

- Spray leak in structure or from overground transfer line

- Surface leak resulting in pool

A summary of the March 15 and 16, 1999 control decision meeting discussions (and subsequent reviews and revisions, as appropriate) for these representative accidents and the potential hazardous conditions that they represented is presented in the rest of this section.

\subsection{Flammable Gas Deflagration-Induced Gas Release from Crust Disturbance}

The representative accident is a flammable gas deflagration due to an induced gas release caused by operations and activities that disturb the Tank 241-SY-101 crust (e.g., waste transfer pump installation, crust disturbance as the waste level falls during the transfer) with subsequent ignition. A list of existing controls that may prevent or mitigate this 
representative accident was made, and then possible new controls were identified and evaluated. Following the selection of controls for the representative accident, the potential hazardous conditions represented by this accident (see Enclosure 6, Part 1) were reviewed and additional controls were selected, if necessary. The control decision discussions are summarized below, and the selected controls are presented in Attachment 2.

\section{Existing Controls}

Safety SSCs - Safety Class (SC): DST/AWF Ventilation

SC: Tank 241-SY-101 Hydrogen Monitor (7.500 ppm*)

SC: Tank 241-SY-101 Ammonia Monitor (3000 ppm*)

* Maximum gas concentrations in the LA-UR-92-3196 Level I controls for mixer pump operation

TSRs - Limiting Condition for Operation (LCO) 3:2.1: DST and AWF Ventilation System

- Administrative Control (AC) 5.9: Flammability Controls (LA-UR-92-3196 Level I mixer pump controls)

Supplemental Controls (Wagoner 1998)

Note: For this representative accident, the mixer pump controls were assumed to effectively control gas retention at depth and, therefore, the only postulated gas releases are from the crust.

\section{Possible New Controls}

Waste level - This control was proposed to protect accident analysis assumptions. This control was not selected based on a consensus that the accident analysis should include sensitively studies for expected waste levels, and if the waste levels assumed in the accident analysis were exceeded, an Unreviewed Safety Question (USQ) evaluation would be triggered.

Minimum Ventilation System Flowrate (400 cfm or higher) - The LA-UR-92-3196 Level II controls include a $400 \mathrm{cfm}$ minimum ventilation system flowrate. requirement. The Refined Safety Analysis Tool analysis showed that the risk from a flammable gas deflagration was not sensitive to ventilation flowrate (analyses performed for 200, 400 and $600 \mathrm{cfm}-$ see Enclosure 11 and HNF-4333). The consensus was that this control should remain as a Level II control.

Flammable gas monitoring (during tank operations and activities that could disturb the crust) - The existing TSR AC 5.11 flammable gas monitoring controls are not applicable to Tank 241-SY-101, and the LA-UR-92-3196 Level I controls on hydrogen and ammonia monitoring are associated with mixer pump operation. The 
consensus was that flammable gas monitoring be selected as a TSR-level control (i.e., to expand the applicability of AC 5.11 to include Tank 241-SY-101 and/or elevate and augment the LA-UR-92-3196 Level Ir flammable gas monitoring controls). There was some discussion on whether there should be an LCO on the hydrogen and ammonia monitoring systems, but the consensus was for a flammable gas monitoring program (i.e., an AC) consistent with other TWRS facilities.

Ignition Controls - The existing TSR AC 5.10 ignition controls are not applicable to Tank 241-SY-101. Ignition controls were selected by consensus as a TSR-level control (i.e., to expand the applicability of AC 5.10 to include Tank 241-SY-101 andi/or elevate and augment the LA-UR-92-3196 Level II ignition controls).

Water Addition Controls (location, rate, volume, temperature) - The consensus was that water addition controls should remain as LA-UR-92-3196 Level II controls. Flammable gas monitoring was the preferred control because if provides a direct measure of the gas release hazard and addresses all gas release mechanisms from the crust. There was some discussion of an interlock to automatically stop water addition on high hydrogen concentration, but the discussion was deferred to the representative flammable gas deflagration crust dissolution accident (see Section 3.2).

Mixer Pump Not Operating (during operations and activities that could disturb the crust) - This control was proposed to protect accident analysis assumptions. This is a LA-UR-92-3196 Level II control, and the consensus was that it should remain as a Level II control because flammable gas monitoring, which was selected as a control, addresses cumulative gas release mechanisms.

Waste Disturbance Size Limits - The difficulty in limiting the size of a waste disturbance, and the impracticality of monitoring for compliance, led to a consensus not to select this control.

Inerting - Although information on the feasibility of inerting Tank 241-SY-101 included in Enclosure 12 was not formally presented at the meeting, the cost and time to implement an inerting system for Tank 241-SY-101 were recognized as major factors against this control. The cost estimate in Enclosure 12 is close to $\$ 2$ million dollars, and implementation of an inerting system would add significant complexity and risk to the efforts to remediate the Tank 241-SY-101 surface level rise condition. In addition, the Refined Safety Analysis Tool analysis showed that an inerted tank does not significantly reduce the risk of a flammable gas deflagration (see Enclosure 11 and the HNF-4333). Based on these considerations, the consensus was that inerting Tank 241-SY-101 not be selected as a control.

Video Camera Monitoring - The consensus was that video camera monitoring should be implemented as a defense-in-depth control recognizing the value of observing crust behavior, but the difficulty of defining criteria that would prompt ceasing operations and activities. 
Time Delay from Mixer Pump Operation - The LA-UR-92-3196 Level II controls include an intrusive control that requires that there be at least a 4 hour waiting period following the last activity that can induce a gas release. The consensus was that this control should remain as a Level II control, because flammable gas monitoring, which was selected as a control, addresses the potential for overlapping gas release events.

Dome Pressure Monitoring - This is a LA-UR-92-3196 Level II control to detect large, rapid gas release events [i.e., a buoyant displacement gas release event (BD GRE)]. While dome pressure monitoring provides a faster indication of a BD GRE than flammable gas monitoring, the consensus was that it would likely not detect gas releases due to crust disturbances since these would not be expected to significantly increase the tank dome pressure.

Attachment 2 is the control decision record of the safety SSCs, TSRs, and defense-indepth controls selected to prevent potential flammable gas deflagration hazardous conditions and postulated accidents caused by induced gas releases from crust disturbance.

\subsection{Flammable Gas Deflagration - Induced Gas Release from Crust Dissolution}

The representative accident is a flammable gas deflagration due to an induced gas release caused by dissolution of the Tank 241-SY-101 crust from planned or inadvertent water addition with subsequent ignition. A list of existing controls that may prevent or mitigate this representative accident was made (including the controls selected above for the flammable gas deflagration crust disturbance accident), and then possible new controls were identified and evaluated. Following the selection of controls for the representative accident, the potential hazardous conditions represented by this accident (see Enclosure 6. Part 1) were reviewed and additional controls were selected, if necessary. The control decision discussions are summarized below, and the selected controls are presented in Attachment 3.

\section{Existing Controls}

Safety SSCs - SC: DST/AWF Ventilation

SC: Tank 241-SY-101 Hydrogen Monitor (7500 ppm*)

SC: Tank 241-SY-101 Ammonia Monitor (3000 ppm*)

* Maximum gas concentrations in the LA-UR-92-3196 Level I controls for mixer pump operation

TSRs - LCO 3.2.1: DST and AWF Ventilation System

AC 5.9: Flammability Controls (LA-UR-92-3196 Level I mixer pump controls) Supplemental Controls (Wagoner 1998)

Tank 241-SY-101 Ignition Controls

Tank 241-SY-101 Flammable Gas Monitoring Controls 
Note: For this representative accident, the mixer pump controls were assumed to effectively control gas retention at depth and, therefore, the only postulated gas releases are from the crust.

\section{Possible New Controls}

Maximum Dilution Flow Rate - Based on the developed gas release model, the maximum water addition flow rate would have to be around $20 \mathrm{gpm}$ or less to ensure that the Lower Flammability Limit (LFL) would not be exceeded. (The actual flow rate is dependent on the crust bubble slurry void fraction - see HNF-4333.) This low dilution water flow rate would place a significant constraint on the Tank 241-SY-101 waste transfer. The consensus was that flammable gas monitoring was the preferred control because it provides a direct measure of the gas release hazard and addresses all gas release mechanisms from the crust.

Maximum Dilution Quantity Without Waste Flow - This control was to limit the total quantity of dilution water that could inadvertently be added to Tank 241-SY-101. The control was based on the developed gas release model that showed it takes more than 1000 gallons of water added under the crust to reach the LFL. (The actual quantity of water is dependent on the water flow rate and the crust bubble slurry void fraction - see HNF-4333.) The concept for this control was to make the capacity of the water reservoir on the waste transfer dilution water skid the same as the maximum quantity of dilution water that could be added without waste transfer flow, and to provide an automatic interlock that shut off the service water supply to the cilution water skid on detecting loss of waste transfer flow. The design for this control would - have been complex to address all of the postulated inadvertent water addition scenarios. It would also have required bypass of the interlock to refill the dilution skid water reservoir prior to each waste transfer pump startup. This would have introduced the opportunity for human errors. The consensus was that flammable gas monitoring with operator action to isolate water sources to Tank 241-SY-101 on high flammable gas concentration was the preferred control (see below).

Flammable Gas Monitoring - This selected control requires flammable gas monitoring whenever there is a planned water addition or whenever there is a potential for an inadvertent water addition to Tank 241-SY-101. If high flammable gas concentrations are detected (i.e., $25 \%$ of the LFL), water sources that are or could be adding water to Tank 241-SY-101 would be isolated (i.e., valves closed and/or lines disconnected). There was considerable discussion on whether isolation of the waste transfer dilution water line should be automatic or could be done by operator action. The gas release model showed that there should be at least 30 minutes between when $25 \%$ of the LFL is reached and when $100 \%$ of the LFL is reached. (The actual time is dependent on the water flow rate and the crust bubble slurry void fraction - see HNF4333.) Based on these conservative gas release model results, the consensus was that. operator action to isolate the dilution water line was acceptable. Operator action also allowed the ability to backflush the waste transfer line into Tank 241-SY-102 while still isolating the dilution water line to Tank 241-SY-101. The Tank 241-SY-101 
Surface-Level-Rise Remediation Project, however, assigned an action to develop a parallel path for the possible incorporation of an automatic dilution water line isolation interlock.

Minimum Ventilation System Flowrate (400 cfm or higher) - See the discussion for the flammable gas deflagration crust disturbance accident.

Attachment 3 is the control decision record of the safety SSCs, TSRs, and defense-indepth controls selected to prevent potential flammable gas deflagration hazardous conditions and postulated accidents caused by induced gas releases from crust dissolution.

\subsection{Flammable Gas Deflagration - Buoyant Displacement Gas Release Event plus} Additional Gas Release from the Crust

The representative accident is a flammable gas deflagration due to an operation or activity that causes the mixer pump to become inoperable with a resulting subsequent $\mathrm{BD}$ GRE and ignition. A list of existing controls that may prevent or mitigate this representative accident was made (including controls selected above for the flammable gas deflagration crust disturbance and dissolution accidents), and then possible new controls were identified and evaluated. Following the selection of-controls for the representative accident, the potential hazardous conditions represented by this accident (see Enclosure 6; Part 1) were reviewed and additional controls were selected, if necessary. The control decision discussions are summarized below, and the selected controls are presented in Attachment 4.

\section{Existing Controls}

Safety SSCs - SC: DST/AWF Ventilation

SC: Tank 241-SY-101 Hydrogen Monitor

SC: Tank 241-SY-101 Ammonia Monitor

TSRs - Tank 241-SY-101 Ignition Controls

Tank 241-SY-101 Flammable Gas Monitoring Controls

\section{Possible New Controls}

Waste Volume Transfer - This control was selected by consensus. The control requires the calculation of the quantity of waste that can be transferred and maintain mixer pump operability (i.e., maintain a sufficient distance between the bottom of the crust and the mixer pump suction to ensure that the mixer pump continues to perform its safety function of controlling gas retention at depth and preventing BD GREs). Based on analysis presented at the control decision meeting (Enclosure 13 - see also HNF-333), mixer pump operability should not be affected as long as the bottom of the crust is at least one (1) foot above the mixer pump suction. However, there are uncertainties in measuring the bottom of the crust, including level monitoring system 
accuracy, and downward growth of the crust subsequent to the waste transfer that must be considered in calculating the maximum permissible waste transfer. The Tank 241-SY-101 waste transfer must then be monitored, and the transfer of waste limited to the maximum calculated quantity.

Tank 241-SY-101 Waste Level - This control has the same objective as the selected control on calculating, monitoring, and limiting waste transfer volume. However, the consensus was that the selected control was preferred versus simply establishing a . lower limit on the level of the crust bottom.

Mixer Pump Performance - Since it was judged as providing significant defense-indepth with respect to ensuring mixer pump operability, the consensus was to elevate the monitoring of mixer performance to a TSR-level control. The control requires monitoring of mixer pump performance, including monitoring parameters such as pump motor current, pump discharge pressure, and the response of waste thermocouples to mixer pump operation. The monitoring results are to be reviewed periodically (at least quarterly) by the Test Review Group (TRG) for signs of mixer pump performance degradation (i.e., loss of mixer pump capability to control gas retention at depth and the prevent BD GREs). If signs of degraded mixer pump performance are detected, the TRG would direct corrective action to restore mixer pump performance, such as the addition of water to Tank 241-SY-101.

Instrument Systems - At the March 15 and 16, 1999 control decision meetings, instrument systems required to implement the selected TSR-level control on calculating, monitoring, and limiting waste transfers from Tank 241-SY-101 to Tank 241-SY-102 (see above) were identified as safety-significant SSCs. Subsequent to the control decision meetings, the safety-significant classification was questioned by the TWRS Design Authority. On the basis that these instrument systems are essential to implement a control that protects against an accident with consequences that could exceed offsite risk evaluation guidelines, the instrument system classification was revised to safety-class. Also, the selection of the specific instrument systems to implement the control was made by cognizant design and operations personnel subsequent to the meeting (i.e., the Tank 241-SY-102 level detection system and the dilution water flow totalizer). Because there is no installed system that can directly measure the bottom of the crust, no specific instrument system was identified as safety-class for this measurement. However, existing TSR AC 5.19 on process instrumentation and measuring and test equipment will ensure the performance of whatever instrument system(s) is(are) used to measure the level of the bottom of the crust.

Siphon Break-Siphoning of waste from Tank 241-SY-101 to Tank 241-SY-102 is a concern since it could lead to the inadvertent transfer of waste and mixer pump. inoperability. At the time of the control decision meetings, the waste transfer system design required operator action to initiate a siphon break following shutdown of the waste transfer pump. With this design, the time to initiate the siphon break (30 minutes) was required to be accounted for in the implementation of the selected 
waste volume transfer control (see above). The Tank 241-SY-101 Surface-LevelRise Remediation Project was assigned an action to assess the possibility of including a passive siphon break in the waste transfer system design. Based on the Project assessment, the waste transfer system design was revised to incorporate a passive siphon break. The passive siphon break was designated safety-class since its failure could lead to inoperability of the mixer pump which could cause the representative accident whose consequences could exceed offsite risk evaluation guidelines.

Attachment 4 is the control decision record of the safety SSCs, TSRs, and defense-indepth controls selected for this representative accident.

\subsection{Flammable Gas Deflagration - General}

The waste transfer hazard analysis resulted in a hazardous condition that was represented. by the existing representative flammable gas deflagration accident for double-shelled tanks (DSTs) (see Enclosure 6, Part 1). Because the existing TSR AC 5.10 ignition controls and AC 5.11 flammable gas monitoring controls do not apply to Tank 241-SY101, this hazardous condition was identified for consideration at the control decision meetings. With the existing flammability controls and the new Tank 241-SY-101 TSRlevel ignition and flammable gas monitoring controls selected above for other Tank 241SY-101 flammable gas deflagration accident scenarios, the control decision meeting consensus was that these controls (see Attachment 5) were sufficient to control this potential hazardous condition.

\subsection{Spray Leak in Structure or from Overground Transfer Line}

The waste transfer hazard analysis resulted in a number of hazardous conditions that were represented by the existing representative spray leak accident, but where issues were identified concerning whether existing controls acceptably prevented and/or mitigated. these hazardous conditions (see Enclosure 6, Part 1). The concerns generally resulted because the Tank 241-SY 101 waste transfer design included an above ground Prefabricated Pump Pit (P3) and a special Tank 241-SY-102-007 riser drop leg enclosure design where the overground transfer line entered Tank 241-SY-102. Attachment 6 presents the consensus on controls that are unique to the Tank 241-SY-101 waste transfer. The safety-functions for the P3, overground transfer encasement and connections, and the riser 241-SY-102-007 drop leg enclosure were taken from the safety functions in the TWRS Final Safety Analysis Report (FSAR) for the above ground portion of waste transfer associated structures (e.g., pits).

There was discussion on whether the P3, overground transfer encasement and connections, and riser 241-SY-102-007 drop leg enclosure were required to maintain their safety function for design basis high wind and seismic events. The structures were already being designed to meet design basis high wind (and associated missiles) criteria and, therefore, this requirement was imposed. The consensus was that these structures need not be seismically qualified, leaving only the existing TSR AC 5.14 emergency preparedness control to mitigate the potential consequences of a seismic event. This was 
justified for several reasons. First, there is a low likelihood of a seismic event during a Tank 241-SY-101 waste transfer. Second, designing the P3 and the riser.241-SY-102007 drop leg enclosure to meet seismic criteria would be difficult, with potentially significant cost and schedule impacts.

Leak detectors in the riser 241-SY-102-007 drop leg enclosure were also discussed, but the consensus was that they were not required for safety. A requirement was imposed, however, that the riser 241-SY-102-007 drop leg enclosure and the overground transfer encasement and connections be designed to withstand the maximum pressure resulting if the drain to Tank 241-SY-102 is plugged and the waste backs up the overground transfer encasement to the P3.

\subsection{Surface Leak Resulting in Pool}

See the control decision meeting discussion of the spray leak accident in Section 3.5 and Attachment 7 for the resulting safety SSCs, TSRs, and defense-in-depth controls that are unique to the Tank 241-SY-10I waste transfer.

\subsection{References}

FDNW, 1999, Transfer Accident Analysis for 101-SY Small Transfers, HNE-4302, Rev. 0, Fluor Daniel Northwest, Inc., Richland, Washington.

FDNW, 1999, Flammable Gas Calculation Note for 101-SY Small Transfer, HNF-4333, Rev. 0, Fluor Daniel Northwest, Inc., Richland, Washington.

LMHC,- Tank Waste Remediation System Basis for Interim Operation, HNF-SD-WMBIO-001, Lockheed Martin Hanford Corporation, Richland, Washington.

LMHC, Tank Waste Remediation System Final Safety Analysis Report, HNF-SD-WMSAR-067, Lockheed Martin Hanford Corporation, Richland, Washington.

LMHC, 1999, Tank 241-SY-101 Surface-Level-Rise Remediation Project Plan, HNF3824, Rev. 0, Lockheed Martin Hanford Corporation, Richland, Washington.

LANL, 1996, A Safety Assessment for Proposed Pump Mixing Operations to Mitigate Episodic Gas Releases in Tank 241-SY-101: Hanford Site, Richland, Washington, LAUR-92-3196, Rev. 14a, Los Alamos National Laboratory, Los Alamos, New Mexico.

Wagoner, J. D., 1998, Contract Number DE-AC06-96RL13200-Supplemental Controls for Continued Operations in Tank 241-SY-241 (Letter 98-SCD-140 to R. D. Hanson FDH), U.S. Department of Energy, Richland Operations Office, Richland, Washington. 


\section{Attachment 1}

Summary of New Tank 241-SY-101 Waste Transfer Controls

Consists of 6 Pages

(Including this Coversheet) 


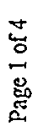

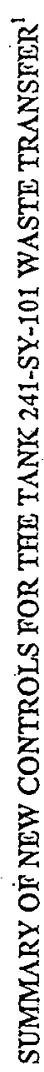

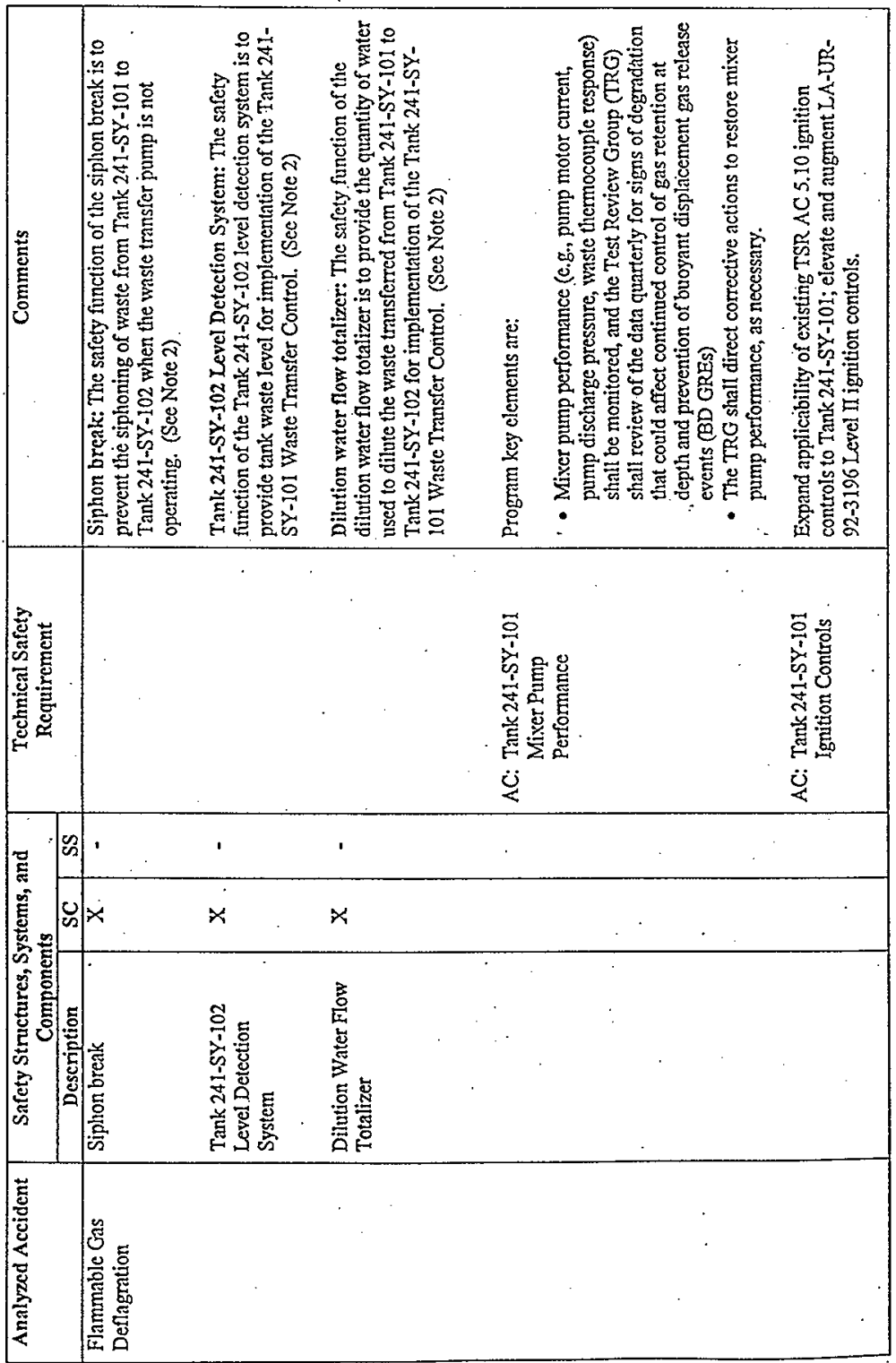




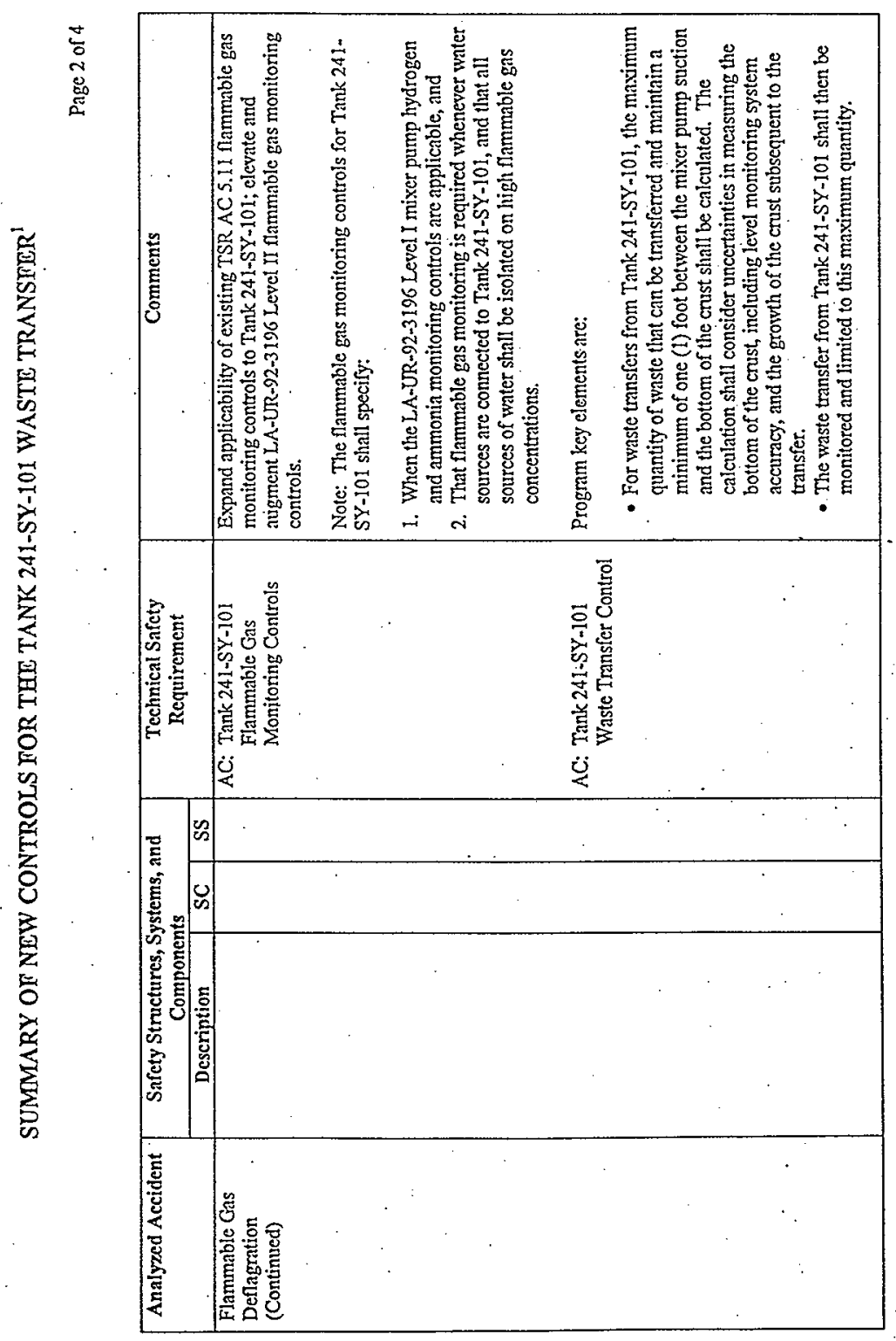




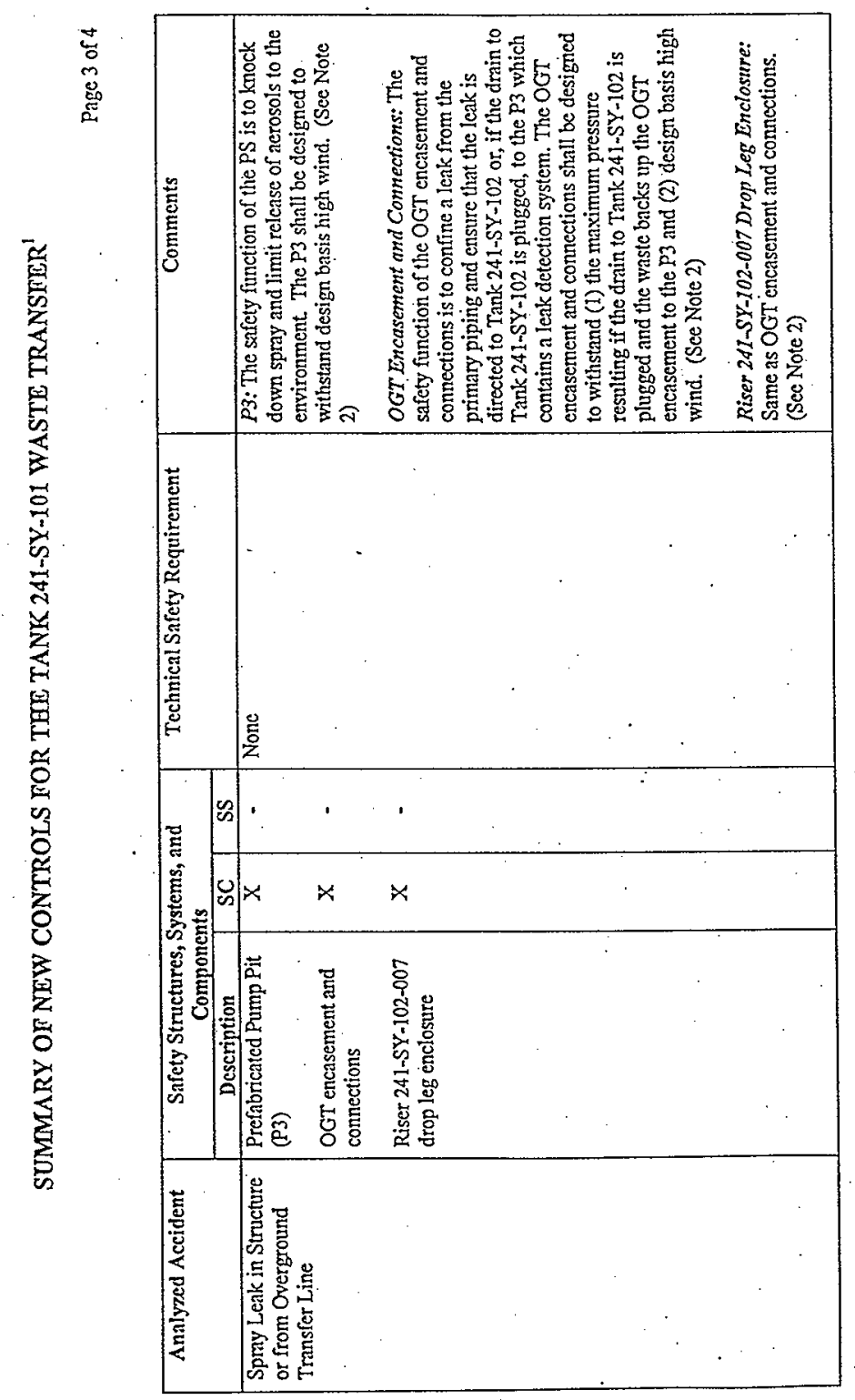



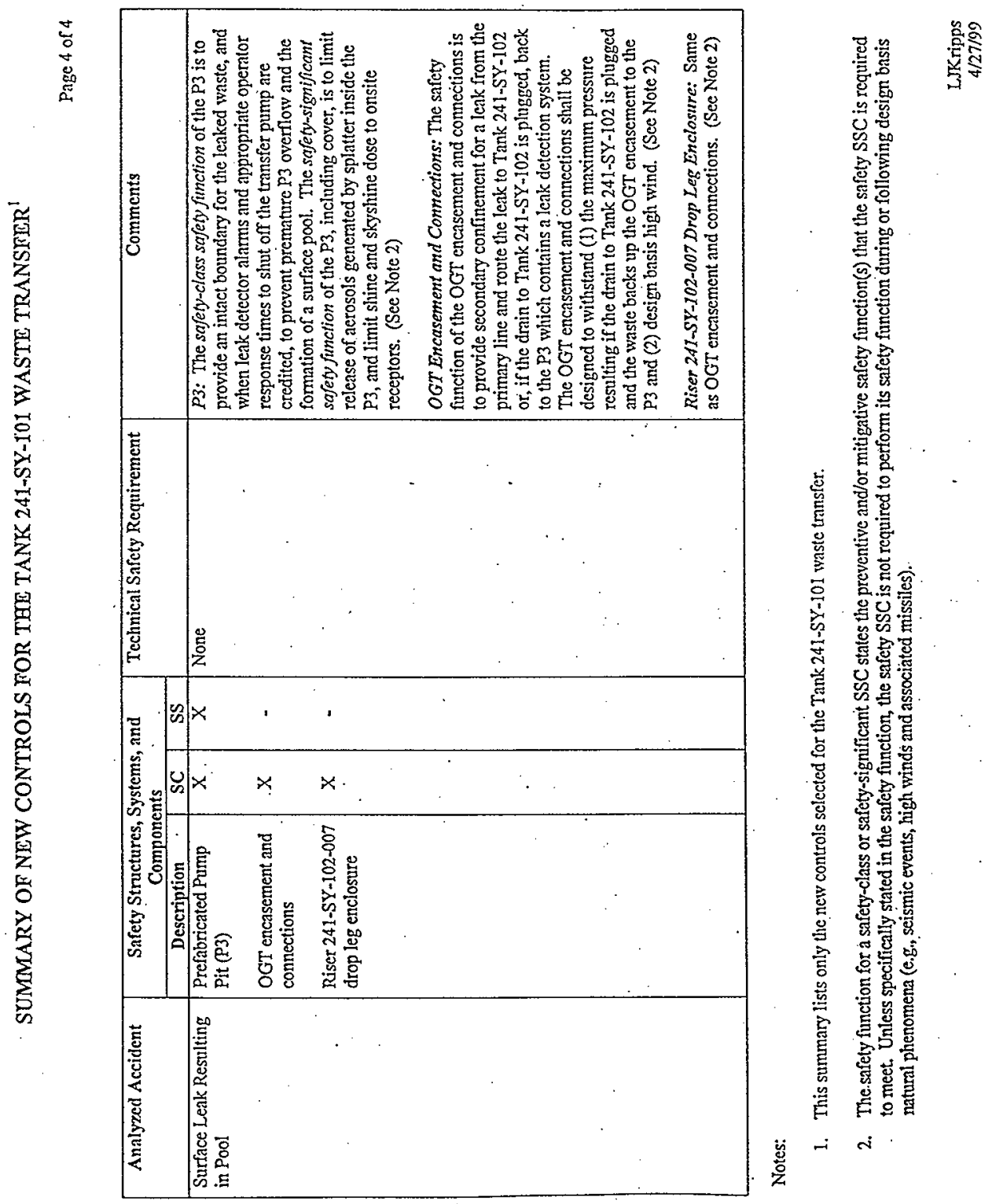


\section{DEFENSE IN DEPTH CONTROLS}

The only new defense-in-depth control identified for the Tank 241-SY-101 waste transfer:

- Video camera monitoring during the waste transfer and during associated activities that involve crust disturbance or dissolution 


\section{Attachment 2}

Control Decision Record for Tank 241-SY-101 Waste Transfer for Flammable Gas Defiagration - Induced Gas Release from Crust Disturbance

Consists of 3 Pages

(Including this Coversheet) 
HAZARD/ACCIDENT: Flammable Gas Deflagration - Induced gas release from crust disturbance

\section{Structures, Systems, and Components (SSCs)}

Note: The list of safety SSCs below does not include the Tank 241-SY-101 mixer pump, level monitoring system, pressure monitoring system, ventilation flowreter, and temperature monitoring syst $\mathrm{cm}$ which are required to implement the Los Alamos National Laboratory (LANL) Safety Assessment (SA) Level Y mixer pump controls (LA-UR-92-3196, Rev. 14a, Table 6-3) since they do not directly prevent or mitigate potential hazardous conditions and postulated accidents related to the Tark.241-SY-241 waste transfer. Operation of the 241-SY-101 mixer pump to reduce the frequency of a flammable gas. deflagration by mixing and releasing flammable gases generated and trapped in the.waste is assumed in the hazard and accident analyses of the Tank 24I-SY-101 waste transfer. The safety analysis of the waste transfer does, however, identify hazardous conditions and postulated accidents that could result in failure of the mixer pump to perform its safety function (see flammable gas deflagrations - buoyant displacement GRE plus additional crust release from the crust).

\begin{tabular}{|c|c|c|c|c|}
\hline \multirow{2}{*}{$\begin{array}{l}\text { Structures, Systems, and } \\
\text { Components }\end{array}$} & \multicolumn{2}{|c|}{ Classification } & \multirow[t]{2}{*}{ Safety Function } & \multirow{2}{*}{ Comments } \\
\hline & SC & SS & & \\
\hline DST/AWF Ventilation & $\therefore$ & . & $\begin{array}{l}\text { Maintain flammable gas concentrations in } \\
\text { tank dome spaces, due to steady state } \\
\text { releases, below } 25 \% \text { of the LFL } \\
\text {. }\end{array}$ & $\begin{array}{l}\text { The DST and AWF } \\
\text { ventilation systems also } \\
\text { reduce the "time at } \\
\text { risk" following a large } \\
\text { gas release eyent. } \\
\text { (GRE). }\end{array}$ \\
\hline *SY.101 Hydrogen Monitor & $X$ & & $\begin{array}{l}\text { Provide indication and alarm for hydrogen. } \\
\text { gas concentration in the Tank } 241-S Y-101 \\
\text { vapor space to the operations staff. }\end{array}$ & $\begin{array}{l}\text { An additional sufety } \\
\text { function of the } S Y-101 \\
\text { hydrogen monitor is to } \\
\text { provide an interlock to } \\
\text { stop mixer pump } \\
\text { operation if hydrogen } \\
\text { coneentration reaches } \\
0.75 \%(7,500 \text { ppm) by } \\
\text { volume. }\end{array}$ \\
\hline $\begin{array}{l}\text { SY-101 Ammonia } \\
\text { Detection System }\end{array}$ & $\bar{x}$ & & $\begin{array}{l}\text { Detect ammonia in the tank } \\
\text { headspace/exhaust gas and alarm on the } \\
\text { data acquisition system (DACS) when a } \\
\text { high level of ammonia exists. }\end{array}$ & $\because$ \\
\hline
\end{tabular}

$S C$ is safety class SS is safety significant

- Existing control 


\section{Technical Safety Requirements (TSRs)}

Note: New controls appear ị bold italics.

\begin{tabular}{|c|c|c|}
\hline Control & Safety Function & Comments \\
\hline $\begin{array}{l}\text { DST and AWF Tank Ventilation } \\
\text { (LCO 3.2.1) }\end{array}$ & $\begin{array}{l}\text { Assure that steady state release of } \\
\text { flammable gas does not accumulate in } \\
\text { flammable concentrations in vapor spaces } \\
\text { of TWRS facilities and structures. }\end{array}$ & $\begin{array}{l}\text { DST and AWF ventilation system } \\
\text { operation also reduces the "lime at risk" } \\
\text { following a large gas release event (GRE). }\end{array}$ \\
\hline $\begin{array}{l}\text { *Flammability Controls (i.e., LA-UR- } \\
\text { 92-3196 Level I mixer pump controls } \\
\text { including supplemental controls) } \\
\text { (AC 5.9) } \\
\qquad\end{array}$ & $\begin{array}{l}\text { Assure effective mitigation and safe } \\
\text { operations of Tank } 241-S Y=101 \text { with } \\
\text { sespect to flammable gas hazards. }\end{array}$ & $\begin{array}{l}\text { The LA-UR-92-3196 Level I controls are } \\
\text { primarily related to mixer pump } \\
\text { operation. The Level I control on gas } \\
\text { concentrations (i.e., maximum hydrogen } \\
\text { concentration and maximum ammonia } \\
\text { concentration) is the only control directly } \\
\text { applieable to preventing or mitigating } \\
\text { potential hazardous conditions and } \\
\text { postulated accidents from the Tank } 241 \text {. } \\
\text { SY-101 waste transfer. }\end{array}$ \\
\hline $\begin{array}{l}\text { Ygnition controls } \\
\text { (Revision to } A C \text { ( 5.10) }\end{array}$ & $\begin{array}{l}\text { Prevent the ignition of flammable gases } \\
\text { that may be present. }\end{array}$ & $\begin{array}{l}\text { Expand applicability of existing TSR AC } \\
5.10 \text { ignition controis fo Tank } 2 \$ 1 S Y Y * \\
101 \text {; elevafe and augment LA-UR-92- } \\
3196 \text { Level II ignition controls. }\end{array}$ \\
\hline $\begin{array}{l}\text { Flammable Gas Afonicoring Controb } \\
\text { (Revision to AC S.11) }\end{array}$ & 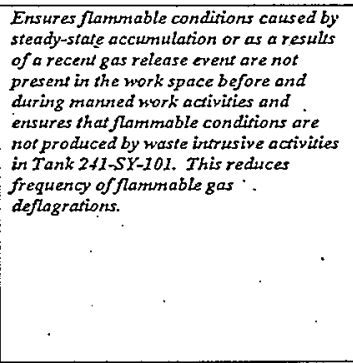 & 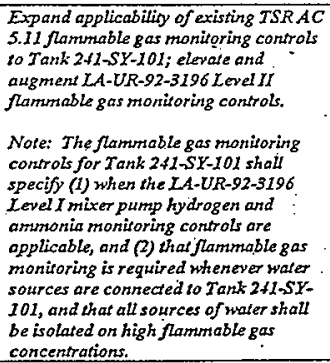 \\
\hline $\begin{array}{l}\text { Emergency Preparedness } \\
\text { (AC 5.16) }\end{array}$ & $\begin{array}{l}\text { Mitigate the consequences of a flammable } \\
\text { gas deflagration. }\end{array}$ & $+\quad+\cdots$, \\
\hline $\begin{array}{l}\text { "HEPA Filter Controls } \\
\text { (AC 5.18) }\end{array}$ & $\begin{array}{l}\text { Reduce consequences from a possible } \\
\text { HEPA fitter failure by limiting the } \\
\text { inventory available for release. }\end{array}$ & $\cdots$ \\
\hline $\begin{array}{l}\text { Frocess Instrumentation and Measuring } \\
\text { and Test Equipment } \\
\text { (AC 5.19) }\end{array}$ & $\begin{array}{l}\text { Ensures instrumentation used to monitor } \\
\text { the concentration of flammable gases is } \\
\text { maintained. }\end{array}$ & -- \\
\hline
\end{tabular}

- Existing control

\section{Defense-in Depth Controls}

Note: New controls appear in bold italics

\begin{tabular}{|c|l|c|}
\hline Control & \multicolumn{1}{|c|}{ Safety Function } & Comments \\
\hline Videa camero monitor & $\begin{array}{l}\text { Visual monitoring during waste tronsfers } \\
\text { and duritg activisies that could involve } \\
\text { coust disturbance or dissolusion to desecs } \\
\text { significant unexpected effects. }\end{array}$ & -2 \\
\hline
\end{tabular}




\section{Attachment 3}

Control Decision Record for Tank 241-SY-101 Waste Transfer for Flammable Gas Deflagration - Induced Gas Release from Crust Dissolution .

Consists of 3 Pages

(Including this Coversheet) 


\section{CONTROL DECISION RECORD FOR TANK 241-SY-101 WASTE TRANSFER}

\section{HAZARD/ACCIDENT: Flammable Gas Deflagration - Induced gas release from crust} dissolution

\section{Structures, Systems, and Components (SSCs)}

Note: The list of safety SSCs below does not include the Tank 24I-SY-101 mixer pump, level monitoning system, pressure monitoring system, ventilation flowmeter, and temperature monitoring system which are tequired to implement the LANL SA. Level I mixer pump controts (LA-UR-92-3196, Rev. 142, Table 6-3) since they do not directly prevent or mitigate potentia! hazardous conditions and postulated accidents related to the Tark 241-SY-241 waste transfer. Operation of the 241-SY-101 mixer pump to reduce the frequency of a flammable gas deflagration by mixing and releasing flammable gases generated and trapped in the waste is assumed in the hazard and accident analyses of the Tank 241-SY-101 waste transfer. The safety analysis of the waste tranifer does, however, identify hazardous conditions and postulated accidents that could result in failure of the mixer pump to petform its safety function (see flammable gas deflagrations - buoyant displacement GRE plus additional crust release from the crust).

\begin{tabular}{|c|c|c|c|c|}
\hline \multirow{2}{*}{$\begin{array}{l}\text { Seructures, Systems, and } \\
\text { Components }\end{array}$} & \multicolumn{2}{|c|}{ Classification } & \multirow[t]{2}{*}{ Safety Function } & \multirow[t]{2}{*}{ Comments } \\
\hline & SC & SS & & \\
\hline DST/AWF Ventilation & $x$ & & $\begin{array}{l}\text { Maintain flammable gas concentrations in } \\
\text { tank dome spaces, due to steady state } \\
\text { releases, below } 25 \% \text { of the LFL- }\end{array}$ & $\begin{array}{l}\text { The DST and AWF } \\
\text { ventilation systems also } \\
\text { reduce the "lime at } \\
\text { risk" following a large } \\
\text { gas release event } \\
\text { (GRE). }\end{array}$ \\
\hline FY-101 Hydrogen Monitor & $\mathrm{x}$ & & $\begin{array}{l}\text { Provide indication and alarm for hydrogen } \\
\text { gas concentration in the Tank } 241 \text {-SY-101 } \\
\text { vapor space to the operations staff. }\end{array}$ & $\begin{array}{l}\text { An additional safety } \\
\text { function of the } S Y-101 \\
\text { hydrogen monitor is to } \\
\text { provide an interlock to } \\
\text { stop mixer pump } \\
\text { operation if hydrogen } \\
\text { concentration reaches } \\
0.75 \%(7,500 \text { ppm) by } \\
\text { volume. }\end{array}$ \\
\hline $\begin{array}{l}\text { SY-101 Ammonia } \\
\text { Detection System }\end{array}$ & $X$ & - & $\begin{array}{l}\text { Detect ammonia in the tank } \\
\text { headspacejexhaust gas and alarm on the } \\
\text { data acquisition system (DACS) when a } \\
\text { high level of ammonia exists. }\end{array}$ & $\cdots$ \\
\hline
\end{tabular}

SC is safety class

SS is safety significant

- Existing control 


\section{Technical Safety Requirements (TSRs)}

Note: New controls appear in bold iralics.

\begin{tabular}{|c|c|c|}
\hline Control & Safety Function & Comments \\
\hline $\begin{array}{l}\text { DST and AWF Tank Ventilation } \\
\text { (LCO 3.2.1) }\end{array}$ & $\begin{array}{l}\text { Assure that steady state release of } \\
\text { fiammable gas does not accumulate in } \\
\text { flammable concentrations in vapor spaces } \\
\text { of TWRS facilities and structures. }\end{array}$ & $\begin{array}{l}\text { DST and AWF ventilation system } \\
\text { operation also reduces the 'time at risk' } \\
\text { following a large gas release event (GRE). }\end{array}$ \\
\hline $\begin{array}{l}\text { Flammability Controls (i.e., LA-UR- } \\
\text { 92-3196 Level I mixer pump controls } \\
\text { including supplemental controls) } \\
\text { (AC 5.9) }\end{array}$ & $\begin{array}{l}\text { Assure effective mitigation and safe } \\
\text { operations of Tank } 241-S Y-101 \text { with } \\
\text { respect to flammable gas hazards. }\end{array}$ & $\begin{array}{l}\text { The LA-UR-92-3196 Level I controls are } \\
\text { primarily related to mixer pump } \\
\text { operation. The Level I control on gas } \\
\text { concentrations (i.e, thaximum hydrogen } \\
\text { concentration and maximum ammonia } \\
\text { concentration) is the only control directly } \\
\text { applicable to preventing or mitigating } \\
\text { potential hazardous conditions and } \\
\text { postulated accidents from the Tank 241- } \\
\text { SY-101 waste transfer. }\end{array}$ \\
\hline $\begin{array}{l}\text { Ignition controls } \\
\text { (Revision to } A C \text { (5.10) }\end{array}$ & $\begin{array}{l}\text { Prevent the ignition of fammable gases } \\
\text { that may be present }\end{array}$ & $\begin{array}{l}\text { Expand applicability of existing TSRAC } \\
5.10 \text { ignition controls to Tank } 241-S Y- \\
101 \text {; elevate and augment LA-UR-92- } \\
3196 \text { Level II ignition controls. }\end{array}$ \\
\hline $\begin{array}{l}\text { Flammable Gas Moniforing Controls } \\
\text { (Revision to AC S.1I) }\end{array}$ & 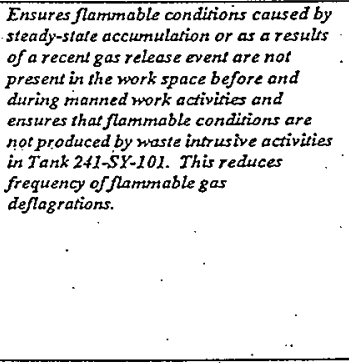 & 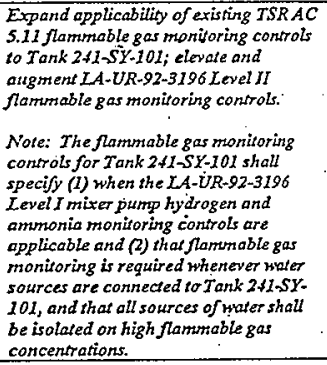 \\
\hline $\begin{array}{l}\text { *Emetgency Preparedness } \\
\text { (AC 5.14) }\end{array}$ & $\begin{array}{l}\text { Mitigate the consequences of a flammable } \\
\text { gas deflagration. }\end{array}$ & 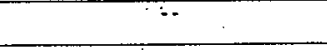 \\
\hline $\begin{array}{l}\text { HEPA Filter Controls } \\
\text { (AC S.18) }\end{array}$ & $\begin{array}{l}\text { Reduce consequences from a possible } \\
\text { HEPA filter failure by limiting the } \\
\text { inventory available for release. }\end{array}$ &.+ \\
\hline $\begin{array}{l}\text { Process Instrumentation and M leasuring } \\
\text { and Test Equipment } \\
\text { (AC } 5,19 \text { ) }\end{array}$ & $\begin{array}{l}\text { Ensures instrumentation used to monitor } \\
\text { the concentration of flammable gases is } \\
\text { maintained. }\end{array}$ & $\cdots$ \\
\hline
\end{tabular}

- Existing control

\section{Defense-in Depth Controls}

Note:New controls appear in bold ifolics

\begin{tabular}{|c|l|l|}
\hline Control & \multicolumn{1}{|c|}{ Safety Function } & Comments \\
\hline Video camera monitor & $\begin{array}{l}\text { Visual monitoring during waste transfers } \\
\text { and durisg activities that could itvolve } \\
\text { crust disturbance or dissolusion to datect } \\
\text { signifucant unexpected effects. }\end{array}$ & \\
\hline
\end{tabular}




\section{Attachment 4}

Control Decision Record for Tank 241-SY-101 Waste Transfer for Flammable Gas Deflagration - Buoyant Displacement GRE Plus Additional Gas Release from the Crust

Consists of 4 Pages

(Including this Coversheet) 


\title{
CONTROL DECISION RECORD FOR TANK 241-SY-101 WASTE TRANSFER
}

\author{
HAZARD/ACCIDENT: Flammable Gas Deflagration -Buoyant displacement GRE plus \\ additional gas release from the crust
}

\section{Structures, Systems, and Components (SSCs)}

Notes: 1. The list of safety SSCs below does not include the Tank 241-SY-101 mixer pump, level monitoring system, pressure monitoring system, ventilation flowmeter, and temperature monitoring system which are required to implement the LANL SA Level I mixer pump controls (LA.UR-92-3196, Rev. 142, T3ble 6-3) since they do not directly prevent or mitigate potential hazardous conditions and postulated accidents related to the Tark 241 -SY-24I waste transfer. Operation of the 241-SY-101 mixer pump to reduce the frequency of a flammable gas deflagration by mixing and releasing flammable gases generated and trapped in the waste is assumed in the hazard and accident analyses of the Tank 241-SY-101 waste teansfer. The safety analysis of the waste transfer does, however, identify hazardous conditions and postulated accidents that could result in failure of the mixer pump to perform its safety function (see flammable gas deflagrations - buoyant displacement GRE plus additional crust release from the crust).

2. New controls appear in bold italics.

\begin{tabular}{|c|c|c|c|c|}
\hline \multirow{2}{*}{$\begin{array}{c}\text { Structures, Systerns, and } \\
\text { Components }\end{array}$} & \multicolumn{2}{|c|}{ Classification } & \multirow[t]{2}{*}{ Safety Function } & \multirow[t]{2}{*}{ Comments } \\
\hline & $\mathrm{SC}$ & SS & & \\
\hline DST/AWF Ventilation & $\mathrm{x}$ & $\therefore$ & $\begin{array}{l}\text { Maintain flammable gas coneentrations in } \\
\text { tank dome spaces, due to steady state } \\
\text { releases, below } 25 \% \text { of the LFL. }\end{array}$ & $\begin{array}{l}\text { The DST and AWF } \\
\text { ventilation systems also } \\
\text { reduce the "time at } \\
\text { risk": following a large } \\
\text { gas release event } \\
\text { (GRE). }\end{array}$ \\
\hline *SY-101 Hydrogen Monitor & $\mathrm{X}$ & $\because$ & $\begin{array}{l}\text { Provide indication and alarm for hydrogen } \\
\text { gas concentration in the Tank } 241-5 Y-101 \text {. } \\
\text { vapor space to the operations staff. }\end{array}$ & $\begin{array}{l}\text { An additional safety } \\
\text { function of the } S Y-101 \\
\text { hydrogen monitor is to } \\
\text { provide an interlock to } \\
\text { stop mixer pump } \\
\text { operation if hydrogen } \\
\text { concentration reaches } \\
0.75 \%(7,500 \text { ppm) by } \\
\text { volume. }\end{array}$ \\
\hline $\begin{array}{l}\text { SY-101 Ammonia } \\
\text { Detection System }\end{array}$ & . $\mathrm{X}$ & - & $\begin{array}{l}\text { Detect ammonia in the tank } \\
\text { headspace/exhaust gas and alarm on the } \\
\text { data acquisition system (DACS) when a } \\
\text { high level of ammonia exists. }\end{array}$ & $\cdots$ \\
\hline Syhon Break & $x$ & . & $\begin{array}{l}\text { The safety function of the siphon break is } \\
\text { to prevent the siph onting of waste from } \\
\text { Tank } 2+1-S Y-101 \text { to Tank } 241-S Y-102 \\
\text { when the waste transfor pump is not } \\
\text { operating. }\end{array}$ & $\begin{array}{l}\text { The siphon break is a } \\
\text { passive design feature. }\end{array}$ \\
\hline $\begin{array}{l}\text { Tank 2f1-SY-102 Level } \\
\text { Detection System }\end{array}$ & $x$ & . & $\begin{array}{l}\text { The safety function of the Tank } 2+1-S Y \text { - } \\
\text { 102 level darection system is to provide } \\
\text { eank waste Level for implementation of the } \\
\text { Tank } 2+1-S Y-101 \text { Waste Transfer } \\
\text { Control. }\end{array}$ & $\begin{array}{l}\text { The SY-102 level } \\
\text { montroring system is a } \\
\text { safety-significant SSC } \\
\text { for other potertial } \\
\text { hasardous conditions } \\
\text { andpostutated } \\
\text { accidents in the } \\
\text { existing TWRS. } \\
\text { Awhorivation Basis. }\end{array}$ \\
\hline $\begin{array}{l}\text { Dudution Woter Flow } \\
\text { Totalizer }\end{array}$ & $x$ & & $\begin{array}{l}\text { The safay function of the dilution water } \\
\text { flow tolatizer is to provide the quantity of } \\
\text { water used to dilute the waste transferred } \\
\text { from Tank } 2+1-S Y-101 \text { to Tank } 2 \$ 1-S Y \text { - } \\
102 \text { for implementation of the Tank } 241- \\
\text { SY-101 Waste Transfer Control }\end{array}$ & 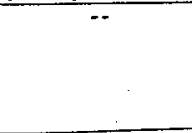 \\
\hline
\end{tabular}

$\mathrm{SC}$ is safety class

SS is safety significant

- Existing control 


\section{Technical Safety Requirements (TSRs)}

Note: .New controls appear in bold italics.

\begin{tabular}{|c|c|c|}
\hline$\therefore \quad$ Control & Safety Function & Comments \\
\hline $\begin{array}{l}\text { *DST and AWF Tank Ventilation } \\
\text { (LCO 3.2.1) }\end{array}$ & $\begin{array}{l}\text { Assure that steady staterelease of } \\
\text { flammable gas does not accumulate in } \\
\text { flammable concentrations in vapor spaces } \\
\text { of TWRS facilities and structures. }\end{array}$ & $\begin{array}{l}\text { DST and AWF ventilation system } \\
\text { operation also reduces the "time at risk" } \\
\text { following a large gas release event (GRE). }\end{array}$ \\
\hline $\begin{array}{l}\text { *Flammability Controls (i.e., LA.UR- } \\
\text { 92-3196 Level I mixer pump controls } \\
\text { including supplemental controls) } \\
\text { (AC 5.9) }\end{array}$ & $\begin{array}{l}\text { Assure effective mitigation and safe } \\
\text { operations of Tank } 241-S Y=101 \text { with } \\
\text { respect to flammable gas hazards. }\end{array}$ & $\begin{array}{l}\text { The LA-UR-92-3196 Level I controls are } \\
\text { primarily related to mixer pump } \\
\text { operation. The Level I control on gas } \\
\text { concentrations (i.e., maximum hydrogen } \\
\text { concentration and maximum ammonia } \\
\text { concentration) is the only control direetly } \\
\text { applicable to preventing or mitigating } \\
\text { potential hazardous conditions and } \\
\text { postulated accidents from the Tank 241-. } \\
\text { SY-101 waste transfer. }\end{array}$ \\
\hline $\begin{array}{l}\text { Tank 2\$ISY-101 Mixer Pump } \\
\text { Performance } \\
\text { (Ravision to AC 5.9) }\end{array}$ & $\begin{array}{l}\text { Identify and mitigate degradation of } \\
\text { Tank } 241-S Y 101 \text { mixer pump } \\
\text { perfonmance caused by interaction of the } \\
\text { pump and the crust to ensure that the } \\
\text { safety function of the mixer pump } \\
\text { (control gas retention af depth and } \\
\text { prevent buoyant displacement GRE) is } \\
\text { maintained. }\end{array}$ & $\begin{array}{l}\text { Program key elements are: } \\
\text { Mixer pump performance (ag., } \\
\text { pump motor current, pump } \\
\text { discharge pressure, waste } \\
\text { thermocouple response) shall be } \\
\text { monitored, and the Test Review } \\
\text { Group (TRG) shall review of the } \\
\text { data quarterly for sigus of } \\
\text { 'degradation that could affect } \\
\text { continued control of gas refention } \\
\text { af depth and prevention of buoyant } \\
\text { displacement gas release events } \\
\text { (BD GREs). } \\
\text { The TRG shall direct corrective } \\
\text { actions to restore mixer pump } \\
\text { performance, as necessary (eg., } \\
\text { add water). }\end{array}$ \\
\hline $\begin{array}{l}\text { Ignition controls } \\
\text { (Revision to AC } 5.10)\end{array}$ & $\begin{array}{l}\text { Prevent the ignition of fammable gases } \\
\text { that may be present. }\end{array}$ & $\begin{array}{l}\text { Expand applicability of existing TSRAC } \\
\text { 5.10 ignition controls to Tank } 241-S Y \text { - } \\
101 \text {; elevate ond augment LA-UR-92- } \\
3196 \text { Level II ignirion controls. }\end{array}$ \\
\hline $\begin{array}{l}\text { Flammable Gas Monisoring Controls } \\
\text { (Revision to AC 5.11) }\end{array}$ & $\begin{array}{l}\text { Ensures flammable conditions caused by } \\
\text { steady-state accumutation or as a results } \\
\text { of a recent gas release event are not } \\
\text { present in the work space before and } \\
\text { during manned work activities and } \\
\text { ensures that fammable conditions are } \\
\text { notproduced by maste intrusive activities } \\
\text { in rank } 241-S Y-101 \text {. Thits reduces } \\
\text { frequency of flamuable gas } \\
\text { deflagrations. }\end{array}$ & 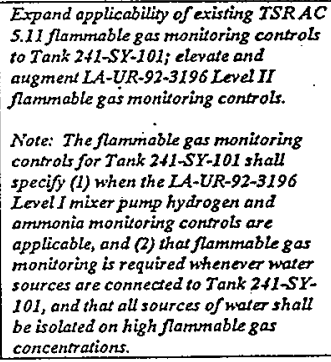 \\
\hline
\end{tabular}




\begin{tabular}{|c|c|c|}
\hline Control & Safely Function & Comments \\
\hline $\begin{array}{l}\text { Tank } 2+1-5 Y-101 \text { Waste Transfer } \\
\text { Controls. } \\
\text { Revision to AC } 5.9 \text { or AC } 5.12 \text { ) }\end{array}$ & $\begin{array}{l}\text { Limis the quantity of whate transferred } \\
\text { from Tank } 241-S Y-101 \text { to ensure that the } \\
\text { mirer punp cortinues to perform its } \\
\text { sofety function fcontrol gas refention of } \\
\text { depth and prevent buoyant displocement } \\
\text { GRE. }\end{array}$ & 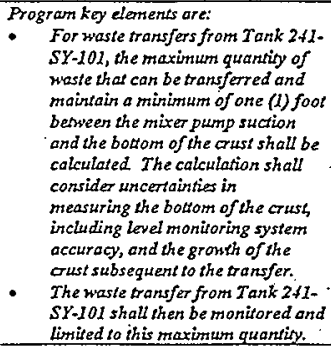 \\
\hline $\begin{array}{l}\text { Emergency Preparedness } \\
\text { (AC 5.14) }\end{array}$ & $\begin{array}{l}\text { Mitigate the consequences of a flammable } \\
\text { gas deflagration. }\end{array}$ & $\cdots$ \\
\hline $\begin{array}{l}\text { *HEPA Filter Controls } \\
\text { (AC 5.18) }\end{array}$ & $\begin{array}{l}\text { Reduce consequences from a possible } \\
\text { HEPA fiter failure by limiting the } \\
\text { inventory available for release. }\end{array}$ & $\cdots$ \\
\hline $\begin{array}{l}\text { Process Instrumentation and Measuring } \\
\text { and Test Equipment } \\
\text { (AC 5.19) }\end{array}$ & $\begin{array}{l}\text { Ensures instrumentation used to monitor } \\
\text { the concentration of flammable gases is } \\
\text { maintained. }\end{array}$ & $\cdots$ \\
\hline
\end{tabular}

- Existing control

\section{Defense-in Depth Controls}

\begin{tabular}{|c|c|c|}
\hline Control & Safety Function & Comments \\
\hline None identified & & \\
\hline
\end{tabular}




\section{Attachment 5}

Control Decision Record for Tank 241-SY-101 Waste Transfer for

Flammable Gas Deflagration - General

Consists of 3 Pages

(Including this Coversheet) 


\section{CONTROL DECISION RECORD FOR TANK 241-SY-101 WASTE TRANSFER}

\section{HAZARD/ACCIDENT: Flammable Gas Deflagration - General}

\section{Structures, Systems, and Components (SSCs)}

Note: The list of safety SSCs below does not include the Tank 241-\$Y-101 mixer pump, level monitoring system, pressure monitoring system, ventilation flowmeter, and temperature monitoring system which are required to implement the LANL SA Level I mixer pump controls (LA-UR-92-3196, Rev. 14a, Table 6-3) since they do not directly prevent or mitigate potential hazardous conditions and postulated accidents related to the Tank 241-SY-241 waste transfer. Operation of the 241-SY-101 mixer pump to reduce the frequency of a flammable gas deflagration by mixing and releasing flammable gases generated and trapped in the waste is assumed in the hazard and accident analyses of the Tank 241-SY-101 waste transfer. The safety analysis of the waste transfer does, however, identify hazardous conditions and postulated accidents that could result in failure of the mixer pump to perform its safty function (see flammable gas deflagrations - buoyant displacement GRE plus * additional crust release from the crust).

\begin{tabular}{|c|c|c|c|c|}
\hline \multirow{2}{*}{$\begin{array}{c}\text { Struetures, Systems, and } \\
\text { Components. }\end{array}$} & \multicolumn{2}{|c|}{ Classification } & \multirow[t]{2}{*}{ Safety Function } & \multirow[t]{2}{*}{ Comments } \\
\hline & SC & ss & & \\
\hline DST/AWF Ventilation & . & & $\begin{array}{l}\text { Maintain flammable gas concentrations in } \\
\text { tank dome spaces, duc to steady state } \\
\text { releases, below } 25 \% \text { of the LFL } \\
\end{array}$ & $\begin{array}{l}\text { The DST and AWF } \\
\text { ventilation systems also } \\
\text { reduce the "time at } \\
\text { risk" following a large } \\
\text { gas release event } \\
\text { (GRE). }\end{array}$ \\
\hline *SY-10I Hydrogen Monitor & $x$ & & $\begin{array}{l}\text { Provide indication and alarm for hydrogen } \\
\text { gas concentration in the Tank } 241-S Y-101 \\
\text { vapor space to the operations staff. } \\
\text {. }\end{array}$ & $\begin{array}{l}\text { An additional safety } \\
\text { function of the } \$ Y-101 \\
\text { hydrogen monitor is to } \\
\text { provide an interlock to } \\
\text { stop mixer pump } \\
\text { operation if hydrogen } \\
\text { concentration reaches } \\
0.75 \%(7,500 \mathrm{ppm}) \text { by } \\
\text { volume. }\end{array}$ \\
\hline $\begin{array}{l}\text { SY-101 Ammonia } \\
\text { Detection System }\end{array}$ & $\mathrm{X}$ & & $\begin{array}{l}\text { Detect ammonia in the tank } \\
\text { headspace'cxhaust gas and alam on the } \\
\text { data acquisition system (DACS) when a } \\
\text { high level of ammonia exists. }\end{array}$ & 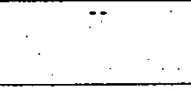 \\
\hline
\end{tabular}

$\mathrm{SC}$ is safety class

SS is safety significant

- Existing control 


\section{Technical Safety Requirements (TSRs)}

Note: New controls appear in bold ieticer.

\begin{tabular}{|c|c|c|}
\hline Control & Safety Function & Comments \\
\hline $\begin{array}{l}\text { "DST and AWF Tank Ventilation } \\
\text { (LCO 3.2.1) }\end{array}$ & $\begin{array}{l}\text { Assure that steady state release of } \\
\text { flammable gas does not accumulate in } \\
\text { flammable concentrations in vapor spaces } \\
\text { of TWRS facilities and structures. }\end{array}$ & $\begin{array}{l}\text { DST and AWF ventilation system } \\
\text { operation also reduces the "time at risk" } \\
\text { following a large gas release event (GRE). }\end{array}$ \\
\hline $\begin{array}{l}\text { * Flammability Controls (i.e., LA.UR- } \\
\text { 92-3196 Level I mixer pump controls, } \\
\text { including rupplemental controls) } \\
\text { (AC 5.9) }\end{array}$ & $\begin{array}{l}\text { Assure effective mitigation and safe } \\
\text { operations of Tank } 241-S Y-101 \text { with } \\
\text { respect to flammable gas hazards. } \\
\text {. }\end{array}$ & $\begin{array}{l}\text { The LA-UR-92-3196 Level I controls are } \\
\text { primarily related to mixet pump } \\
\text { operation. The Level I control on gas } \\
\text { concentrations (i.e., maximum hydrogen } \\
\text { concenteation and maximum ammonis } \\
\text { concentration) is the only control directly } \\
\text { applicable to preventing or mitigating } \\
\text { potential hazardous conditions and } \\
\text { postulated aecidents from the Tank 241- } \\
\text { SY-101 waste transfer. }\end{array}$ \\
\hline $\begin{array}{l}\text { Ignition controls } \\
\text { (Revision to } A(5.10)\end{array}$ & $\begin{array}{l}\text { Prevent the ignition of Jammable gases } \\
\text { that may be present. }\end{array}$ & $\begin{array}{l}\text { Expand applicability of existing TSRAC } \\
\text { 5.10 ignition controls to Tants } 24 I-S Y- \\
101 \text {; elevate and augment } L A-U R-92- \\
3196 \text { Level } I I \text { ignition controls. }\end{array}$ \\
\hline $\begin{array}{l}\text { Flammable Gas Monitoring Controls } \\
\text { (Revision to AC S.JI) }\end{array}$ & $\begin{array}{l}\text { Ensures flammable conditions caused by } \\
\text { steady-state accumulation or as a results } \\
\text { of a recent gas release event are not } \\
\text { present in the mork space before and } \\
\text { during manned work activities and } \\
\text { ensures that fammable conditions are } \\
\text { not produced by waste instusive activities } \\
\text { in Tank } 241 \text { SY-101. This reduces } \\
\text { frequency of flamurs able gas } \\
\text { deflagrations. }\end{array}$ & 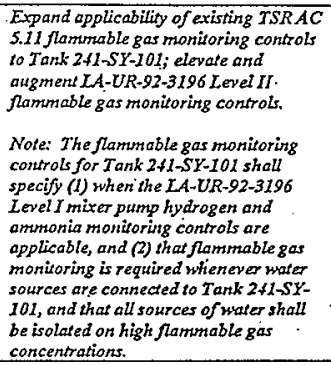 \\
\hline $\begin{array}{l}\text { Transfer Controls - Waste } \\
\text { Compatibility Controls } \\
\text { (AC 5.12) }\end{array}$ & $\begin{array}{l}\text { Ensure final tank states remain within } \\
\text { analyzed topography of the flammable gas } \\
\text { deflagrations accident. }\end{array}$ & $\begin{array}{lll}\cdot & \cdots & \\
\end{array}$ \\
\hline $\begin{array}{l}\text { Emergency Preparedness } \\
\text { (AC 5.14). }\end{array}$ & $\begin{array}{l}\text { Mitigate the consequences of a flammable } \\
\text { gas deflagration. }\end{array}$ & $\cdots$ \\
\hline $\begin{array}{l}\text { Excavation Controls } \\
\text { (AC S.17) }\end{array}$ & Prevent ignition of flammable gases. & $\cdots$ \\
\hline $\begin{array}{l}\text { HEPA Filter Controls } \\
\text { (AC 5.18) }\end{array}$ & $\begin{array}{l}\text { Reduce consequences from a possible } \\
\text { HEPA filter failure by limiting the } \\
\text { inventory available for release. }\end{array}$ & $\cdots$ \\
\hline $\begin{array}{l}\text { Process Instrumentation and Measuring } \\
\text { and Test Equipment } \\
\text { (AC 5.19) }\end{array}$ & $\begin{array}{l}\text { Ensures instrumentation used to monitor } \\
\text { the concentration of flammable gases is } \\
\text { maintained. }\end{array}$ & $\cdots$ \\
\hline
\end{tabular}

- Existing control

\section{Defense-in Depth Controls}

\begin{tabular}{|l|l|c|}
\hline \multicolumn{1}{|c|}{ Control } & \multicolumn{1}{|c|}{ Safety Function } & Comments \\
\hline * Flush transfer lines after use & $\begin{array}{l}\text { Reduce waste material in transfer lines to } \\
\text { limit the production of flamma ble gases. }\end{array}$ & $\cdots$ \\
\hline
\end{tabular}

- Existing control 


\section{Attachment 6}

Control Decision Record for Tank 241-SY-101 Waste Transfer for

Spray Leak in Structure or from Overground Transfer Line

Consists of 2 Pages

(Including this Coversheet) 
CONTROL DECISION RECORD FOR TANK 241-SY-101 WASTE TRANSFER

HAZARD/ACCIDENT: Spray Leak in Structure or from Overground Transfer (OGT) Line

Note: The below listed safety structures, systems, and components (SSCs), technical safety requirements (TSRs), and defense-in-depth controls only include those that are unique to the Tank 241-SY-101 waste transfer.

\section{Structures, Systems, and Components (SSCs)}

\begin{tabular}{|c|c|c|c|c|}
\hline \multirow{2}{*}{$\begin{array}{l}\text { Structures, Systems, and } \\
\text { Components }\end{array}$} & \multicolumn{2}{|c|}{ Classification } & \multirow[t]{2}{*}{ Safety Function } & \multirow[t]{2}{*}{ Comments } \\
\hline & SC & SS & & \\
\hline $\begin{array}{l}\text { Prefabricated Pump Pit . } \\
\text { (P3)* }\end{array}$ & $x$ & . & $\begin{array}{l}\text { Krock down spray and limit release of } \\
\text { aerosols to the environment. }\end{array}$ & $\begin{array}{l}\text { The P3 shall be } \\
\text { designed to withstand } \\
\text { design basis high wind. }\end{array}$ \\
\hline $\begin{array}{l}\text { OGT encasement and } \\
\text { connections* } \\
\text { - }\end{array}$ & $\bar{x}$ & . & $\begin{array}{l}\text { Confine a leak from the primary piping and } \\
\text { ensure that the leak is directed to Tank } \\
241-S Y-102 \text { or, if the drain to Tank } 241 \text {. } \\
\text { SY-102 is plugged, to the P3 which. } \\
\text { contains a leak detection system. }\end{array}$ & $\begin{array}{l}\text { The OGT encasement. } \\
\text { and connections shill } \\
\text { be designed to } \\
\text { withstand (1) the } \\
\text { maximum pressure } \\
\text { resulting if the drain to } \\
\text { Tank } 241-5 Y=102 \text { is } \\
\text { plugged and the waste } \\
\text { backs up the OGT } \\
\text { encasement to the P3 } \\
\text { and (2) design basis } \\
\text { high wind. }\end{array}$ \\
\hline $\begin{array}{l}\text { Riser 241-SY-102-007 Drop } \\
\text { Leg Enclosure" }\end{array}$ & $x$ & & Same as OGT encasement and connections. & $\begin{array}{l}\text { Comments for OGT } \\
\text { encasement and } \\
\text { connections above are } \\
\text { also applicable to the } \\
\text { riser } 241-S Y-102 \text { drop } \\
\text { leg enclosure. }\end{array}$ \\
\hline
\end{tabular}

$\mathrm{SC}$ is safety class

SS is safety significant

- Additional temporary shielding and administrative controls shall be used to maintain facility worker radiation exposures ALARA

Technical Safety Requirements (TSRs)

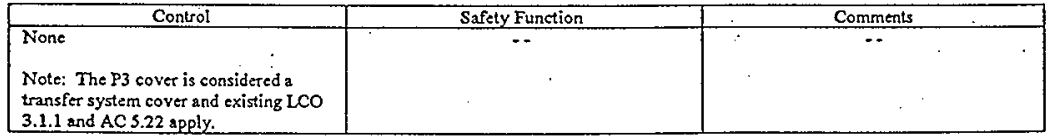

\section{Defense-in Depth Controls}

\begin{tabular}{|c|c|c|}
\hline Control & Safety Function & Comments \\
\hline None identified & $\ldots$ & $\ldots$ \\
\hline
\end{tabular}


Attachment 7

Control Decision Record for Tank 241-SY-101 Waste Transfer for Surface Leak Resulting in Pool

Consists of 3 Pages

(Including this Coversheet) 


\section{CONTROL DECISION RECORD FOR TANK 241-SY-101 WASTE TRANSFER}

\section{HAZARD/ACCIDENT: Surface Leak Resulting in Pool}

Note: The below listed safety structures, systems, and components (SSCs), technical safety requirements (TSRs), and defense-in-depth controls only include those that are unique to the Tank 241-SY-10I waste transfer.

\section{Structures, Systems, and Components (SSCs)}

\begin{tabular}{|c|c|c|c|c|}
\hline \multirow{2}{*}{$\begin{array}{l}\text { Structures, Systemss, and } \\
\text { Components }\end{array}$} & \multicolumn{2}{|c|}{ Classification } & \multirow[t]{2}{*}{ Safety Function } & \multirow[t]{2}{*}{ Comments } \\
\hline & SC & SS & & \\
\hline $\begin{array}{l}\text { Prefabricated Fump Pit } \\
\text { (P3)* }\end{array}$ & $x$ & $x$ & $\begin{array}{l}\text { The safety-elass safety function of the P3 } \\
\text { is to provide an intact boundary for the } \\
\text { leaked waste, and when leak detector } \\
\text { alams and appropriate operator response } \\
\text { times to shut off the transfer pump are } \\
\text { credited, to prevent premature P3 } \\
\text { overflow and the formation of a surface } \\
\text { pool. } \\
\text { The safety-significant safety function of } \\
\text { the P3, including cover, is to limit release } \\
\text { of aerosols generated by splatter inside } \\
\text { the P3, and limit shine and skyshine dose } \\
\text { to onsite receptors. }\end{array}$ & $\begin{array}{l}\text { The P3 shall be designed to } \\
\text { withstand design basis high } \\
\text { wind. }\end{array}$ \\
\hline $\begin{array}{l}\text { OGT encasement and } \\
\text { connections* }\end{array}$ & $\bar{x}$ & & $\begin{array}{l}\text { Provide secondary confinement for leaks } \\
\text { from the primary line and route the leak } \\
\text { to Tank } 241-S Y-102 \text { or, if the drain to } \\
\text { Tank } 241-S Y-102 \text { is plugged, back to the } \\
\text { P3 which contains a leak detection } \\
\text { system. }\end{array}$ & $\begin{array}{l}\text { The OGT encasement and } \\
\text { connections shall be designed to } \\
\text { vithstand (1) the maximum } \\
\text { pressure resulting if the drain to } \\
\text { Tank } 241-S Y=102 \text { is plugged and } \\
\text { the waste backs up the OGT } \\
\text { encasement to the } P 3 \text { and (2) } \\
\text { design basis high wind }\end{array}$ \\
\hline $\begin{array}{l}\text { Riser 241-SY-102-007 Drop } \\
\text { Leg Enclosure* } \\
\end{array}$ & $\bar{x}$ & & $\begin{array}{l}\text { Same as OGT encasement and } \\
\text { connections. }\end{array}$ & $\begin{array}{l}\text { Comments for OGT encasement } \\
\text { and connections above are also } \\
\text { applicable to the riser } 241 \text {-SY- } \\
102 \text { drop leg enclosure. }\end{array}$ \\
\hline
\end{tabular}

$\mathrm{SC}$ is safety class

$S S$ is safety significant

- Additional temporary shielding and administrative controls shall be used to maintain facility worker radiation exposures ALARA

Technical Safety Requirements (TSRs)

\begin{tabular}{|l|c|c|}
\hline \multicolumn{1}{|c|}{ Control } & Safety Function & Comments \\
\hline None & $\cdots$ &. \\
Note: The PPP cover is considered a & &. \\
transfer system cover and existing LCO & & \\
3.1.1 and AC 5.22 apply. & & \\
\hline
\end{tabular}


Defense-in Depth Controls

\begin{tabular}{|l|l|c|}
\hline \multicolumn{1}{|c|}{ Control } & \multicolumn{1}{|c|}{ Safety Function } & Comments \\
\hline $\begin{array}{l}\text { PPP and Riser 241-SY-101 drop leg } \\
\text { enclosure drains }\end{array}$ & $\begin{array}{l}\text { Allow leak to drain back to Tarks 241- } \\
\text { SY-101 or 241-SY-102. }\end{array}$ & $-\cdots$ \\
\hline
\end{tabular}




\title{
APPENDIX N
}

\author{
DRAFT HNF-4264 \\ PROCESS CONTROL PLAN
}




\section{DISTRIBUTION SHEET}

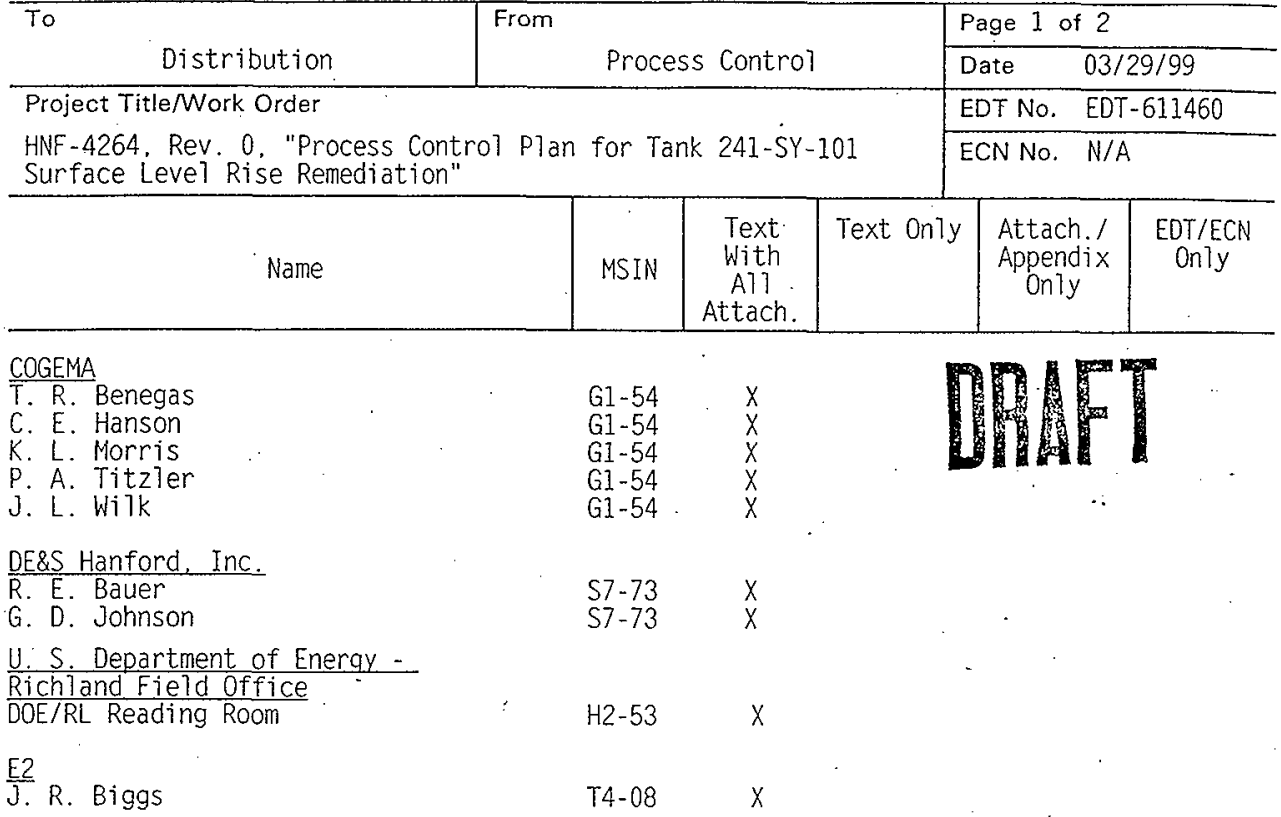

Fluor Daniel Northwest

G. W. Ryan

B4-47

G\&P Consulting. Inc.

3. M. Grigsby

R1-49

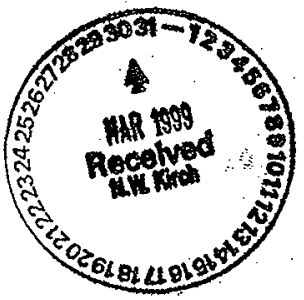

Lockheed Martin Hanford Corp.

W. B. Barton

$\mathrm{R} 2-12$

$\mathrm{R} 2-12$

$\mathrm{R} 1-56$

M. F. Erhart

R2-11

S. D. Estey

K. D. Fowler

R2-11

D. C. Hedengren

N. W. Kirch

$\mathrm{R} 2-11$

R2 -11

W. J. Powell

S5-13

R. W. Reed

T4-07

R. L. Schlosser

R1-56

L. M. Sasakj

L. A. Stauffer

$\mathrm{R} 2-12$

R2-11

T.C.S.R.C.

Rl-10

$x$
$x$
$x$
$x$
$x$
$x$
$x$
$x$
$x$
$x$
$x$
$x$
$x$
$x$
$x$

Lockheed Martin Services. Inc.

Central Files

B1-07

$x$

Merrick \& Company

S. W. Shaw

G1-54

$x$

HNF-4519

Revision 0 
DISTRIBUTION SHEET

\begin{tabular}{|c|c|c|c|c|c|}
\hline \multirow[b]{2}{*}{ Distribution } & \multirow{2}{*}{\multicolumn{3}{|c|}{ Process Control }} & \multicolumn{2}{|c|}{ Page 2 of 2} \\
\hline & & & & \multicolumn{2}{|c|}{ Date $\quad 03 / 29 / 99$} \\
\hline \multirow{2}{*}{\multicolumn{4}{|c|}{$\begin{array}{l}\text { Project Title/Work Order } \\
\text { HNF-4264, Rev. 0, "Proc } \\
\text { Surface Level Rise Reme }\end{array}$}} & \multicolumn{2}{|c|}{ EDT No. EDT-611460 } \\
\hline & & & & \multicolumn{2}{|c|}{ ECN No. N/A } \\
\hline \multicolumn{2}{|l|}{ Name } & $\begin{array}{c}\text { Text } \\
\text { With } \\
\text { All } \\
\text { Attach. }\end{array}$ & Text Only & $\begin{array}{l}\text { Attach. } \\
\text { Appendix } \\
\text { Only }\end{array}$ & $\begin{array}{c}\text { EOT/ECN } \\
\text { Only }\end{array}$ \\
\hline
\end{tabular}

Numatec Hanford Corp.

K. S. Witwer

L6-13. X

Pacific Northwest National Laboratory

J. W. Brothers

P. A. Meyer

c. W. Stewart

$\begin{array}{ll}K 9-20 & x \\ K 7-15 & x \\ K 7-15 & x\end{array}$
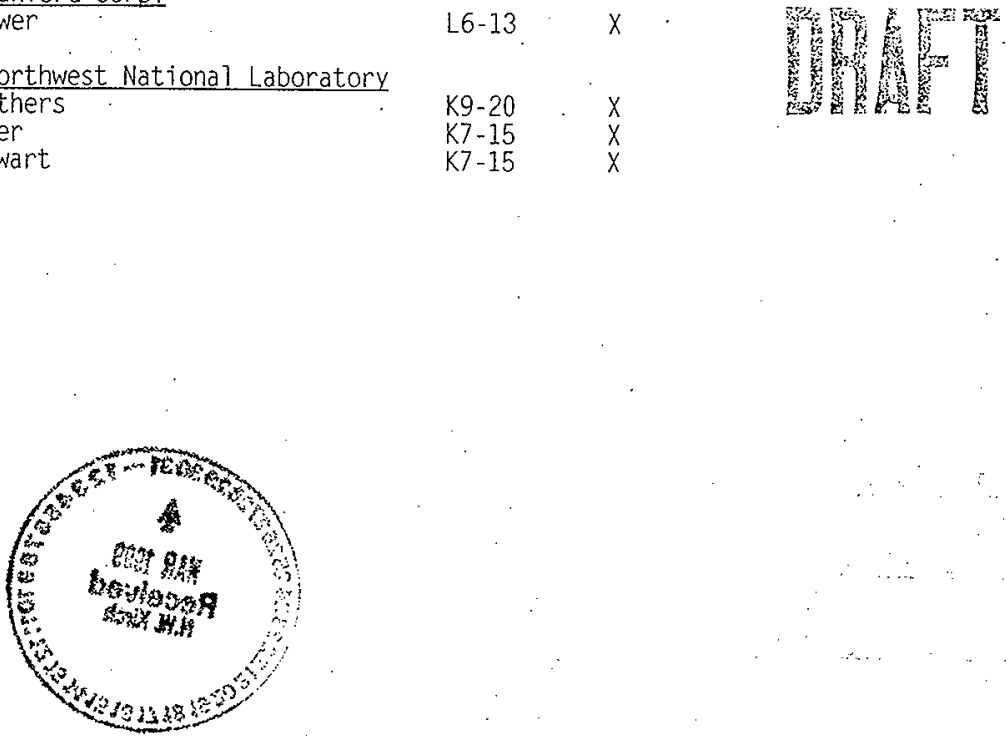


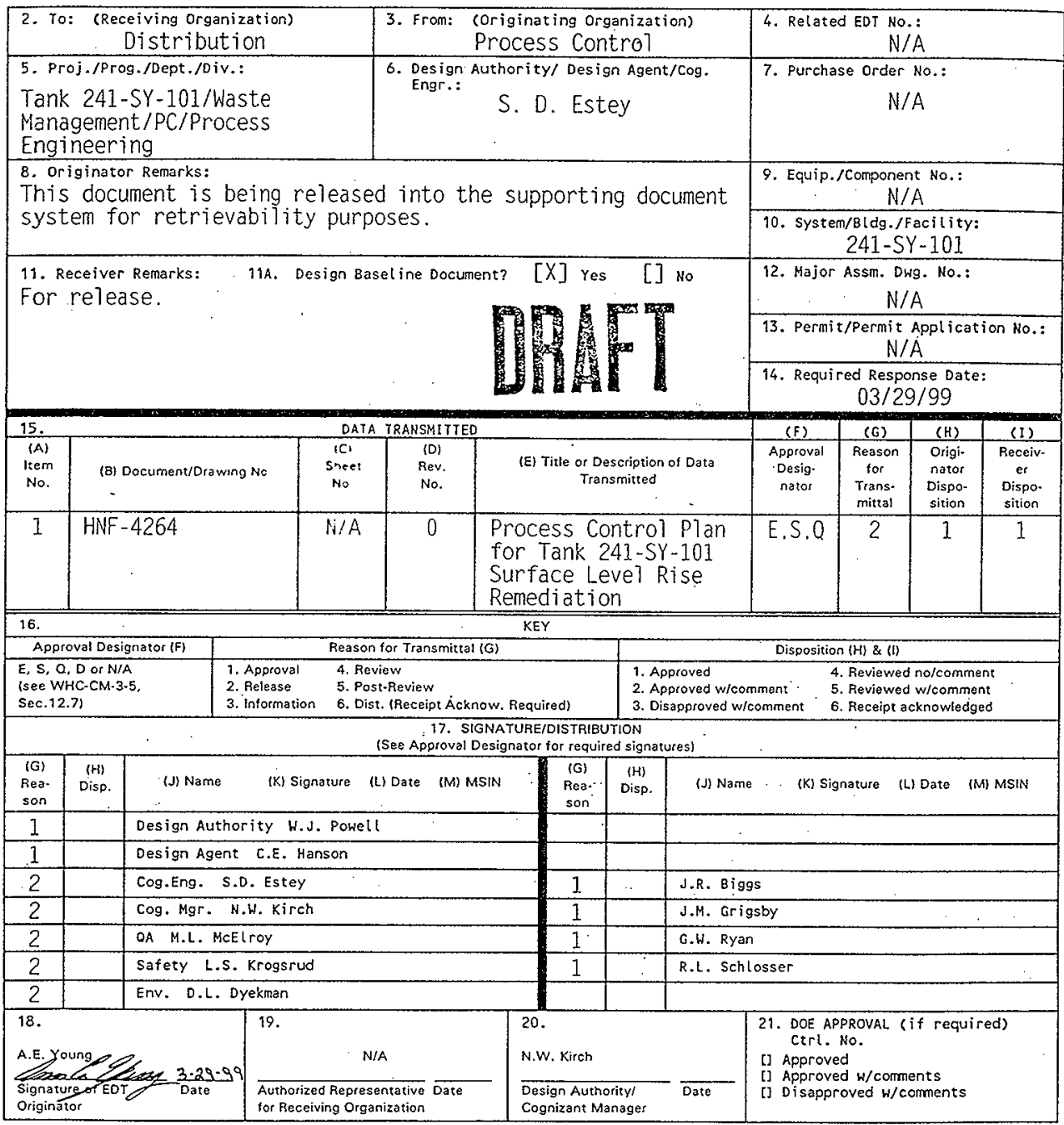

$80-7400-172-2(05 / 96)$ GEFO97 


\section{Process Control Plan for Tank.241-SY-101 Surface Level Rise Remediation}

S. D. Estey

Lockheed Martin Hanford, Corp. , Richland. WA 99352

EOT/ECN: EDT-611460 UC: 2070

Org Code: 74850 CACN/COA: 108963/BA10

B\&R Code: EW 3120074 Total Pages:

Key Words: Tank 241-SY-101, Tank SY-101, SY-101. SY Farm. Mitigation, Transfer, Overground. Pump. Ppp. Piping. Pump Pit, Drop Leg. New

Generation Transfer Pump. NGTP. Prefabricated Pump Pit

Abstract:

TRADEMARK DISCLAIMER. Reference herein to any specific commercial product, process, or service by trade name, trademark, manufacturer, or otherwise, does not necessarily constitute or imply its endorsement, recomendation, or favoring by the United States Government or any agency thereof or its contractors or subcontractors.

Printed in the United States of America. To obtain copies of this doccment, contact: Document Control Services, P.O. Box 950, Mailstop H6-08, Richland WA 99352, Phone (509) 372-2420; Fax $(509) 376-4989$. 


\section{Process Control Plan for Tank 241-SY-101 Surface-Level Rise Remediation}

Table of Contents

1.0 Introduction. 1

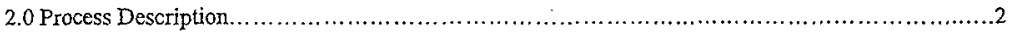

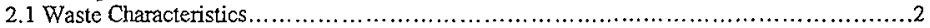

2.1.1 Waste Solias Composition Dependence on Waste Dilution and Temperature.......2

2.1.2 Waste Viscosity Dependence on Waste Dilution and Temperature.................... 3

2.1.3 Waste Critical Velocity Dependence on Waste Dilution and Temperature..........6

2.1.4 Waste Compatibility with Tank 241-SY-102 Wastes..............................7

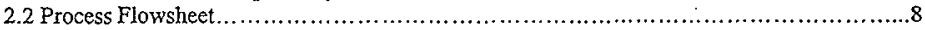

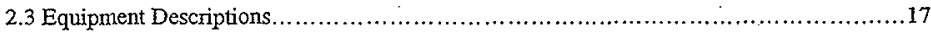

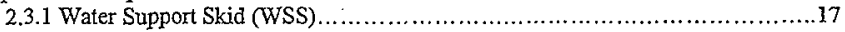

2.3.2 Tank 241-SY-101 Prefabricated Pump Pit (PPP) and NGTP (P-350) .............19

2.3.3 Waste Transfer Line.............................................................20

2.3.4 Tank 241-SY-102 Drop Leg..............................................20

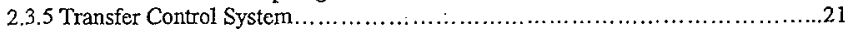

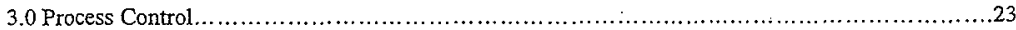

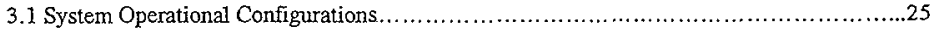

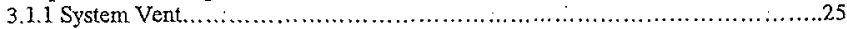

3.1.2 Normal Transfer Line Flush or Preheat.....................................26

3.1.3 Normal P-350 Ouflet Line Flush or Preheat.....................................27

3.1.4 Normal P-350 Dilution Line Flush or Preheat ..................................28

3.1.5 Normal Vent Header Flush to Tank 241-SY-101 .............................29

3.1.6 Normal Vent Header Flush to Transfer Line ......................................30 30

3.1.7 Normal P-350 Internal Flush...............................................31

3.1.8 Emergency Transfer Line Flush...................................................32

3.1.9 Emergency P-350 Outlet Line Flush...........................................33

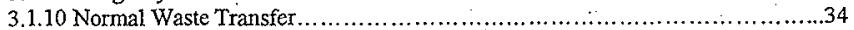

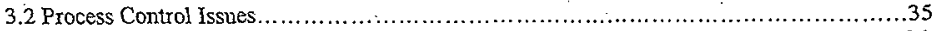

3.2.1 Control of Slurry Transfer ...................................................36

3.2.1.1 Operational Control Devices .....................................

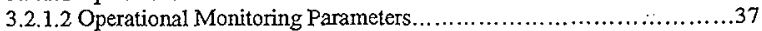

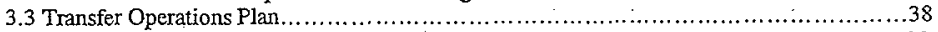

3.3.1 Transfer System Preheat....................................................38

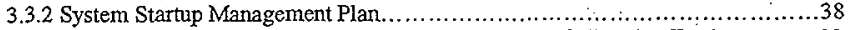

3.3.2.1 Magnetic Flow Meter (FE-367 \& FE-374) Calibration Testing..........38

3.3.2.2 Ammonia and VOC Emissions Testing...............................39

3.3.2.3 Testing to Optimize System Flow Rates.................................39

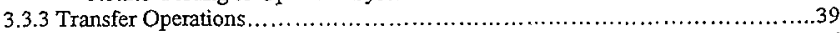

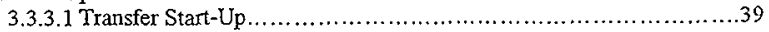

3.3.3.2 Controlled Transfer Shut-Down..................................40

3.3.3.3 Emergency Transfer Shut-Down and Flushing............................40

3.4 Process Sampling Requirements and Schedule........................................41

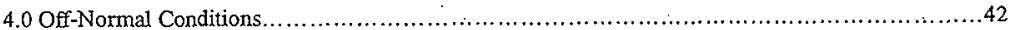

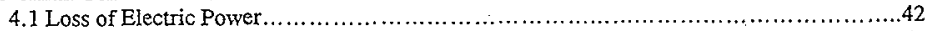

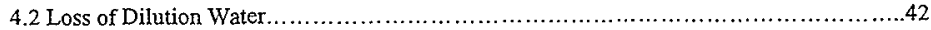

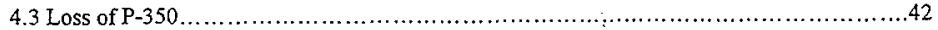

4.4 Excessive SY-Farm Ventilation System Ammonia or VOC Emissions....................42

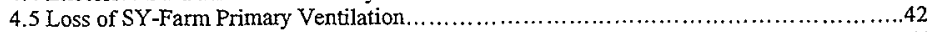

4.6 Loss of SY-Farm Annulus Ventilation. ................................................. 42 
4.7 Transfer Line Leak

5.0 References......

Appendix A: Index of Technical Operating Requirements

List of Tables

2.1.2.1 In-Situ Tank 241-SY-101 Apparent Viscosity. ...........................................5

2.1.2.2 Ir-Situ Tank 241-SY-101 Physical Properties.................................................

2.1.2.3 In-Situ Tank 241-SY-101 Apparent Viscosity.................................................

2.1.2.4 Slurry Viscosity Behavior at $120^{\circ} \mathrm{F}$ and $50 \mathrm{sec}^{-1}$ Shear Rate....................................

2.1.4.1 Preliminary FY-99 Core Sample Characterization...................................................

2.2.1 A Permissible Process Limits for Normal Waste Transfer..........................................10

2.2.1B Estimated Stream Characterization Ranges for Normal Waste Transfer .............................11

2.2.2 Permissible Process Limits for Transfer Line Flush .......................................... 12

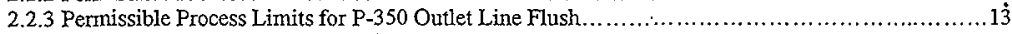

2.2.4 Permissible Process Limits for P-350 Internal Flush.............................................. 14

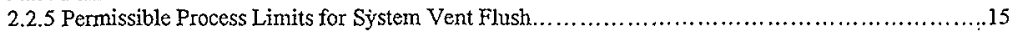

2.2.6 Permissible Process Limits for System Vent....................................................16

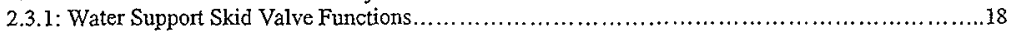

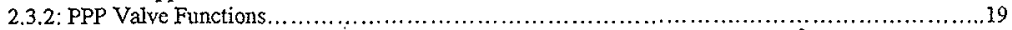

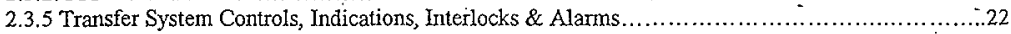

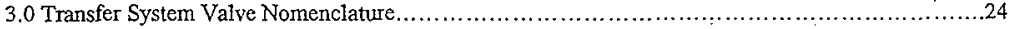

\section{List of Figures}

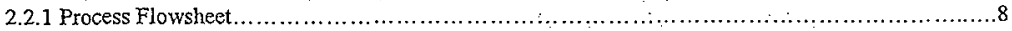

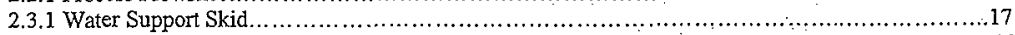

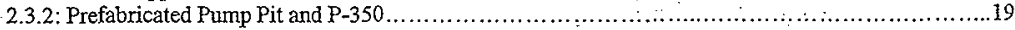

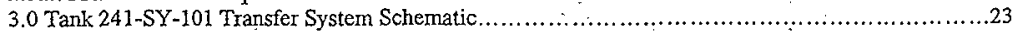

\section{List of Acronyms}

AC - Administrative Control

-ASSD - Anti-Siphoning Slurry Distributor

DCP - DACS Control Panel

DSTT - Double-Shell Tank

FCP - Farm Control Panel

gpm - gallons per minute

kgal - thousand gallons

MCC-Motor Control Center

NGTP - New Generation Transfer Pump

ppm - parts per million

PPP - Prefabricated Pump Pit

SST - Single Shell Tank

TSR - Technical Safety Requirement

VFD - Variable Frequency Drive

WSS - Water Support Skid

WSCP - Water Skid Control Panel 


\subsection{Introduction}

The tank 241-SY-101 transfer system was conceived and designed to address the immediate needs presented by rapidly changing waste conditions in tank 241-SY-101. Within the last year or so, the waste in this tank has exhibited both unexpected and extreme behavior (Rassat et al. 1999) in the form of rapidly increasing crust growth. This growth has been brought about by a rapidly increasing rate of gas entrapment within the crust. It has been conceived that the lack of crust agitation beginning upon the advent of mixer pump operations may have set-up a more consolidated, gas impermeable barrier when compared to a crust regularly broken up by the prior buoyant displacement events within the tank. A contributing factor may also be ongoing radioactive decay reducing average tank waste temperatures and producing more solids precipitation in the form of crust.

The crust growth rate is such that by September 1999, the waste level within the tark will violate regulatory definitions of a double-shell tank (DST). The immediate, short-term mitigation activity is to transfer 100 $\mathrm{kgal}$ of convective wastes from this tank into tank 241-SY-102 beginning in September 1999. Additional mitigation activities are also planned on less constrained schedules. The net affect of the $100 \mathrm{kgal}$ transfer and follow-on mitigation activities for tank 241-SY-101 is strongly believed to be the remediation of tank $241-S Y-101$ as a flammable gas safety concern.

To facilitate design, construction, and operation, the transfer system conveys waste from tank to tank via a transfer line composed of an overground, flexible hose. The transfer system utilizes an off-the-shelf waste transfer pump, known alternately as the new generation transfer pump (NGTP) or P-350. Instrumentation and control features are kept as simple as possible to facilitate the mitigation activity yet comply with the necessary safety constraints. The design incorporates a pressurized, heated water supply to provide a high degree of operational flexibility and reliability by limiting the concentration of vaste slumies in transfer. The design incorporates features to limit the uncontrolled introduction of water into tank 241-SY-101 and to limit the uncontrolled introduction of undiluted waste into the transfer system. 


\subsection{Process Description}

\subsection{Waste Characteristics}

From a physical standpoint, the bulk behavior of the convective wastes from tank 241 -SY-10i is of great concern to a transfer system. These wastes are a supersaturated, high-salt material with a high specific gravity and high viscosity. These properties exist at the normal in-situ waste temperature of $120^{\circ} \mathrm{F}$. This transfer system poses the potential to, upon a process upset, to allow the waste to be cooled to ambient (i.e., approximately atmosphenic) temperatures. At these low temperatures, both the degree of waste supersaturation and viscosity sky-rockets, posing the scenario of essentially freezing solid in the transfer line. Driven by these concerns, both water ditution and temperature control are specified for the transfer of tank 241-SY-101 wastes.

As a result of these estimated behaviors, the volumetric dilution range specified for the waste transfer system varies from 2 parts waste to 1 part water to 1 part waste to 2 parts water. The mean dilution ratio is specified as 1 part waste to 1 part water. The low dilution limit is specified due to concerns about the build-up of high salt concentrations in tank 241-SY-102. Some of the 200 West area SST saltwell wastes possess high concentrations of phosphate. Interim stabilization activities accumulate these wastes in tank 241-SY-102. By limiting the nitrate/nitrite salt concentrations in tank 241-SY-102, the probability of phosphate precipitation will be minimized. The high dilution limit is specified from a desire to limit the impact of tank 241-SY-101 transfer activities on operational DST volume.

\subsubsection{Waste Solids Composition Dependence on Waste Dilution and Temperature}

The volume percent precipitated solids contained in the in-situ convective regions of tank 241-SY-101 are stated as $5 \%$ to $25 \%$ with a mean of $15 \%$. This corresponds to the solids concentration at $120^{\circ} \mathrm{F}$. During the actual transfer of waste from tank 241-SY-101 to tank 241-SY-102, the waste will be in the piping system for only a few seconds. It is prudent to assume that no dissolution of precipitated solids occurs during shurry transfer. Therefore, the solids concentrations in the transferred waste are diluted proportional the dilution volume of water. Assuming that tank 241-SY-101 waste with 25 vol\% solids is diluted with water at the low dilution limit, the maximum expected solids concentration in the transfer line is:

$$
[2(25 \text { vol } \%)+1(0 \text { vol \% })] \div(2+1)=17 \text { vol } \%
$$

Likewise, the mean slurry solids concentration derived the mean value of 241-SY-101 convective waste solids concentration and the mean water dilution yields:

$$
[1(15 \text { vol } \%)+1(0 \text { vol } \%)] \div(1+1)=7.5 \text { vol } \%
$$

The resulting slurry solids concentration is the transfer line is expected to range from about 2 vol\% to 17 vol\% with 7.5 vol\% as the mean.

\section{Insoluble Solids}

The insoluble solids concentration of 241-SY-101 the convective layer is estimated to be 3 weight percent or less. This is consistent with laboratory data and expert opinion. The concentration would be slightly lower on a volumetric basis because of the higher density of solids. The lab data (Steen 1999) indicate insoluble metals ( $\mathrm{Ca}, \mathrm{Cr}, \mathrm{Fe}, \mathrm{Mn}, \mathrm{Ni}, \mathrm{Si}$, and $\mathrm{U}$ ) are present at around 0.5 weight percent. This corresponds to approximately 1 to 1.5 weight percent as metal oxides in the waste. The remainder of the solids is at least partially soluble, depending on temperature and concentration. 


\section{Dissolution/Precipitation Kinetics}

The overall kinetics of dissolution will be measured in the dilution and mixing study (Estey 1999a). The consensus of tank waste chemistry experts is that dissolution of the nitrate, nitrite, carbonate, and phosphate solids should be fairly rapid (minutes). This may not have much effect on transfer properties, as the transit time to tank 241-SY-102 will be less than one minute. Dissolution of oxalate is expected to take longer (hours).

Some precipitation of aluminum hydroxide is expected to occur because of the reduced $\mathrm{pH}$ of the diluted waste. This is known to be a slow process (days) and will not affect the pipeline behavior of the waste during the transfer. Although not expected to be a problem in the pipeline because of dilution, the precipitation of phosphates might occur within minutes and precipitation of oxalate and fluoro-phosphates within hours. The phosphate concentration in $241-\mathrm{SY}-101$ waste is fairly low at around 0.5 weight percent (Steen 1999). Precipitation of phosphates or fluoro-phosphate double salts may occur upon mixing with high phosphate saltwell liquors in 241-SY-102. However, this is neither a pumping nor a pipeline transfer issue.

The effect of the water dilution ratio on solids dissolution has been studied using OLI Systems Inc. Environmental Simulation Program (ESP). The simulations indicate that dissolution of soluble salts is 87 percent complete at a dilution of 35 parts water to 100 parts waste and 98 percent complete at 50 parts water to 100 parts waste (Reynolds 1998). Further dilution actually tesults in a slight increase in solids because of $\mathrm{pH}$-induced precipitation of ahuminum hydroxide.

These data support the preliminary conclusion that a dilution of 35 parts water to 100 parts waste is adequate, but a ratio of at least 50 parts water to 100 parts waste is desired. The target dilution range is from 50 to 150 parts water to 100 parts waste. Experimental results using actual waste samples are expected in April 1999 (Estey 1999a).

The effect of dilution water temperature on solubility has also been modeled (Reynolds 1998). Increasing the temperature of the dilution water does not have as great an effect as increasing the dilution ratio. At a dilution ratio of 30 parts water to 100 parts waste, approximately $25 \%$ more soluble solids are present using $85^{\circ} \mathrm{F}$ dilution water than $130^{\circ} \mathrm{F}$ water. The target temperature range for dilution water has been specified as $110-130^{\circ} \mathrm{F}$ to allow operational flexibility. Any dilutions using water in this temperature range will result in lower overall solids concentrations.

A specific regards the net effect of diluting 241-SY-101 waste with water at a nominal 1:1 ratio and allowing the mixture to equilibrate and cooi to $65^{\circ} \mathrm{F}$ (which could happen in the discharge drop leg in 241SY-102 if a siphon break occurred before line flushing). Although not modeled, it is anticipated that the final solids concentration would be lower than the initial, just-mixed concentration. That is, dissolution with the diluent is expected to have a stronger effect than the reduction in temperature. Figure 1 indicates that a 1:1 dilution is about 3 times more dilution water than is necessary to dissolve all $\mathrm{NaNO}_{3}$ at the temperature of $241-\mathrm{SY}-101\left(120^{\circ} \mathrm{F}\right)$. Even upon cooling to $65^{\circ} \mathrm{F}$, much more $\mathrm{NaNO}_{3}$ will be dissolved in the diluted waste than in the original 241-SY-101 waste.

\subsubsection{Waste Viscosity Dependence on Waste Dilution and Temperature}

The question of the viscosity of slurries is highly complex and essentially indeterminate. The viscosity and viscosity behavior of many liquids, such as water, is rvell defined. However, when suspended solids are included in a liquid (i.e., a slurry), no universally known method exists to specify the viscosity of a slurry, even if other physical properties of the slurry are well known. For example, whereas most liquids can be considered Newtonian fluids, most slurries cannot. The only way the viscosity of an actual slurry in a specific application can be positively determined is to measure it in that application. Such a measurement cannot be made in the application of the transfer from tank 241-SY-101. 
The best known means of estimating a slurry viscosity from other known slurry parameters is via an "Einstein" type relationship. This relationship can at best be considered as only a rough rule-of-thumb. In its simplest form, this relationship expresses the slurry viscosity as-a linear function of the carrier liquid viscosity and an exponential function of the solids loading or slurry density. Some terms are useful to define:

$$
\begin{aligned}
& c=\text { carnier or liquid phase of a slurry } \\
& d=\text { dispersed or solid phase of a sluny } \\
& m=\text { bulk property of a slurry } \\
& \alpha=\text { phase volume fraction in a slury (dimensionless) } \\
& \rho=\text { phase density of a sturry (units of mass per volume) } \\
& \mu=\text { dynamic viscosity (units of mass per length per time) }
\end{aligned}
$$

The following relationships apply:

$$
\begin{aligned}
& \alpha_{c}+\alpha_{d}=1 \\
& \rho_{\mathrm{rn}}=\alpha_{c} \rho_{\mathrm{c}}+\alpha_{\mathrm{d}} \rho_{\mathrm{d}} \\
& \rho_{\infty}=\rho_{\mathrm{m}} \text { at infinite dilution, where } \rho_{\mathrm{m}}=\rho_{\mathrm{c}}
\end{aligned}
$$

$\alpha_{d}$ must be distinguished from the volume fraction of settled solids. Setted solids always contain void volumes occupied by the liquid phase so that the volume fraction of settled solids will be greater than the volume fraction of dispersed solids, AKA true solids.

The desired quantity is the slurry viscosity $\mu_{m}$. A simplified "Einstein" relationship can then be defined as:

$$
\mu_{m}=\mu_{c} \exp \left[k\left(\frac{\rho_{m}-\rho_{\infty}}{\rho_{\infty}}\right)\right] \quad \text { where "k" is an arbitrary constant }
$$

Therefore, the slurry viscosity becomes a function of the carrier liquid viscosity and the difference in density between the siurry and its carrier liquid.

To determine the constant in the "Einstein" relation, the value of $\mu_{\mathrm{m}}$ nust be known for at least one set of $\mu_{e}, \rho_{a}$, and $\rho_{m}$ values. $\rho_{m}$ is a value nailed down fairly well for the waste in question. The range of $\rho_{m}$ values for tank $241-\mathrm{SY}-101$ convective wastes at $120^{\circ} \mathrm{F}$ is stated as 1.45 to $1.75 \mathrm{gm} / \mathrm{cc}$ with a mean of 1.60 $\mathrm{gm} / \mathrm{cc}$. For tank 241-SY-101 wastes, the value of $\rho_{c}$ at any non-infinite dilution is not known with much precision. The only thing that can be positively stated for tank $241-\mathrm{SY}-101$ waste is that at infinite dilution, $\rho_{\mathrm{m}}=\rho_{\mathrm{c}}=1.0 \mathrm{gm} / \mathrm{cc}$.

Tingey et al. (1994) and Stewart (1996) document viscosity analyses performed on tank 24I-SY-101 wastes. The former investigated material from core 22 taken during Window $\mathrm{C}$ while the latter reported results from ball theometer testing in tank 241-SY-101. Both references report Non-Newtonian, shearthinning (thixotropic) behavior of the tank wastes.

Analyses documented in Tingey et al. (1994) looked at parameters of $\rho_{m}$, settled solids density, settled solids volume fraction, filtered solids weight fraction, and viscosity at a $400 \mathrm{sec}^{-1}$ shear rate at a $0,10,20$, 35 , and 50 vol $\% 2 \mathrm{M} \mathrm{NaOH}$ dilution and 50,70 , and $90^{\circ} \mathrm{C}$. The results indicate that little difference could be noted between $\rho_{\mathrm{m}}$ and the settled solids density at any dilution or temperature. Differences in viscosity, volume percent settled solids, and weight percent filtered solids showed much more variation at differing dilutions and temperatures. In this application, $2 \mathrm{M} \mathrm{NaOH}$ can be considered equivalent to water.

Tingey et al. (1994) reported a dynamic viscosity of $40 \mathrm{cP}$ at a $400 \mathrm{sec}^{-1}$ shear rate for undiluted waste at 50 ${ }^{\circ} \mathrm{C}$. Stewart (1996) reported ball rheometer viscosity behavior with an uncertainty factor of two, shown in Table 2.1.2.1. 
Table 2.1.2.1 In-Situ Tank 241-SY-101 Apparent Viscosity

\begin{tabular}{|l|l|l|l|l|}
\hline Shear rate $\left(\mathrm{sec}^{-1}\right)$ & 1 & 10 & 100 & 400 \\
\hline Viscosity $(\mathrm{cP})$ & -600 & $\sim 150$ & $\sim 80$ & $\sim 40$ \\
\hline
\end{tabular}

The viscosity results from both references for undiluted wastes at tank temperature and a $400 \mathrm{sec}^{-1}$ shear rate show good agreement. When shear rate is expressed as the pipe flow velocity divided by the pipe inner radius, a $6 \mathrm{ft} / \mathrm{sec}$ flow velocity corresponds to a shear rate of about $50 \mathrm{sec}^{-1}$. in a $3^{\prime \prime}$ ID pipe. At this shear rate, Stewart (1996) indicates an in situ waste viscosity of about $100 \mathrm{cP}$

A summary of selected data for tank $241-S Y-101$ waste at $50^{\circ} \mathrm{C}$ at various water dilutions from Tingey et al. (1994) is shown in Table 2.1.2.2.

Table 2.1.2.2 In-Situ Tank 241-SY-101 Physical Properties

\begin{tabular}{|l|l|l|l|l|l|}
\hline $\begin{array}{l}\text { Dilution ' } \\
\text { Property }\end{array}$ & 0 vol\% & 10 vol\% & 20 vol\% & 35 vol\% & $\begin{array}{l}50 \text { vol\% } \\
\text { ( }\end{array}$ \\
\hline $\begin{array}{l}\text { Apparent } \\
\text { Viscosity at } 400 \\
\text { sec }^{-1}(\mathrm{cP})\end{array}$ & 39.4 & 35.8 & 12.3 & 6.8 & 2.9 \\
\hline $\begin{array}{l}\text { Vol\% settled } \\
\text { solids }\end{array}$ & 100 & 100 & 96 & 89 & 34 \\
\hline $\begin{array}{l}\text { Wt\% filtered } \\
\text { solids }\end{array}$ & 83 & 60 & 68 & 40 & 25 \\
\hline $\begin{array}{l}\text { Settled solids } \\
\text { density }\end{array}$ & 1.72 & 1.68 & 1.59 & 1.51 & 1.42 \\
\hline Slurry density & 1.72 & 1.68 & 1.60 & 1.48 & 1.34 \\
\hline
\end{tabular}

The value of 50 yol\% dilution corresponds to the minimum dilution specified for the waste transfer system. Based on the shear viscosity behavior reported by Tingey et al. (1994), the viscosity at $50 \mathrm{sec}^{-1}$ shear rate would appear to be 2.4 times larger than the value at $400 \mathrm{sec}^{-1}$. The viscosity of water at $50^{\circ} \mathrm{C}$ is $0.55 \mathrm{cP}$.

For a $50 \mathrm{sec}^{-1}$ shear rate, tank $241-\mathrm{SY}-101$ waste viscosities can be derived from data in Tingey et a1. (1994) and Stewart (1996). These are shown in Table 2.1.2.3:

Table 2.1.2.3 In-Situ Tank 241-SY-101 Apparent Viscosity

\begin{tabular}{|l|l|l|l|l|l|}
\hline $\begin{array}{l}\text { Dilution } \\
\text { Property }\end{array}$ & 0 vol\% & 10 vol\% & 20 vol\% & 35 vol\% & 50 vol\% \\
\hline $\begin{array}{l}\text { Apparent } \\
\begin{array}{l}\text { Viscosity at } 50 \\
\sec ^{-1}(\mathrm{cP})\end{array}\end{array}$ & 100 & 85 & 30 & 16 & 7.0 \\
\hline
\end{tabular}

This suggests a slutry viscosity expression in the form of:

$$
\begin{aligned}
& \mu_{m}=0.55 c P * \exp \left[k\left(\frac{\rho_{m}-1.0^{\mathrm{gm}} / c c}{1.0^{\mathrm{gm} /} / c c}\right)\right] \quad \text { where } \\
& 100 c P=0.55 c P * \exp \left[k\left(\frac{1.6^{\mathrm{gm} / c c}-1.0^{\mathrm{gm} / c c}}{1.0^{\mathrm{gm}} / \mathrm{cc}}\right)\right]
\end{aligned}
$$

since $\mu_{\mathrm{tn}}=100 \mathrm{cP}$ when $\rho_{\mathrm{m}}=1.6 \mathrm{gm} / \mathrm{cc}$. This yields $\mathrm{k}=8.67$. 
Therefore, at $50^{\circ} \mathrm{C},\left(\sim 120^{\circ} \mathrm{F}\right)$ and a shear rate of $50 \mathrm{sec}^{-1}$, the expression for the slurry viscosity produced by the waste transfer system becomes:

$$
\mu_{m}=0.55 c P * \exp \left[8.67 *\left(\frac{\rho_{m}-1.0^{g m} / c c}{1.0 g m / c c}\right)\right]
$$

This expression yields the results shown in Table 2.1.2.4.

Table 2.1.2.4 Slurry Viscosity Behavior at $120^{\circ} \mathrm{F}$ and $50 \mathrm{sec}^{-1}$ Shear Rate

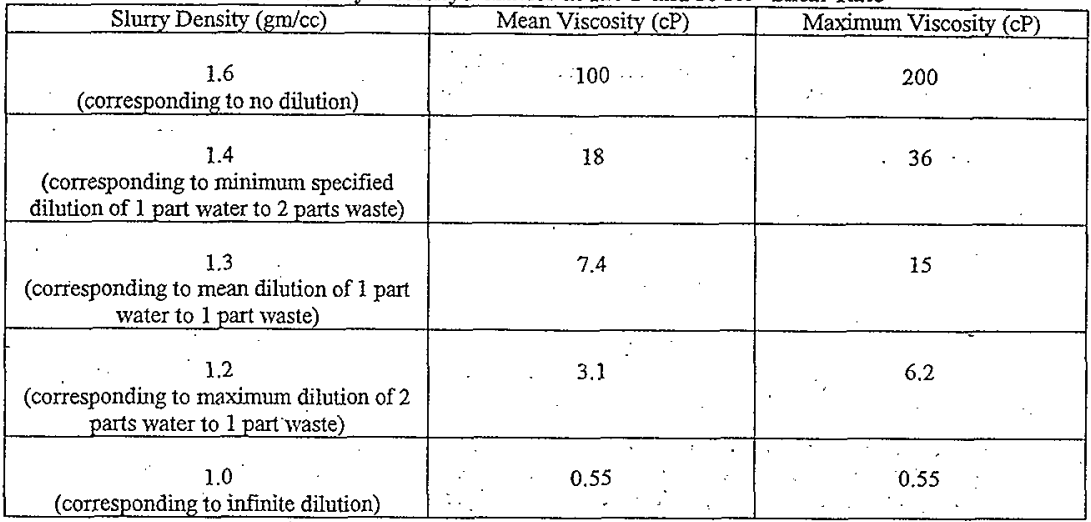

From the above table, at the specified waste transfer system operating temperature of $120^{\circ} \mathrm{F}$, the minimum specified dilution of 1 part by volume water to 2 parts by volume waste yields a slurry with an estimated viscosity of less than $30 \mathrm{cP}$. Only in the extreme of low dilution at the high viscosity bound does it exceed $30 \mathrm{cP}$. At the mean 1:1 dilution, the expected shurry viscosity is about $7.5 \mathrm{cP}$ with an expected maximum of $15 \mathrm{cP}$.

\subsubsection{Waste Critical Velocity Dependence on Waste Dilution and Temperature}

Critical velocity in slurry flow is an estimated fluid flow velocity at which the effects of random, turbulent fluid motions provide enough agitation to keep individual solid particles in the slumy suspended in the slurry. The idea is that if the velocity of slurry transport is kept above the critical velocity, that solids deposition and the attendant potential of line plugging, can be avoided. The concept of a critical velocity is generally acknowledged as having no hard scientific definition, but rather results from experimental data fits as determined from various researchers.

A review of many critical velocity corellations as applied to Hanford tank wastes has been performed (Estey \& Hu 1998). Specific application of the concept to the tank 241-SY-101 transfer has also been performed by PNNL (Onishi \& Recknagle 1999). Both analysis surveys indicate that a specified slurry flow velocity of $6 \mathrm{ft} / \mathrm{sec}$ meet all practical requirements for critical velocity, provided some amount of water dilution of the waste is performed.

The specific analyses documented by PNNL indicate that there are values of water dilution and slurry temperature that optimize (i.e., minimize) the resultant critical velocity. The concept behind this finding is that high carrier liquid viscosities are more efficient at momentum transfer to solid particles, yet impose 
higher pressure drops in piping and require larger velocities to achieve turbulent flow. In contrast, low carrier liquid viscosities make possible turbulent flow at lower velocities, yet are less efficient ant transferring momentum to the solid particles in a slurry.

Both increasing water dilution and, to a lesser extent increasing slurry temperature, lower the carrier liquid viscosity in a slury. At higher values of changes in water dilutions and temperatures, the affect on critical velocity is small. However, very evident in the PNNL findings is that no water dilution of tank 241-SY101 wastes results in a significant carrier liquid viscosity. The net effect is to require extremely high flow velocities to achieve turbulent flow in the transport of undiluted wastes. This result is strong evidence for the need of at least some water dilution of tark 241-SY-101 wastes.

\subsubsection{Waste Compatibility with Tank 241-SY-102 Wastes}

The tank 241-SY-101 level-rise remediation project acknowledges the need to perform a waste compatibility assessment (Fowler 1995; Mulkey 1997) for this transfer. This assessment must be successfully competed. in order for the 100-kgal waste transfer to occur in September 1999. At this time, any abnormal or limiting findings are not anticipated for this waste compatibility assessment.

Table 2.2.4.1 shows the preliminary chemical compound distribution based on FY-99 core sample of tank 241-SY-I01.

Tablc 2.1.4.1 Preliminary FY-99 Core Sample Characterization

\begin{tabular}{|c|c|c|}
\hline Chemical Spccics & $\begin{array}{c}\text { Mass Percentage of Waste } \\
\text { Reported to Two Significant Figures }\end{array}$ & $\begin{array}{c}\text { Mass Percentage of Waste } \\
\text { Normalized to Two Significant Figures }\end{array}$ \\
\hline $\mathrm{H}_{2} \mathrm{O}$ & 40 & 39 \\
\hline $\mathrm{Na}$ & 19 & 18 \\
\hline $\mathrm{Al}_{\mathrm{OH})_{4}}$ & 12 & 12 \\
\hline $\mathrm{NO}_{3}$ & 11 & 11 \\
\hline $\mathrm{NO}_{2}$ & 11 & 11 \\
\hline $\mathrm{OH}$ & 2.8 & 2.7 \\
\hline $\mathrm{CO}_{3}$ & 2.2 & 2.1 \\
\hline $\mathrm{C}_{2} \mathrm{O}_{4}$ & 1.3 & 1.3 \\
\hline $\mathrm{Cl}^{\mathrm{CHO}}$ & 0.85 & 0.82 \\
\hline $\mathrm{SiO}_{2}$ & 0.75 & 0.72 \\
\hline $\mathrm{PO}_{4}$ & 0.64 & 0.62 \\
\hline $\mathrm{Cr}_{2} \mathrm{O}_{3}$ & 0.55 & 0.53 \\
\hline $\mathrm{SO}_{4}$ & 0.50 & 0.48 \\
\hline $\mathrm{K}$ & 0.35 & 0.34 \\
\hline $\mathrm{C}_{2} \mathrm{H}_{3}$ & 0.35 & 0.34 \\
\hline & 0.18 & 0.17 \\
\hline
\end{tabular}




\subsection{Process Flowsheet}

\section{TANK 241-SY-101 Transfer System Process Lines}

1) Water Support Skid Inlet

2) Water Support Skid Outlet

3) PPP Water Supply Line

4) P-350 Internal Flush Line

5) P-350 Dilution Water Line

6) P-350 Waste Inlet

7) P-350 Outlet

8) Flush Cross Connect

9) Transfer Line

10) System Vent

Figure 2.2.I Process Flowsheet

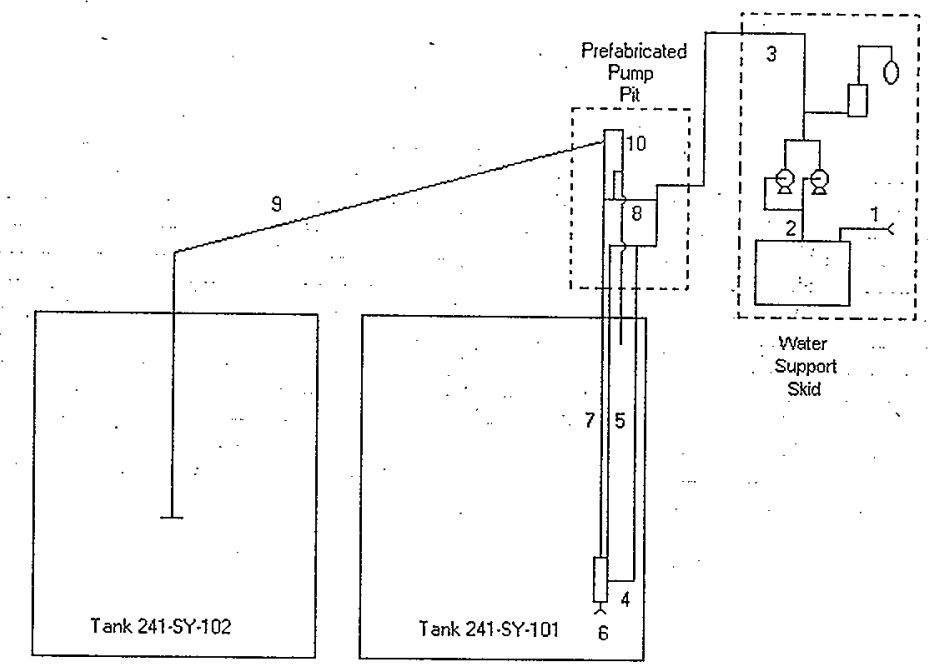




\section{Tank 241-SY-101 Transfer System Process Flow Modes}

Normal Waste Transfer

Normal Flush and/or Preheat Modes

- Transfer Line Fush

- P-350 Outlet Line Fiush

- P-350 Dilution Line Flush

- Vent Header Flush to 241-SY-101

- Vent Header Flush to Transfer Line

- P-350 Internal Flush

Emergency Flush Modes

- Transfer Line Flush

- P-350 Ontlet Line Flush

System Vent

\section{Explanation of Flowsheet Symbols}

(N/A ): not applicable, as this section of process piping is valyed out from the piping sections in active use -or - this paranieter has no meaning for the flow mode in question.

(-): Process piping is in active use but the parameter value is not of specific concern to the process.

However, spẹcification of parameter value/limits requites prudent engineering judgement

(R): symbol used for waste transfer operations expressing the required transfer flow rate as a variable to be optimized depending upon determination of the process piping diameter. Waste transfer flow control is specifically stated as a flow velocity requirement as opposed to a flow rate requirement. Specifying the transfer flowrate as a variable allows the convenient expression of the allowable waste and dilution water flowrates.

For process line flushes, the primary objective is to simply displace process waste fluid from the lines and replace it with fresh water. Prudent engineering suggests that additional requirements be stated to maximize the efficiency of the flush within the limits of the transfer system infrastructure (i.e., a volumetric flush water flow rate of $70 \mathrm{gpm}$ ). The specified process line flush volume is equal to the larger of either:

-Two times the volume of the process line being flushed

-Two minutes of flow at the specified line flow velocity

Where permissible within the equipment performance limits, the process line flush velocity is recommended to exceed $4 \mathrm{ft} / \mathrm{sec}$. This velocity is estimated to exceed typical critical velocities for the process lines and would therefore maximize the effectiveness of a flush.

The P-350 internal flush requirement is stated as flow tate of approximately $10 \mathrm{gpm}$. The P-350 internal flush volume and temperature limits are then defined by the limits on water addition to tank 241-SY-101 (i.e., a volume not to exceed the capacity of the water skid tank that is within the water addition temperature limits of $110^{\circ} \mathrm{F}$ to $130^{\circ} \mathrm{F}$ ).

Tables 2.2.1 through 2.2.6 show the estimated flow parameters and compositions associated with the various transfer system process flow modes. 
Table 2.2.1A Permissible Process Limits for Normal Waste Transfer

\begin{tabular}{|c|c|c|c|c|c|c|c|c|c|c|}
\hline $\begin{array}{l}\text { Fluid/Flow } \\
\text { Parameter }\end{array}$ & $\begin{array}{l}\text { Water } \\
\text { Skid } \\
\text { Inlet } \\
(1)\end{array}$ & $\begin{array}{c}\text { Water } \\
\text { Skid } \\
\text { Outlet } \\
(2)\end{array}$ & $\begin{array}{l}\text { PPP } \\
\text { Water } \\
\text { Supply } \\
\text { Line } \\
\text { (3) }\end{array}$ & $\begin{array}{c}\text { P-350 } \\
\text { Internal } \\
\text { Flush } \\
\text { Line } \\
(4)\end{array}$ & $\begin{array}{c}\text { P-350 } \\
\text { Water } \\
\text { Dilution } \\
\text { Line } \\
\text { (5) }\end{array}$ & $\begin{array}{c}\text { P-350 } \\
\text { Waste } \\
\text { Inlet } \\
(6)\end{array}$ & $\begin{array}{c}\text { P-350 } \\
\text { Outiet } \\
(7)\end{array}$ & $\begin{array}{c}\text { Flush } \\
\text { Cross- } \\
\text { Connect } \\
(8)\end{array}$ & $\begin{array}{l}\text { Transfer } \\
\text { Line } \\
\text { (9) }\end{array}$ & $\begin{array}{l}\text { Vent } \\
\text { Line } \\
\text { (10) }\end{array}$ \\
\hline Flow Rate & - & $\begin{array}{l}1 / 3 R \text { to } \\
2 / 3 R \\
\text { not to } \\
\text { exceed } \\
70 \text { gpm }\end{array}$ & $\begin{array}{c}1 / 3 \mathrm{R} \\
\text { to } \\
2 / 3 \mathrm{R} \\
\text { not to } \\
\text { exceed } \\
70 \mathrm{gpm}\end{array}$ & $\mathrm{N} / \mathrm{A}$ & $\begin{array}{c}1 / 3 R \\
\text { to } \\
2 / 3 R \\
\text { not to } \\
\text { exceed } \\
70 \mathrm{gpm} \\
\end{array}$ & $\begin{array}{c}1 / 3 R \\
10 \\
2 / 3 R\end{array}$ & $\mathrm{R}$ & $N / A$ & $\mathrm{R}$ & $N / A$ \\
\hline $\begin{array}{c}\text { Flush } \\
\text { Volume } \\
\end{array}$ & N/A. & N/A & $N / A$ & N/A & $N / A$ & N/A & N/A & $N / A$ & N/A & N/A \\
\hline $\begin{array}{c}\text { Flow } \\
\text { Velocity } \\
(\mathrm{A} / \mathrm{sec})\end{array}$ & - & - & - & N/A & - & - & $\geq 6$ & N/A & $\geq 6$ & $N / A$ \\
\hline $\begin{array}{l}\text { Temperature } \\
(\mathrm{F})\end{array}$ & - & $\begin{array}{c}110 \\
10 \\
130 \\
\end{array}$ & $\begin{array}{c}110 \\
\text { to } \\
130\end{array}$ & N/A & $\begin{array}{c}110 \\
\text { to } \\
130\end{array}$ & - & $\begin{array}{c}110 \\
\text { to } \\
130\end{array}$ & N/A & $\begin{array}{c}110 \\
\text { to } \\
130\end{array}$ & $N / A$ \\
\hline $\begin{array}{l}\text { Viscosity } \\
\text { (cP) }\end{array}$ & - & $\begin{array}{c}0.50 \\
10 \\
0.62\end{array}$ & $\begin{array}{c}0.50 \\
\text { to } \\
0.62\end{array}$ & N/A & $\begin{array}{c}0.50 \\
\text { to } \\
0.62\end{array}$ & $\begin{array}{c}50 \\
\text { to } \\
200\end{array}$ & $\begin{array}{l}2 \\
\text { to } \\
15 \\
\end{array}$ & $N / A$ & $\begin{array}{l}2 \\
\text { to } \\
15\end{array}$ & $N / A$ \\
\hline $\begin{array}{l}\text { Density } \\
\left(\text { (zarns/cc }^{2}\right)\end{array}$ & $\because 1$ & $<1$ & $<1$ & N/A & $<1$ & $\begin{array}{c}1.45 \\
\text { to } \\
1.75 \\
\end{array}$ & $\begin{array}{c}1.16 \\
\text { to } \\
1.50 \\
\end{array}$ & N/A & $\begin{array}{c}1.16 \\
\text { to } \\
1.50 \\
\end{array}$ & N/A \\
\hline $\begin{array}{c}\text { Mass \% } \\
\text { Non-Soluble } \\
\text { Solids }\end{array}$ & 0 & 0 & 0 & N/A & 0 & $\begin{array}{c}1 \\
\text { to } \\
3\end{array}$ & $\begin{array}{c}0 \\
\text { to } \\
2\end{array}$ & N/A & $\begin{array}{c}0 \\
\text { to } \\
2\end{array}$ & N/A \\
\hline
\end{tabular}


Table 2.2.1B Estimated Stream Characterization Ranges for Normal Waste Transfer

\begin{tabular}{|c|c|c|c|c|c|c|c|c|c|c|}
\hline $\begin{array}{l}\text { Fluid/Flow } \\
\text { Parameter }\end{array}$ & $\begin{array}{l}\text { Water } \\
\text { Skid } \\
\text { Inlet } \\
\text { (1) }\end{array}$ & $\begin{array}{l}\text { Water } \\
\text { Skid } \\
\text { Outlet } \\
\text { (2) }\end{array}$ & $\begin{array}{c}\text { PPP } \\
\text { Water } \\
\text { Supply } \\
\text { Line } \\
\text { (3) }\end{array}$ & $\begin{array}{l}\text { P-350 } \\
\text { Intenal } \\
\text { Flush } \\
\text { Line } \\
\text { (4) }\end{array}$ & $\begin{array}{c}\text { p-350 } \\
\text { Water } \\
\text { Dilution } \\
\text { Line } \\
(5)\end{array}$ & $\begin{array}{c}\text { P-350 } \\
\text { Waste } \\
\text { Inlet } \\
(6)\end{array}$ & $\begin{array}{c}\text { P-350 } \\
\text { Outlet } \\
(7)\end{array}$ & $\begin{array}{l}\text { Flush } \\
\text { Cross- } \\
\text { Connect } \\
\text { (8) }\end{array}$ & $\begin{array}{c}\text { Transfer } \\
\text { Line } \\
\text { (9) }\end{array}$ & $\begin{array}{l}\text { Vent } \\
\text { Line } \\
(10)\end{array}$ \\
\hline $\begin{array}{c}\text { Volume \% } \\
\text { Solids }\end{array}$ & $<0.01$ & $<0.01$ & $<0.01$ & N/A & $<0.01$ & $\begin{array}{c}5 \\
10 \\
25\end{array}$ & $\begin{array}{c}2 \\
\text { to } \\
17\end{array}$ & N/A & $\begin{array}{c}2 \\
\text { to } \\
17\end{array}$ & $N / A$ \\
\hline $\begin{array}{l}\text { Mass \% } \\
\text { Sodium }\end{array}$ & 0 & 0 & 0 & N/A & 0 & $\begin{array}{c}14.2 \\
\text { to } \\
23.8 \\
\end{array}$ & $\begin{array}{c}7 \\
\text { to } \\
17\end{array}$ & $N / A$ & $\begin{array}{c}7 \\
\text { to } \\
17\end{array}$ & N/A \\
\hline $\begin{array}{l}\text { Mass \% } \\
\text { Hydroxide }\end{array}$ & 0 & 0 & 0 & N/A & 0 & $\begin{array}{c}4 \\
\text { to } \\
12\end{array}$ & $\begin{array}{c}2 \\
\text { to } \\
9\end{array}$ & N/A & $\begin{array}{c}2 \\
\text { to } \\
9\end{array}$ & $N / A$ \\
\hline $\begin{array}{l}\text { Mass \% } \\
\text { Carbonate }\end{array}$ & 0 & 0 & 0 & $N / A$ & 0 & $\begin{array}{c}2 \\
\text { to } \\
6\end{array}$ & $\begin{array}{c}1 \\
\text { to } \\
4\end{array}$ & N/A & $\begin{array}{c}1 \\
\text { to } \\
4\end{array}$ & $\mathrm{~N} / \mathrm{A}$ \\
\hline $\begin{array}{l}\text { Mass \% } \\
\text { Aluminum }\end{array}$ & 0 & 0 & 0 & N/A. & 0 & $\begin{array}{l}1.5 \\
\text { to } \\
4.5\end{array}$ & $\begin{array}{c}0 \\
\text { to } \\
3\end{array}$ & $N / A$ & $\begin{array}{c}0 \\
\text { to } \\
3\end{array}$ & $\mathrm{~N} / \mathrm{A}$ \\
\hline $\begin{array}{c}\text { Mass } \% \\
\text { Other } \\
\text { Constituents }\end{array}$ & 0 & 0 & 0 & N/A & 0 & $\begin{array}{c}2 \\
\text { to } \\
6\end{array}$ & $\begin{array}{c}1 \\
\text { to } \\
4\end{array}$ & N/A & $\begin{array}{c}1 \\
\text { to } \\
4\end{array}$ & $N / A$ \\
\hline
\end{tabular}


Table 2.2.2 Permissible Process Limits for Transfer Line Flush

\begin{tabular}{|c|c|c|c|c|c|c|c|c|c|c|}
\hline $\begin{array}{l}\text { Fluid/Flow } \\
\text { Parameter }\end{array}$ & $\begin{array}{l}\text { Water } \\
\text { Skid } \\
\text { Inlet } \\
(1)\end{array}$ & $\begin{array}{l}\text { Water } \\
\text { Skid } \\
\text { Outlet } \\
(2)\end{array}$ & $\begin{array}{l}\text { PPP } \\
\text { Water } \\
\text { Supply } \\
\text { Line } \\
(3)\end{array}$ & $\begin{array}{c}\text { P-350 } \\
\text { Internal } \\
\text { Flush } \\
\text { Line } \\
(4)\end{array}$ & $\begin{array}{c}\text { P-350 } \\
\text { Water } \\
\text { Dilution } \\
\text { Line } \\
(5)\end{array}$ & $\begin{array}{c}\text { P-350 } \\
\text { Waste } \\
\text { Inlet } \\
(6)\end{array}$ & $\begin{array}{c}\text { P-350 } \\
\text { Outlet } \\
(7)\end{array}$ & $\begin{array}{l}\text { Flush } \\
\text { Cross- } \\
\text { Connect } \\
(8)\end{array}$ & $\begin{array}{c}\text { Transfer } \\
\text { Line } \\
\text { (9) }\end{array}$ & $\begin{array}{l}\text { Vent } \\
\text { Line } \\
(10)\end{array}$ \\
\hline $\begin{array}{l}\text { Flow } \\
\text { Rate }\end{array}$ & - & $\begin{array}{l}<70 \\
\text { gpm }\end{array}$ & $\begin{array}{l}<70 \\
\mathrm{gpm}\end{array}$ & $\mathrm{N} / \mathrm{A}$ & N/A & N/A & N/A & $\begin{array}{l}<70 \\
\mathrm{gpm}\end{array}$ & $\begin{array}{l}<70 \\
\mathrm{gpm}\end{array}$ & $N / A$ \\
\hline $\begin{array}{l}\text { Flush } \\
\text { Volume } \\
\text {. }\end{array}$ & $\begin{array}{l}\text { 2xline } \\
\text { volume } \\
\text { or } 2 \\
\text { minutes } \\
\text { of flow, } \\
\text { which- } \\
\text { ever is } \\
\text { greater }\end{array}$ & $\begin{array}{l}2 \times l i n e \\
\text { volume } \\
\text { or } 2 \\
\text { minutes } \\
\text { of flow, } \\
\text { which- } \\
\text { ever is } \\
\text { greater }\end{array}$ & $\begin{array}{l}2 x l i n e \\
\text { volume } \\
\text { or } 2 \\
\text { minutes } \\
\text { of flow, } \\
\text { which- } \\
\text { ever is } \\
\text { greater }\end{array}$ & N/A & N/A & N/A & N/A & $\begin{array}{c}2 \times l i n e \\
\text { volume } \\
\text { or } 2 \\
\text { minutes } \\
\text { of flow, } \\
\text { which- } \\
\text { ever is } \\
\text { greater }\end{array}$ & $\begin{array}{l}2 x \text { line } \\
\text { volume } \\
\text { or } 2 \\
\text { minutes } \\
\text { of flow, } \\
\text { which- } \\
\text { ever is } \\
\text { greater }\end{array}$ & N/A \\
\hline $\begin{array}{c}\text { Flow } \\
\text { Velocity } \\
\left({ }^{\mathrm{ft}} / \mathrm{sec}\right)\end{array}$ & - & - & $=$ & N/A & N/A & N/A & N/A & 4 to 6 & 4 to 6 & N/A \\
\hline $\begin{array}{c}\text { Temperature } \\
\left({ }^{\circ} \mathrm{F}\right)\end{array}$ & - & $\begin{array}{c}110 \\
\text { to } \\
130\end{array}$ & $\begin{array}{c}110 \\
\text { to } \\
130\end{array}$ & N/A & N/A & N/A & N/A & $\begin{array}{c}110 \\
\text { to } \\
130\end{array}$ & $\begin{array}{l}110 \\
\text { to } \\
130\end{array}$ & N/A \\
\hline $\begin{array}{l}\text { Viscosity } \\
\text { (cP) }\end{array}$ & - & $\begin{array}{c}0.50 \\
\text { to } \\
0.62 \\
\end{array}$ & $\begin{array}{c}0.50 \\
\text { to } \\
0.62\end{array}$ & $N / A$ & $N / A$ & N/A & $N / A$ & $\begin{array}{c}0.50 \\
\text { to } \\
0.62\end{array}$ & $\begin{array}{c}0.50 \\
\text { to } \\
0.62\end{array}$ & N/A. \\
\hline $\begin{array}{l}\text { Density } \\
(\text { (Eams/oc) }\end{array}$ & $<1$ & $<1$ & $<1$ & N/A & $N / A$ & N/A & N/A & $<1$ & $<1$ & N/A \\
\hline $\begin{array}{l}\text { Volume \% } \\
\text { Solids }\end{array}$ & $<0.01$ & $<0.01$ & $<0.01$ & N/A & $N / A$ & N/A & $N / A^{\circ}$ & $<0.01$ & $<0.01$ & N/A \\
\hline $\begin{array}{c}\text { Mass \% } \\
\text { Water }\end{array}$ & 100 & 100 & 100 & $N / A$ & N/A & N/A & $N / A$ & 100 & 100 & $N / A$ \\
\hline $\begin{array}{l}\text { Mass \% } \\
\text { Non-Soluble } \\
\text { Solids }\end{array}$ & 0 & 0 & 0 & N/A & $N / A$ & N/A & $N / A$ & 0 & 0 & N/A \\
\hline
\end{tabular}


Table 2.2.3 Permissible Process Limits for P-350 Outlet Line Flush

\begin{tabular}{|c|c|c|c|c|c|c|c|c|c|c|}
\hline $\begin{array}{l}\text { Fluid/Flow } \\
\text { Parameter }\end{array}$ & $\begin{array}{l}\text { Water } \\
\text { Skid } \\
\text { Inlet } \\
\text { (1) }\end{array}$ & $\begin{array}{l}\text { Water } \\
\text { Skid } \\
\text { Ontlet } \\
(2)\end{array}$ & $\begin{array}{l}\text { PPP } \\
\text { Water } \\
\text { Supply } \\
\text { Line } \\
(3)\end{array}$ & $\begin{array}{l}\text { P-350 } \\
\text { Intemal } \\
\text { Flush } \\
\text { Line } \\
(4)\end{array}$ & $\begin{array}{c}\text { P-350 } \\
\text { Water } \\
\text { Dilution } \\
\text { Line } \\
(5)\end{array}$ & $\begin{array}{c}\text { P-350 } \\
\text { Waste } \\
\text { Inlet } \\
(6)\end{array}$ & $\begin{array}{c}\text { P-350 } \\
\text { Outlet } \\
(7)\end{array}$ & $\begin{array}{l}\text { Flush } \\
\text { Cross- } \\
\text { Connect } \\
\text { (8) }\end{array}$ & $\begin{array}{l}\text { Transfer } \\
\text { Line } \\
(9)\end{array}$ & $\begin{array}{l}\text { Vent } \\
\text { Line } \\
(10)\end{array}$ \\
\hline Flow Rate & - & $\begin{array}{l}<70 \\
\text { gpm }\end{array}$ & $\begin{array}{l}<70 \\
\mathrm{gpm}\end{array}$ & N/A & N/A & $\begin{array}{l}<70 \\
\text { gpm }\end{array}$ & $\begin{array}{l}<70 \\
\text { gpm }\end{array}$ & $\begin{array}{l}<70 \\
\mathrm{gpm}\end{array}$ & N/A & N/A \\
\hline $\begin{array}{l}\text { Flush } \\
\text { Volume }\end{array}$ & $\begin{array}{l}2 \times \text { line } \\
\text { volume } \\
\text { or } 2 \\
\text { minutes } \\
\text { of flow, } \\
\text { which- } \\
\text { ever is } \\
\text { greater }\end{array}$ & $\begin{array}{l}2 \times \text { line } \\
\text { volume } \\
\text { or } 2 \\
\text { minutes } \\
\text { of flow, } \\
\text { which- } \\
\text { ever is } \\
\text { greater }\end{array}$ & $\begin{array}{l}2 x \text { line } \\
\text { volume } \\
\text { or } 2 . \\
\text { minutes } \\
\text { of flow, } \\
\text { which- } \\
\text { ever is } \\
\text { greater }\end{array}$ & N/A & $N / A$ & $\begin{array}{l}2 x \text { line } \\
\text { volume } \\
\text { or } 2 \\
\text { minutes } \\
\text { of flow, } \\
\text { which- } \\
\text { ever is } \\
\text { greater }\end{array}$ & $\begin{array}{l}2 \times l i n e \\
\text { volume } \\
\text { or } 2 \\
\text { minutes } \\
\text { of flow, } \\
\text { which- } \\
\text { ever is } \\
\text { greater }\end{array}$ & $\begin{array}{l}2 \times l i n e \\
\text { volume } \\
\text { or } 2 \\
\text { minutes } \\
\text { of flow, } \\
\text { which- } \\
\text { ever is } \\
\text { greater }\end{array}$ & N/A & N/A \\
\hline $\begin{array}{c}\text { Flow } \\
\text { Velocity } \\
\left({ }^{\mathrm{A}} / \mathrm{sec}\right)\end{array}$ & - & - & - & N/A & $N / A$ & - & 4 to 6 & 4 to 6 & $N / A$ & $N / A$ \\
\hline $\begin{array}{c}\text { Temperature } \\
(\mathrm{F})\end{array}$ & - & $\begin{array}{c}110 \\
\text { to } \\
130\end{array}$ & $\begin{array}{c}110 \\
\text { to } \\
130 \\
\end{array}$ & N/A & N/A & $\begin{array}{c}110 \\
\text { to } \\
130\end{array}$ & $\begin{array}{c}110 \\
\text { to } \\
130\end{array}$ & $\begin{array}{l}110 \\
\text { to } \\
130\end{array}$ & $\mathrm{~N} / \mathrm{A}$ & N/A \\
\hline $\begin{array}{l}\text { Viscosity } \\
\text { (cP) }\end{array}$ & - & $\begin{array}{c}0.50 \\
\text { to } \\
0.62 \\
\end{array}$ & $\begin{array}{c}0.50 \\
10 \\
0.62 \\
\end{array}$ & N/A & $N / A$ & $\begin{array}{c}0.50 \\
\text { to } \\
0.62 \\
\end{array}$ & $\begin{array}{c}0.50 \\
\text { to } \\
0.62\end{array}$ & $\begin{array}{c}0.50 \\
\text { to } \\
0.62 \\
\end{array}$ & N/A & N/A \\
\hline $\begin{array}{l}\text { Density } \\
(\text { grans } / \text { cc })\end{array}$ & $<1$ & $<1$ & $<1$ & N/A & N/A. & $<1$ & $<1$ & $<1$ & N/A & N/A \\
\hline $\begin{array}{l}\text { Volume \% } \\
\text { Solids }\end{array}$ & $<0.01$ & $<0.01$ & $<0.01$ & N/A & N/A & $<0.01$ & $<0.01$ & $<0.01$ & $N / A$ & N/A \\
\hline $\begin{array}{c}\text { Mass \% } \\
\text { Water }\end{array}$ & 100 & 100. & 100 & N/A & $N / A$ & 100 & 100 & 100 & N/A & N/A \\
\hline $\begin{array}{c}\text { Mass \% } \\
\text { Non-Soluble } \\
\text { Soliđs }\end{array}$ & 0 & 0 & 0 & $N / A$ & $\mathrm{~N} / \mathrm{A}$ & 0 & 0 & 0 & $N / A$ & N/A \\
\hline
\end{tabular}


Table 2.2.4 Permissible Process Limits for P-350 Internal Flush

\begin{tabular}{|c|c|c|c|c|c|c|c|c|c|c|}
\hline $\begin{array}{c}\text { Fluid/Flow } \\
\text { Parameter } \\
\end{array}$ & $\begin{array}{l}\text { Water } \\
\text { Skid } \\
\text { Inlet } \\
\text { (1) }\end{array}$ & $\begin{array}{l}\text { Water } \\
\text { Skid } \\
\text { Outlet } \\
(2)\end{array}$ & $\begin{array}{c}\text { PPP } \\
\text { Water } \\
\text { Supply } \\
\text { Line } \\
(3) \\
\end{array}$ & $\begin{array}{c}\text { P-350 } \\
\text { Internal } \\
\text { Flush } \\
\text { Line } \\
\text { (4) }\end{array}$ & $\begin{array}{c}\text { P-350 } \\
\text { Water } \\
\text { Dilution } \\
\text { Line } \\
\text { (5) }\end{array}$ & $\begin{array}{c}\text { P-350 } \\
\text { Waste } \\
\text { Inlet } \\
(6)\end{array}$ & $\begin{array}{c}\text { P-350 } \\
\text { Outlet } \\
(7)\end{array}$ & $\begin{array}{c}\text { Flush } \\
\text { Cross- } \\
\text { Connect } \\
(8)^{\circ}\end{array}$ & $\begin{array}{c}\text { Transfer } \\
\text { Line } \\
(9)\end{array}$ & $\begin{array}{l}\text { Vent } \\
\text { Line } \\
\text { (10) }\end{array}$ \\
\hline Flow Rate & - & $\begin{array}{l}\sim 10 \\
\mathrm{gpm}\end{array}$ & $\begin{array}{l}\sim 10 \\
\text { gpm }\end{array}$ & $\begin{array}{l}\sim 10 \\
\mathrm{gpm}\end{array}$ & $N / A$ & $\begin{array}{l}\sim 10 \\
\mathrm{gpm}\end{array}$ & N/A & N/A & N/A & $\mathrm{N} / \mathrm{A}$ \\
\hline $\begin{array}{c}\text { Flush } \\
\text { Volume }\end{array}$ & - & - & - & - & N/A. & - & N/A & N/A & N/A & N/A \\
\hline $\begin{array}{l}\text { Flow } \\
\text { Velocity } \\
(\mathrm{t} / \mathrm{sec})\end{array}$ & - & - & - & - & N/A & - & N/A & $N / A$ & N/A & N/A \\
\hline $\begin{array}{c}\text { Temperature } \\
\left({ }^{\circ} \mathrm{F}\right)\end{array}$ & - & $\begin{array}{l}110 \\
\text { to } \\
130\end{array}$ & $\begin{array}{c}110 \\
\text { to } \\
130\end{array}$ & $\begin{array}{c}110 \\
\text { to } \\
130\end{array}$ & $N / A$ & $\begin{array}{c}110 \\
\text { to } \\
130\end{array}$ & N/A & N/A & N/A & $\mathrm{N} / \mathrm{A}$ \\
\hline $\begin{array}{l}\text { Viscosity } \\
\text { (cP) }\end{array}$ & - & $\begin{array}{l}0.50 \\
\text { to } \\
0.62\end{array}$ & $\begin{array}{c}0.50 \\
\text { to } \\
0.62\end{array}$ & $\begin{array}{c}0.50 \\
\text { to } \\
0.62\end{array}$ & N/A & $\begin{array}{l}0.50 \\
\text { to } \\
0.62\end{array}$ & N/A & N/A & N/A & N/A \\
\hline $\begin{array}{l}\text { Density } \\
(\text { \&ams } / \mathrm{sc})\end{array}$ & $<1$ & $<1$ & $<1$ & $<1$ & N/A & $<1$ & N/A & $N / A$ & N/A & N/A \\
\hline $\begin{array}{l}\text { Volume \% } \\
\text { Solids }\end{array}$ & $<0.01$ & $<0.01$ & $<0.01$ & $<0.01$ & N/A & $<0.01$ & N/A & N/A. & N/A & N/A \\
\hline $\begin{array}{l}\text { Mass \% } \\
\text { Water }\end{array}$ & 100 & 100 & 100 & 100 & N/A & 100 & N/A & N/A & N/A & $\mathrm{N} / \mathrm{A}$ \\
\hline $\begin{array}{c}\text { Mass \% } \\
\text { Non-Soluble } \\
\text { Solids }\end{array}$ & 0 & 0 . & 0 & 0 & N/A & 0 & $N / A$ & N/A & N/A & N/A \\
\hline
\end{tabular}


Table 2.2.5 Permissible Process Limits for System Vent Flush

\begin{tabular}{|c|c|c|c|c|c|c|c|c|c|c|}
\hline $\begin{array}{l}\text { Fluid/Flow } \\
\text { Parameter }\end{array}$ & $\begin{array}{l}\text { Water } \\
\text { Skid } \\
\text { Inlet } \\
(1)\end{array}$ & $\begin{array}{l}\text { Water } \\
\text { Skid } \\
\text { Outlet } \\
(2)\end{array}$ & $\begin{array}{l}\text { PPP } \\
\text { Water } \\
\text { Supply } \\
\text { Line } \\
(3)\end{array}$ & $\begin{array}{c}\text { P-350 } \\
\text { Internal } \\
\text { Flush } \\
\text { Line } \\
\text { (4) }\end{array}$ & $\begin{array}{c}\text { P-350 } \\
\text { Water } \\
\text { Dilution } \\
\text { Line } \\
\text { (5) }\end{array}$ & $\begin{array}{c}\mathrm{P}-350 \\
\text { Waste } \\
\text { inlet } \\
(6)\end{array}$ & $\begin{array}{c}\text { P-350 } \\
\text { Outlet } \\
(7)\end{array}$ & $\begin{array}{c}\text { Flush } \\
\text { Cross- } \\
\text { Connect } \\
(8)\end{array}$ & $\begin{array}{c}\text { Transfer } \\
\text { Line } \\
(9)\end{array}$ & $\begin{array}{l}\text { Vent } \\
\text { Line } \\
\text { (10) }\end{array}$ \\
\hline Flow Rate & - & $\begin{array}{l}<70 \\
\mathrm{gpm}\end{array}$ & $\begin{array}{l}<70 \\
\text { gpm }\end{array}$ & N/A & N/A & $\mathrm{N} / \mathrm{A}$ & $\mathrm{N} / \mathrm{A}$ & $\begin{array}{l}<70 \\
\mathrm{gpm}\end{array}$ & N/A & $\begin{array}{l}<70 \\
\mathrm{gpm}\end{array}$ \\
\hline $\begin{array}{c}\text { Flush } \\
\text { Volume }\end{array}$ & $\begin{array}{l}2 x \text { line } \\
\text { volume } \\
\text { or } 2 \\
\text { minutes } \\
\text { of flow, } \\
\text { which- } \\
\text { ever is } \\
\text { greater }\end{array}$ & $\begin{array}{l}2 \text { dine } \\
\text { volume } \\
\text { or } 2 \\
\text { minutes } \\
\text { of flow, } \\
\text { which- } \\
\text { ever is } \\
\text { greater }\end{array}$ & $\begin{array}{l}2 \text { xline } \\
\text { volume } \\
\text { or } 2 \\
\text { minutes } \\
\text { of flow, } \\
\text { which- } \\
\text { ever is } \\
\text { greater }\end{array}$ & N/A & N/A & N/A & N/A & $\begin{array}{l}2 \times l i n e \\
\text { volume } \\
\text { or } 2 \\
\text { minutes } \\
\text { of flow, } \\
\text { which- } \\
\text { ever is } \\
\text { greater }\end{array}$ & $N / A$ & $\begin{array}{l}\text { 2xline } \\
\text { volum } \\
\text { e or } 2 \\
\text { minute } \\
\mathrm{s} \text { of } \\
\text { flow, } \\
\text { which- } \\
\text { ever is } \\
\text { greater }\end{array}$ \\
\hline $\begin{array}{c}\text { Flow } \\
\text { Velocity } \\
(\mathrm{f} / \mathrm{sec})\end{array}$ & - & - & - & N/A & $N / A$ & N/A & N/A & 4 to 6 & N/A & 4 to 6 \\
\hline $\begin{array}{l}\text { Temperature } \\
\cdot \quad\left({ }^{\circ} \mathrm{F}\right)\end{array}$ & - & $\begin{array}{c}110 \\
\text { to } \\
130\end{array}$ & $\begin{array}{c}110 \\
\text { to - } \\
130\end{array}$ & N/A & N/A & N/A & N/A & $\begin{array}{c}110 \\
\text { to } \\
130\end{array}$ & N/A & $\begin{array}{c}110 \\
\text { to } \\
130\end{array}$ \\
\hline $\begin{array}{c}\text { Viscosity } \\
\text { (cP) }\end{array}$ & - & $\begin{array}{c}0.50 \\
\text { to } \\
0.62\end{array}$ & $\begin{array}{c}0.50 \\
\text { to } \\
0.62\end{array}$ & N/A & N/A & N/A & $N / A$ & $\begin{array}{c}0.50 \\
\text { to } \\
0.62\end{array}$ & N/A & $\begin{array}{c}0.50 \\
\text { to } \\
0.62\end{array}$ \\
\hline $\begin{array}{l}\text { Density } \\
(\text { grams } / \infty)\end{array}$ & $<1$ & $<1$ & $<1$ & N/A & N/A & N/A & N/A & $<1$ & N/A & $<1$ \\
\hline $\begin{array}{l}\text { Volume \% } \\
\text { Solids }\end{array}$ & $<0.01$ & $<0.01$ & $<0.01$ & N/A & N/A & N/A & N/A & $<0.01$ & $N / A$ & $<0.01$ \\
\hline $\begin{array}{c}\text { Mass } \% \\
\text { Water }\end{array}$ & 100 & 100 & 100 & N/A & N/A & N/A & N/A & 100 & N/A & 100 \\
\hline $\begin{array}{c}\text { Mass \% } \\
\text { Non-Solubie } \\
\text { Solids }\end{array}$ & 0 & 0 & 0 & N/A & N/A & $N / A$ & N/A & 0 & N/A & 0 \\
\hline
\end{tabular}


Table 2.2.6 Permissible Process Limits for System Vent

\begin{tabular}{|c|c|c|c|c|c|c|c|c|c|c|}
\hline $\begin{array}{l}\text { Fluid/Flow } \\
\text { Parameter }\end{array}$ & $\begin{array}{l}\text { Water } \\
\text { Skid } \\
\text { Inlet } \\
(1)\end{array}$ & $\begin{array}{l}\text { Water } \\
\text { Skid } \\
\text { Outiet } \\
\text { (2) }\end{array}$ & $\begin{array}{c}\text { PPP } \\
\text { Water } \\
\text { Supply } \\
\text { Line } \\
(3) \\
\end{array}$ & $\begin{array}{c}\text { P-350 } \\
\text { Intemal } \\
\text { Flush } \\
\text { Line } \\
(4)\end{array}$ & $\begin{array}{c}\text { P-350 } \\
\text { Water } \\
\text { Dilution } \\
\text { Line } \\
(5)\end{array}$ & $\begin{array}{c}\text { P-350 } \\
\text { Waste } \\
\text { Inlet } \\
(6)\end{array}$ & $\begin{array}{c}\text { P-350 } \\
\text { Outlet } \\
(7)\end{array}$ & $\begin{array}{l}\text { Flush } \\
\text { Cross- } \\
\text { Connect } \\
(8)\end{array}$ & $\begin{array}{c}\text { Transfer } \\
\text { Line } \\
(9)\end{array}$ & $\begin{array}{l}\text { Vent } \\
\text { Line } \\
\text { (10) }\end{array}$ \\
\hline Flow Rate & - & - & $=$ & $N / A$ & N/A & $\mathrm{N} / \mathrm{A}$ & - & $N / A$ & - & - \\
\hline $\begin{array}{c}\text { Flush } \\
\text { Volume }\end{array}$ & - & - & - & N/A & N/A & N/A & - & N/A & - & - \\
\hline $\begin{array}{c}\text { Flow } \\
\text { Velocity } \\
(\mathrm{A} / \mathrm{sec})\end{array}$ & - & - & - & $N / A$ & $N / A$ & $N / A$ & - & N/A & - & - \\
\hline $\begin{array}{c}\text { Temperature } \\
\left({ }^{\circ} \mathrm{F}\right) \\
\end{array}$ & - & - & - & N/A & $\mathrm{N} / \mathrm{A}$ & N/A & - & N/A & - & - \\
\hline $\begin{array}{l}\text { Viscosity } \\
\text { (cP) }\end{array}$ & $=$ & - & - & N/A & N/A & N/A & - & N/A & - & - \\
\hline $\begin{array}{l}\text { Density } \\
(\text { yarms } / c c)\end{array}$ & - & - & $=$ & N/A & N/A & N/A & - & N/A & - & - \\
\hline $\begin{array}{c}\text { Volume \% } \\
\text { Solids }\end{array}$ & - & - & - & N/A & N/A & N/A & - & $N / A$ & - & - \\
\hline $\begin{array}{c}\text { Mass \% } \\
\text { Water } \\
\end{array}$ & - & - & - & N/A & N/A & N/A & - & N/A & $=$ & - \\
\hline $\begin{array}{l}\text { Mass \% } \\
\text { Non-Soluble } \\
\text { Solids }\end{array}$ & $\therefore$ & - & - & N/A & N/A & N/A & - & $N / A$ & - & - \\
\hline
\end{tabular}




\subsection{Equipment Descriptions}

\subsubsection{Water Support Skid}

A dedicated water supply for dilution and flushing is provided with the transfer system. The major features are two water supply pumps, a 2000-gallon supply tank, and a 75-gallon air pressurized emergency flush accumulation tank. The latter supplies the capability to flush the system in the event of loss of electrical power. Figure 2.3.1 shows a schematic of the Water Support Skid.

Figure 2.3.1 Water Support Skid

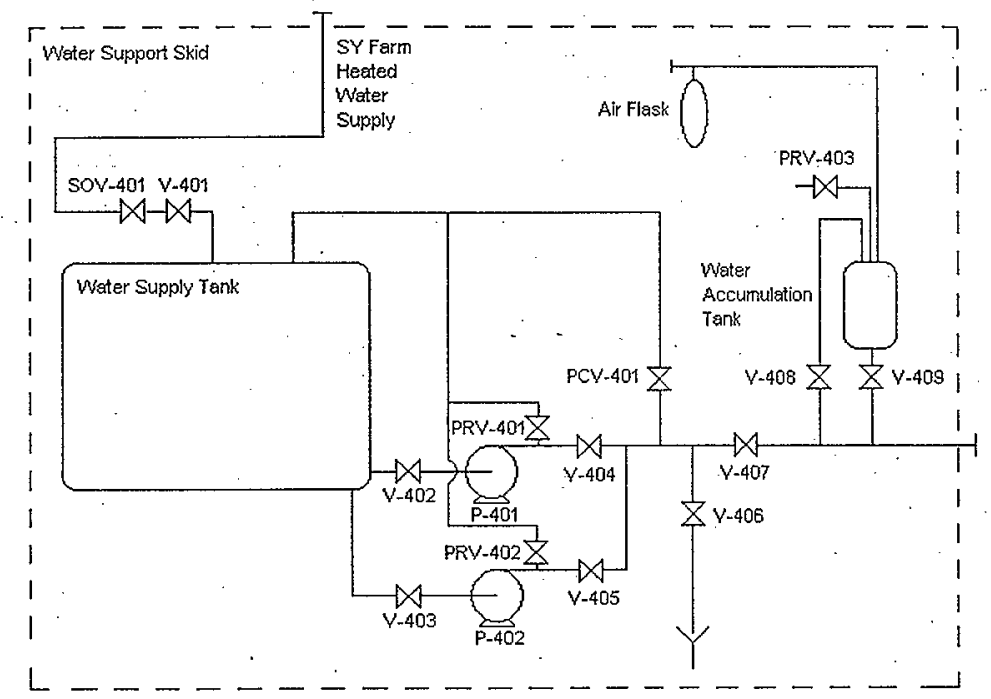


The Water Support Skid contains the process routing values listed in Table 2.3.1

Table 2.3.1: Water Support Skid Valwe Functions

\begin{tabular}{|l|l|}
\hline Valve Identifier & Description of Vaive Function \\
\hline SOV-401 & Water Supply Tank NTK-401 Solenoid Shutoff Valve \\
\hline V-401 & Water Supply Tank NTK-401 Isolation Valve \\
\hline V-402 & Water Pump P-401 Inlet Isolation Valve \\
\hline V-403 & Water Pump P-402 Inlet Isolation Valve \\
\hline PRV-401 & Water Pump P-401 Relief Valve \\
\hline V-404 & Water Pump P-401 Outlet Isolation Valve \\
\hline PRV-402 & Water Pump P-402 Relief Valve \\
\hline V-405 & Water Pump P-402 Outlet Isolation Valve \\
\hline PCV-401 & Water Supply Line Pressure Regulating Valve \\
\hline V-406 & Water Supply Line Drain Valve \\
\hline V-407 & Water Supply Line Isolation Valve \\
\hline V-408 & Emergency Flush Accumulation Tank ACC-401 Upstream Isolation Valve \\
\hline PRV-403 & Emergency Flush Accumulation Tank ACC-401 Relief Valve \\
\hline V-409 & Emergency Flush Accumulation Tank ACC-401 Downstream Isolation Valve \\
\hline
\end{tabular}

During steady-state dilution flow operation the water skid is capable of providing water skid is capable of providing water at $110^{\circ} \mathrm{F}$ to $130^{\circ} \mathrm{F}$. The maximum flow rate of $70 \mathrm{gpm}$ is specified. This flow rate can be maintained for the duration required to accomplish the specified transfer of 100 to $150 \mathrm{kgal}$ of tank 241 SY-101 waste.

The design of the water support skid ensures that in the event of a component failure, no more than 2000 gallons of raw water could be added to either tank 241-SY-101 or 241-SY-102. Upon a loss of electric power, the air pressurized water flush accumulation tank provides a means to clear the process lines of waste slurry. 


\subsubsection{Tank 241-SY-101 Prefabricated Pump Pit (PPP) and NGTP (P-350)}

The PPP at tank 241-SY-101 contains waste and water supply routing valves for the transfer system, various instrumentation, and the mounting for the P-350. The PPP also provides for a drain, seal loop, and system high-point vent as a siphon break, which return to tank 241-SY-101. The PPP is capable of operating with a drain flow rate of $20 \mathrm{gpm}$. A representation of the PPP and P-350 is shown in Figure 2.3.2.

Figure 2.3.2: Prefabricated Pump Pit and P-350

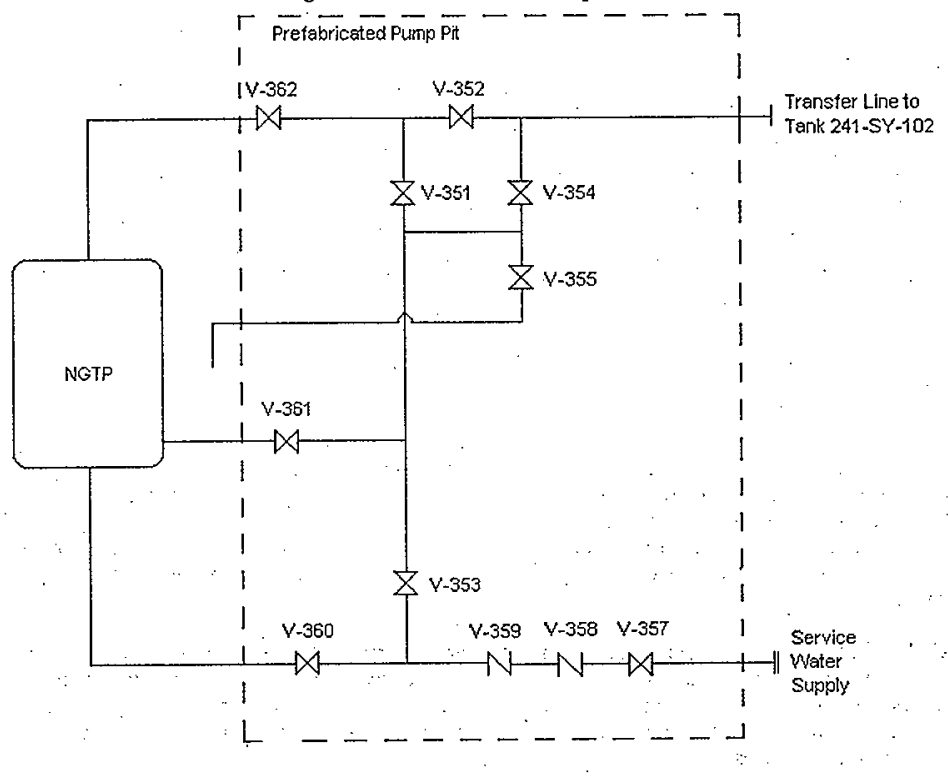

The PPP contains the process routing values listed in Table 2.3.2

Table 2.3.2: PPP Valve Functions

\begin{tabular}{|l|l|}
\hline Valve Identifier & Description of Valve Function \\
\hline V-351 & Transfer Line Flush Isolation Valve \\
\hline V-352 & Transfer Line Isolation Valve \\
\hline V-353 & Flush Water Isolation Valve \\
\hline V-354 & Upstream Vacuum Break Valve \\
\hline V-355 & Downstream Vacuum Break Valve \\
\hline V-357 & Upstream Service Water Isolation Valve \\
\hline V-358 & Upstream Service Water Check Valve \\
\hline V-359 & Downstream Service Water Check Valve \\
\hline V-360 & Downstream Service Water Isolation Valve \\
\hline V-361 & P-350 Internal Flush Isolation Valve \\
\hline V-362 & P-350 Dilution Water IsolationValve \\
\hline
\end{tabular}




\subsubsection{Waste Transfer line}

The waste transfer line is an overground, 2 in $\mathrm{DD}$, armored hose conveying system wastes at velocities of 6 $\mathrm{ft} / \mathrm{sec}(60 \mathrm{gpm})$ or greater. The transfer line incorporates bends with radii no less than five line diameters to minimize flow disruptions and associated probability of solids deposition. The pipeline is approximately $125 \mathrm{ft}$ long, the slope of $1 / 33$ to $1 / 16$.

\subsubsection{Tank 241-SY-102 Drop leg}

A submerged drop leg at tank 241-SY-102 is incorporated to minimize SY-Farm ventilation system ammonia and VOC concentrations. This device is known as the anti-siphoning slurry distributor (ASSD). The primary purpose of the ASSD is to minimize the direct contact of tank 241-SY-101 convective wastes with tank atmosphere. This purpose was indicated as justified based on ammonia characterization information for tank 24I-SY-10] wastes (101-SY TCR) and engineering analysis of subsequent waste ammonia behavior when cxposed to a tank atmosphere (Hedengren 1999). Minimizing the direct contact of the tank 241-SY-101 wastes with the air minimizes the mass transfer of ammonia from the waste slurry. to the tank atmosphcrc. Additionally, by submerging the dropleg discharge, the ammonia in the transferred wastes will seek $10 \mathrm{entcr}$ liquid phase equilibria with the large amount of aqueous tank 24I-SY-102 supernate. By being ripudly absorbed into this supemate, the probability of large, immediate ammonia releases from tank $241.51 \cdot 102$ will be minimized.

Along with its priman function, the design of the ASSD incorporates other performance enhancing features.

The drop leg disclarge design injects the transferred wastes into tank 241-SY-102 horizontally at a depth of 160 inches. To accomplish this, the drop leg outlet has openings in the horizontal direction, diverting the flow from the axial to the radial direction in the tank. This design and location minimizes the probability of disturbing the presently settled solids of high TRU activity while providing reasonable mixing of the incoming wastes considering the waste volumes and flow rates involved. The horizontal openings at the discharge are sized to maintain a total flow cross-sectional area at least equivalent to that of the 2 inch transfer line.

The ASSD also serves as a siphon break device for the transfer system. At the top of the 4 inch dropleg, the diameter transitions to 2 inches through a nozzle. In the vicinity of the nozzle are a number of siphonbreak holes in the 4-inch pipe. The combination of the hole location and the nozzle provides for a vacuum break to prevent tank-to-tank siphoning while minimizing the amount of process fluid entering the tank headspace through the holes.

The drop leg outlet is positioned at 160 inches for the following reasons:

The 160 " position is specified to achieve a balance between:

1) Concerns against minimizing agitation of the TRU settled solids in 102-SY while optimizing mixing of incoming 101-SY shurry with 102-SY supernate indicate the dropleg outlet should be located as high off the bottom as possible.

2) Desiring to maximize the operating volumes in 102-SY indicates a location as close to the bottom as possible. This would allow larger batch transfers out of 102-SY without exposing the dropleg nozzles to atmosphere - a situation not desired because of the ammonia issues associated with 101-SY wastes.

3) Adhering to a $160^{\prime \prime}$ minimum liquid level for 101-SY transfer satisfies Operations requirement to keep 102-SY level higher than $130 "$. 


\subsubsection{Transfer Control System}

Control of the waste transfer system is achieved by the manual positioning of the system routing values and operation of the system pumps.

The pumps are $\mathrm{P}-350$ and the water supply pumps (P-401 and $\mathrm{P}-402)$ on the Water Support Skid. Control of the water pumps is via on/off switches. P-350 incorporates a VFD so in addition to the on/off switches, the pump speed is controlled via a locked keypad.

Limited instrumentation capability is provided with the system. Mass flow/flow density capabilities are not included in the design because of the short runs of system lines and the short transit times incorporated with them severely limit the response time required to control the composition of the transfer line slurry. Cost and schedule limitations also precluded the incorporation of this sort of instrumentation. Controlling the volumetric ratio of the transfer line flowrate to the dilution water flowrate (dilution water pressure and/or valve position and/or P-350 speed) provides control of mass flow and density.

The prime operational concerns are protected by a limited system of interlocks and design features. These operational concerns and the associated interlocks/alarms/design features (shown in parenthesis) are listed below:

1) Do not to fill the transfer line with undiluted waste or water supply lines with any waste upon an electrical or mechanical failure ( protective features include (a) interlock to shutdown P350 upon detection of low dilution water flow at the farm control panel; (b) interlock to shutdown of the P-350 upon detection of high dilution water flow at the farm control panel, (c) alarm indicating high pressure upstream the flush water isolation during transfer operations; (d) two service water check valves V-358 and V-359 in the PPP; (e) the air pressurized emergency water flush tank on the water support skid)

2) Do not allow an electrical or mechanical failure to result in uncontrolled water addition to tanks 241-SY-101 or -102 (protective features include (a) 2000 gal capacity of the water skid supply tank ensures no more than this volume of water can be added to the tanks upon loss of electrical power).

Instrumentation and/or controls are provided at three locations for the transfer system. These are:

The PPP (Farm control panel) where the field operator is stationed. At this location, the PPP routing and control valves are positioned and operated, and an emergency P-350 shutdown switch is provided. Local leak detection alarms are provided for the PPP and transfer line.

The Remote control location (DACS control console) where the DACS operator is stationed. The P-350 on-off switch is located here. A summary alarm is provided for all leak detection systems.

The water skid (Water Skid control console) where another operator is stationed. This location provides the water supply valve and pump controls.

The MCC where the P-350 VFD is located and the P-350 speed is controlled/set (this location is not permanently manned). 
Table 2.3.5 Transfer System Controls, Indications, Interlocks \& Alarms

\begin{tabular}{|c|c|c|}
\hline Type & Description & Location \\
\hline \multirow[t]{4}{*}{ Control } & P-350 on/off & DCP \\
\hline & P-350 emergency shutoff & $\mathrm{FCP}, \mathrm{DCP}$ \\
\hline & P-350 speed control/setting & $\widehat{\mathrm{MCC}}$ \\
\hline & Transfer system valve position administrative control & PPP, WSS \\
\hline \multirow[t]{14}{*}{ Indication } & P-350 on/off & FCP, DCP \\
\hline & $\mathrm{P}-40 \mathrm{I} / \mathrm{P}-402$ on/off & WSCP \\
\hline & Transfer line volumetric flow indication & FCP, DCP \\
\hline & Transfer line temperature indication & FCP, DCP \\
\hline & Transfer line pressure indication & FCP \\
\hline & Service water volumetric flow indication & WSCP, FCP \\
\hline & Service water volumetric flow totalizer & WSCP, FCP \\
\hline & WSS inlet hose temperature & WSCP \\
\hline & NTK -401 temperature & WSCP \\
\hline & WSS outlet hose temperature & WSCP \\
\hline & WSS accumulator temperature & WSCP \\
\hline & Service water supply pressure at WSS & WSCP \\
\hline & Service water supply pressure at PPP & $\mathrm{FCP}$ \\
\hline & Service water supply temperature at PPP & FCP,$D C P$ \\
\hline \multirow[t]{3}{*}{ Interlock } & Service water high/low flow rate shuts down P-350 & $\mathrm{FCP}$ \\
\hline & NTK-401 low water level shuts off NTK -401 heat trace & WSS \\
\hline & & \\
\hline \multirow[t]{3}{*}{ Alarm } & PPP \& transfer line/drop leg leak detection indication & FCP, DCP, local \\
\hline & Low service water supply temperature & FCP, DCP \\
\hline & Low seal loop level & FCP, DCP \\
\hline \multirow[t]{3}{*}{$\therefore$} & PPP transfer mode V-353 leak-by pressure switch & FCP, DCP \\
\hline & NTK -401 low water level & WSCP \\
\hline & NTK-401 high water level & WSCP \\
\hline
\end{tabular}

$D C P=D A C S$ Control Panel

FCP $=$ Farm Control Panel

$\mathrm{MCC}=$ Motor Control Center

WSS $=$ Water Support Skid

WSCP $=$ Water Skid Control Panel 


\subsection{Process Control}

The transfer system valve arrangement is indicated in Figure 3.0 with the nomenclature described in Table 3.0. This listing of valves constitutes all valves in the transfer system and is used in describing the modes of operation.

Figure 3.0 Tank 241-SY-101 Transfer System Schematic

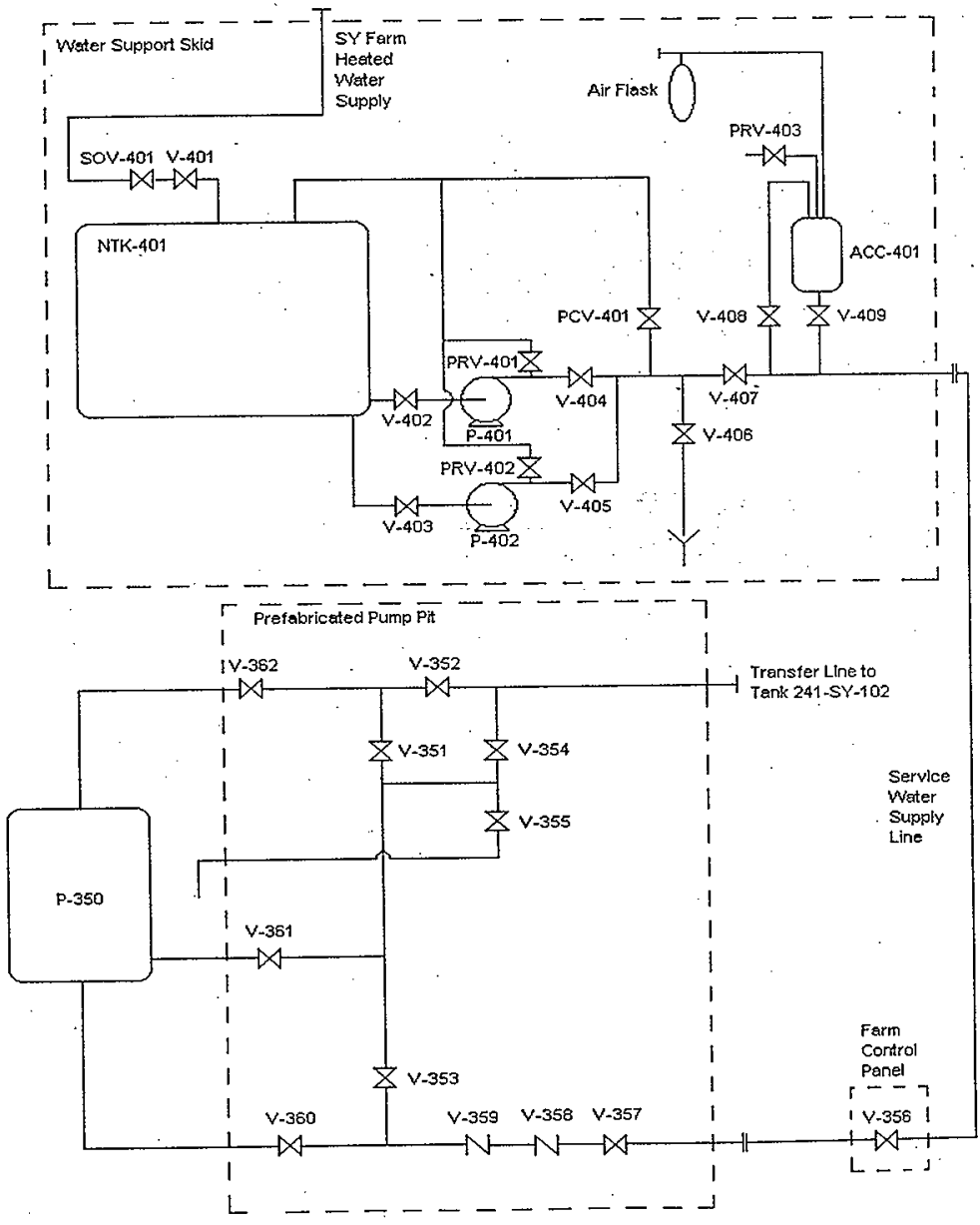


Table 3.0 Transfer System Valve Nomenclature

\begin{tabular}{|l|l|}
\hline Valve Description & Valve Function \\
\hline SOV-401 & WSS: Water Supply Tank NTK-401 Solenoid Shutoff Valve \\
\hline V-401 & WSS: Water Supply Tank NTK-401 Isolation Valve \\
\hline V-402 & WSS: Water Pump P-401 Infet Isolation Valve \\
\hline V-403 & WSS: Water Pump P-402 Inlet Isolation Valve \\
\hline PRV-401 & WSS: Water Pump P-401 Relief Valve \\
\hline V-404 & WSS: Water Pump P-40I Outlet Isolation Valve \\
\hline PRV-402 & WSS: Water Pump P-402 Relief Valve \\
\hline V-405 & WSS: Water Pump P-402 Outlet Isolation Valve \\
\hline PCV-401 & WSS: Water Supply Line Pressure Regulating Valve \\
\hline V-406 & WSS: Water Supply Line Drain Valve \\
\hline V-407 & WSS: Water Supply Line Isolation Valve \\
\hline V-408 & WSS: Emergency Flush Accumulation Tank ACC-401 Upstream Isolation Valve \\
\hline PRV-403 & WSS: Emergency Flush Accumulation Tank ACC-401 Relief Valve \\
\hline V-409 & WSS: Emergency Flush Accumulation Tank ACC-401 Downstream Isolation Valve \\
\hline V-351 & PPP: Transfer Line Flush Isolation Valve \\
\hline V-352 & PPP: Transfer Line Isolation Valve \\
\hline V-353 & PPP: Flush Water Isolation Valve \\
\hline V-354 & PPP: Upstream Vacuum Break Valve \\
\hline V-355 & PPP: Downstream Vacuum Break Valve \\
\hline V-356 & FCP: Service Water Throttle Valve \\
\hline V-357 & PPP: Upstream Service Water Isolation Valve \\
\hline V-358 & PPP: Upstream Service Water Check Valve \\
\hline V-359 & PPP: Downstream Service Water Check Valve \\
\hline V-360 & PPP: Downstream Service Water Isolation Valve \\
\hline V-361 & PPP: P-350 Internal Flush Isolation Valve \\
\hline V-362 & PPP: P-350 Dilution Water IsolationValve \\
\hline
\end{tabular}


3.1 System Operational Configurations

\subsubsection{System Vent}

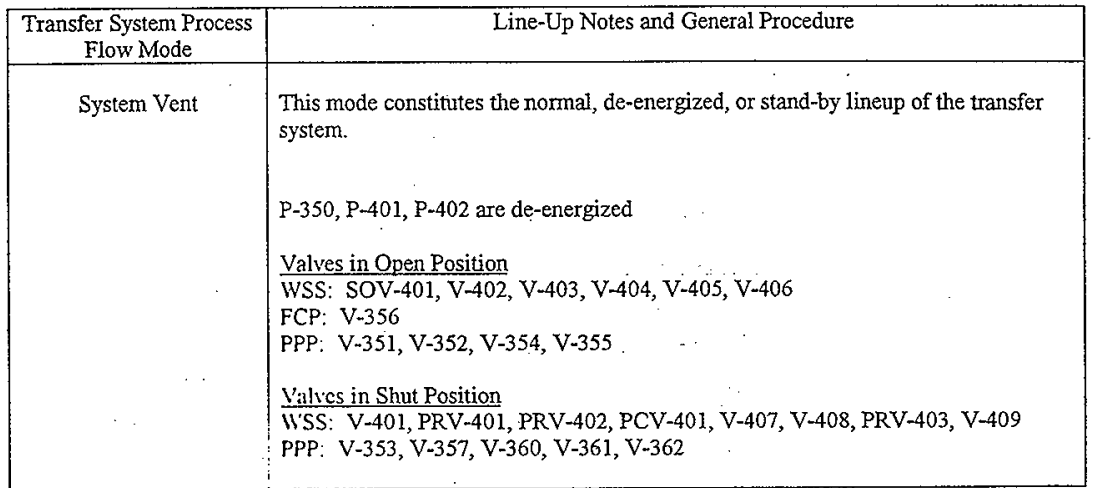

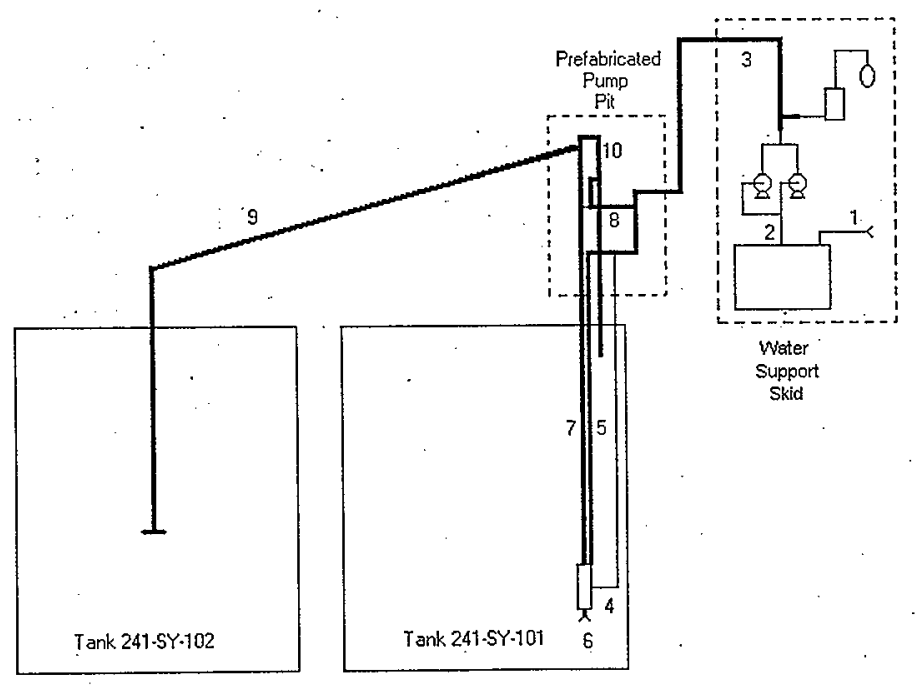




\subsubsection{Normal Transfer Line Flush or Preheat}

\begin{tabular}{|c|c|}
\hline $\begin{array}{c}\text { Transfer System Process } \\
\text { Flow Mode } \\
\end{array}$ & Line-Up Notes and General Procedure \\
\hline $\begin{array}{l}\text { Normal Transfer Line } \\
\text { Flush or Preheat }\end{array}$ & $\begin{array}{l}\text { This mode is established immediately prior to or immediately following waste } \\
\text { transfer operations, to either flush or pre-heat system lines. } \\
\text { P-350 is de-energized } \\
\text { P-401 and/or P-402 are energized and running as necessary to provide flush water } \\
\text { pressure/flow rate as needed. } \\
\text { Valves in Open Position } \\
\text { WSS: SOV-401, V-401, V-402, V-403, V-404, V-405, V-407 } \\
\text { FCP: V-356 } \\
\text { PPP: V-352, V-353, V-357, V-360 } \\
\text { Valves in Shut Position } \\
\text { WSS: PRV-401, PRV-402, PCV-401, V-406, V-408, PRV-403, V-409 } \\
\text { PPP: V-351, V-354, V-355, V-361, V-362 }\end{array}$ \\
\hline
\end{tabular}

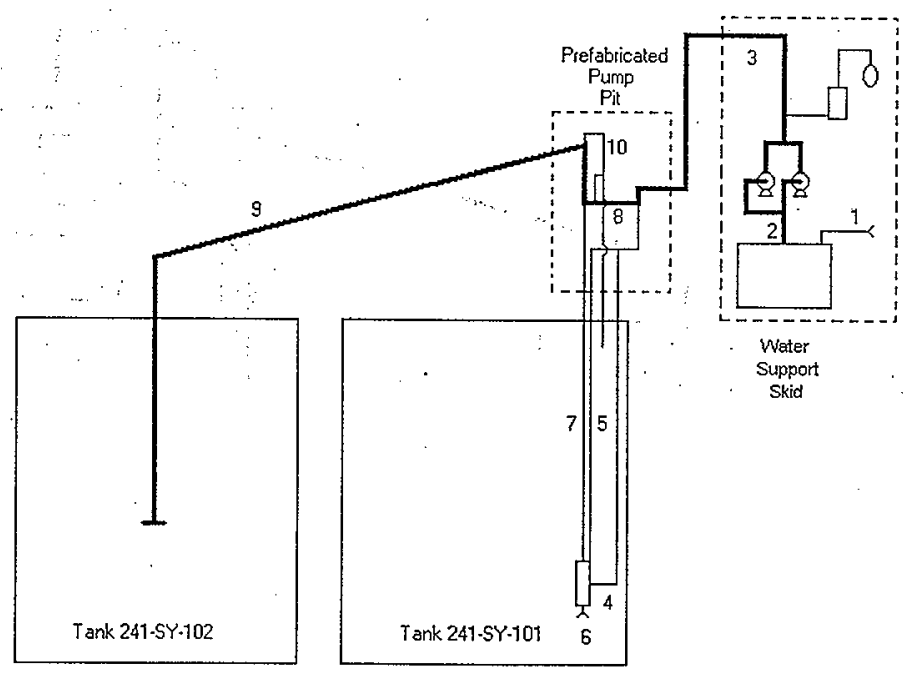


3.1.3 Normal P-350 Outlet Line Flush or Preheat

\begin{tabular}{|c|c|}
\hline $\begin{array}{c}\text { Transfer System Process } \\
\text { Flow Mode }\end{array}$ & Line-Up Notes and General Procedure \\
\hline $\begin{array}{l}\text { Normal P-350 Outlet } \\
\text { Line Flush } \\
\text { Or Preheat }\end{array}$ & $\begin{array}{l}\text { This mode is established immediately prior to or immediately following waste } \\
\text { transfer operations, to either flush or pre-heat system lines. } \\
\text { P-350 is de-energized } \\
\text { P-401 and/or P-402 are energized and running as necessary to provide flush water } \\
\text { pressure } \\
\text { Valves in Open Position } \\
\text { WSS: SOV-401, V-401, V-402, V-403, V-404, V-405, V-407 } \\
\text { FCP: V-356 } \\
\text { PPP: V-351, V-353, V-357, V-360 } \\
\text { Valves in Shut Position } \\
\text { WSS: PRV-401, PRV-402, PCV-401, V-406, V-408, PRV-403, V-409 } \\
\text { PPP: V-352, V-354, V-355, V-361, V-362 }\end{array}$ \\
\hline
\end{tabular}

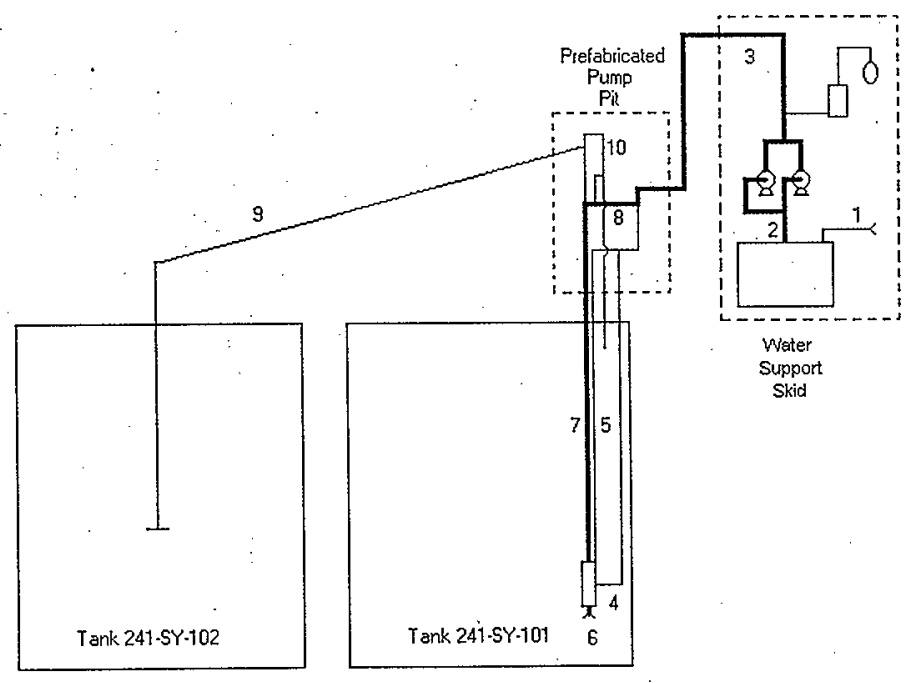




\subsubsection{Normal P-350 Dilution Line Flush or Preheat}

\begin{tabular}{|c|c|}
\hline $\begin{array}{c}\text { Transfer System Process } \\
\text { Flow Mode }\end{array}$ & Line-Up Notes and General Procedure \\
\hline $\begin{array}{l}\text { Normal P-350 Dilution } \\
\text { Line Flush Or Preheat }\end{array}$ & $\begin{array}{l}\text { This mode is established immediately prior to or immediately following waste } \\
\text { transfer operations, to either flush or pre-lieat system lines. } \\
\text { P-350 is de-energized } \\
\text { P-401 and/or P-402 are energized and running as necessary to provide flush water } \\
\text { pressure } \\
\text { Valves in Open Position } \\
\text { WSS: SOV-401, V-401, V-402, V-403, V-404, V-405, V-408 } \\
\text { FCP: V-356 } \\
\text { PPP: V-357, V-362 } \\
\text { Valves in Shut Position } \\
\text { WSS: PRV-401, PRV-402, PCV-401, V-406, V-408, PRV-403, V-409 } \\
\text { PPP: V-351, V-352, V-353, V-354, V-355, V-360, V-361 }\end{array}$ \\
\hline
\end{tabular}

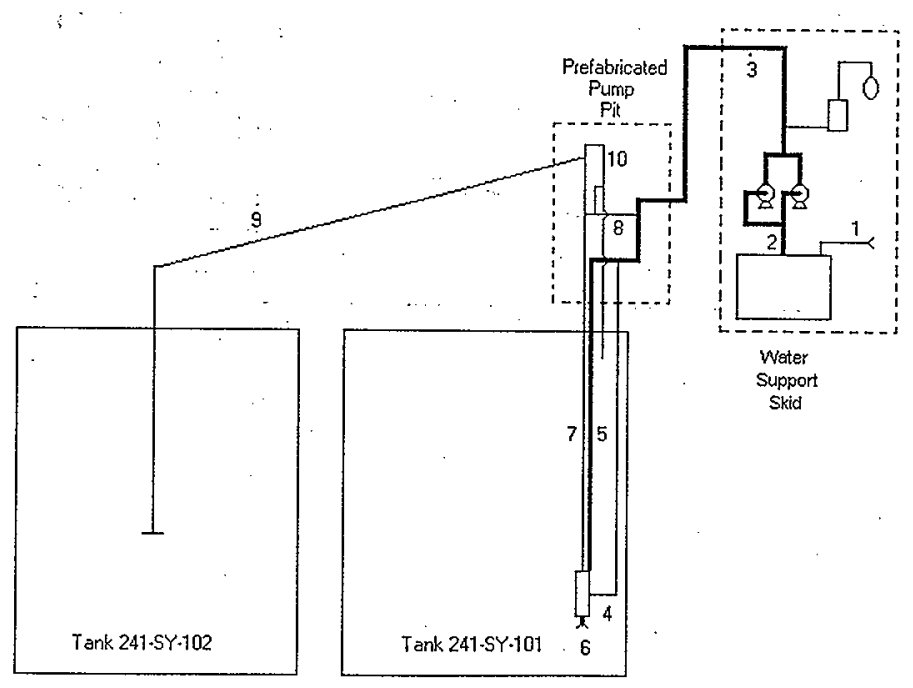




\subsubsection{Normal Vent Header Flush to Tank 241-SY-101}

\begin{tabular}{|l|l|}
\hline $\begin{array}{l}\text { Transfer System Process } \\
\text { Flow Mode }\end{array}$ & \multicolumn{1}{|c|}{ Line-Up Notes and General Procedure } \\
$\begin{array}{l}\text { Normal Vent Header } \\
\text { Flush to Tank } \\
241-S Y-101\end{array}$ & $\begin{array}{l}\text { This mode is used to clear the system vent line of potential contamination with } \\
\text { outlet to tank 241-SY-101. } \\
\text { P-350 is de-energized }\end{array}$ \\
& $\begin{array}{l}\text { P-401 and/or P-402 are energized and nunning as necessary to provide flush water } \\
\text { pressure }\end{array}$ \\
& $\begin{array}{l}\text { Valves in Open Position } \\
\text { WSS: SOV-401, V-402, V-403, V-404, V-405, V-406 } \\
\text { FCP: V-356 } \\
\text { PPP: V-351, V-352, V-355, V-357, V-360 }\end{array}$ \\
& $\begin{array}{l}\text { Valves in Shut Position } \\
\text { WSS: V-401, PRV-401, PRV-402,PCV-401, V-407, V-408, PRV-403, V-409 } \\
\text { PPP: V-353, V-354, V-361, V-362 }\end{array}$ \\
\hline
\end{tabular}

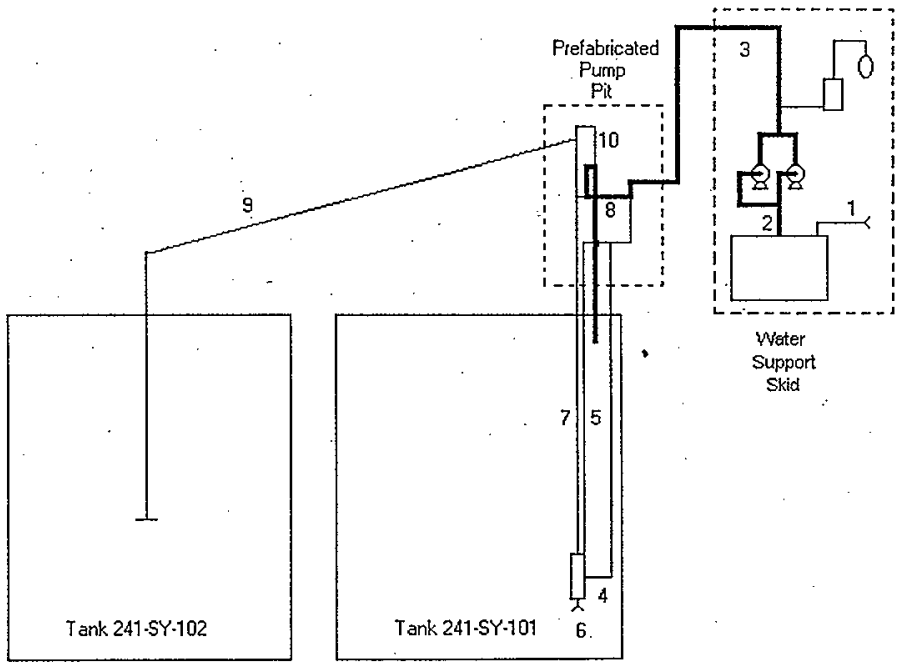




\subsubsection{Normal Vent Header Fiush to Transfer Line}

\begin{tabular}{|l|l|}
\hline $\begin{array}{l}\text { Transfer System Process } \\
\text { Flow Mode }\end{array}$ & \multicolumn{1}{|c|}{ Line-Up Notes and General Procedure } \\
$\begin{array}{l}\text { Normal Vent Header } \\
\text { Flush to Transfer Line }\end{array}$ & $\begin{array}{l}\text { This mode is used to clear the system vent line of potential contamination with } \\
\text { routing to tank 241-SY-102 via the transfer line. } \\
\text { P-350 is de-energized }\end{array}$ \\
& $\begin{array}{l}\text { P-401 and/or P-402 are energized and running as necessary to provide flush water } \\
\text { pressure }\end{array}$ \\
& $\begin{array}{l}\text { Valves in Open Position } \\
\text { WSS: SOV-401, V-402, V-403, V-404, V-405, V-406 } \\
\text { FCP: V-356 } \\
\text { PPP: V-351, V-352, V-354, V-357, V-360 } \\
\\
\text { Valves in Shut Position } \\
\text { WSS: V-401, PRV-401, PRV-402, PCV-401, V-407, V-408, PRV-403, V-409 } \\
\text { PPP: V-353, V-355, V-361, V-362 }\end{array}$ \\
\hline
\end{tabular}

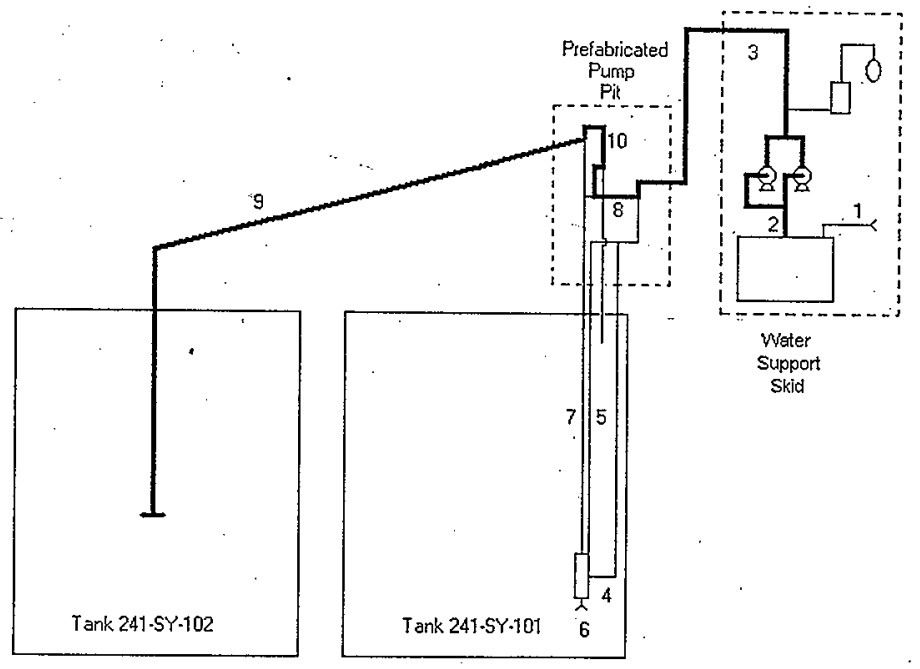




\subsubsection{Normal P-350 Internal Flush}

\begin{tabular}{|c|c|}
\hline $\begin{array}{c}\text { Transfer System Process } \\
\text { Flow Mode } \\
\end{array}$ & Line-Up Notes and General Procedure \\
\hline $\begin{array}{l}\text { Normal P-350 Internal } \\
\text { Flush }\end{array}$ & $\begin{array}{l}\text { This mode is established immediately following P-350 operations in accordance } \\
\text { with manufacturer recommendations. } \\
\text { P-350 is de-energized } \\
\text { P-401 and/or P-402 are energized and running as necessary to provide flush water } \\
\text { pressure } \\
\text { Valves in Open Position } \\
\text { WSS: SOV-401, V-402, V-403, V-404, V-405, V-406 } \\
\text { FCP: V-356 } \\
\text { PPP: V-357, V-360, V-361 } \\
\text { Valves in Shut Position } \\
\text { WSS: PRV-401, PRV-402, PCV-401, V-406, V-408, PRV-403, V-409 } \\
\text { PPP: V-351, V-352, V-353, V-354, V-355, V-362 }\end{array}$ \\
\hline
\end{tabular}

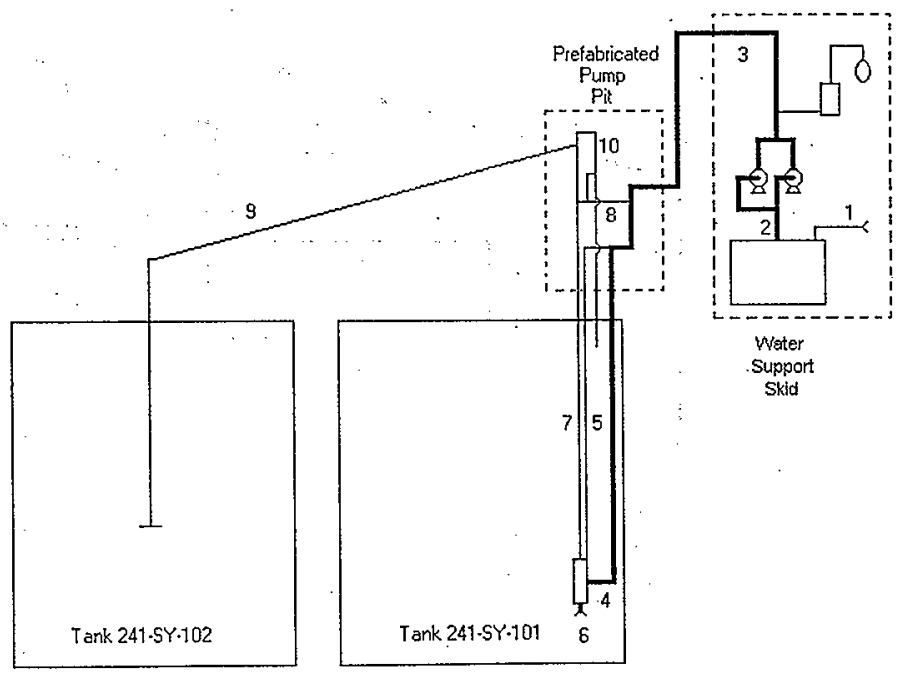




\subsubsection{Emergency Transfer Line Flush}

\begin{tabular}{|c|c|}
\hline $\begin{array}{c}\text { Transfer System Process } \\
\text { Flow Mode }\end{array}$ & Line-Up Notes and General Procedure \\
\hline $\begin{array}{l}\text { Emergency Transfer } \\
\text { Line Flush }\end{array}$ & $\begin{array}{l}\text { This mode is established immediately upon loss of electrical power, P-350, or } \\
\text { dilution water supply. } \\
\text { P-350, P-401 and P-402 are de-energized } \\
\text { Valves in Open Position } \\
\text { WSS: SOV-401, V-401, V-402, V-403, V-404, V-405, V-409 } \\
\text { FCP: V-356 } \\
\text { PPP: V-352, V-353, V-357, V-360 } \\
\text { Valves in Shut Position } \\
\text { WSS: PRV-401, PRV-402, PCV-401, V-406, V-407, V-408, PRV-403 } \\
\text { PPP: V-351, V-354, V-355, V-361, V-362 }\end{array}$ \\
\hline
\end{tabular}

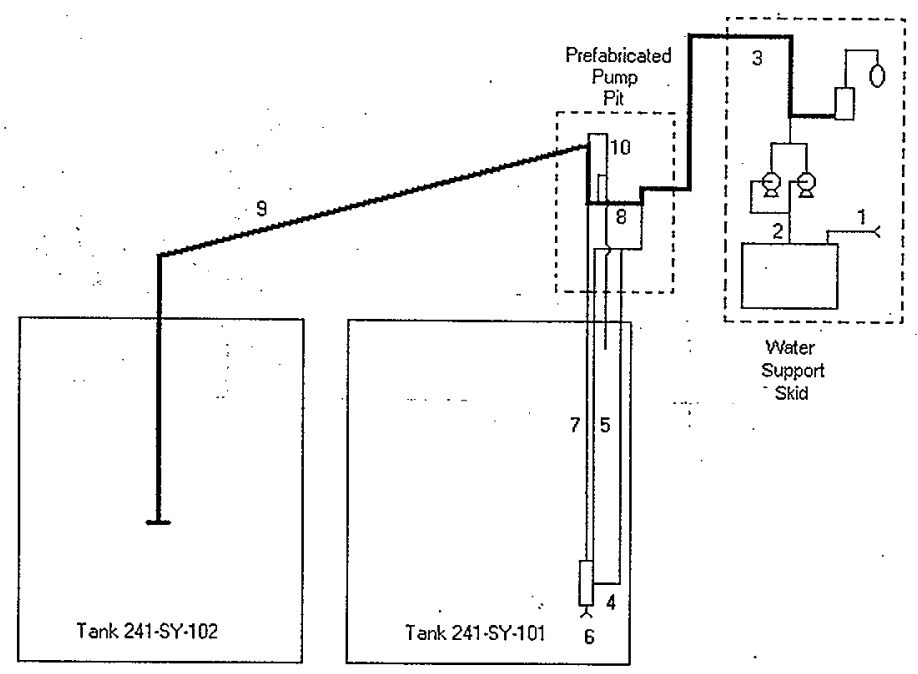




\subsubsection{Emergency P-350 Outlet Line Flush}

\begin{tabular}{|c|c|}
\hline $\begin{array}{c}\text { Transfer System Process } \\
\text { Flow Mode }\end{array}$ & Line-Up Notes and General Procedure \\
\hline $\begin{array}{l}\text { Emergency P-350 Outlet } \\
\text { Line Flush }\end{array}$ & $\begin{array}{l}\text { This mode is established immediately prior to or immediately following waste } \\
\text { transfer operations, to either flush or pre-heat system lines. } \\
\text { P-350, P-401 and P-402 are de-energized } \\
\text { Valves in Open Position } \\
\text { WSS: SOV-401, V-401, V-402, V-403, V-404, V-405, V-409 } \\
\text { FCP: V-356 } \\
\text { PPP: V-351, V-353, V-357, V-360 } \\
\text { Valves in Shut Position } \\
\text { WSS: V-351, V-354, V-355, V-361, V-362 } \\
\text { PPP: V-352, V-354, V-355, V-361, V-362 }\end{array}$ \\
\hline
\end{tabular}

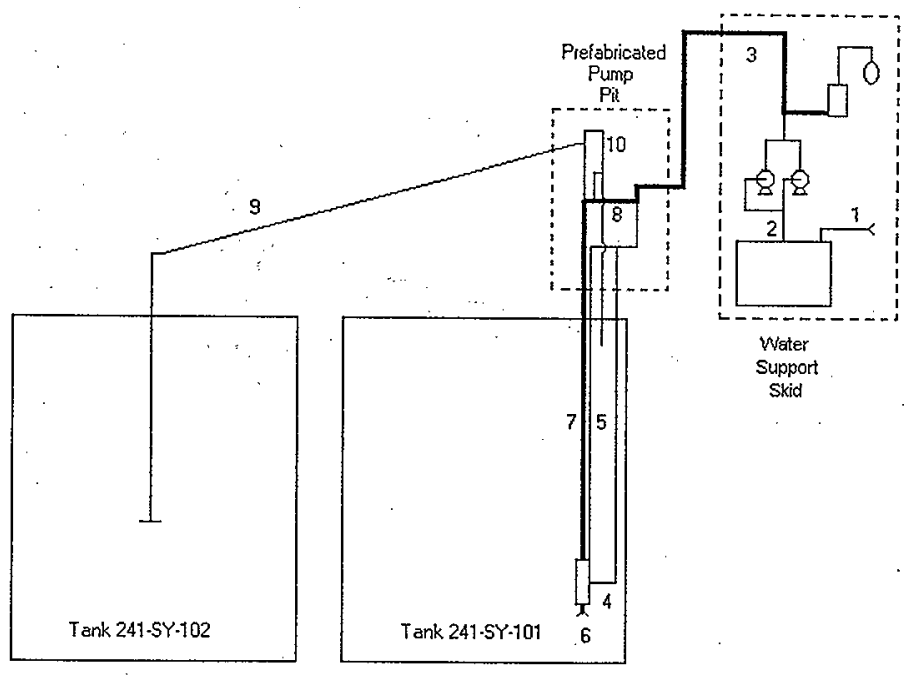




\subsubsection{Normal Waste Transfer}

\begin{tabular}{|c|c|}
\hline $\begin{array}{c}\text { Transfer System Process } \\
\text { Flow Mode }\end{array}$ & Line-Up Notes and General Procedure \\
\hline Normal Waste Transfer & $\begin{array}{l}\text { This mode is used to generate, control, and transfer waste slurry from tank } 241-S Y \text { - } \\
101 \text { to tank } 241-S Y-102 \text {. } \\
\text { P-350 is energized and tunning as necessary to provide a specified volumetric flow } \\
\text { rate through the transfer line. } \\
\text { P-401 and/or P-402 are energized and nunning as necessary to provide dilution } \\
\text { water flow to the P-350 inlet. } \\
\text { Valves in Open Position } \\
\text { WSS: SOV-401, V-4012, V-402, V-403, V-404, V-405, V-407 } \\
\text { FCP: V-356 } \\
\text { PPP: V-351, V-352, V-357, V-362 } \\
\text { Valves in Shut Position } \\
\text { WSS: PRV-401, PRV-402, PCV-401, V-406, V-408, PRV-403, V-409 } \\
\text { PPP: V-353, V-354, V-355, V-360, V-361 }\end{array}$ \\
\hline
\end{tabular}

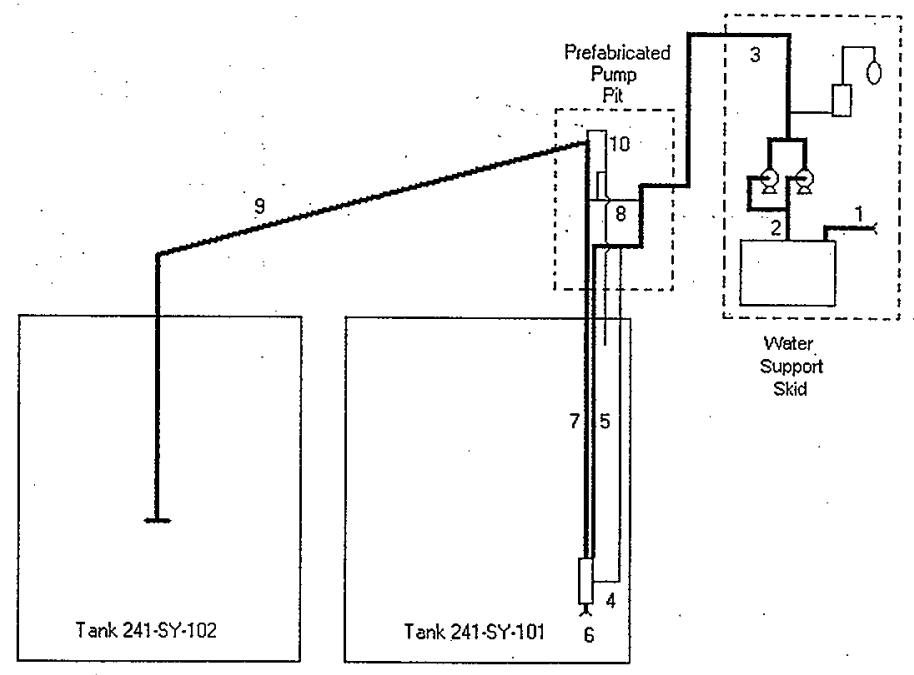




\subsection{Process Control Issues}

The operational limit of tank 241-SY-101 is 406 inches and the projected level after the $100 \mathrm{kgal}$ transfer is approximately 420 inches - well above the 406 -inch level. The $100,000 \mathrm{kgal}$ value comes from the desire to reduce the level by 36 inches, to avoid filling the tank to a level above the primary/ secondary tank interface. The $100 \mathrm{kgal}$ waste transfer is specified for three reasons:

1) $100 \mathrm{kgal}$ is about the largest transfer without untoward impacts on DST operational volume and planning

2) $100 \mathrm{kgal}$ represents about a $10 \%$ volume reduction allowing a $10 \%$ water back-dilution. Current thinking holds that this should be enough to dissolve the crust and eliminate gas retention problem.

3) Any more than $100 \mathrm{kgal}$ for the transfer system will create interference problems between the crust and the P-350 inlet

It is currently estimated that the in-situ viscosity of the convective wastes in tank 241-SY-101 are expected to be in the range of $5010200 \mathrm{cP}$ at a 50 per second shear rate. Although the P-350 would have the most versatility if the inlet were placed as low in the tank as possible. However, concerns about the physical properties of settled solids in this tank and uncertainties about corresponding waste viscosities has dictated placing the pump inlct well above the settled solids layer in the well mixed convective regions of the waste at an elevation of $8 \mathrm{n}$ abovc tank bottom.

The removal of l(K) kpil of waste from tank 241-SY-101 wills both reduce the heat load in the tank while increasing the surfice area to volume ratio of the waste contained in the tank. Both of these effects work to lower the bulk waste icmporaturcs in the tank. The result of such a temperature reduction, in the absence of any water dilution. may be to precipitate additional salts resulting in additional crust growth, potentially negating the bencfit of the waste removal. This issue has been analyzed (Antoniak 1998). Results show that initially, the removal of $100 \mathrm{kgal}$ of waste should lower the bulk temperature of the tank wastes by $5^{\circ} \mathrm{F}$. Additionally, removal of $150 \mathrm{kgal}$ of waste from the tank should cause the precipitation of solids might amount to the equivalent of 18 inches of waste depth, but that the convective waste temperature would be largely unaffected. Additional operational actions will serve to alleviate concerns over additional solids precipitation. Back dilution is specified as the next step in remediation activities for this tank, and it is known that the affects of planned water dilution greatly outweigh the opposing physical effects of cooling of tank wastes (Conner 1999; Reynolds 1998). Further reduction of tank 241-SY-101heat-loss rate via reduction of the tank annulus ventilation rate remains a viable option.

The waste transfer controls for the transfer system have been identified (Krips, 1999). New controls have been identified as requiring four TSR revisions, designation of one new safety class and a few new safety significant pieces of equipment, and the application of some existing TSR controls to the transfer activity. Analyzed accidents include various flammable gas deflagration scenarios, spray leaks from transfer system structures or the overground transfer line, surface leaks resulting in a pool. Identified safety structures, systems, and components include:

- Tank 241-SY-101 level monitoring systems

- Tank 241-SY-101 level detection system

- Service water flow totalizer

- Transfer line flow monitoring system

- Instrumentation required to implement new Tank 241-SY-101 Waste Transfer Controls

- The PPP

- The over ground transfer line encasement and connections

- The drop leg enclosure on riser 241-SY-102-007.

The TSRs were specified as required revisions to ACs 5.9 (Tank 241-SY-101 Mixer Pump Performance), 5.10 (Ignition Controls), 5.11 (Flammable Gas Monitoring Controls), and 5.12 (Tank 241-SY-101 Waste Transfer Controls). In specific to tank 241-SY-101 waste transfer activities, these AC revisions include:

- Identifying when mixer pump hydrogen and ammonia controls are applicable 
- Define the termination of activities upon detection of a high hydrogen or ammonia concentration to include all waste intrusive activities including water addition, activities in the dome space, and activities anywhere in the SY-Farm

- Monitor tank 241-SY-101 mixer pump performance for signs that changing tank waste conditions may degrade its safety function, and if this degradation is due to cnist interference, add water to the tank

- The maximum waste transfer permitted from the tank is that which would result in a one-foot separation between the mixer pump inlet and the bottom of the crust. This requirement entails an orchestration of multiple measurement uncertainties and waste behavior estimations.

- The PPP, the over ground transfer line encasement and connections, and the drop leg enclosure all constitute physical barriers that function to confine leakage, limit aerosol emissions, and route leakage back to the waste tanks.

Newly identified defense-in-depth controls are limited to video camera monitoring of tank 241-SY-101 waste when remediation-related, waste intrusive activities are involved, and to control the water addition temperature within the specified $110^{\circ} \mathrm{F}$ to $130^{\circ} \mathrm{F}$ band.

\subsubsection{Control of Slurry Transfer}

The primary operational concern of the transfer system is to prevent line plugging due to inadvertent cooling of undiluted waste within the system transfer lines. The transfer system incorporates multiple features to protect against this occurrence:

1) Heat tracing on the Water Support Skid and the overground transfer line to protect against temperature induced solids precipitation within transfer lines.

2) Multiple temperature indication incorporated throughout the transfer system.

3) Maximum permitted water flow rates based upon support infrastructure heating capabilities.

4) Heated water dilution and flush capabilities to either protect against the insertion of saturated salt solutions in system transfer lines - or - to remove these solution immediately should an upset condition introduce them to the transfer lines.

5) An emergency, air powered, 75 gallon heated water flush accumulation tank to provide flush capability to the system should a loss of electric power occir.

6) Water supply line and waste transfer line magnetic flow meters providing volumetric flow indication. These flow rates are the primary indication of the dilution ratio achieved within the P-350 and are the primary operational control parameters. P-350 pump speed, transfer control valve positions, and the Water Support Skid regulation pressure are all adjusted to maintain the desired waste transfer and dilution water supply flow rates.

Operationally, the primary objective is achieved by diluting tank 241-SY-101 wastes with heated water and controlling the dilution ratio (flow rate of dilution water/flow rate of undiluted waste). The design of the P350 assures that the dilution ratio is expressed by:

$$
\begin{aligned}
& D R=\frac{T F}{D F}=\frac{(S F-D F)}{D F} \\
& \mathrm{DR}=\text { dilution ratio } \\
& \mathrm{TF}=\text { tank } 241-\mathrm{SY}-101 \text { waste flow rate } \\
& \mathrm{DF}=\text { dilution water flow rate } \\
& \mathrm{SF}=\text { slurry flow rate }
\end{aligned}
$$

During steady state transfer operations, the value of $D R$ is maintained in the range of 0.5 to 2.0 . The 2.0DR limit has signiffcant short-term implications since violating this limit produces the immediate zesult of filling the transfer line with concentrated salt solution. This is undesired since conceivable upset conditions could result in solids precipitation and potential plugging of the transfer line. The 0.5-DR limit is not as time critical as the low-end limit since this results in the addition of unneeded volume into the DST system. 
During start-up and shutdown of the transfer system, the high end of the steady-state DR range must be exceeded. In fact, immediately at the point of intended P-350 start/stop, the value of DR must be in the tange of $0 \leq D R \leq 0.5$. This range is achieved by ensuring that the $P-350$ outlet flow rate is less than the dilution water flow rate (SF $<D F$ ) at P-350 start-up or shut down. When shutting down the P-350, the DR value, as close to 0,0 as possible, must be maintained for a sufficient period of time. This time period should constitute a few tens of seconds and will ensure that the transfer lines contain essentially infinitely diluted waste (i.e., water). A DR value of 0.0 is achieved when $S F=D F$.

\subsubsection{Operational Control Devices}

\section{Control of Flush Water Flow to PPP}

- WSS outlet pressure regulation valve V-9

- FCP service water throttle valve V-356

\section{Control of Dilution Water Flow to PPP}

- WSS outlet pressure regulation valve V-9

- FCP service water throttle valve V-356

Control of Transfer Line Flow

- P.350 VFD.

\subsubsection{Operational Monitoring Parameters}

Flush Water Flow Rate to PPP

Service Water Line Magnetic Flow Meter

- Primary: FCP Indication FI-374A

- Secondary: DCP Indication FI-367B

Service Water Line Flow Temperature

- Primary: FCP Indication TI-373A

- Secondary: DCP Indication TI-373B

Service Water Line Supply Pressure: FCP Indication PI-372

\section{Control of Dilution Water Flow to PPP}

Service Water Line Magnetic Flow Meter

- Primary: FCP Indication FI-374A

- Secondary: DCP Indication FI-367B

Service Water Line Flow Temperature

- Primary: FCP Indication TI-373A

- Secondary: DCP Indication TI-373B

Service Water Line Supply Pressure: FCP Indication PI-372

Control of Transfer Line Flow

Transfer Line Magnetic Flow Meter

- Primary: FCP Indication FI-367A

- Secondary: DCP Indication FI-367B 
P-350 Outlet Flow Temperature

- Primary: FCP Indication TI-369A

- Secondary: DCP Indication TI-369B

Transfer Line Pressure: FCP Indication PI-368

Other Control Devices and Methods

Service water volumetric flow totalizer (FQI-374)

WSS inlet hose; NFK-401; outlet hose; accumulator temperatures (TI-410, -412, -414; -415)

PPP \& transfer line/drop leg leak detection indication alarms (ANN-365, ANN-366)

Low seal loop level alarm

PPP transfer mode V+3.53 leak-by pressure alarm (ANN-370)

NTK-401 low/low-low water lcicl alarms (LAL-416/LALL-416)

NTK-401 highligh-hygh water Ievel alarms (LAH-416/LAHH-416)

ESH\&Q Ammonia ind VOC Monitoping in SY-Tank Farm

- Detection of 25 ppmin immonia or TBD ppm VOC at ground level requires mask use in-farm

- Detection of $300 \mathrm{ppm}$ ammonia or TBD ppm VOC at ground level requires transfer system shutdown

\subsection{Transfer Operations Plan}

\subsubsection{Transfer System Preheat}

Immediately prior to waste transfer operations, those portions of the transfer line that will see waste slurry are preheated by performing a heated water flush. These line sections include the transfer line and the P-. 350 outlet line. These flushes will add assurance and a smoothing effect to the line temperature profiles before the introduction of wastes.

Once the system lines have been preheated, transfer operations must begin immediately or the preheat operation must be repeated.

\subsubsection{System Startup Management Plan}

The system startup management plan or pre-operational testing accomplishes a number of goals for transfer system operations. These include

- Magnetic Flow Meter Calibration Testing

- Ammonia and VOC Emissions Testing

- Testing to Optimize System Flow Rates

Ideally, each of these objectives will be accomplished in the same series of tests.

\subsubsection{Magnetic Flow Meter (FE-367 \& FE-374) Calibration Testing}

This test serves to calibrate the transfer system magnetic flow meters (FE-367 \& FE-374) to actual system conditions. The general technique will be to compare integrated flow meter readings against actual tank 
level changes. The indicated dilution water and waste slurxy flow rates from the respective magnetic flow meters are integrated over the pump run times and calibrated against the level rise in tank 241-SY-102. Practical level measurement difficulties in tank 241-SY-101 preclude its level change from being used as a volumetric measurement.

\subsubsection{Ammonia and VOC Emissions Testing}

Ammonia is indicated as being an extensive problem for the tank 241-SY-101 transfer effort (Hedengren 1999). The estimated ammonia concentrations in tank 241-SY-101 waste, and the estimated behavior of ammonia in those wastes when exposed to air, has driven incorporation of the ASSD into the transfer system. The primary purpose of the ASSD is to minimize the direct contact of tank 241-SY-101 convective wastes with tank atmosphere.

\subsubsection{Testing to Optimize System Flow Rates}

An additional part of this test will be to set the P-350 VFD for the desired steady-state waste transfer slurry flow rate. A minimum transfer rate of $60 \mathrm{gpm}$ is needed to achieve a flow velocity of $6 \mathrm{ft} / \mathrm{sec}$. The dilution water flow can be supplied to the PPP at a rate of up to $70 \mathrm{gpm}$. While not to exceed $70 \mathrm{gpm}$, efficient operation indicates a steady state dilution water flow rate close to the high capacity limit is desired. The desired $D R$ is one part waste to one part water by volume. At a dilution water flow rate of $60 \mathrm{gpm}$, the allowed waste flow rate would range between $30 \mathrm{gpm}$ and $120 \mathrm{gpm}$ within dilution limits. This would resuit in a transfer flow rate of $90 \mathrm{gpm}$ to $180 \mathrm{gpm}$. Therefore, specifying a dilution water flow rate of 60 gpm and a transfer flow xate of $120 \mathrm{gpm}$ is a good balance between transfer efficiency and operating margin. The P-350 VFD should be set to produce a $120 \mathrm{gpm}$ flow rate at the $60 \mathrm{gpm}$ dilution water flowrate.

\subsubsection{Transfer Operations}

The transfer system is designed to be a simple system to minimize training requirements and the probability of component/interface requirements that could compromise the system's operating reliability.

\subsubsection{Transfer Start-Up}

In order to initiate a waste transfer from tank 241-SY-101 to tank 241-SY-102, the waste level in tank 241SY-102 must be greater than 180 inches ( $500 \mathrm{kgal}$ ) to limit ammonia emissions from the surface of the supernate. Additionally, upon completion of the $100 \mathrm{kgal}$ of tank 241-SY-101 waste transfer, the resulting supernate level in tank 241-SY -102 cannot exceed 270 inches (750 kgal) in order to provide reserve operational volume for ongoing salt well pumping activities. This adds the constraint that the $100 \mathrm{kgal}$ waste transfer at a nominal 1:1 water dilution cannot result in the addition of more than $250 \mathrm{kgal}$ to tank 241-SY-102,

Initiating the waste transfer operations refers to the transition from the stand-by vent condition to the normal transfer operation condition. This transition is achieved by first warning any section of system piping which, if not performed, could subject tank wastes to temperatures below $110^{\circ} \mathrm{F}$. This preheat is accomplished by performing three system flushes/preheats in rapid succession. These are:

1) Normal Transfer Line Fish or Preheat (Section 3.1.2)

2) Normal P-350 Outlet Line Flush or Preheat (Section 3.1.3)

3) Normal P-350 Dilution Line Flush or Preheat (Section 3.1.4)

Next, the Normal Waste Transfer (Section 3.1.10) is established. To do this, the dilution water flow is first started. Throttle valve V-356 at the FCP is adjusted to the desired dilution water flow rate of $60 \mathrm{gpm}$. P 350 is then started at its pre-selected speed. If needed, this speed can be adjusted to obtain the desired slurry transfer flow rate. The specifications of the transfer system that at no time during normal transfer operations can the waste transfer flow rate exceed twice the dilution water flow rate. Therefore, the slurry transfer flow rate should never exceed three times the dilution water flow rate. 


\subsubsection{Controlled Transfer Shut-Down}

A controlled system shutdown is essentially the reverse of the normal transfer start-up. The idea is to adjust dilution water and P-350 flow rates to minimize the waste concentration in the transfer line prior to stopping P-350. Once the maximum dilution has been achieved in the transfer line and P-350 has been shut down, the three standard system flushes are performed followed by placing the system in the System Vent line-up (Section 3.1.1). The flushes to be performed are:

1) Normal Transfer Line Flush or Preheat (Section 3.1.2)

2) Normal P-350 Outlet Line Flush or Preheat (Section 3.1.3

In order to minimize waste concentrations in the transfer line to shut down P-350, the dilution water flow rate is set to at least $60 \mathrm{gpm}$. Next, the speed of P-350 is slowly adjusted downwards until the transfer line flow rate is $60 \mathrm{gpm}$ (or equal to the dilution water flow rate). Once the 60-gpm transfer flow rate is achieved, purnps $\mathrm{P}-350, \mathrm{P}-401$ and/or $\mathrm{P}-402$ are stopped. At this point, the flush sequence above is performed, followed by establishing the System Vent line-up.

\subsubsection{Emergency Transfer Shut-Down and Flushing}

Emergency transfer shut down and flushing is the evolution that is serviced by ACC-401 on the WSS. This accumulator and its supporting equipment is used to respond to a major upset condition that requires the uncontrolled shut down of $\mathrm{P}-350$. This condition might result from a loss of service water, a loss of electric power, or detection of high airborne contaminant concentrations. The objective is to clear the transfer line of tanks wastes and is achieved by flushing this line to both tanks 241-SY-102 and 241-SY-101. This is achieved by establishing in the following order:

1) Emergency Transfer Line Flush (Section 3.1.8)

2) Emergency P-350 Ouflet Line Flush (Section 3.1.9)

To make the transition from normal transfer operations to these flush evolutions, the following are performed. Upon the occurrence of the necessary upset condition, immediately stop pumps P-350, P-401 and/or P-402. The FCP operator will then shut or check shut V-354, V-355, V-356, V-360, V-361, and V362. The FCP operator then opens or checks open V-351, V-352, V-353. Next the.WSCP.operator shuts $\mathrm{V}-407$ and opens $\mathrm{V}-409$. When approximately two-thirds of the ACC-401 volume has been flushed, V-409 is shut. Then the FCP operator then shuts V-352 and opens V-362. Next, the WSCP operator again opens $\mathrm{V}-409$ to flush the remaining one-third of $\mathrm{ACC}-401$ volume, followed by shutting $\mathrm{V}-409$. At this point the System Vent line-up (Section 3.1.1) is established. Subsequently, ACC-401 can be recharged to repeat emergericy flushing sequences if necessary. 


\subsection{Process Sampling Requirements and Schedule}

Since the actual transfer rate of $100 \mathrm{kgal}$ of tank $241-\mathrm{SY}-101$ should occur at $60 \mathrm{pgm}$. This means that the total transfer should be completed on the order of about 30 hours of continuous run time. Once the process has started and is running smoothly, there is no reason to shut the system down until the transfer is complete. As such, the time scale is so short that grab sampling and subsequent analysis of tank 241-SY102 wastes could not be used as a process control feature. Once the transfer is complete, or if a system. shutdown followed by significant downtime occurs due to some off-normal condition, grab sampling may be warranted. The need for such sampling and analysis may be dictated by process engineering or other oversight/management authority during actual transfer operations.

Otherwise, sampling requirements will be stated as standard grab-sample waste-compatibility analysis, both prior and subsequent to the $100-\mathrm{kgal}$ waste transfer. Such analyses will provide information on supernate compositional changes that can be related to a volume of transferred tank 241-SY-101 wastes required to effect such a composition change. 


\subsection{Off-Normal Conditions}

\subsection{Loss of Electric Power}

This concern of this condition is to minimize the probability of line plugging. In this case, the action is to manually activate the Water Support Skid water accumulation tank and perform emergency system flushing as soon as possible.

\subsection{Loss of Dilution Water}

Upon loss of dilution water supply, the low water supply pressure detected at the PPP should trip the P-350 to minimize the amount of undiluted slurry pumped into the transfer line. If this interlock does not operate properly, the operation onus is to stop the P-350 as soon as possible. This will be immediately followed by manual activation of the Water Support Skid water accumulation tank to perform emergency system flushing as soon as possible. Both of these actions are designed to minimize the probabilities of salt precipitation in the transfer line resulting in a line plug.

\subsection{Loss of P-350}

Upon loss of dilution water supply, the low water supply pressure detected at the PPP should trip the P-350 to minimize the amount of undiluted slurry pumped into the transfer line. If this interlock does not operate properly, the operation onus is to stop the P-350 as soon as possible. This will be immediately followed by manual activation of the Water Support Skid water accumulation tank to perform emergency system flushing as soon as possible. Both of these actions are designed to minimize the probabilities of salt precipitation in the transfer line resulting in a line plug.

\subsection{Excessive SY-Farm Ventilation System Ammonia or VOC Emissions}

This condition is the result of the agitation and chemical alteration of the 241-SY-101 wastes as they commingle with the wastes in tank 241-SY-102. Therefore, the recovery action will be either a controlled reduction of the rate or shutdown of 241-SY-101 waste transfer. Ideally, if a correlation between the rate of waste transfer and concentration of off gases can be demonstrated, the corrective action for an undesired gas concentration or rate of concentration change may be to reduce the rate of waste transfer. A reduction in the rate of waste transfer would be preferable to a controlled shutdown of transfer operation. A controlled shutdown is preferable to an evacuation of the tank farm with the consequent emergency shutdown of the transfer system.

\subsection{Loss of SY-Farm Primary Ventilation}

The concern here is the uncontrolled build-up of gas and vapor concentrations within the tank headspaces. . Initiating a controlled shutdown of the 241-SY-101 waste transfer will minimize this buildup.

\subsection{Loss of SY-Farm Annulus Ventilation}

The concern here is the loss of leak detection capability. Initiating a controlled shutdown of the tank 241SY-101 waste transfer minimizes consequences.

\subsection{Transfer Line Leak}

Responses to this condition may be dictated by the severity of the leak. A primary safety concern will be to minimize the amount of a potential environmental release. Upon detection of a small-contained leak, a controlled shutdown of the waste transfer system with subsequent water flushes will be specified. Upon a major leak or line break, an immediate P-350 shutdown is desired. 


\subsection{Transfer Line Plug}

Recovery from pipeline plugging will utilize heated, pressurized water. Water pressure is gradually cycled on the plug. The slow nature of the pressure cycling prevents packing of the plug. The reapplication of the heated water increases the driving force for dissolution of soluble solids. The pressure can be cycled up to the system rating. If the plug is not immediately removed, the effect is to eventually create a small flow path through the solids plug. Eventually, the flow path will be enlarged through erosion and or dissolution, and the plug should fail under the applied pressure, clearing the line.

This pressurized, heated water can be supplied by either the normal water supply pumps (P-401/-402), or the air pressurized water accumulation tank (ACC-1). Both sources can cycle water pressure to a plug. In the case of the water supply pumps, this can be accomplished with the pressure control valve PCV-401, or for ACC-1, by recharging its air flask. The PPP valve arrangement is such as to allow pressure to be applied to cause flow in the transfer line to either tank. 
HNF-4264

\subsection{References}

Antoniak, Z. I., 1998, Thermal Analysis of Tank 241-SY-101 Crust Growth and Partial Retrieval, TWS99.11, Pacific Northwest National Laboratory

Erhart. M. F., 1999, Functional Requirements and Technical Criteria for the 24I-SY-101 RAPID Mitigation System, HNF-3885, Lockheed Martin Hanford Corporation

Estey, S. D. 1999a, "First Revision to Letter of Instruction for Composition Studies on Samples Supporting Tank 241-SY-101 Level Growth Mitigation/Remeđiation," Interoffice Memo 74B50-99-011 to J. R. Jewett, dated February 8.

Estey, S. D. ,1999b, "Anticipated Dynamic Viscosity and Solids Concentration of Slurries Produced During the Dilution and Transfer of Tank 241-SY-101 Wastes to Tank 241-SY-102," Interoffice Memo 74B50-99017 to W. J. Powell, dated February 11.

Estey, S. D. and T. A. Hu, 1998, Flow Velocity Analysis for Avoidance of Solids Deposition During Transport of Hanford Tank Waste Slurries, HNF-2728, Lockheed Martin Hanford Corporation.

Fowler, K. D., 1995, Tank Farm.Waste Compatibility Program, WHC-SD-WM-OCD-015, Rev. 1, Westinghouse Hanford Company

Hedengren, D. C., 1999, "Ammonia Concentrations from the Transfer of Waste from TANK 241-SY-101 to TANK 241-SY-102," Interoffice Memo 74B40-99-045 to N. W. Kirch, dated March 11.

Krips, L., 1999, Tank 241-SY-101 Waste Transfer Control Summary, (DRAFT)

Meyer, P. A and B. E. Wells, 1999, Potential for Buoyant Displacement Gas Release in Tank 241-SY-102 after Transfer from Tank 241-SY-101: An Initial Evaluation, TWS99.14, Pacific Northwest National Laboratory

Mulkey, C. H., 1997, Data Quality Objectives for the Waste Compatibility Program, HNF-SD-WM-DQO001, Rev 2, Lockheed Martin Hanford Corporation

Onishi, Y, and K. P. Recknagle, 1999, SY-101 Slurry Transfer Meeting Minutes, TWS99.23, Pacific Northwest National Laboratory

Rassat, S. D., P. A. Gauglitz, S. M. Caley, L. A. Mahoney, D. P. Mendoza, 1999, A Discussion of SY-101 Crust Gas Retention and Release Mechanisms, PNNL-12092, Pacific Northwest National Laboratory

Reynolds, D. A., 1998, "Prediction of Dilution and Temperature Effects on Waste from Tank 241-SY101," Interoffice Memo 74B50-98-061 to N. W. Kirch, dated December 15.

Steen, F. H., 1999, "Compatibility Analysis Results for Tank 241-SY-101 Core Composites," Letter WMH-9951091 to K. M. Hall, dated February 24.

Stewart, C. W, 1996, In Situ Rheology and Gas Volume in Hanford Double-Shell Waste Tanks, PNNL11296, Pacific Northwest National Laboratory.

Tingey, J. M, P. R. Bredt, and E. H. Shade, 1994, The Effects of Heating and Dilution On the Rhelogical and Physical Properties of Tank 241-SY-101 Waste, PNL-10198, Pacific Northwest Laboratory 


\section{Appendix A: INDEX OF TECHNICAL OPERATING REQUIREMENTS}

A.1 Basis for Interim Operations (BIO) Controls

A.2 Operating Specification Document (OSD) Controls

A.3 Environmental Controls

A.4 Industrial Safety (Tank Farm HASP) Controls

A.5. Waste Compatibility/Waste Acceptance Controls - TBD 


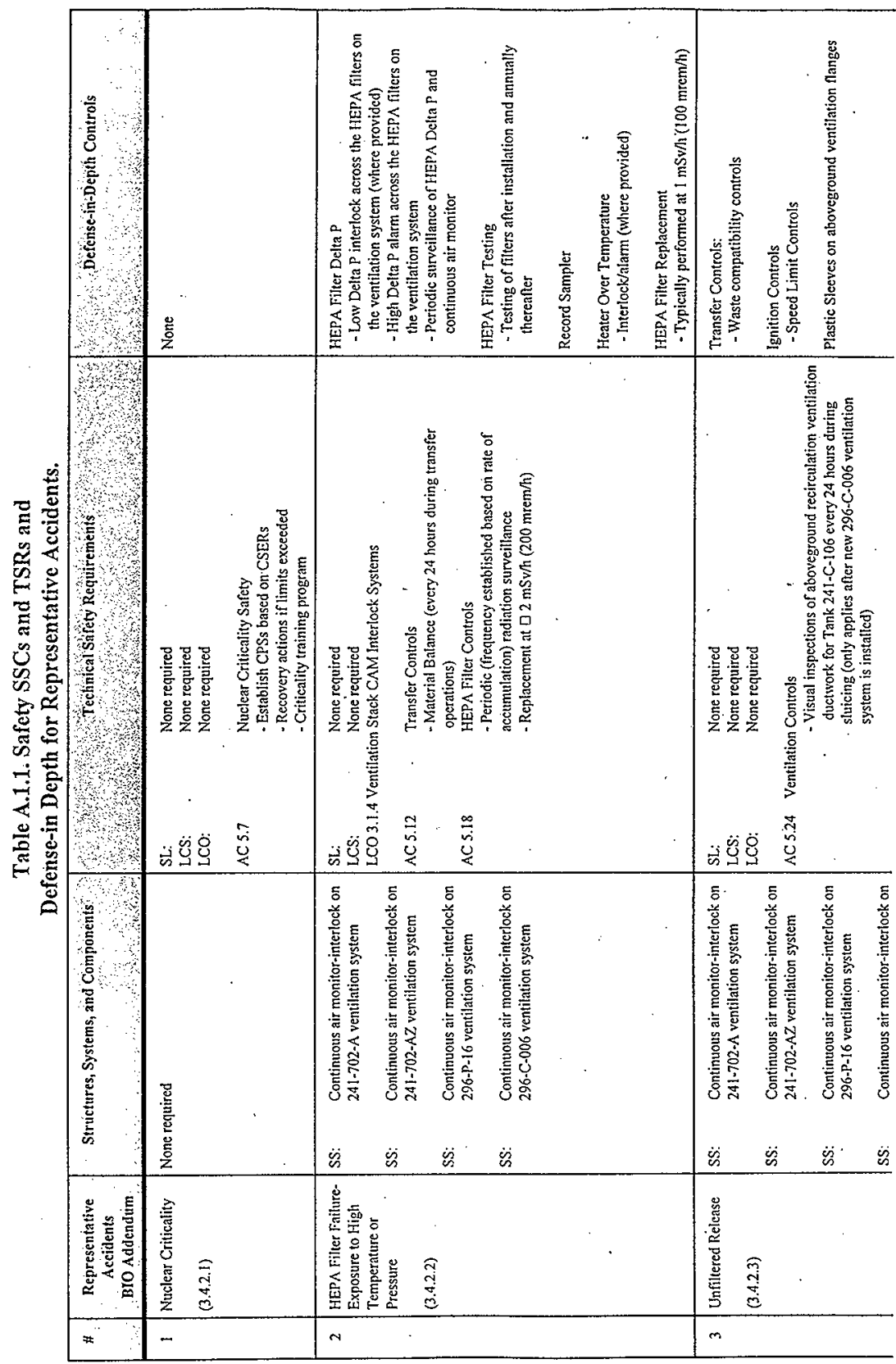




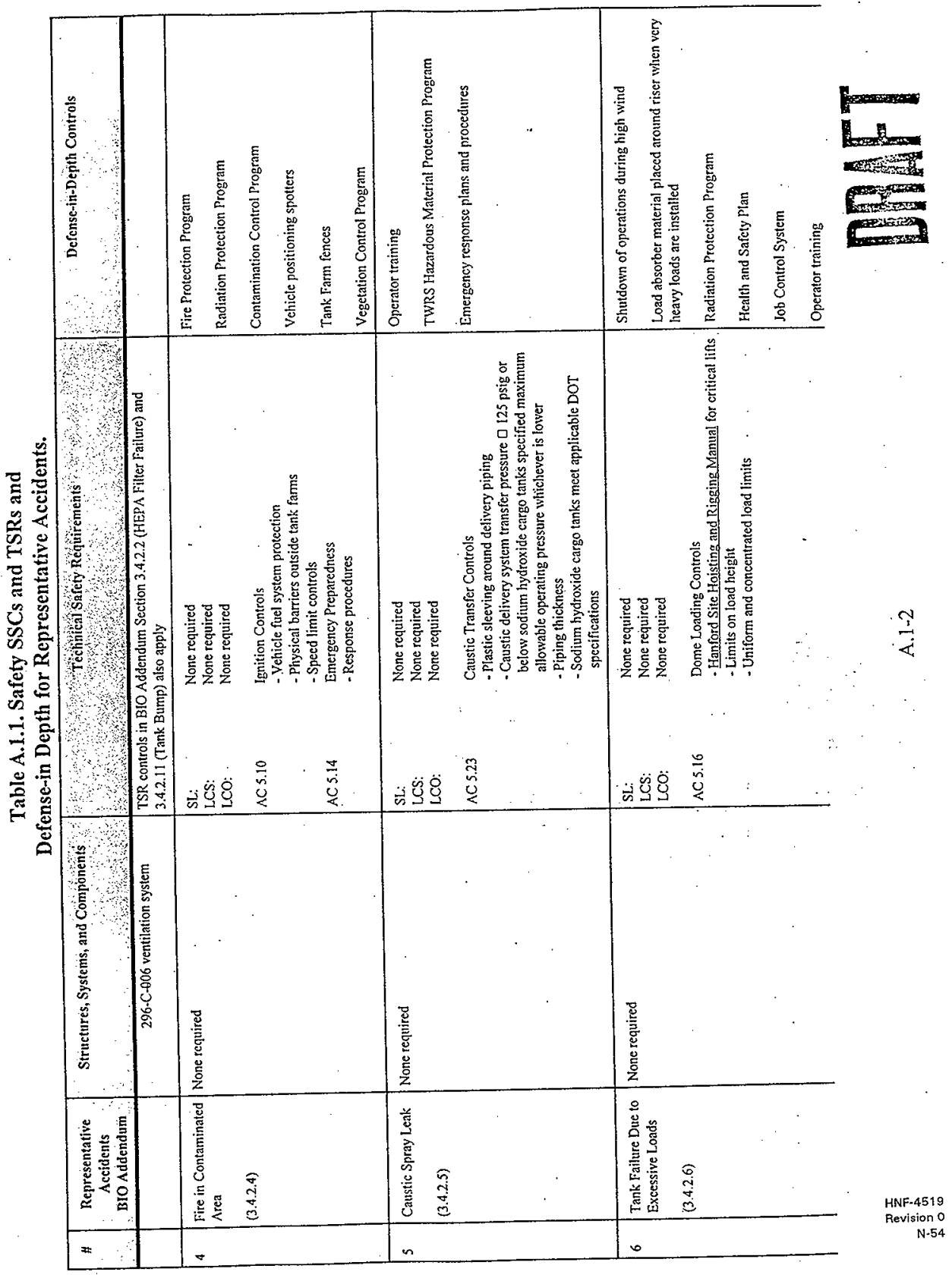



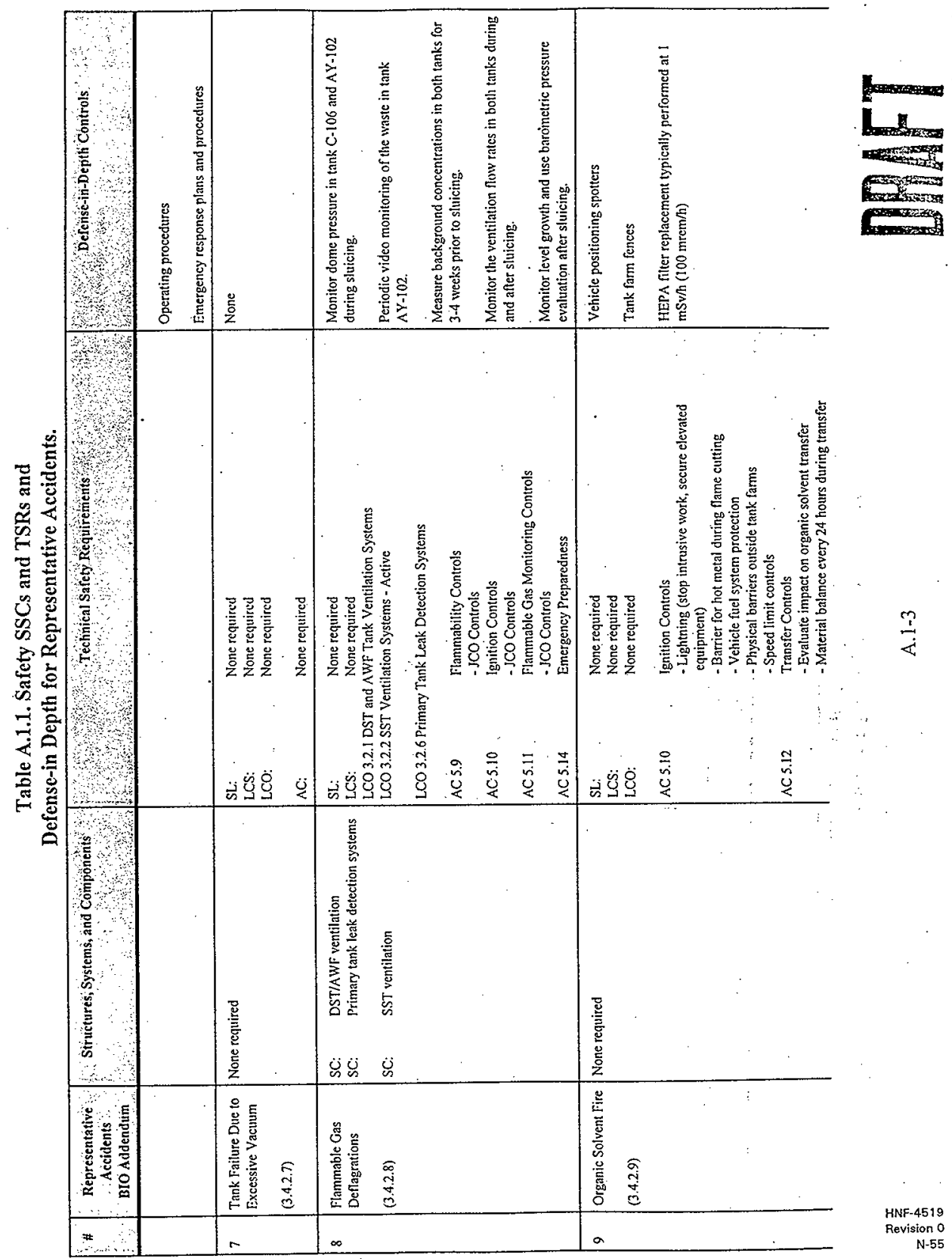



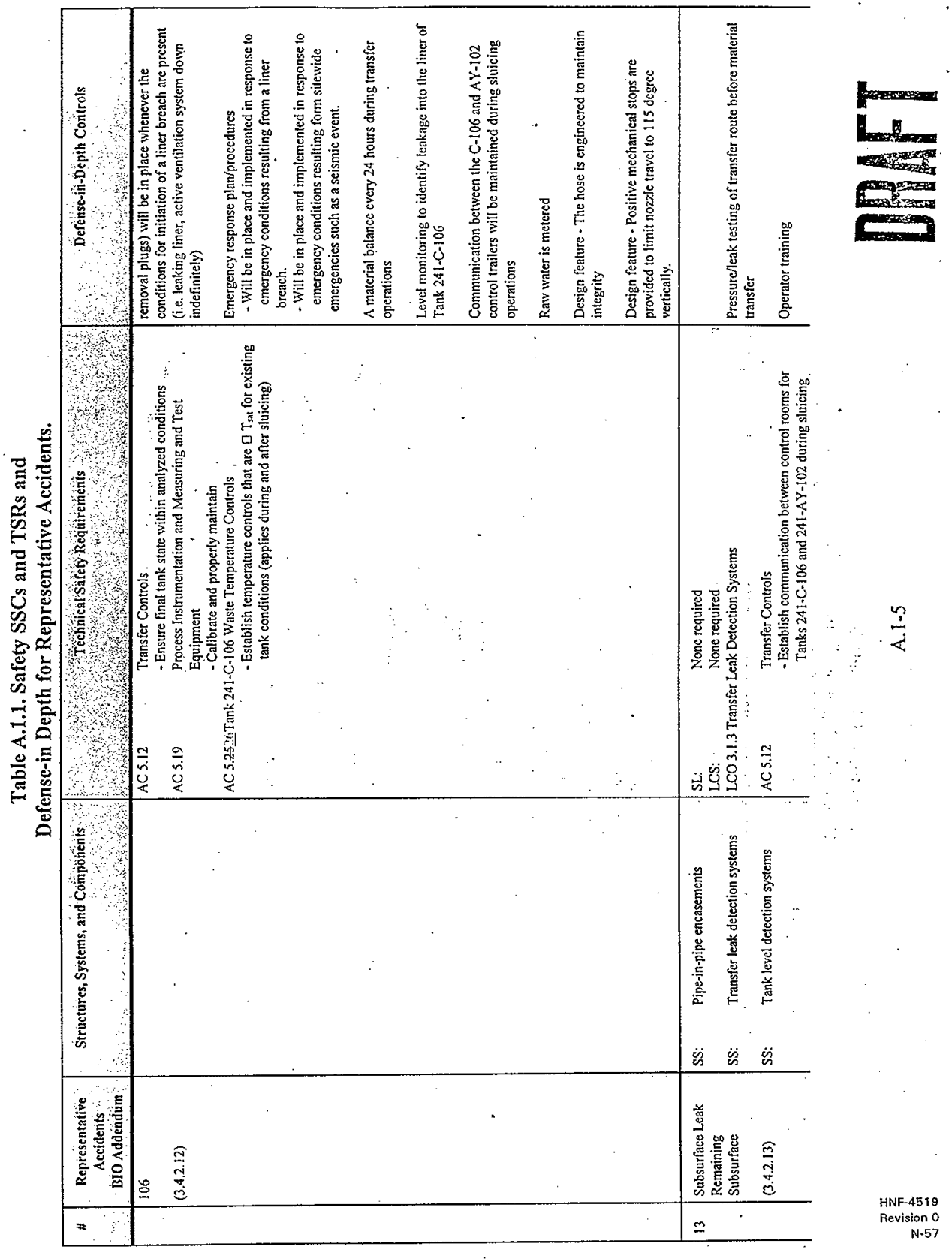



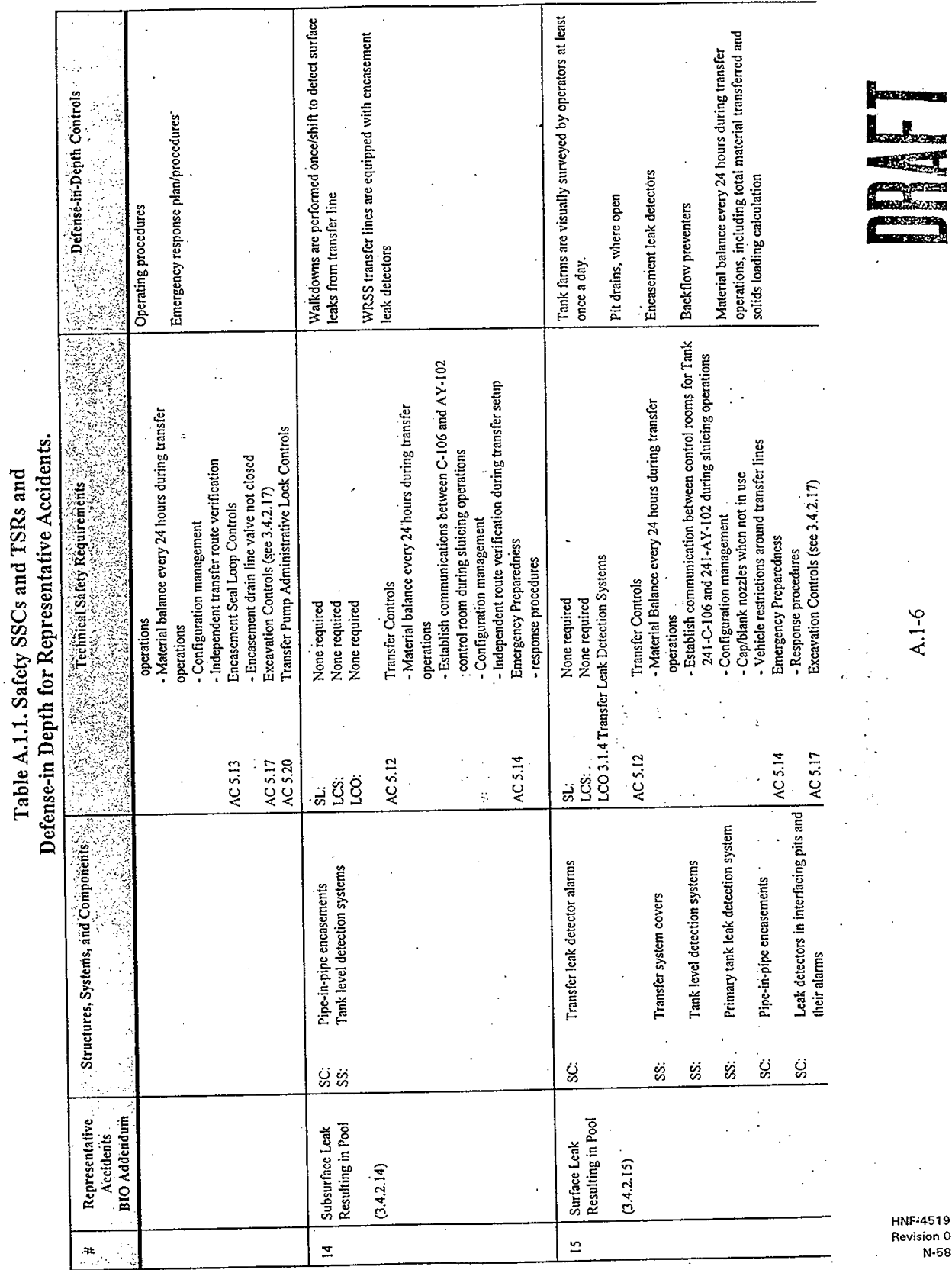

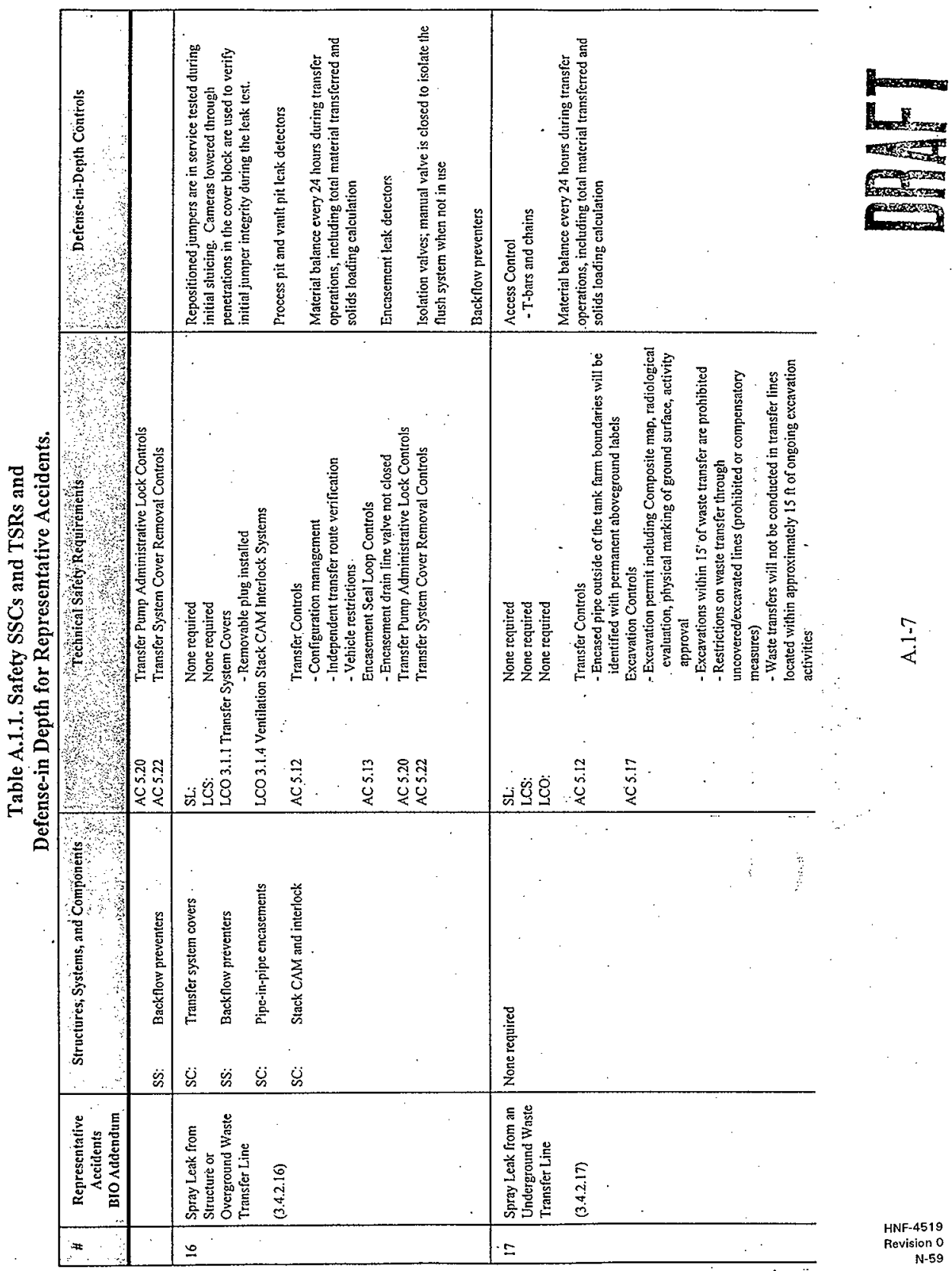

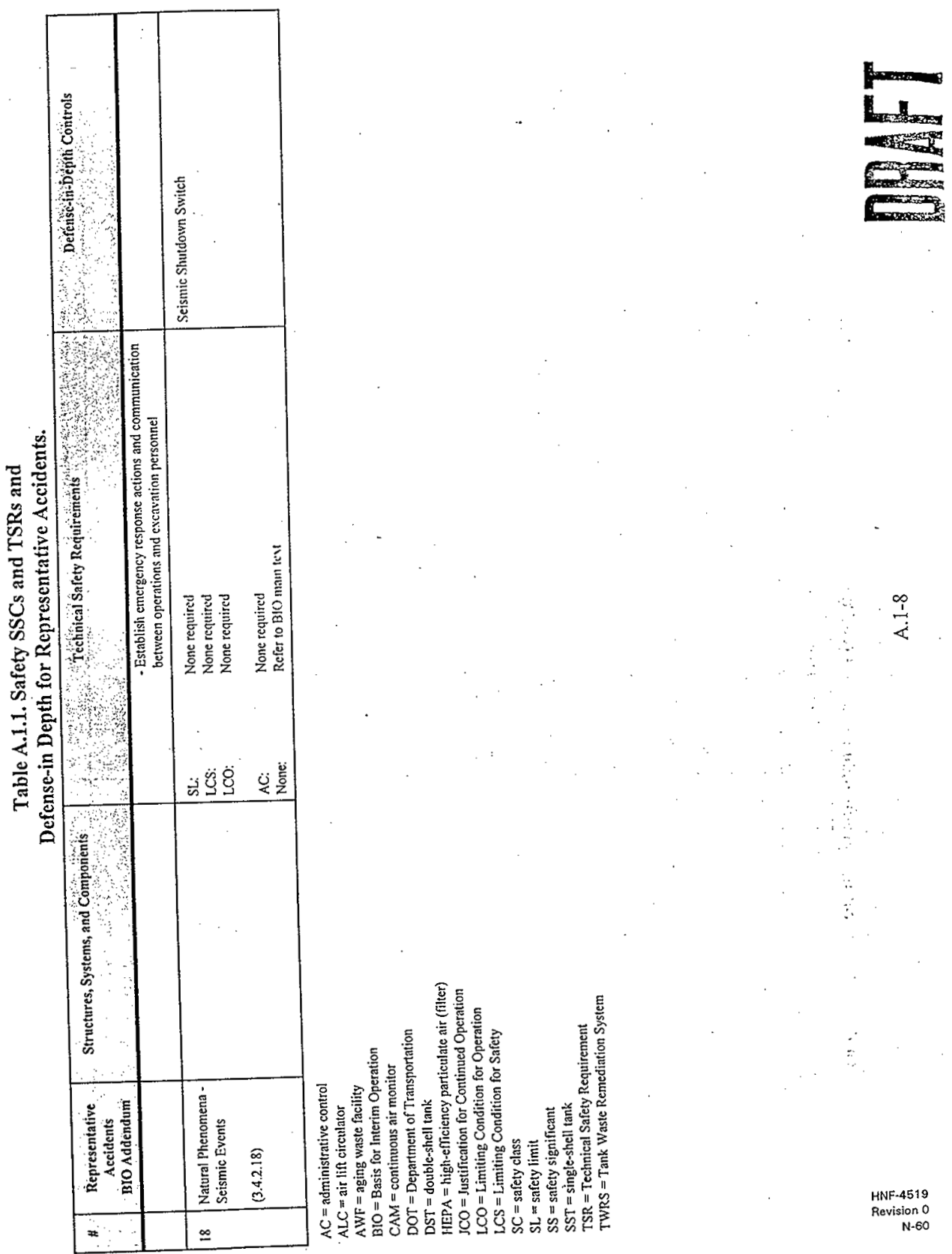

$\stackrel{\infty}{4}$

HNF -4519

Revision 0 N.60 

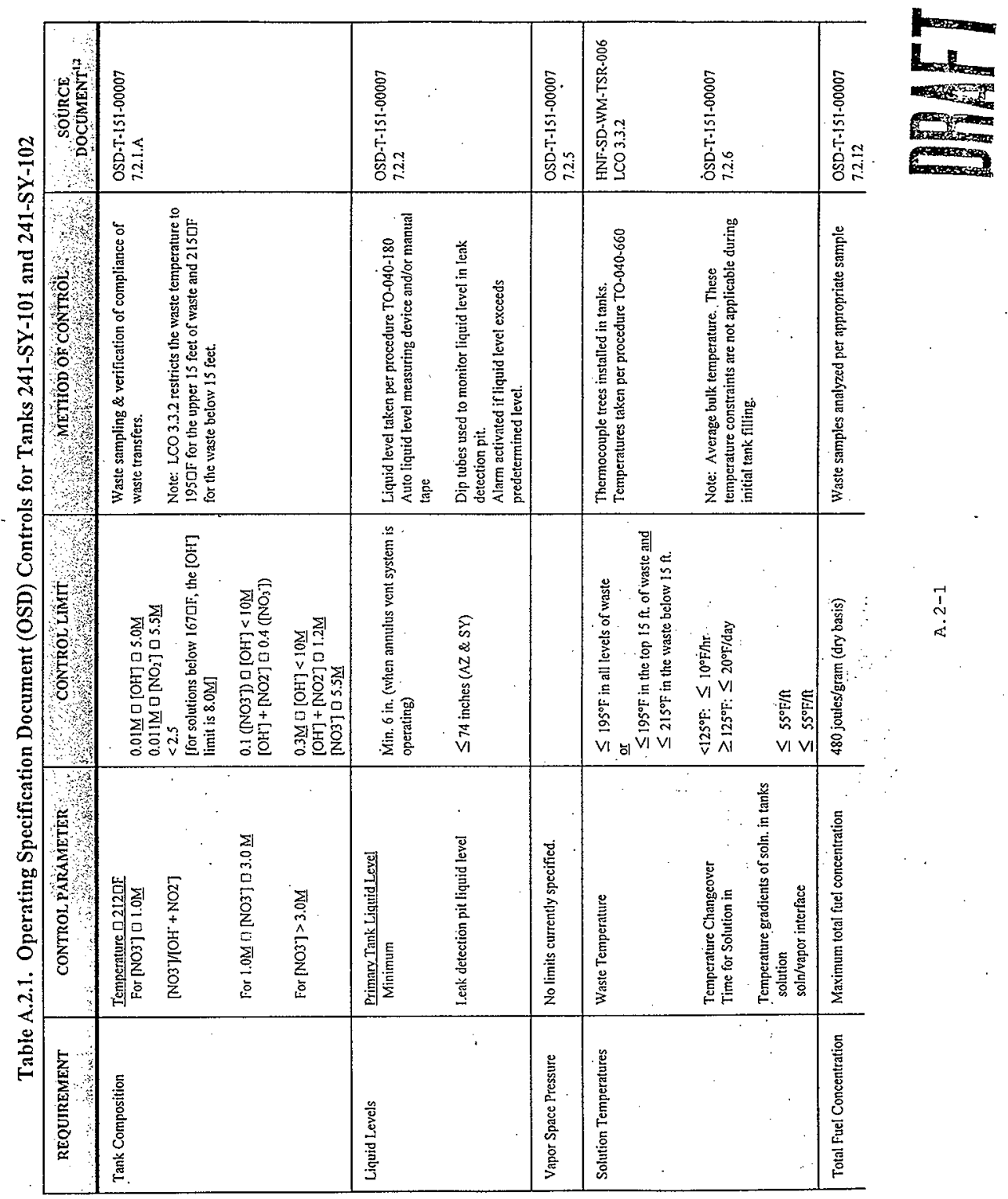


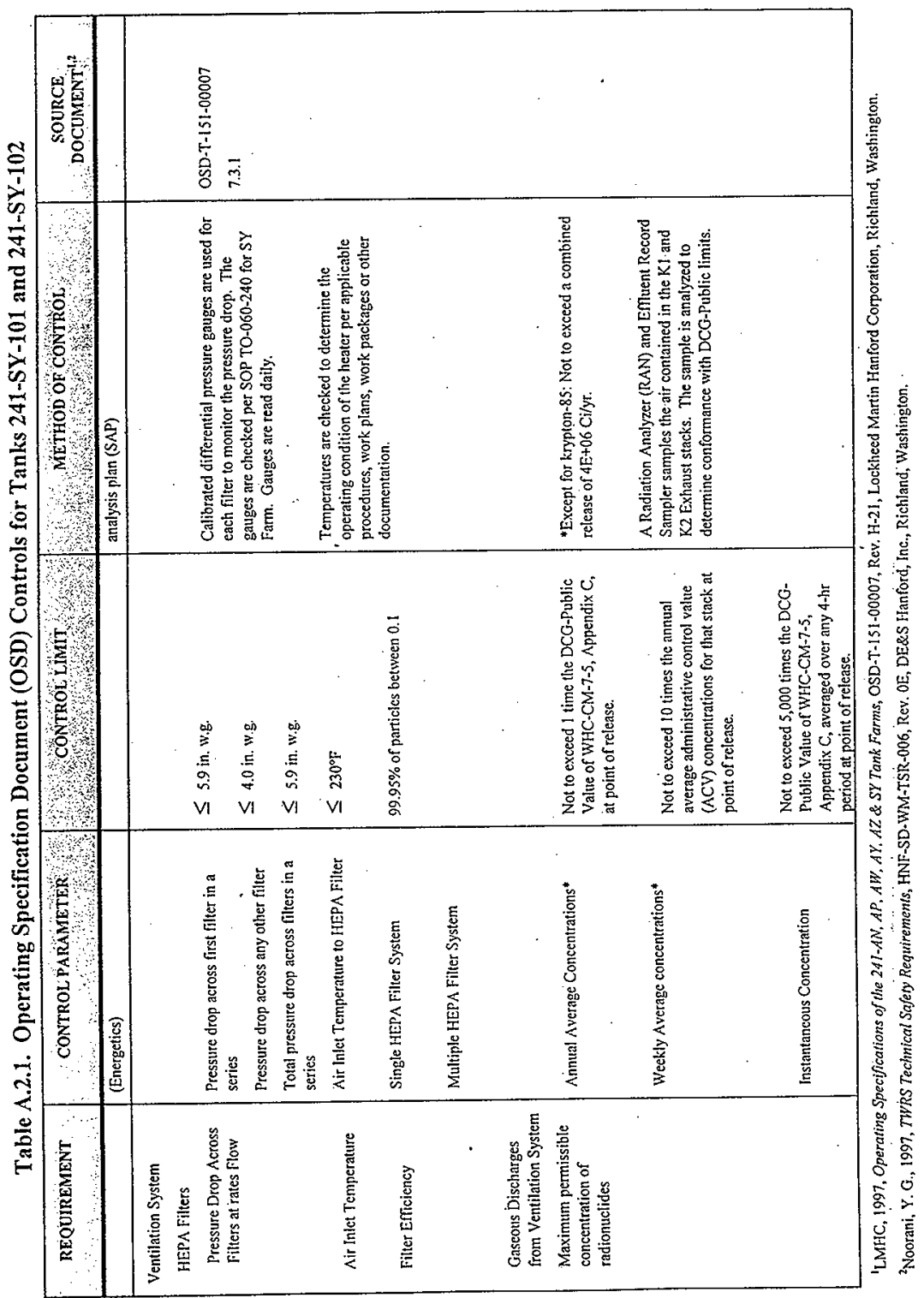



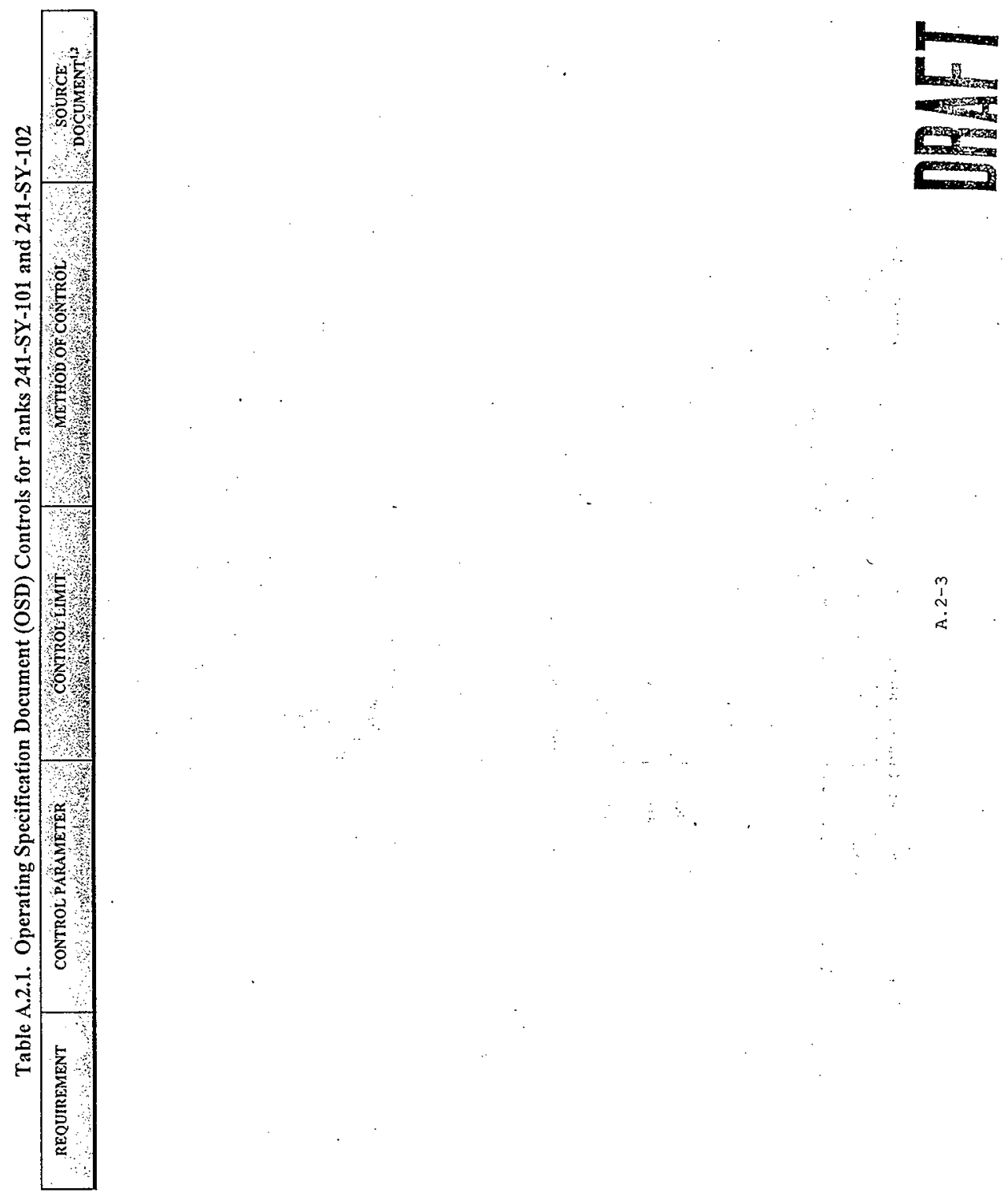


\section{Environmental Controls}

\section{REFERENCES}

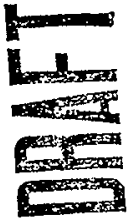

A. 3-1 

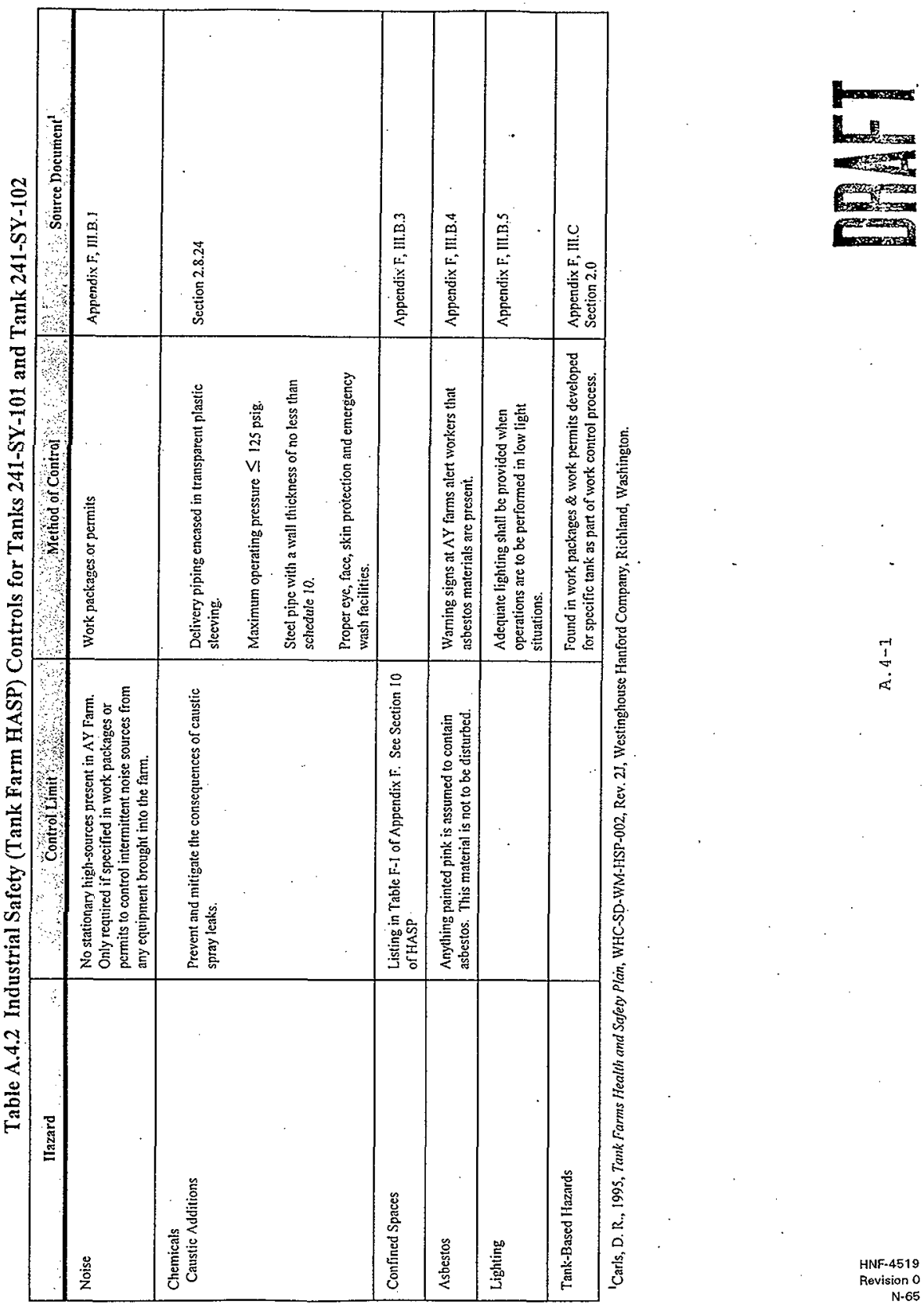

$\frac{5}{4}$ 


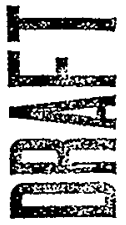



15

HNF-4519

Revision 0 N-66 

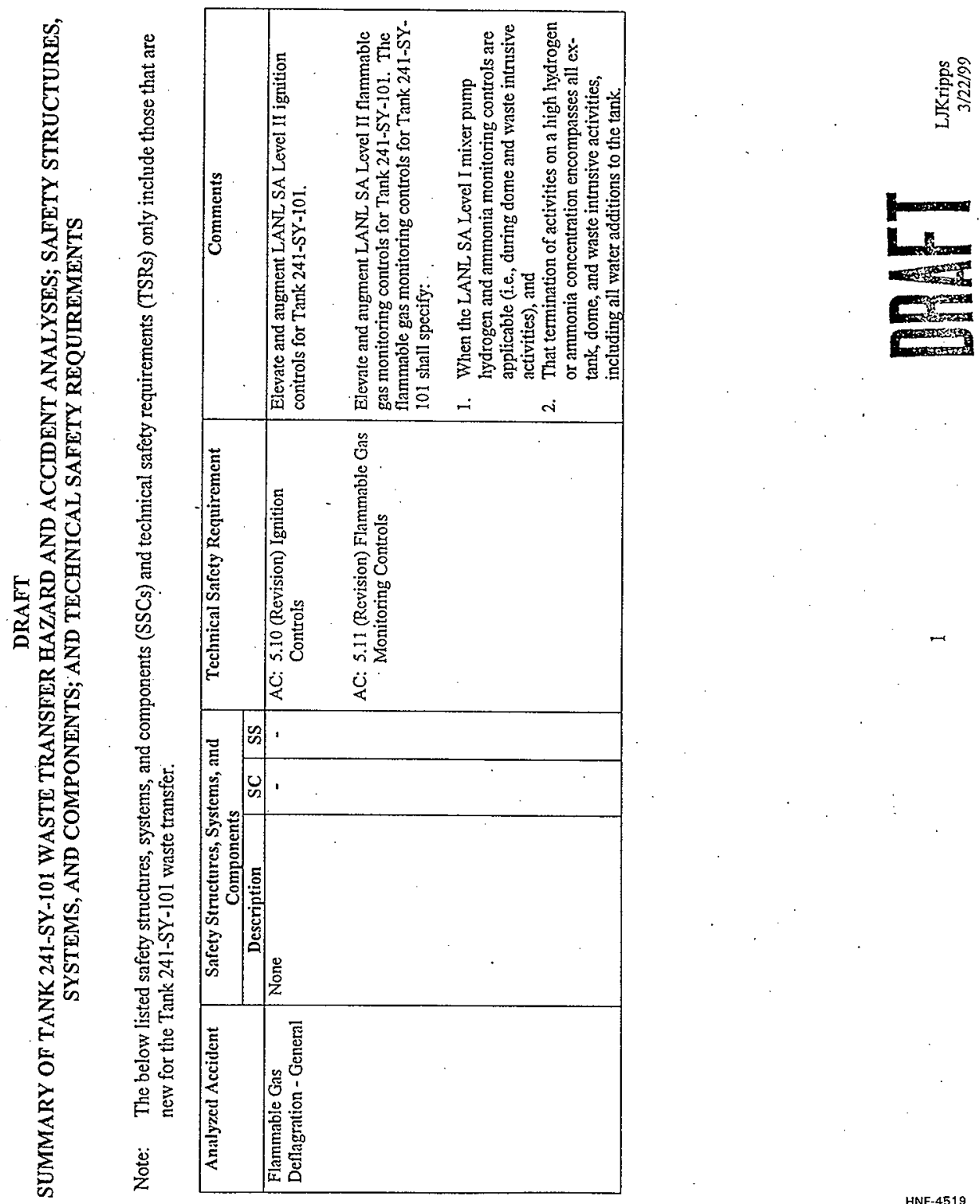

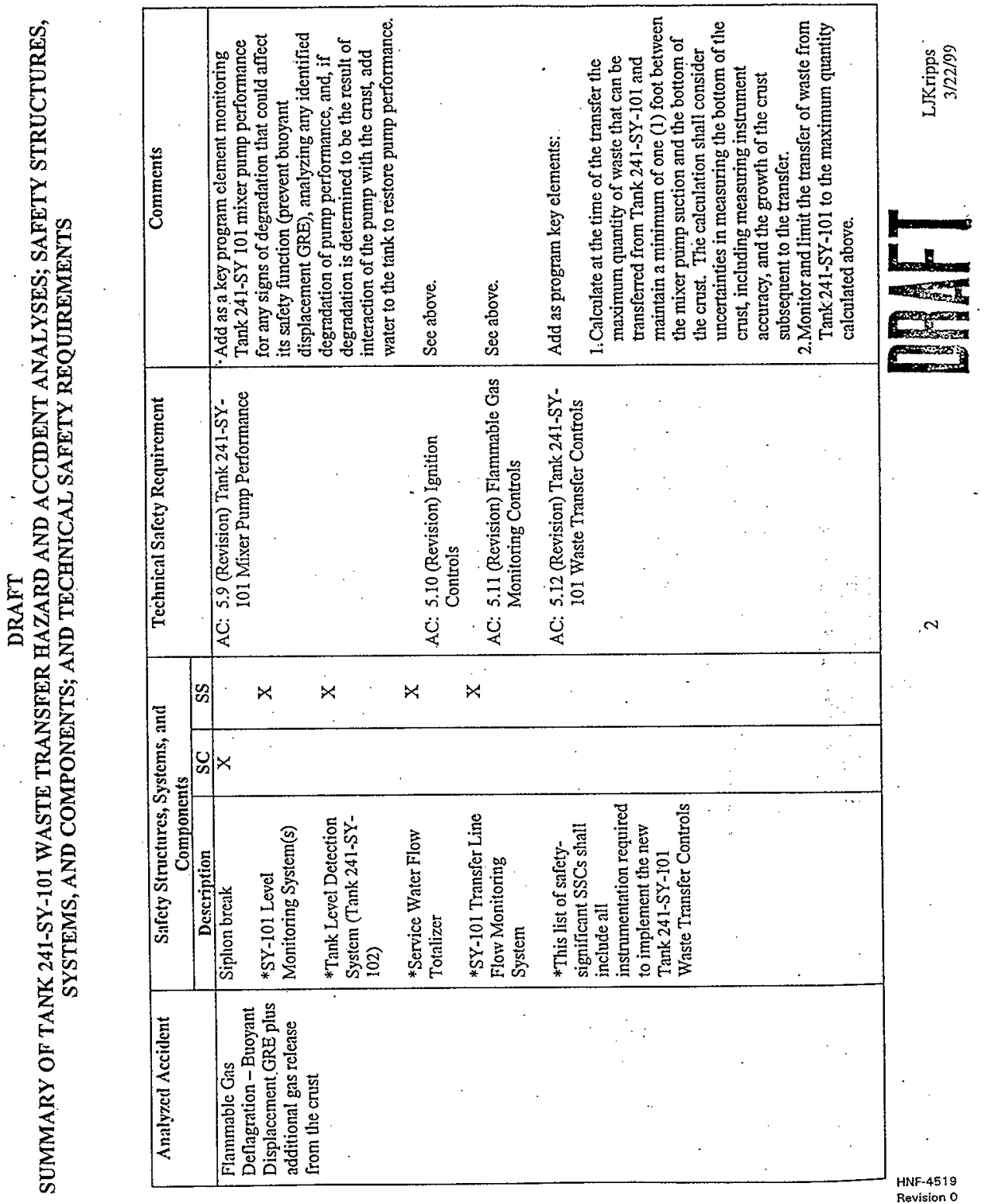

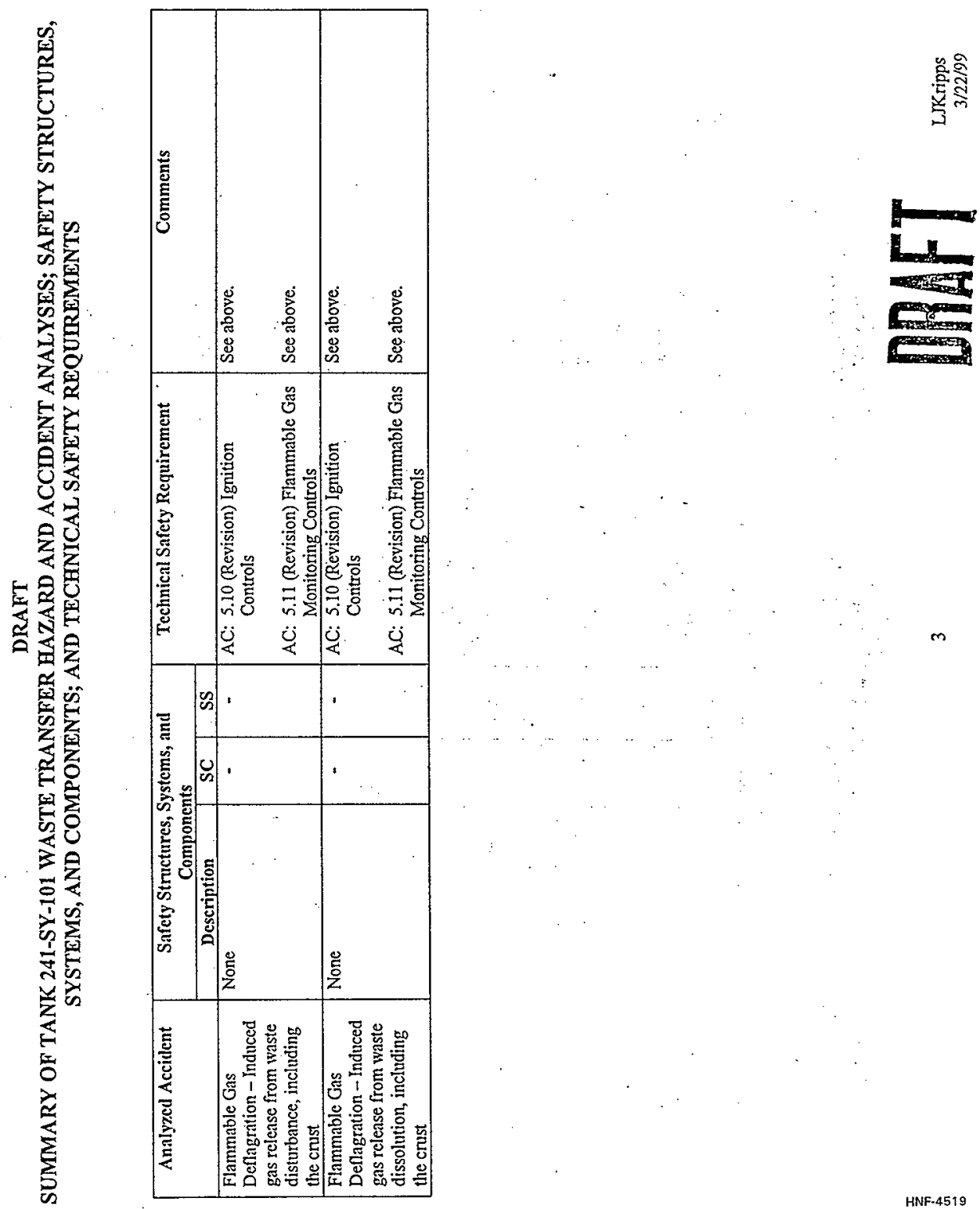


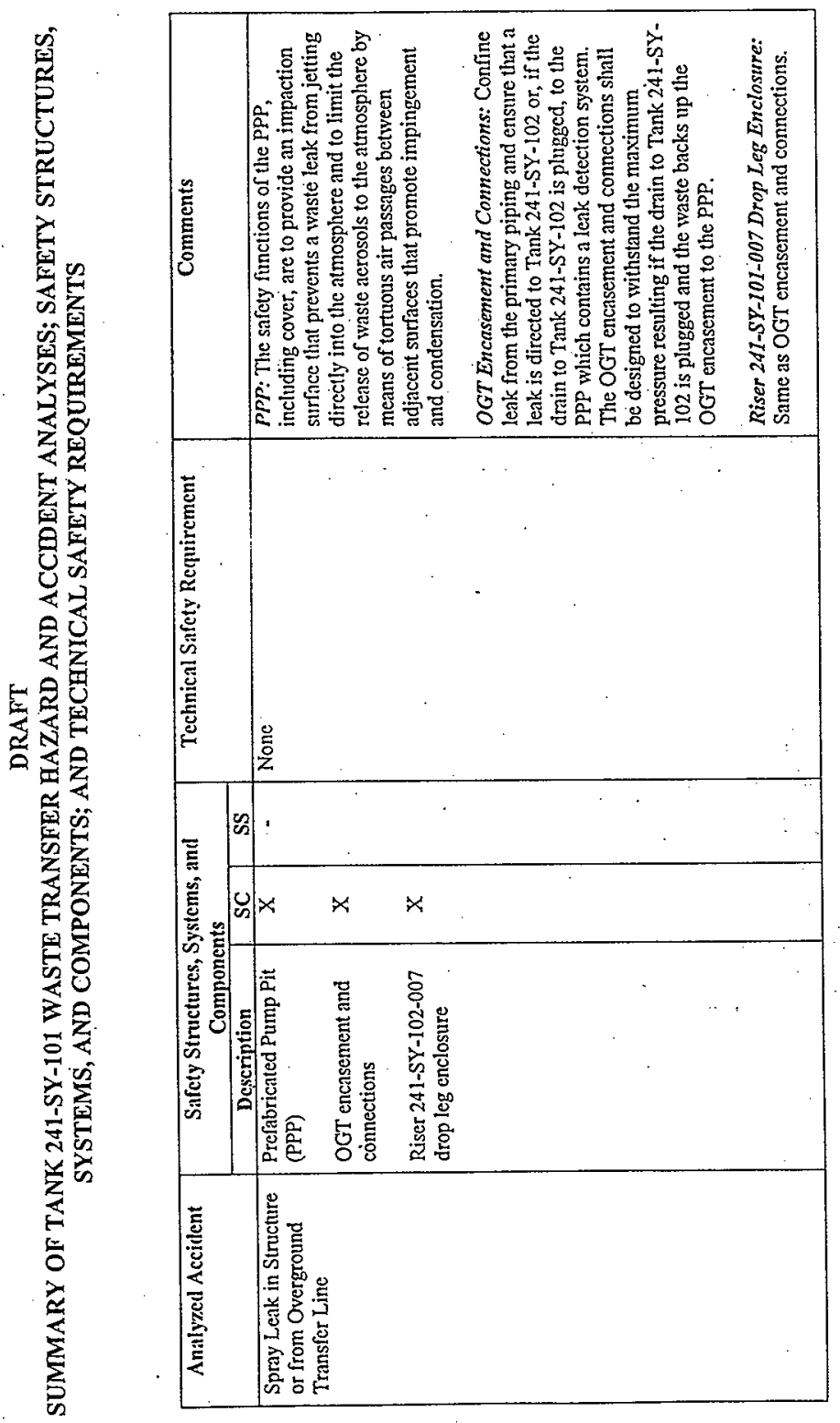

ํㅡㄹ 옳

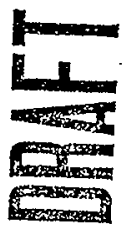




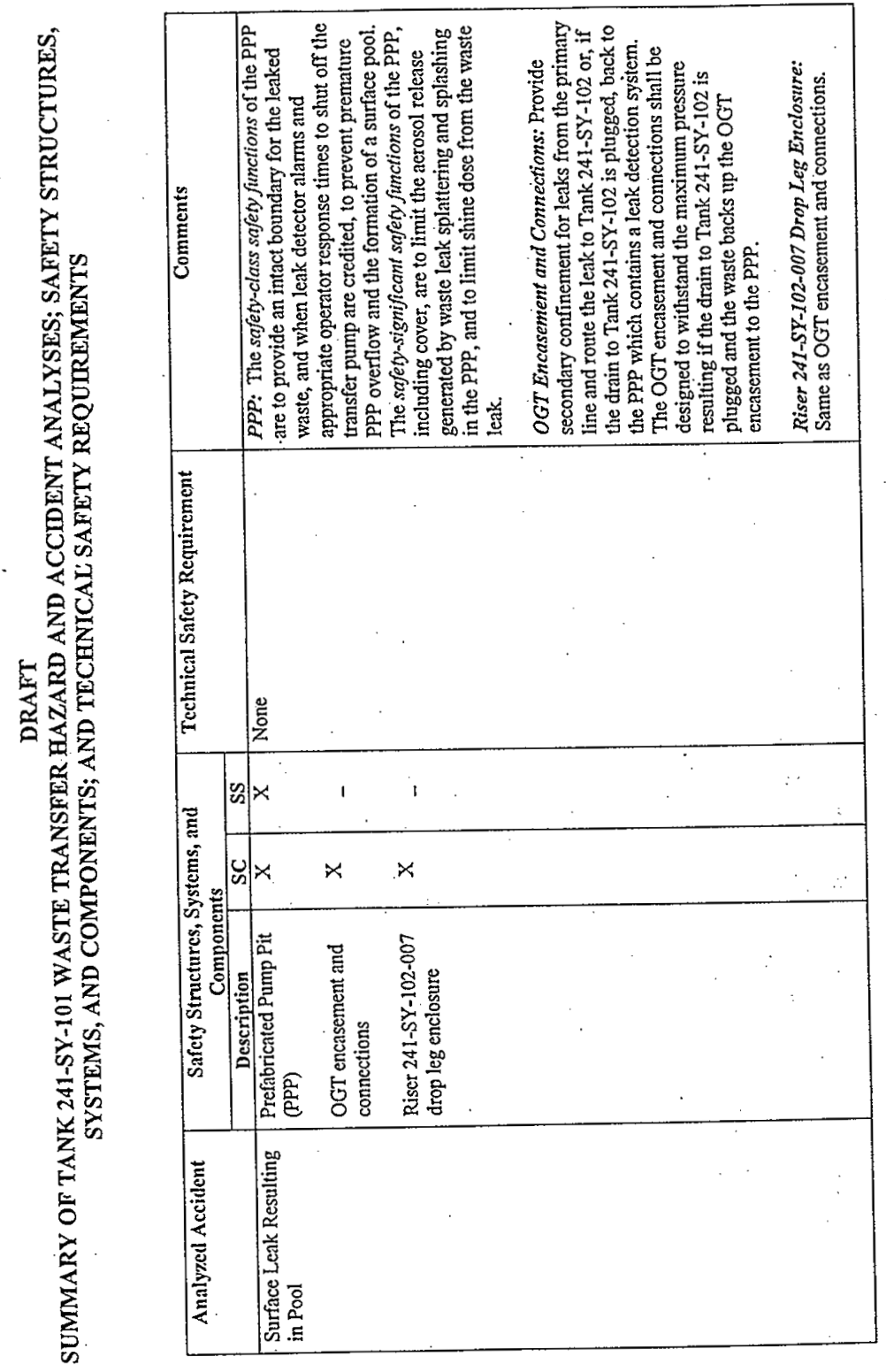




\section{DEFENSE IN DEPTH CONTROLS}

The only new defense-in-depth controls identified for the Tank 241-SY-101 waste transfer are:

Video camera monitoring during the waste transfer and during associated activities that involve crust disturbance or dissolution

Dilution water temperature 


\section{DISTRIBUTION SHEET}

To

Distribution

Project Title/Work Order

Design Review Report for the SY-101 Rapid Mitigation System (HNF-4519)

* Central Fileo B/-07

$\begin{array}{ll}\text { DPC }-H 6-08 & \text { Name } \\ \text { DOEReading Room } & \text { H2 }-53\end{array}$

M. G. Al-Wazani

$T$. R. Benegas

J. R. Biggs

J. W. Bloom

D. L. Dyekman

M. F. Exhart

J. D. Guberski

C. E. Hanson

J. W. Hobbs

H. R. Hopkins

R. A. Huckfeldt

C. E. Jensen

L. S. Krosrud

R. E. Larsen

D. C. Larson

R. H. Lipfert

M. L. McEroy

T. C. Oten

L. E. Pokos

R. S. Popielarcyk

W. J. Powell

R. E. Raymond

R. W. Reed

D. A. Reynolds

S. H. Rifaey

c. C. Scaief

C. P. Seilhymer

C. P. Shaw

R. L. SchIosser

S. U. Zaman

H. H. Ziada

M. H. Brown

PNoL Tech
From

Equipment Engineering

PNNL Tech f̌ith P8-55

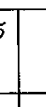

\begin{tabular}{|c|c|c|c|c|}
\hline MSIN & $\begin{array}{c}\text { Text } \\
\text { With All } \\
\text { Attach. }\end{array}$ & Text Only & $\begin{array}{c}\text { Attach./ } \\
\text { Appendix } \\
\text { Only }\end{array}$ & $\begin{array}{c}\text { EDT/ECN } \\
\text { Only }\end{array}$ \\
\hline R1-56 & $x$ & & & \\
\hline
\end{tabular}

\begin{tabular}{|l|}
\hline Page 1 of 1 \\
\hline Date May 19, 1999 \\
\hline EDT No. 624019 \\
\hline
\end{tabular}

ECN No. N/A 